\title{
Subglacial Conditions of the Kamb Ice Stream and its Response to Environmental Change
}

Laurine Nathalie van Haastrecht

Victoria University of Wellington

A thesis submitted to the Victoria University of Wellington in fulfilment of the requirements for the degree of

Doctor of Philosophy 

In dedication to my family, for their unwavering support at every stage of my life. 



\section{Acknowledgements}

Firstly, I would like to thank both my fantastic supervisors, Nicholas Golledge and Huw Horgan. Their academic and emotional support over the last three years has been amazing, as well as their knowledge and pushing me right until the end. I could not have done this without you and I truly mean that.

I'd also like to thank all the fantastic staff at the Antarctic Research Centre, in particular both Dao Polsiri and Michelle Dow, for the tireless support whatever the question, friendly chats, and useful advice. I'd also like to thank Aleksandr Beliaev for the infinite amount of patience he must have had for my hundreds of emails and questions when something had gone wrong on the computer side of things, and I cannot express how grateful I am for all his help. My next thank you is to all the fantastic students at the Antarctic Research Centre, who have made the past three years infinitely more fun, either through breaks, fun chats, and both emotional and academic support. In particular, I'd like to thank Hannah Chorley for the ever present emotional support, fantastic friendship and inappropriate conversations, and Dan Lowry, Marjolaine Verret, Laura-May Baratin and Dominic Evanzia for all their help and support.

I would like to thank my fantastic family, who have given me unconditional support throughout my many years of study. They have stood by me every moment of the way, especially during the difficult times and have never doubted my ability to finish. Their support has meant everything to me. I'd also like to add a special mention to Nick and his family, who have provided much support, play dates and baking .

The next thank you goes to my amazing partner, José Miguel, who has been an unwavering force by my side and has been there with endless love (and snacks) to help me push through to the end. Without your support I don't know how I would have finished and will forever be grateful. Another thank you goes to his amazing family, 
who received me with open arms and support while I was living in Chile.

To all my Antarctic fieldwork partners, in particular Andrew, Caitlin, Gary and Bob, you have all made for amazing Antarctic research seasons filled with so much fun, hard work, and fond memories.

Lastly I'd like to thank all the institutions that have enabled me to carry out this research and provided funding, Victoria University of Wellington, Antarctic Research Centre, Antarctica New Zealand, New Zealand Antarctic Research Institute, and the University of Otago. 


\section{Abstract}

The Siple Coast ice streams, which drain the West Antarctic Ice Sheet into the Ross Ice Shelf, are susceptible to temporal changes in flow dynamics. The Kamb Ice Stream on the Siple Coast, stagnated approximately 160 years ago, thought to partially be the result of basal water diversion. The character of its subglacial environment can exert an important control on long- and short-term ice sheet and ice stream fluctuations. Were the Kamb Ice Stream to reactivate in response to subglacial or future climate change, it would have the potential to contribute more substantially to ice discharge into the Ross Ice Shelf. Therefore, it is important to characterise the present-day subglacial environment and climatic conditions that may reactivate this flow. This study investigates the present-day subglacial conditions of the Kamb Ice Stream and how these conditions may be affected by environmental perturbations.

Due to the difficult nature of making direct observations of ice sheet basal conditions, other methods are employed to investigate the response of the Kamb Ice Stream to environmental change. Active source seismic surveying data obtained during the 2015/16 and 2018/19 austral summer seasons provides an instantaneous snapshot of the present-day basal conditions. Flowline and whole-continent numerical ice sheet modelling is used to investigate the longer-term response of the Kamb Ice Stream and the West Antarctic Ice Sheet.

Amplitude analysis of seismic lines indicate saturated till beneath the Ross Ice Shelf in the vicinity of the grounding zone, which is supported by retreat rates of the Kamb Ice Stream grounding zone post-stagnation. Seismic reflection imaging suggests potential dewatered till conditions beneath the grounded Kamb Ice Stream. Flowline modelling of the Kamb Ice Stream indicates that changes to the water content of the subglacial sediments appear to be self regulating, with high reversibility over centennial timescales. Oceanic temperature forcings are the key driver of change of the Kamb Ice Stream, and the ice stream is susceptible to topographic pinning points in $2 \mathrm{D}$ and lateral drag. 
Future glaciological change is more likely to occur in response to oceanic than to atmospheric temperature perturbations. Results from 3D continent-wide modelling experiments also find that precipitation increases offset the effect of air temperature perturbations and influence subglacial conditions, indicating more dynamic ice stream behaviour on the Siple Coast.

This study has worked to re-enforce and strengthen our existing understanding of the Kamb Ice Stream and its sensitivity to environmental change. Future work using higher-resolution simulations and a higher density of observational data may help refine these results. 


\section{Contents}

Figures $\quad$ xiii

$\begin{array}{ll}\text { Tables } & \text { xvii }\end{array}$

Abbreviations $\quad$ xix

1 Introduction and Background $\quad 1$

1.1 Antarctic Glaciological System . . . . . . . . . . . . . . . . . . 1

1.1 .1 Ice Sheets . . . . . . . . . . . . . . . . . . . . 1

1.1 .2 Ice Shelves . . . . . . . . . . . . . . . . . . 2

1.1 .3 Ice Streams . . . . . . . . . . . . . . . . . . . . 2

1.1.4 Grounding Zone . . . . . . . . . . . . . . . . . . . . 4

1.1.5 Subglacial Environment of the Antarctic Ice Sheet . . . . . . . . 6

1.2 Geographical Setting . . . . . . . . . . . . . . . . . . . . . 14

1.2.1 West Antarctic Ice Sheet . . . . . . . . . . . . . . . . . . . . . . 14

1.2 .2 Ross Ice Shelf . . . . . . . . . . . . . . . . . . . . . . . 15

1.2.3 Kamb Ice Stream . . . . . . . . . . . . . . . . . . . . . . . 18

1.3 Aim and Research Questions . . . . . . . . . . . . . . . . 18

1.3.1 Research Questions . . . . . . . . . . . . . . . . . . . . 19

1.4 Active Source Seismology . . . . . . . . . . . . . . . . . . . . . 20

1.4.1 Development in Ice Environments . . . . . . . . . . . . . . 20

1.4 .2 Application . . . . . . . . . . . . . . . . . . . . . . . . . . . . .

1.5 Ice Sheet Models . . . . . . . . . . . . . . . . . . . . . 22

1.5.1 Development of Ice Sheet Models . . . . . . . . . . . . . . 22

1.5.2 The Parallel Ice Sheet Model . . . . . . . . . . . . . . . . . . 25

1.6 Thesis Structure . . . . . . . . . . . . . . . . . . 26 
2 Kamb Ice Stream Seismic Investigation 29

2.1 Methodology . . . . . . . . . . . . . . . . . . . 30

2.1.1 Data Acquisition . . . . . . . . . . . . . . . 30

2.1.2 Data Processing - Seismic Reflection Lines . . . . . . . . . . . 32

2.1.3 Data Processing - Amplitude Analysis . . . . . . . . . . . . . . 34

2.2 Results . . . . . . . . . . . . . . . . . . . . . . . . 38

2.2.1 Seismic Reflection Lines . . . . . . . . . . . . . . . 38

2.2 .2 Acoustic Impedance of the Bed . . . . . . . . . . . . . . . . 43

2.3 Interpretation . . . . . . . . . . . . . . . . . . . . . 46

2.3.1 Subglacial Environment _. . . . . . . . . . . . . . 46

2.3.2 Grounding Zone Position and Sediments . . . . . . . . . . . . . 47

2.3 .3 Off-Shore Sediments . . . . . . . . . . . . . . . . 48

2.3.4 Acoustic Basement . . . . . . . . . . . . . . . . . . 49

2.4 Discussion . . . . . . . . . . . . . . . . . . . . . . . . . . . . . . 49

2.4.1 Grounding Zone Location . . . . . . . . . . . . . . . . 50

2.4.2 Subglacial Properties . . . . . . . . . . . . . . . . . 51

2.4 .3 Comparison to Adjacent Ice Streams . . . . . . . . . . . . . . . 54

2.4.4 Utilisation in Model Studies . . . . . . . . . . . . . . . . . 55

2.4.5 Limitations and Assumptions . . . . . . . . . . . . . . 55

3 Kamb Ice Stream Flowline Simulations $\quad 59$

3.1 Theoretical Background . . . . . . . . . . . . . . . . . . 59

3.1 .1 Ice Dynamics . . . . . . . . . . . . . . . . . . 60

3.1 .2 Mass Conservation . . . . . . . . . . . . . . . . 61

3.1 .3 Ice Rheology . . . . . . . . . . . . . . . . . . . . . . 61

3.1 .4 Subglacial Environment . . . . . . . . . . . . . 63

3.1.5 Calving . . . . . . . . . . . . . . . . 66

3.1.6 Grounding Zone . . . . . . . . . . . . . . . . . . . 67

3.2 Methodology . . . . . . . . . . . . . . . 68

3.2 .1 Input Data Sets . . . . . . . . . . . . . . . . . . 68

3.2.2 Smoothing and Evolution . . . . . . . . . . . . . . 72

3.2.3 Model Spin-up . . . . . . . . . . . . . . . . . 72

3.2 .4 Analysis . . . . . . . . . . . . . . . . . 73

3.2.5 Hydrological Controls . . . . . . . . . . . . . . . 76

3.2.6 Future Projections and Impacts . . . . . . . . . . . . . . . . 76

3.3 Results . . . . . . . . . . . . . . . . . . . . . . 78

3.3.1 Till Water Storage and Decay Rates . . . . . . . . . . . 78 
3.3.2 Atmospheric Temperature and Precipitation Changes . . . . . . 87

3.3.3 Oceanic Temperature Changes . . . . . . . . . . . . . . . . . 91

3.3.4 Combined Scenarios . . . . . . . . . . . . . . . . . . . . . . . 99

3.4 Discussion: Hydrological Changes in the Subglacial Environment . . . . 102

3.4.1 Temporal Responses of the Subglacial Environment . . . . . . . 102

3.4 .2 Spatial Variation . . . . . . . . . . . . . . . . . 103

3.5 Discussion: Projecting Future Change . . . . . . . . . . . . . . . . 103

3.5.1 Pinning Points and Grounding Zone Retreat . . . . . . . . . . . 104

3.5.2 Ice Stream Sensitivity . . . . . . . . . . . . . . . 105

3.5.3 Reactivation of the Kamb Ice Stream . . . . . . . . . . . . . . 106

3.5.4 Model Limitations and Assumptions . . . . . . . . . . . . . 107

4 West Antarctic Ice Sheet Simulations $\quad 111$

4.1 Methodology . . . . . . . . . . . . . . . . . 111

4.1 .1 Analysis . . . . . . . . . . . . . . . . . . . 113

4.1.2 Hydrological Controls . . . . . . . . . . . . . . . . . . 116

4.1.3 Atmospheric Temperature and Precipitation Perturbations . . . 116

4.1.4 Geothermal Heat Flux Changes . . . . . . . . . . . . . . . 116

4.2 Results . . . . . . . . . . . . . . . . . . . . . 117

4.2.1 Hydrological Changes . . . . . . . . . . . . . . . . . . . 117

4.2.2 Atmospheric Temperature and Precipitation Perturbations . . . 121

4.2.3 Geothermal Heat Flux Sensitivity . . . . . . . . . . . . . . . . . 127

4.3 Discussion . . . . . . . . . . . . . . . . . . . . . . . . . . . . . . 128

4.3.1 Kamb Ice Stream Responses . . . . . . . . . . . . . . . . . . . . 128

4.3.2 Subglacial Variation . . . . . . . . . . . . . . . . . . 128

4.3 .3 Adjacent Ice Streams . . . . . . . . . . . . . . . . . . . . . . . . 129

4.3.4 Wider Implications on the Ross Sea Sector . . . . . . . . . . . . 129

4.3.5 Geothermal Heat Flux . . . . . . . . . . . . . . . . . . . . . 132

4.3.6 Model Limitations and Assumptions . . . . . . . . . . . 133

5 Synthesis 135

5.1 Combined Use of Seismic and Model Data . . . . . . . . . . . . . . 135

5.2 Subglacial Conditions . . . . . . . . . . . . . . . . . . . 137

5.2.1 Kamb Ice Stream Subglacial Conditions . . . . . . . . . . . . . 137

5.2.2 Kamb Ice Stream Responses and Thresholds . . . . . . . . . . . 139

5.3 Model Limitations . . . . . . . . . . . . . . . . . . . . . . . . . . . . . 140 
6 Conclusions 143

6.1 Chapter Summaries . . . . . . . . . . . . . . . . . . . . 143

6.2 Key Conclusions . . . . . . . . . . . . . . . . . . . . . . . 144

6.3 Further Research . . . . . . . . . . . . . . . . . . . . 146

6.3.1 Ice Stream Velocity Changes . . . . . . . . . . . . . . . . . 146

6.3.2 Effects of Model Resolution . . . . . . . . . . . . . . . 147

6.3.3 Till Beneath Seismic Line KIS1516-1 . . . . . . . . . . . . . . 147

$\begin{array}{ll}\text { References } & 149\end{array}$ 


\section{Figures}

1.1 Schematic drawing of an ice sheet grounding zone . . . . . . . . . 5

1.2 Simplified Marine Ice Sheet Instability _ . . . . . . . . . . . . . 6

1.3 Subglacial till cycle . . . . . . . . . . . . . . . . . 8

1.4 Cross-section of subglacially deforming sediments . . . . . . . . . . 8

1.5 Antarctic subglacial lakes and drainage patterns . . . . . . . . . . . 11

1.6 Models of geothermal heat flux . . . . . . . . . . . . . . . . 13

1.7 Geographical setting map . . . . . . . . . . . . . . . 15

1.8 Future Antarctic Ice Sheet model scenarios . . . . . . . . . . . . . . . . 17

1.9 Acoustic impedance and subglacial material interpretation . . . . . . . 22

1.10 Ice sheet model complexities . . . . . . . . . . . . . . . . . . . . 24

2.1 Seismic survey locations . . . . . . . . . . . . . . . . . . . 31

2.2 Seismic Processing Sequence . . . . . . . . . . . . . . . . . . . . . . . . . . . . . . . 32

2.3 AVA, phase angles and incident angles . . . . . . . . . . . . . 35

2.4 Amplitude selection and extraction . . . . . . . . . . . . . . . 37

2.5 Interpreted seismic survey line KIS1819-1 . . . . . . . . . . . . . . . . 40

2.6 Interpreted seismic survey line KIS1819-2 . . . . . . . . . . . . . . . . . 41

2.7 Interpreted seismic survey line KIS1516-1 . . . . . . . . . . . . . . . 43

2.8 Calculated acoustic impedance for KIS1516 and KIS1819 . . . . . . . . 45

2.9 Simplified view of the subglacial processes and sediments . . . . . . . . 46

2.10 Bulk density and acoustic impedance . . . . . . . . . . . . . . . . . 48

2.11 Seismic survey locations with extended grounding zone . . . . . . . . 51

2.12 Till and ice acoustic impedance and porosity . . . . . . . . . . . . . . 54

3.1 Kamb Ice Stream flowline location . . . . . . . . . . . . . . . . . 70

3.2 Original Kamb Ice Stream starting parameters . . . . . . . . . . . . . . 71

3.3 Final ensemble flowline choices . . . . . . . . . . . . . . . . . . 74

3.4 Standard deviation against mean absolute error of percentage difference 75 
3.5 Grounded ice rate of change . . . . . . . . . . . . . . . . . . 79

3.6 Flowline ice velocities . . . . . . . . . . . . . . . . . . . 81

3.7 Flowline basal stresses . . . . . . . . . . . . . . . . . . . . 83

3.8 Flowline basal temperature, melt rate and friction . . . . . . . . . . 86

3.9 Atmospheric temperature forcing ice thickness rate of change . . . . . . 88

3.10 Atmospheric temperature forcing basal ice velocity . . . . . . . . . . . 89

3.11 Atmospheric temperature forcing basal shear stress . . . . . . . . . . . 90

3.12 Atmospheric temperature forcing basal yield stress . . . . . . . . . . . 90

3.13 Atmospheric temperature forcing basal frictional heating . . . . . . . . 91

3.14 Oceanic temperature forcing ice thickness rate of change . . . . . . . . 93

3.15 Oceanic temperature forcing basal ice velocity . . . . . . . . . . . . . . 94

3.16 Oceanic temperature forcing basal shear stress . . . . . . . . . . . . 95

3.17 Oceanic temperature forcing basal yield stress . . . . . . . . . . . . 96

3.18 Oceanic temperature forcing ice shelf basal melt rate . . . . . . . . . . 97

3.19 Oceanic temperature forcing basal frictional heating . . . . . . . . . . . 98

3.20 Combined scenario ice thickness changes (Locations $a-d$ ) . . . . . . 100

3.21 Combined scenario ice thickness changes (Locations $e-h$ ) . . . . . . . 101

3.22 Future projection ice surface elevation . . . . . . . . . . . . . . . . . 102

3.23 Ice sheet sensitivity . . . . . . . . . . . . . . . . . 106

3.24 Ice shelf buttressing effect . . . . . . . . . . . . . . . . 107

4.1 Whole continent surface and basal ice velocity, ice surface elevation, and ice extent . . . . . . . . . . . . . . . . . . 115

4.2 Ice surface elevation of the WAIS with changing amount of effective water stored in the till . . . . . . . . . . . . . . . . . 118

4.3 Surface ice velocity of the WAIS with changing amount of effective water stored in the till . . . . . . . . . . . . . . . . . . . . . . 119

4.4 Basal ice velocity of the WAIS with changing amount of effective water stored in the till . . . . . . . . . . . . . . . . . . . 120

4.5 Basal melt of the WAIS with changing amount of effective water stored in the till . . . . . . . . . . . . . . . . . . . . . 121

4.6 Ice surface elevation and basal melt with changing atmospheric temperatures and precipitation . . . . . . . . . . . . . . . . . . . 124

4.7 Surface and basal ice velocities with changing atmospheric temperatures and precipitation . . . . . . . . . . . . . . . . . 126

4.8 Changes in basal melt with changing geothermal heat flux . . . . . . . 127

4.9 Grounding zone evolution in West Antarctica . . . . . . . . . . . . . . 131 
4.10 Remotely sensed estimates of geothermal heat flux . . . . . . . . . 133

5.1 Modelled effective pressure estimates . . . . . . . . . . . . . 138

5.2 Comparison of ice-sheet model results from different hybrid model schemes142

6.1 Effects of resolution on the modelled central western coast of Greenland 147 



\section{Tables}

2.1 Seismic survey acquisition parameters . . . . . . . . . . . . 31

2.2 Glaciomarine sediment, ice, and ocean water physical properties . . . . 38

3.1 Input options and parameter choices . . . . . . . . . . . . . . 69

3.2 Ensemble parameter options . . . . . . . . . . . . . . . . 73

3.3 Final simulation parameters . . . . . . . . . . . . 76

4.1 PISM input options and parameter choices . . . . . . . . . . . . 113 



\section{Abbreviations}

\section{Acronyms / Abbreviations}

AGC Automatic gain control

AI Acoustic impedance

AIS Antarctic Ice Sheet

BIS Bindschadler Ice Stream

CDP Common depth point

DSDP Deep Sea Drilling Project

EAIS East Antarctic Ice Sheet

EISMINT European Ice Sheet Modeling Initiative

ELRA Elastic Lithosphere-Relaxed Asthenosphere

f.ETISH fast Elementary Thermomechanical Ice Sheet

FRIS Filchner-Ronne Ice Shelf

GMST Global mean surface temperatures

GZW Grounding zone wedge

HSSW High Salinity Shelf Water

ISMIP Ice Sheet Model Intercomparison Project

ISSM Ice Sheet System Model

KIS Kamb Ice Stream 
MAE Mean absolute error

MISI Marine Ice Sheet Instability

MISMIP Marine Ice Sheet Model Intercomparison Project

NMO Normal moveout

PDD positive degree dag

PIG Pine Island Glacier

PISM Parallel Ice Sheet Model

RCP Representation Concentration Pathway

$\mathrm{RC} \quad$ Reflection coefficient

RIS Ross Ice Shelf

RMS Root mean squared

RSU Ross Sea Unconformity

SCIS Siple Coast Ice Streams

SD Standard deviation

SIA Shallow ice approximation

SSA Shallow shelf approximation

TAM Transantarctic Mountains

TG Thwaites Glacier

TWTT Two-way travel time

WAIS West Antarctic Ice Sheet

WIS Whillans Ice Stream 


\section{Introduction and Background}

\subsection{Antarctic Glaciological System}

\subsubsection{Ice Sheets}

The Antarctic Ice Sheet (AIS) has large scale interactions with the rest of the Earth's systems. It influences global sea level, is altered in size during climatic changes, and adds or removes fresh water from the ocean. The AIS affects global climate by reflecting incoming solar radiation from snow and ice surfaces, and physically perturbs atmospheric circulation by deflecting air masses (Benn \& Evans, 2010). Ice sheets erode their beds, and can transport sediment and debris thousands of kilometres. The weight of ice sheets contributes to driving viscous flows in the underlying mantle, which in turn affects land surface elevation and Earth's gravitational field. The AIS is characterised by grounded ice flowing at different velocities from the centre of the ice sheet towards the margins and into ice shelves (see Section 1.1.2). Areas of faster ice flow are mostly defined by ice streams (see Section 1.1.3) or outlet glaciers. Up to four kilometres thick, the AIS is underlain by bedrock, sediments, water saturated sediments, and subglacial lakes. Flow of the ice sheet and ice shelves is largely driven by gravitational forces and is variably restrained by basal friction (Schoof, 2006). Ice sheets flow due to three main mechanisms; creep (i.e. internal ice deformation), basal sliding due to the presence of basal water, and basal sliding as a result of soft bed subglacial deformation. Due to gravitational driving stresses, all glaciers flow by creep, however, liquid water presence is typically needed for basal sliding and saturated beds are necessary for soft sediment deformation. The presence of both basal water, as well as soft deformable beds, can contribute to fast ice flow (see Section 1.1.3). 


\subsubsection{Ice Shelves}

Approximately $80 \%$ of the AIS drains through its surrounding ice shelves, regulating the rate at which ice is discharged into the ocean (Alley et al., 2016; Pritchard et al., 2012). However, ice shelves are also one of the more vulnerable aspects of the Antarctic glaciological system (DePoorter et al., 2013). These ice shelves are formed from continental outlet glaciers and ice streams which flow and spread into oceanic embayments (Alley et al., 2007; Paolo et al., 2015). They are in contact with both the ocean and the atmosphere, which are dynamic and changeable (Bromirski \& Stephen, 2012) and are particularly sensitive to atmospheric and oceanic forcings (Ashmore et al., 2017; Pritchard et al., 2012). Oceanic forcing is known to play a much larger role in the mass balance of the ice shelf than atmospheric forcings, and consequently changes in sea water temperatures can have large effects on the mass balance of an ice shelf (Pritchard et al., 2012; Jacobs et al., 1992; Smedsrud \& Jenkins, 2004).

Even though ice shelves themselves are not grounded, they have the ability to buttress the grounded ice sheet, through intermittent pinning on the seabed and lateral stresses which reduce or counteract some of the longitudinal stresses at the grounding zone (Goldberg, Holland \& Schoof, 2009; Ashmore et al., 2017). It has been observed that ice velocities and discharge increase as a result of ice shelf collapse (e.g. after the collapse of both Larsen A and B; Dupont \& Alley, 2005; Alley et al., 2016; Scambos et al., 2004). The potential loss of buttressing ice shelves makes the West Antarctic Ice Sheet (WAIS) vulnerable to rapid ice loss during climatic warming as global sea temperature rise significantly enhances basal melt rates (DePoorter et al., 2013). As a result, ice shelves strongly modulate AIS ice discharge and the eustatic sea level (Ashmore et al., 2017).

\subsubsection{Ice Streams}

Ice streams are areas of faster flow within an ice sheet, and often flow orders of magnitude faster than their surrounding ice. Ice streams currently discharge approximately $90 \%$ of AIS ice and sedimentary outputs (Rignot et al., 2011). Therefore, their stability and behaviour are important to the overall mass balance and dynamics of the AIS (Bennett, 2003). A complex system of tributaries extends hundreds to thousands of kilometres into the AIS interior and feed ice stream trunks that are typically tens of kilometres in width, hundreds of kilometres in length, and flow velocities between 0 to 800 m per year (Stokes \& Clarke, 1999; Rignot et al., 2011; Bamber, Vaughan \& Joughin, 2000). 
Ice streams can be either topographically constrained, or constrained by areas of slower moving ice surrounding the faster channel, and are defined as topographic ice streams or pure ice streams, respectively. Both types of ice stream frequently occupy areas of topographic lows, as the thicker ice can lead to a faster velocity and greater driving stress at the bed (Bennett, 2003; Cuffey \& Patterson, 2010). Thicker ice has higher basal temperatures enhancing basal sliding due to melting (Benn \& Evans, 2010). A thick layer of deforming till can be developed through the movement of subglacial sediments, which results from ice flow over unconsolidated beds, and facilitates more rapid ice flow than pure internal deformation (Alley et al., 1986; Alley, 1989). A low, basal effective pressure (i.e. the difference between the water pressure and the ice overburden pressure at the ice base) is often associated with faster ice stream flow and is thought to be fundamental to glacier dynamics (Boulton \& Hindmarsh, 1987). This is observed on both the Whillans Ice Stream (WIS) and Bindschadler Ice Stream (BIS; Blankenship et al., 1987; Blankenship et al., 1986; Kamb, 2001). There is also growing evidence that soft, deformable sediments are a requirement for faster ice flow, and understanding the subglacial environment is important to understand ice stream location and behaviour (Winsborrow, Clark \& Stokes, 2010).

The velocity, thickness, and grounding zone (i.e. the zone where the ice begins to float and transition from the ice sheet to the ice shelf) locations of ice streams are variable both spatially and temporally, with Antarctic observations showing stagnation, deceleration, acceleration, lateral migration and thinning of ice streams (Joughin \& Tulaczyk, 2003; Livingstone et al., 2012; Rignot, 2008; Retzlaff \& Bentley, 1993). The complex mechanisms that control this variable ice flow are not well characterised (Vaughan \& Arthern, 2007); however, subglacial conditions exert an important control on long- and short-term ice stream fluctuations (Anandakrishnan et al., 2007; Winsborrow et al., 2010; Bougamont et al., 2015; Colleoni et al., 2018). Other controlling mechanisms are thought to include oceanic temperatures, sea level changes, atmospheric temperatures, as well as physical conditions such as topographical pinning points, meltwater beneath ice streams, and drainage basin size (Livingstone et al., 2012).

\section{Siple, Shirase, and Gould Coast Ice Streams}

Some of the world's only pure ice streams (i.e. they are not topographically defined, but instead shear zones mark their boundaries; Truffer \& Echelmeyer, 2003) are located on Siple, Shirase, and Gould Coasts, on the WAIS side of the Ross Ice Shelf (RIS), which discharge approximately $40 \%$ of the ice from the entire WAIS into the RIS (Price 
et al., 2001). These ice streams are considered to be of particular interest as they are likely important to the stability of the WAIS under changing climatic conditions (Bennett, 2003; Alley \& Bindschadler, 2001). These ice streams range between 300 to $500 \mathrm{~km}$ in length, up to $50 \mathrm{~km}$ wide, and $1 \mathrm{~km}$ thick, with ice velocities of 100 to 800 $\mathrm{m}$ per year (Bennett, 2003). Between the ice streams the ice sheet is frozen to the bed, and these margins are characterised by lateral shear zones and crevasses (Bentley, Lord \& Liu, 1998). The Kamb Ice Stream (KIS) and BIS both overlie local sedimentary basins, whereas the surrounding non-streaming areas overlie areas with thin or no basal sediments (Peters et al., 2006; Winsborrow, Clark \& Stokes, 2010).

The Siple Coast Ice Streams (SCIS) display ice flow velocity variation, both between the ice streams, as well as variation of internal ice velocities. This is observed in the stagnated KIS (see Section 1.2.3), the stagnation and reactivation of the WIS 850 and 450 years ago, respectively, and the currently flowing BIS (Joughin et al., 2002; Joughin \& Tulaczyk, 2002; Retzlaff \& Bentley, 1993; Conway et al., 2002; Catania et al., 2012). Pure ice streams are essentially unstable, and as some of these glaciers are currently thinning, a reduction of driving stress could lead to ice velocity deceleration (Joughin et al., 2002). However, some of these ice streams have thickening ice accumulation areas, such as the KIS. The KIS currently has a positive mass balance, as there is no ice discharge from its system (Joughin \& Tulaczyk, 2002; Pritchard et al., 2012). Due to the thinning of the WIS, some ice flow which previously discharged into the KIS currently discharges into the WIS instead (Conway et al., 2002). Grounding zones of the SCIS have also experienced advance and retreat over the previous centuries (Catania et al., 2012), with suggestions that they could experience punctuated rather than continuous change with changes to the discharge regime (Elsworth \& Suckale, 2016). Bougamont and others (2015) have also shown that instability and weak basal resistance in the upper region of the KIS can lead to major restructuring of the SCIS flow, and the potential reactivation of the KIS (van der Wel, Christoffersen \& Bougamont, 2013). This high variability over relatively short timescales makes it difficult to utilise short term observations for meaningful, long term conclusions. However, short term observations can be combined with centennial to millennial ice sheet modelling in order to understand their response to future environmental change and geologic constraints.

\subsubsection{Grounding Zone}

The point where the ice begins to float and transition from the ice sheet to the ice shelf is called the grounding zone (Figure 1.1), which is applicable in areas where the 
ice surface gradient is low, and there is a larger transition zone between barely floating and lightly grounded ice (Benn \& Evans, 2010). Identification of the grounding zone is possible from surface elevation data; due to the transition in basal friction, and is observable as a break in slope, as well as a high gradient zone (Dowdeswell et al., 1994; Rignot et al., 1997). It is also observable in both radar and seismic data surveys conducted over grounding zone areas (e.g. Jezek et al., 1979; Ananadakrishnan et al., 2007; Catania, Hulbe \& Conway, 2010; Horgan et al., 2017).

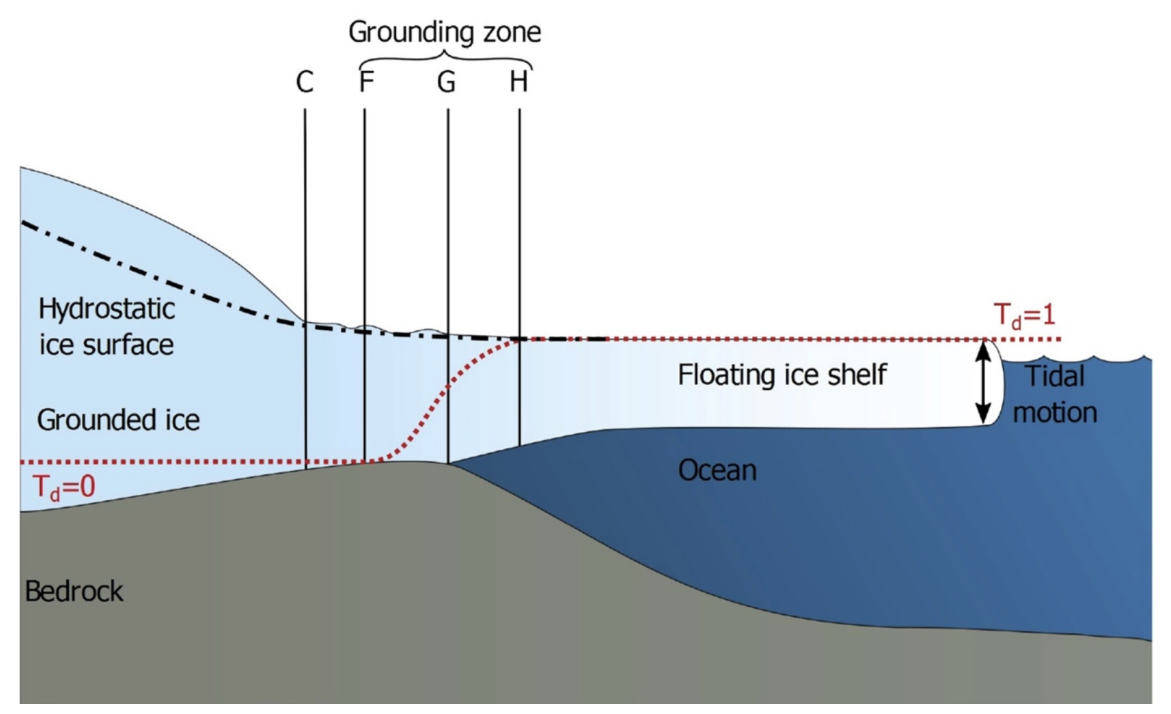

Fig. 1.1 Schematic drawing of an ice sheet grounding zone (adapted from Friedl et al. 2020 and references therein). The schematic indicates the true landward limit of tidal ice flexure (F), the true grounding line $(\mathrm{G})$, landward limit of freely floating ice $(\mathrm{H})$, and the coupling line $(\mathrm{C})$. The hydrostatic ice surface is indicated by the black dashed line, while the red dotted line indicates the amplitude of tidal flexure on grounded ice $\left(\mathrm{T}_{d}=0\right)$ and on freely floating ice $\left(\mathrm{T}_{d}=1\right)$

\section{Marine Ice Sheet Instability}

The stability of the grounding zone to retreat or advance depends on the system's response to an initial ice thickness perturbation, and in particular whether feedback processes increase or decrease the initial perturbation. In the Marine Ice Sheet Instability (MISI) theory, a key feedback exists between the ice thickness and ice discharge at the grounding zone, as well as the bed slope beneath the ice sheet. Generally the ice discharge (or ice flux, $Q$ ), increases with ice thickness at the grounding zone, and these are related by a power-law relationship (Weertman, 1974; Schoof, 2007a; Tsai et al., 2015). If the marine ice sheet is based on a reverse bed slope (i.e. where the bed slopes downward away from the ocean), an initial retreat in grounding zone position will lead to an increase in ice thickness and an increase in ice discharge at 
the grounding zone (Figure 1.2, panel a). This increase in ice discharge could lead to further, self-sustaining, grounding zone retreat.

In idealised, unbuttressed ice streams, this positive feedback process means that there is no stable grounding zone position in sections of reversed bed slopes (Figure 1.2, panel b; Schoof, 2007a, 2007b). However, in realistic ice stream systems the buttressing effect of ice shelves has a stabilising effect on marine ice sheets (Goldberg, Holland \& Schoof, 2009; Gudmundsson, 2013; Fürst et al. 2016; Pattyn, 2018). Jamieson and others (2012) as well as Gudmundsson and others (2012) present simulations that show the ability of grounding zones to stabilise on reverse bed slopes, where ice stream width and retreat history, as well as bed topography, can inhibit retreat, for example through the presence of pinning points. Large sections of the WAIS rest on bed slopes that deepen away from the ocean, which highlights the relevance of MISI on this potentially unstable ice sheet (Fretwell et al., 2013). Ice streams are also sensitive to changes of grounding zone force balances (Waibel et al., 2018), and small changes could propagate up the ice streams, affecting ice discharge and ice sheet mass balance (Payne et al., 2007).
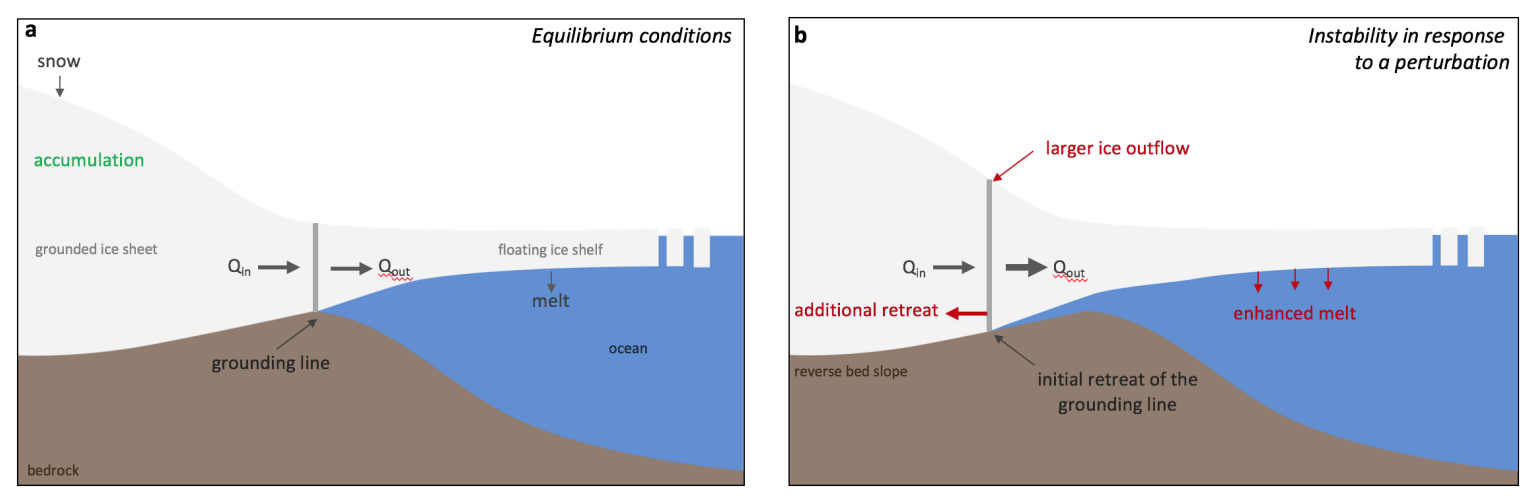

Fig. 1.2 Schematic of the Marine Ice Sheet Instability processes that lead to a potential unstable retreat of the grounding zone showing the initial geometry and ice fluxes of a marine ice sheet under equilibrium conditions (a) and the start of self-sustained grounding zone retreat due to climatic changes (b). $Q$ refers to the incoming and outgoing ice fluxes of the ice sheet. Modified from Church and others (2013).

\subsubsection{Subglacial Environment of the Antarctic Ice Sheet}

The character of the subglacial environment can exert an important control on longand short-term fluctuations in ice sheet and ice stream flow. It is therefore important to characterise the subglacial environment and processes in order to predict future ice stream flow, and is the focus of many studies (e.g. Scambos et al., 2009; Bougamont et al., 2015; Anandakrishnan et al., 2007; Colleoni et al., 2018; Stearns et al., 2008; 
Winsborrow et al., 2010). Many subglacial processes and conditions, such as till friction angle, sediment saturation and porosity, basal deformation, and subglacial till hydrological coupling are not well constrained or quantified (Bougamont et al., 2015). Some studies have shown that, for example, basal friction from an increase in icesediment contact has the ability to slow and thicken ice (Alley et al., 2007), whereas an increase in basal meltwater may accelerate flow (Stearns et al., 2008). These processes are particularly important near and beneath ice streams, where subglacial hydrology and thermal regimes play an important role in their overall velocity (Bougamont et al., 2015; Schoof, 2004; Joughin \& Alley, 2011). Figures 1.3 and 1.4 illustrate the effects of changing water content and pressure can have on subglacial sediment deformation and basal sliding. Basal conditions also play a large role in pinning the ice shelf at the grounding zone, and determining whether ice streams are stagnated (e.g. KIS; Catania et al., 2006) or flowing (e.g. WIS, which has previously been stagnant; Hulbe \& Fahnestock, 2007). The influence of warmer climatic conditions on AIS basal conditions remains a focus area of studies, as well as the related effects this may have on ice stream and ice sheet velocity. Therefore, there is still a need to focus efforts on characterising the subglacial environment from observations, as the interactions between processes are inadequately quantified (Bougamont et al., 2015; Bueler \& Brown, 2009). 

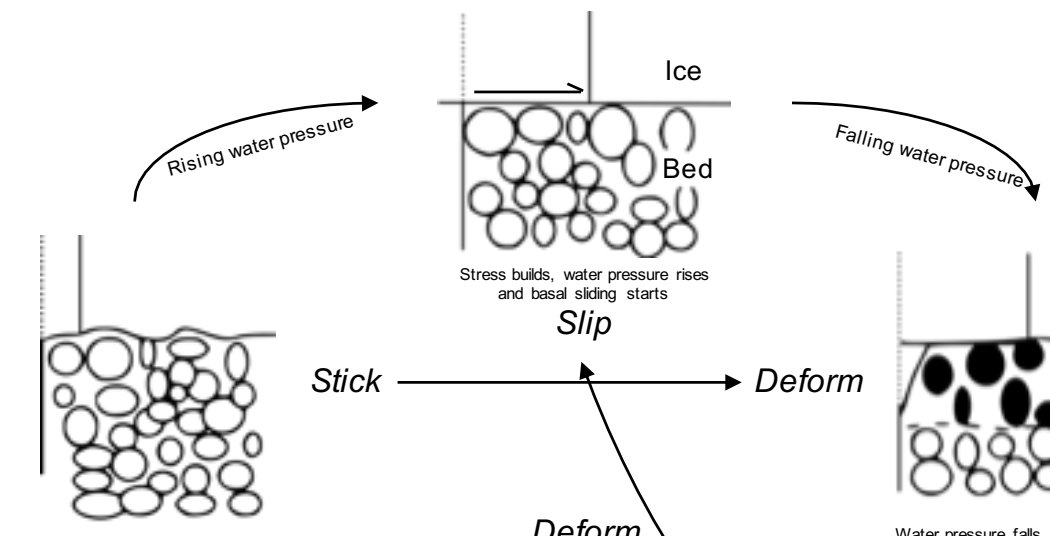

Water pressure falls below threshold for

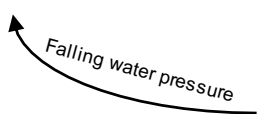

Stress builds, water pressure rises

Slip
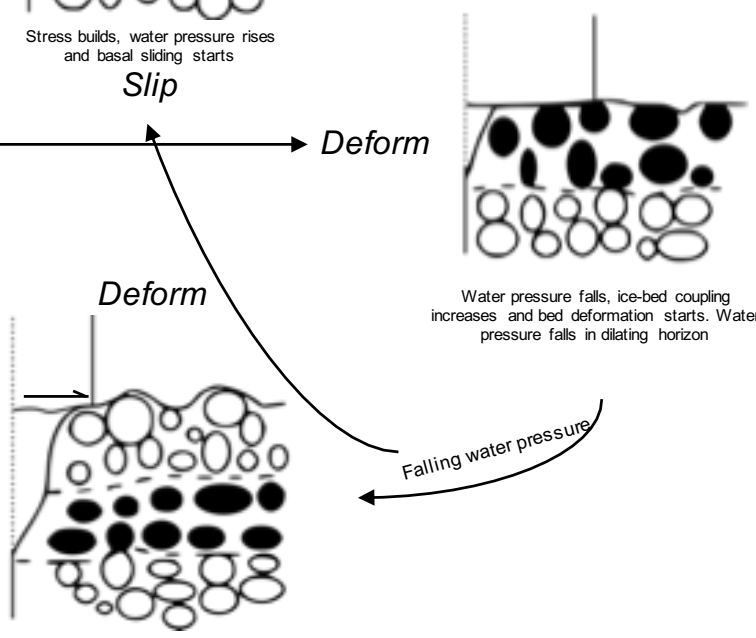

Deformation concentrates at

level of maximum water pressure

Fig. 1.3 The subglacial till cycle illustrates how changes in water pressure can lead to, or reduce, subglacial deformation, change basal sliding velocities and increase ice-bed coupling. Modified from Evans and others (2006).

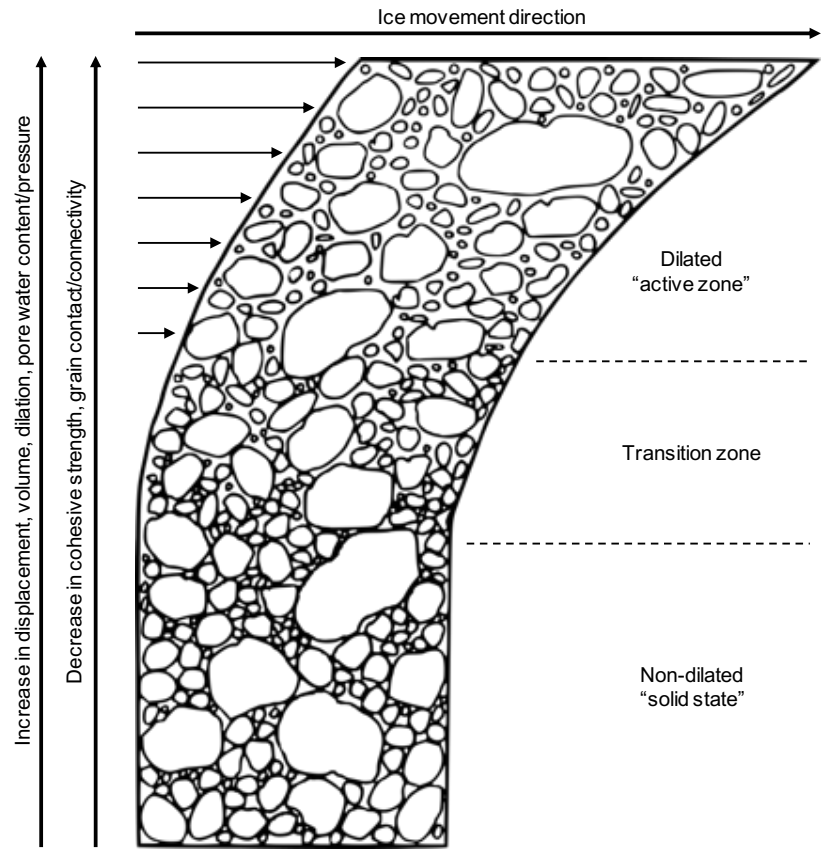

Fig. 1.4 A simplified till cross section illustrates the zonation of a relatively homogeneous subglacially deforming material and its relationship to dilation, displacement, sediment volume, cohesive strength, connectivity and pore water pressure. Modified from Evans and others (2006). 


\section{Basal Sedimentary Controls on the Antarctic Ice Sheet}

Sediments that have a high porosity can provide a weaker, more easily deformable subglacial environment that reduces basal drag, increases basal sliding, and consequently facilitates faster ice flow (Boulton \& Jones, 1979; Bentley, 1987; Boulton \& Hindmarsh, 1987; Brisbourne et al., 2017). Large areas of the WAIS rest on weak, unconsolidated sediments, which is thought to enable the relatively rapid ice flow of the SCIS into the RIS (Blankenship et al., 1986; Kamb, 2001).

The driving stresses of these ice streams are approximately an order of magnitude lower than other outlet glaciers, yet these ice streams have comparable ice velocities (Alley et al., 1986; Rignot et al., 2011). Interesting contrasts are also exhibited in these ice streams, for example, studies suggest that the WIS is underlain by up to $13 \mathrm{~m}$ deformable sediments, which have a high porosity of approximately $48 \%$, as well as a heterogeneous grain size (Blankenship et al., 1987; Tulaczyk et al., 2001). A similar layer has been observed beneath the BIS, which has a higher porosity of approximately 50-60\% (Kamb, 2001). Till porosity varies widely over the WIS area, and is likely also dependent on the hydrological conditions (Blankenship et al., 1986; Luthra et al., 2016). Borehole observations from the WIS showed that it moves over soft, unconsolidated till, and suggest that $70-80 \%$ of this motion is due to basal sliding (Dowdeswell, ÓCofaigh \& Pudsey, 2004). Deformation of a thin sediment layer is thought to contribute approximately $25 \%$ of the total ice flow (Engelhardt \& Kamb, 1998; Tulaczyk et al., 1998). Borehole experiments show that approximately $80 \%$ of movement of the BIS is shown to be due to sediment deformation (Kamb, 2001). Even though the SCIS are often associated with deformable till and ice flow due to basal slip, the role of subglacial deformation and hydrology remains an area of investigation as its full contribution toward ice flow is not well characterised (e.g. Bougamont et al., 2015; Brisbourne et al., 2017; Diez et al., 2018).

\section{Basal Hydrological Controls on the Antarctic Ice Sheet}

Early studies (e.g. Iken, 1972; Budd et al., 1979; Bindschadler, 1983) highlighted the possible link between basal sliding and subglacial water pressure. Basal ice conditions can range from a warm bed at pressure melting point, with liquid water in saturated sediments, subglacial lakes and conduits, to a cold and frozen bed (Pattyn, 2010; Carter et al., 2009). Observational evidence has established that there is an active subglacial drainage system of saturated till beneath the AIS, with subglacial lakes connected by water conduits (see Figure 1.5; Wingham et al., 2006; Fricker \& Scambos, 2009; Gray 
et al., 2005; Fricker et al., 2007). Subglacial water can lubricate the bed and reduce basal drag, which increases sliding, alters the thermal regime, and warms the basal ice (Fricker et al., 2007; Stearns et al., 2008; Winsborrow et al., 2010). Conversely, water can also form channels and conduits, concentrating subglacial discharge, which slow ice flow due to an increase in the basal drag (Downs et al., 2018) and water "piracy" has been suggested as a possible reason for KIS stagnation (Retzlaff \& Bentley, 1993; Anandakrishnan \& Alley, 1997).

Basal temperatures and the pressure melting point are important factors for the presence of subglacial melting and meltwater. As the pressure melting point is a function of ice thickness, it can be estimated for most of Antarctica (Fretwell et al., 2013); however, the basal temperature distribution is not well quantified and is largely derived from modelling studies that incorporate modelled geothermal heat fluxes (e.g. Pollard et al., 2005; Shapiro \& Ritzwoller, 2004; Fox Maule et al., 2005; Purucker, 2013; An et al., 2015; Martos et al., 2017).

Ice overburden pressure, determined by bed topography, surface topography, and gravity influence water storage and location beneath ice sheets. Water will flow along the steepest hydrological potential gradient towards areas of low hydrological potential (Figure 1.5; Shreve, 1972; Livingstone et al., 2013). In Antarctica, subglacial lakes form readily in topographic basins due to the continent's overall low hydrological potential gradient (Le Brocq et al., 2009; Livingstone et al., 2013; Willis et al., 2016; Wright \& Siegert, 2012). Earlier studies such as Smith and others (2009), detected 124 subglacial lakes by ICESat, while more recent studies identified over 400 smaller subglacial lakes beneath the AIS using satellite imagery, as well as larger lakes such as Lake Vostok (Figure 1.5; Siegert et al., 2016). The presence of these active lakes are evidence of the non steady-state component of subglacial hydrology beneath the AIS. Where topography does not provide much influence on ice flow, the subglacial sedimentary and hydrological conditions have a higher degree of control over the behaviour, rate and extent of ice stream development and flow (Blankenship et al., 1986; Engelhardt \& Kamb, 1998; Tulaczyk et al., 1998; Bougamont et al., 2015; Schoof, 2004; Joughin \& Alley, 2011). 


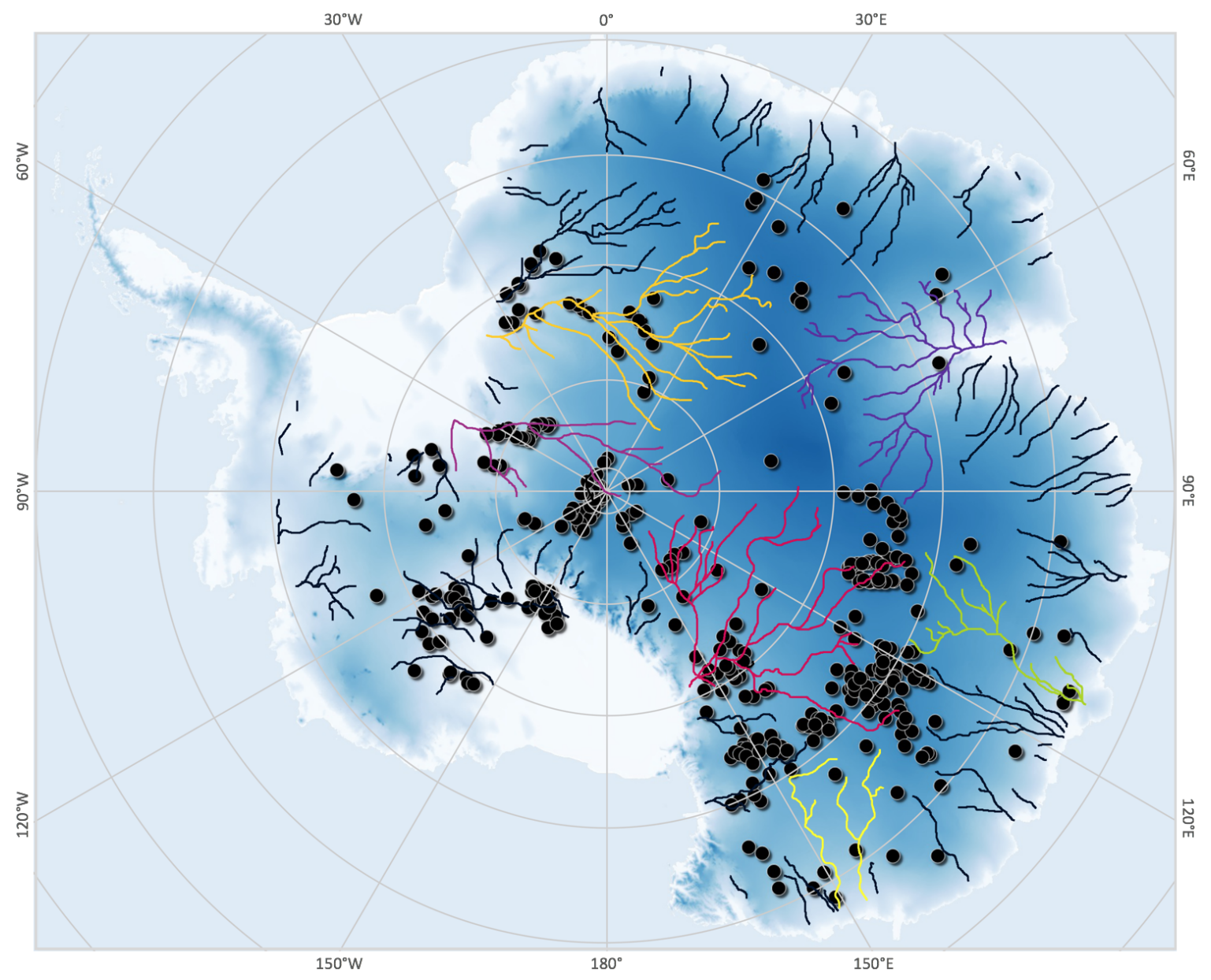

Fig. 1.5 The location of 400 known Antarctic subglacial lakes, the ice-sheet surface elevation, and large-scale flow paths of subglacial water. Some of the larger drainage basins are coloured where no specififc significance is attached to the colours. Adapted from Siegert, Le Brocq and Payne (2009) and Siegert and others (2005).

Studies show a wide range of basal conditions beneath ice streams. For example, the stability of the Institute and Möller Ice Streams discharging ice into the Filchner-Ronne Ice Shelf (FRIS) are inferred to be influenced by a combination of basal sediments and water, and to have potentially experienced instabilities in the past (Bingham \& Siegert, 2007a; Ross et al., 2012; Jordan et al., 2013; Rippin et al., 2014; Siegert et al., 2016). Water from multiple subglacial lakes beneath the Recovery Glacier is thought to exert an important control on ice flow, and a large subglacial lake was inferred from surface slope analysis (Siegert \& Bamber, 2000; Bell et al., 2007; Le Brocq et al., 2008; Fricker et al., 2014). In the Slessor Glacier, two of the three main contributing tributaries are thought to be driven largely by internal deformation, and one by the presence of water and sediments (Rippin et al., 2003; Rippin et al., 2004). The main channel of the Slessor glacier also has small subglacial lakes identified beneath, as well 
as a thick sediment layer thought to play an important role in ice dynamics (Bamber et al., 2006; Shepherd et al., 2006; Smith et al., 2009). In another example, Smith (1997) contrasted areas of both dilated and lodged till along a seismic line beneath the Rutford Ice Stream.

\section{Geothermal Heat Flux}

Affecting the basal interface of the ice sheet, the GHF is an important control and boundary condition that helps determine whether melt or freezing is occurring beneath an ice sheet (Joughin et al., 2004; Pollard et al., 2005; Joughin et al., 2009; Golledge et al., 2014). Significant spatial variation of the GHF is known beneath the WAIS, because it overlies areas of volcanic activity and the West Antarctic Rift System (WhiteGaynor et al., 2019; Van Wyk de Vries et al., 2018). However, direct observations and measurements of the GHF are limited, as measurements are difficult to obtain, and as a result, GHF models interpret the GHF distribution differently (Figure 1.6). These maps show the spatial variation of GHF, with panels $\mathrm{E}$ and $\mathrm{F}$ showing the most recent models based on seismic data (An et al., 2015) and high resolution magnetic measurements (Martos et al., 2017). There is also significant variation between the two models. 

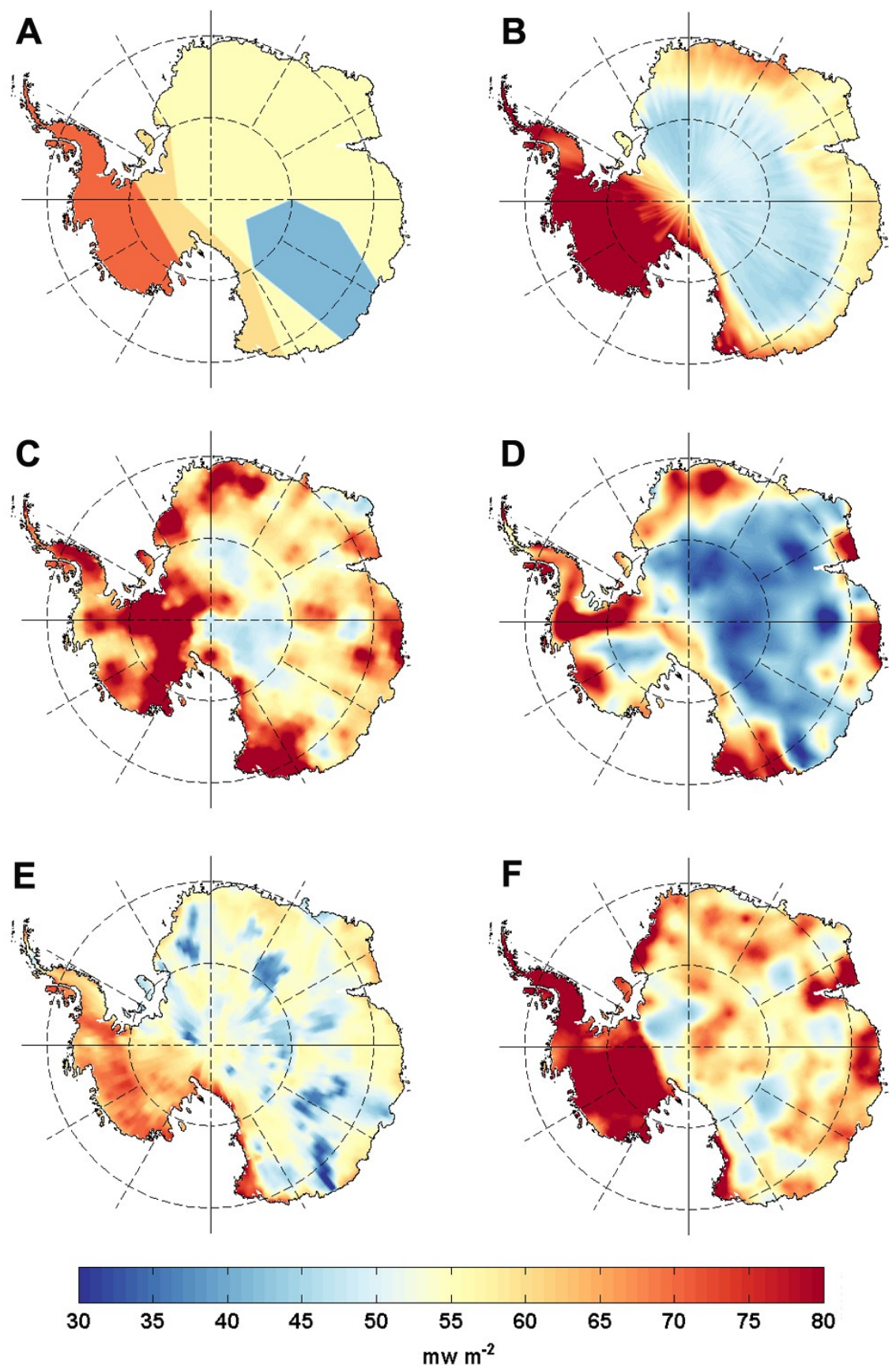

Fig. 1.6 Models of geothermal heat flux. (A) Pollard et al., (2005); (B) Shapiro and Ritzwoller (2004); (C) Fox Maule et al., (2005); (D) Purucker, (2013); (E) An et al., (2015) and (F) Martos et al., (2017). Figure from Van Liefferinge (2018).

The few measurements from direct observations that exist (e.g. Figure 4.10), such as $69 \mathrm{~mW} \mathrm{~m}^{-2}$ inferred at Siple Dome (Engelhardt, 2004), are similar to average continental crust GHF estimations (e.g. $71 \mathrm{~mW} \mathrm{~m}^{-2}$, Davies \& Davies, 2010). It is unclear whether the value at Siple Dome is representative of the entire West Antarctic 
GHF; however, it has been used to infer melt and refreezing rates beneath the WAIS (Joughin et al., 2004; Joughin et al., 2009). Other measurements, such as those from the WIS grounding zone and Whillans subglacial lake (Begeman et al., 2017; Fisher et al., 2015) show a range of values over a $100 \mathrm{~km}$ distance, from $88 \pm 7 \mathrm{~mW} \mathrm{~m}^{-2}$ to 285 $\pm 80 \mathrm{~mW} \mathrm{~m}^{-2}$, respectively. Both Martos and others (2017) and An and others (2015) infer lower values by a factor of two at the Byrd ice core site, of $136 \pm 22 \mathrm{~mW} \mathrm{~m}^{-2}$ and $68 \mathrm{~mW} \mathrm{~m}^{-2}$, respectively (Figure 1.6), while Carson and others (2014, and references therein) present borehole GHF measurements between 60 and $164 \mathrm{~mW} \mathrm{~m}^{-2}$ from the McMurdo Sound and Western Ross Sea. Thus, there is still a large uncertainty of the GHF beneath the WAIS, including the Ross Sea Sector.

\subsection{Geographical Setting}

\subsubsection{West Antarctic Ice Sheet}

As the world's largest store of fresh water, the AIS holds approximately $26.1 \times 10^{6} \mathrm{~km}^{3}$ of ice (including the fringing ice shelves), spread over an area of $13.9 \times 10^{6} \mathrm{~km}^{2}$ (Fretwell et al., 2013). The AIS is composed of two 'sub-ice sheets', the East Antarctic Ice Sheet (EAIS) and the WAIS, separated by the Transantarctic Mountains (TAM) which run across the continent. Approximately $8.5 \%$ of the total grounded ice is below sea level, as most of the WAIS, and large sections of the EAIS, are grounded below sea level (Lythe et al., 2001; Bamber et al., 2007). If the AIS were to melt completely, it could contribute an equivalent of up to $58.3 \mathrm{~m}$ of sea-level rise (Fretwell et al., 2013). While the EAIS is the larger of the two ice sheets, it is also the more stable when subjected to increases in ocean and atmospheric temperatures (Sugden et al., 1995; Marchant et al., 2002; Siegert, 2008). Large sections of the WAIS are grounded below sea level and lie on bedrock that slopes towards the interior of the ice sheet (Fretwell et al., 2013). This makes the WAIS more vulnerable to the risk of MISI, where atmospheric and oceanic warming could result in increased melting and recession of the grounding zone (Bamber et al., 2009). Complete melting of the WAIS could raise global sea level by an average of $4.3 \mathrm{~m}$ (Fretwell et al., 2013), however, Bamber and others (2009) predict a sea level rise of approximately $3.3 \mathrm{~m}$ if WAIS melting occurred due to MISI. Figure 1.7 shows the location of the WAIS, RIS and the KIS. 


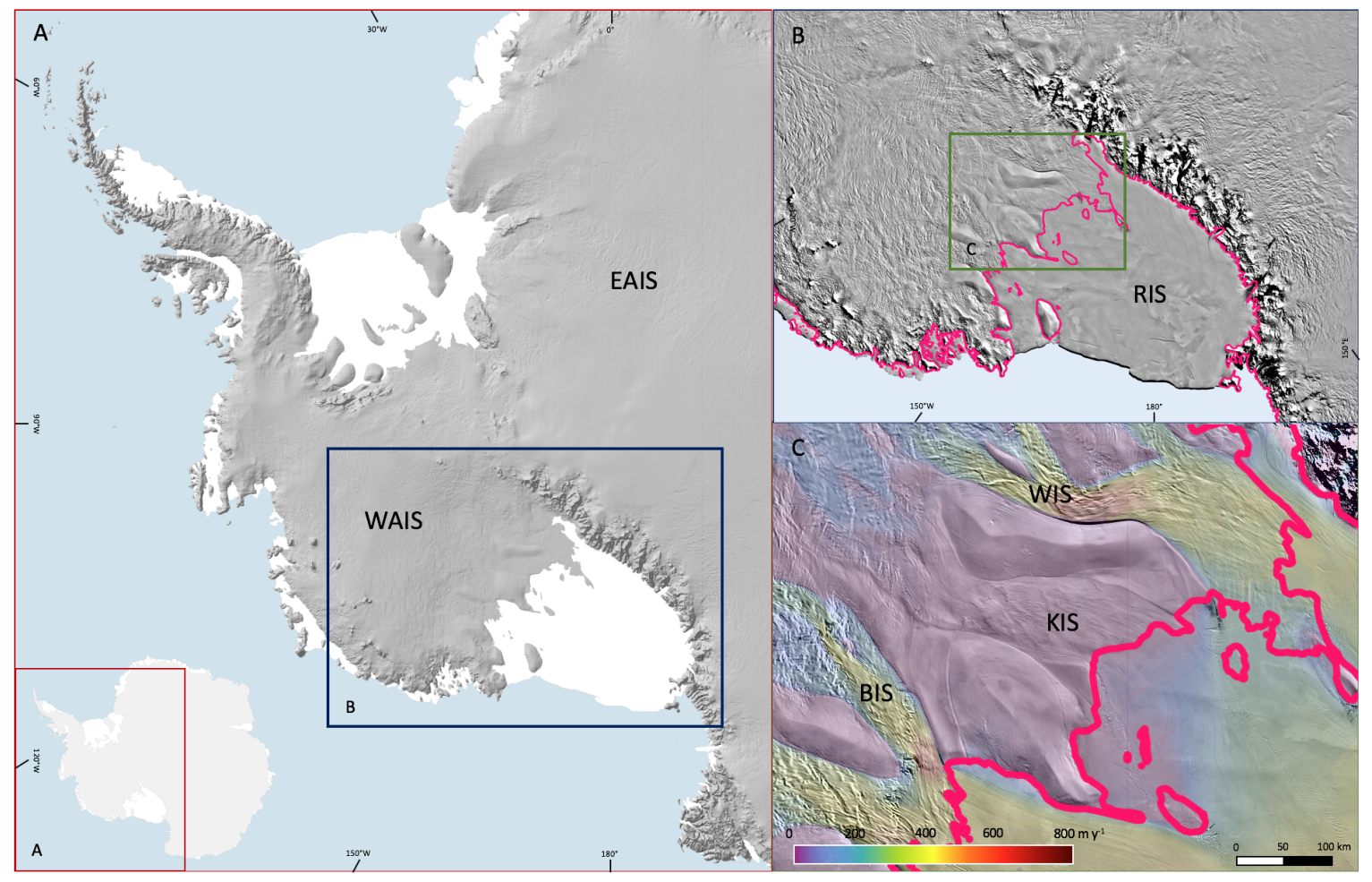

Fig. 1.7 Series of maps showing the location of the West and East Antarctic Ice Sheets (WAIS and EAIS respectively; A), the Ross Ice Shelf (RIS; B), and some of the Siple Coast ice streams (C; Kamb Ice Stream - KIS; Whillans Ice Stream - WIS; Bindschadler Ice Stream - BIS). Maps A, B, and $\mathrm{C}$ show the MODIS MOA surface morphology (Haran et al., 2014), while map C also has the MEaSUREs ice velocity data overlain (Rignot, Mouginot \& Scheuchl, 2011). The grounding line (pink) is inferred from the MEaSUREs ice velocity data (Rignot et al., 2011). Data and sources are found in Quantarctica3 (Matsuoka, Skoglund \& Roth, 2018)

\subsubsection{Ross Ice Shelf}

The RIS is the world's largest ice shelf. It buttresses ice flow from the EAIS through the TAM outlet glaciers, and ice flow from the WAIS ice streams (Denton, 2000; Rignot et al., 2008; Anderson et al., 2002; Pollard et al., 2015). The RIS is an important interface between the two ice sheets and the ocean, and understanding the ice shelf's response to past climatic change, as well as its present-day state and processes, is important for projections of future change. The potential loss of the RIS as a buttressing ice shelf makes the WAIS vulnerable to rapid ice loss during climatic warming (DePoorter et al., 2013). Ice-sheet model simulations suggest that collapse of the RIS would accelerate global sea level rise due to faster ice discharge from the ice streams (Figure 1.8; Golledge et al., 2015; DeConto \& Pollard, 2016). Determining the rates at which physical processes, such as ice shelf melt, basal sliding, subglacial 
deformation, crevassing and rifting, occurred in the past can improve our models for future change predictions. 
a

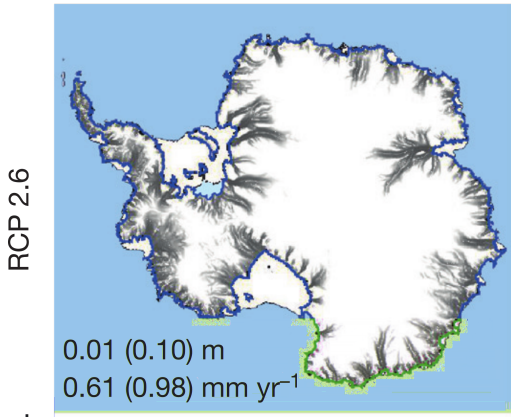

d

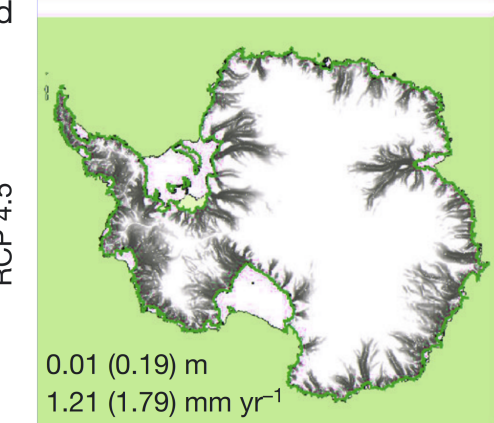

g
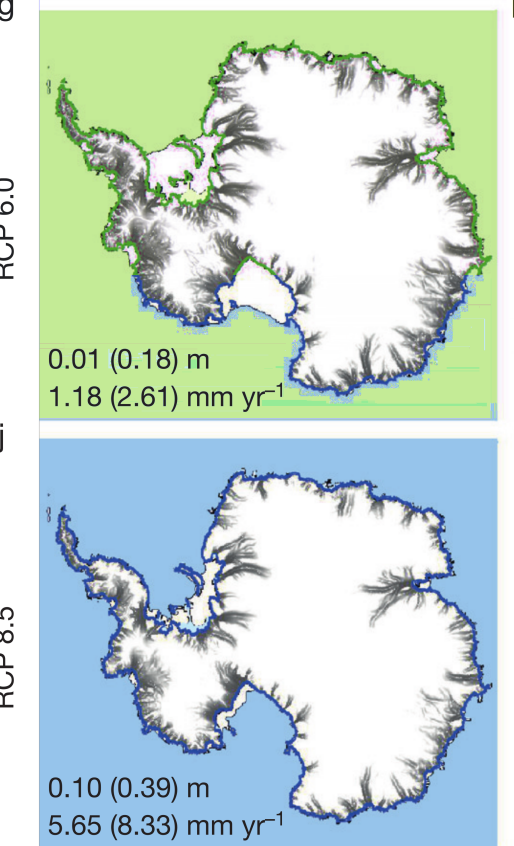

b
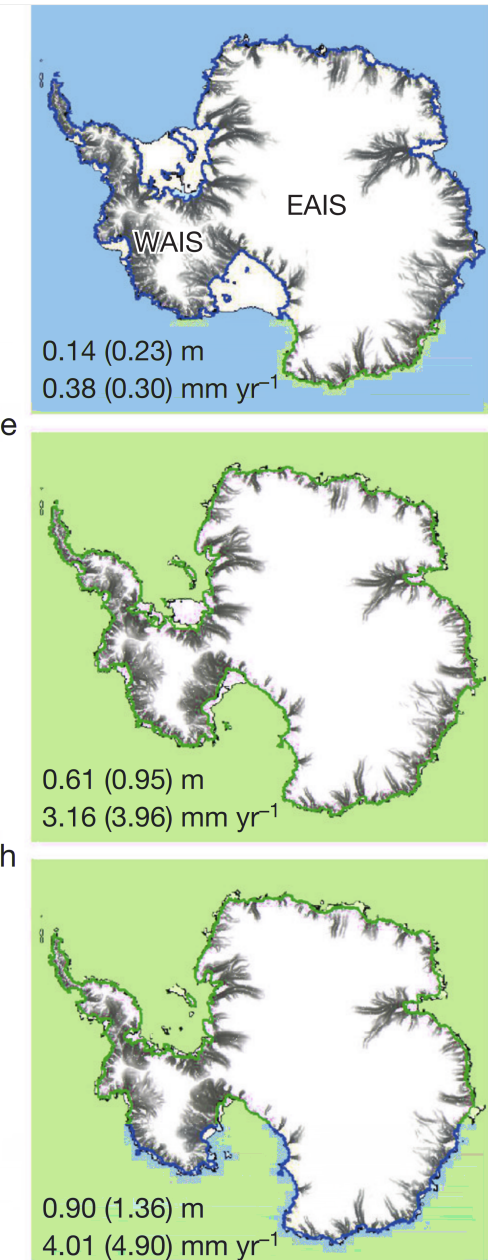

k

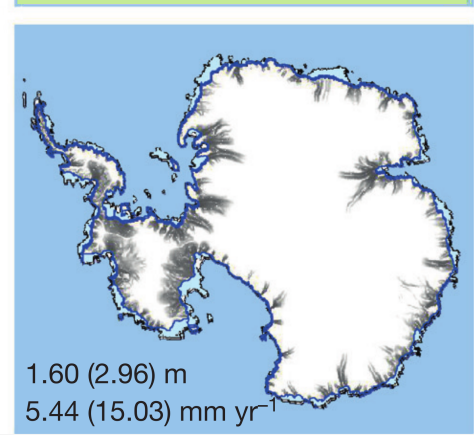

C
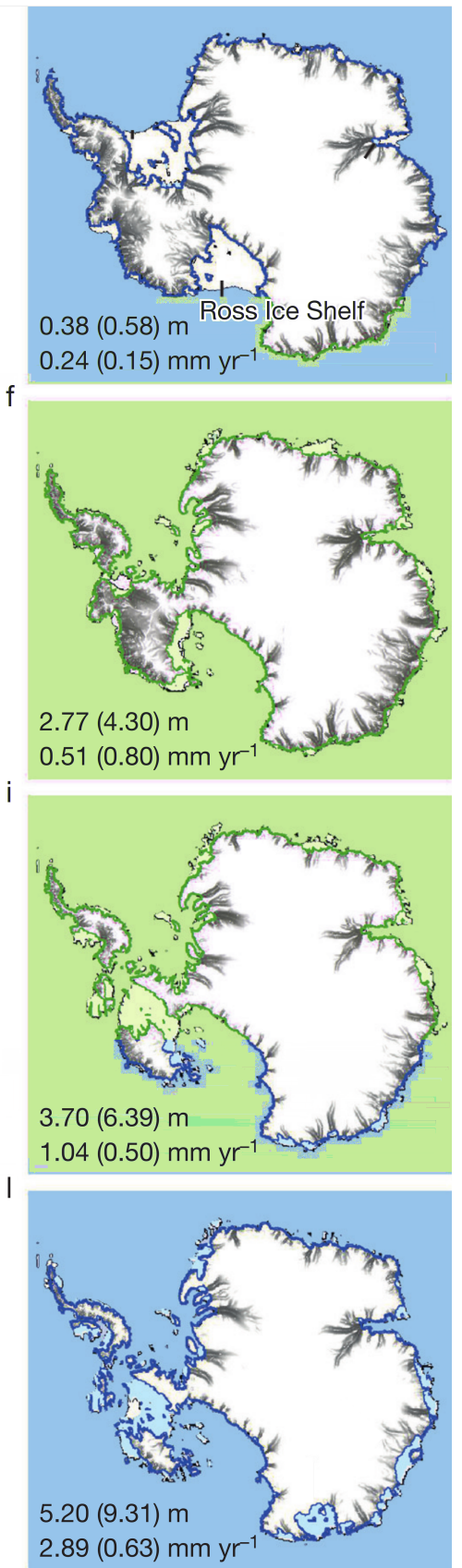

Forced

$\longrightarrow$ Committed $\longrightarrow$

Fig. 1.8 Future modelled ice sheet evolution under Representative Concentration Pathway (RCP) based warming scenarios at $2100 \mathrm{CE}(\mathrm{a}, \mathrm{d}, \mathrm{g}, \mathrm{j}), 2300 \mathrm{CE}(\mathrm{b}, \mathrm{e}, \mathrm{h}, \mathrm{k})$ and $5000 \mathrm{CE}(\mathrm{c}, \mathrm{f}, \mathrm{i}, \mathrm{l})$. The magnitudes and rates of sea-level contributions are shown for each panel, for both high and low grounding zone sensitivity experiments (which are shown in the parentheses). Faster ice velocities are indicated in grey, slower in white. WAIS, West Antarctic Ice Sheet; EAIS, East Antarctic Ice Sheet; (Golledge et al., 2015). 


\subsubsection{Kamb Ice Stream}

The KIS is one of the six main ice streams that drain the WAIS into the RIS. Current observations of the KIS show that it is stagnated (Figure 1.7) approximately 160 years ago (Retzlaff \& Bentley, 1993; Catania et al., 2006), likely as a result of a switch of the subglacial drainage system from sheet to channelised flow (Catania et al. 2006). Satellite radar interferometry and GPS surveys have measured present-day surface ice velocities of less than $10 \mathrm{~m} \mathrm{y}^{-1}$ (Conway et al., 2002; Rignot et al., 2011; Engelhardt \& Kamb, 2013), and drilling through the ice stream confirmed that sections of the KIS are frozen to the bed, but liquid water was also found (Engelhardt \& Kamb, 2013). It is likely that the KIS stagnated due to changes in the subglacial sedimentary and hydrological environment, and there are indications that this could be occurring on the WIS (Anandakrishnan et al., 2001; Bindschadler et al., 1996; Peters \& Ananadakrishnan, 2007; Luthra et al., 2016). Radar surveys show agreement with seismic data and borehole results, which show basal variation of frozen and non-frozen areas (Catania et al., 2003; Jacobel et al., 2009). The non-frozen sections could favour fast flow in the future and aid the reactivation of the KIS (Vogel et al., 2005). However, these well-lubricated sections are not present over the entire ice stream. A low, basal effective pressure was also observed by Kamb (2001) in parts of the KIS from borehole experiment analyses. Borehole results indicate a frozen bed near the sticky spot, where it was found that water was unable to easily drain from the borehole, compared to rapid draining in a borehole further away from the sticky spot (Engelhardt, 2004; Luthra et al., 2017). Two other boreholes were drilled near the edge of the sticky spot, where one encountered a $1.4 \mathrm{~m}$ deep water body, and the other drained water after a delay, which suggested there might be some freezing of the bed (Engelhardt, 2004). Analyses of till from beneath other SCIS showed some similarities, such as similar measured mean till porosity the KIS, WIS, and BIS, but also differences, for example that the KIS had overall lower minimum porosity, more variability, and higher maximum till strength (Kamb, 2001).

\subsection{Aim and Research Questions}

The aim of this thesis is to asses how the subglacial environment has a controlling effect on the KIS and its present-day state, and how this may change under future climate change scenarios. 


\subsubsection{Research Questions}

In this research the three following questions are addressed:

1. What are the present-day subglacial properties beneath the Kamb Ice Stream and its grounding zone, and how do we best incorporate or assimilate these in our ice sheet model?

This question is investigated using active source seismology surveys, which provide remote observations of the subglacial environment. Analysis of the seismic data has the potential to provide an insight to the subglacial environment, specifically the sedimentary, deformational and hydrological aspects. Analyses from other ice streams will also be compared, to understand what similarities and differences are observed and inferred between the different ice streams. This research question is explored using seismic data analysis in Chapter 2.

2. What are the responses and thresholds to changing mechanical processes and boundary conditions of the Kamb Ice Stream subglacial environment and its grounding zone?

The second research question aims to characterise how changing boundary conditions of the KIS and RIS affect the mechanical processes that occur at the basal interface, how these affect its ice flow, and at which temporal scales threshold changes are observed. This is investigated using numerical ice sheet modelling, where the KIS and RIS are modelled over the next 1000 years. It also investigates whether the KIS returns to its original state, or whether there is a new state, and whether a steady-state or equilibrium is reached. The numerical modelling allows threshold values to be quantified. This research question is explored using both flowline and whole continent numerical modelling in Chapters 3 and 4.

\section{How will these present-day conditions change under future climatic changes?}

The last research question addresses how the KIS and RIS respond to climatic changes. This question focuses on identifying and quantifying potential changes in subglacial mechanical processes and threshold responses under increasing oceanic and atmospheric warming over the next 1000 years. This research question is explored using both flowline and whole continent numerical modelling in Chapters 3 and 4. 


\subsection{Active Source Seismology}

Active source seismic surveying enables imaging of areas which cannot easily be observed directly, at a relatively low cost and effort compared to other techniques, such as drilling through an ice sheet.

\subsubsection{Development in Ice Environments}

With some of the earliest active source seismic data collected in Antarctica during the Byrd Antarctic Expedition II in 1933-35 on the Bay of Whales (Poulter, 1947), there is a long history of using active source seismic techniques to understand the continent.

This early survey used buried explosive seismic sources and geophones (which convert the analogue ground movement signal into an electrical seismic signal). Following this, surveys conducted in the early 1950s used very similar techniques, with the Norwegian-British-Swedish Antarctic Expedition of 1949-52 burying TNT explosives 2-12 m deep (Robin, 1953; Robin, 1958). In subsequent decades, a multitude of studies (e.g. Bell, 1966; Röthlisberger, 1972; Kirchner \& Bentley, 1979; Determann, Thyssen \& Englehart, 1988; Beaudoin, ten Brink \& Stern, 1992; Smith, 1997) utilised active source seismology to understand ice properties and the subglacial environment in Antarctica. However, acquisition techniques have remained relatively similar (with the exception of data recording and drilling technology improvements). More recent studies (e.g. Smith, 2007; Horgan et al., 2013; Luthra et al., 2016; Horgan et al., 2017; Luthra et al., 2017; Smith et al., 2018), including this one, still utilise explosive seismic sources buried into the ice (often at 20-30 m depths) and some burial of the geophones (0-0.5 m) to conduct seismic surveys in Antarctica. What has changed since the early 1930s, is our ability to process and analyse the collected seismic data, with studies focusing on the quantitative determination of subglacial and seafloor properties using the analysis of seismic amplitudes, and their relationship to material acoustic impedance (e.g. Smith, 1997a, 1997b, 2007; Holland \& Anandakrishnan, 2009; Smith et al., 2015; Smith et al., 2018; see Section 2.1).

\subsubsection{Application}

Seismic data are used in this study to characterise the subglacial environment beneath the KIS, its grounding zone, and beneath the ocean cavity. Seismic waves can be reflected, refracted, and transmitted at an interface that has an abrupt change in seismic velocity and physical properties, and generally the larger the contrast between 
two layers, the stronger the reflection (Mussett \& Khan, 2000). Estimating subglacial acoustic impedance and comparing results to known subglacial properties allows subglacial lithology to be determined (e.g. Figure 1.9). It is also possible to use acoustic impedance as a proxy for porosity, which can be used to distinguish between deforming and non-deforming sediments (Blankenship, 1986; Alley et al., 1986; Alley et al., 1987). A porosity of $30 \%$ or lower would indicate a non-deforming (lodged) sediment, and values closer to $40 \%$ indicate shear deformation of saturated sediments (as the shear deformation often causes dilation and a resultant higher porosity). Other parameters, for example fluid presence, sediment type, and sediment roughness, are also important to characterise in order to understand basal sliding, deformation and hydrology (Holland \& Anandakrishnan, 2009). Seismic reflection amplitudes can aid in the characterisation of subglacial properties such as liquid water presence, sediment and rock types, basal roughness, sediment physical properties (e.g. porosity, thickness, saturation, deformation, consolidation), and water thickness (Smith, 1997a, 1997b, 2007; Holland \& Anandakrishnan, 2009; Smith et al., 2015). Understanding these characteristics is important in order to identify broader scale subglacial mechanisms, such as subglacial hydrology, basal sliding, subglacial till deformation, and internal deformation. Seismic data analysis enables characterisation and quantification of the subglacial environment. These constraints can then be used both as guidance for numerical modelling parameter choices (i.e. to constrain input parameters), and vice versa, where model experiments and parameter choices may help understand the seismic data analysis. 


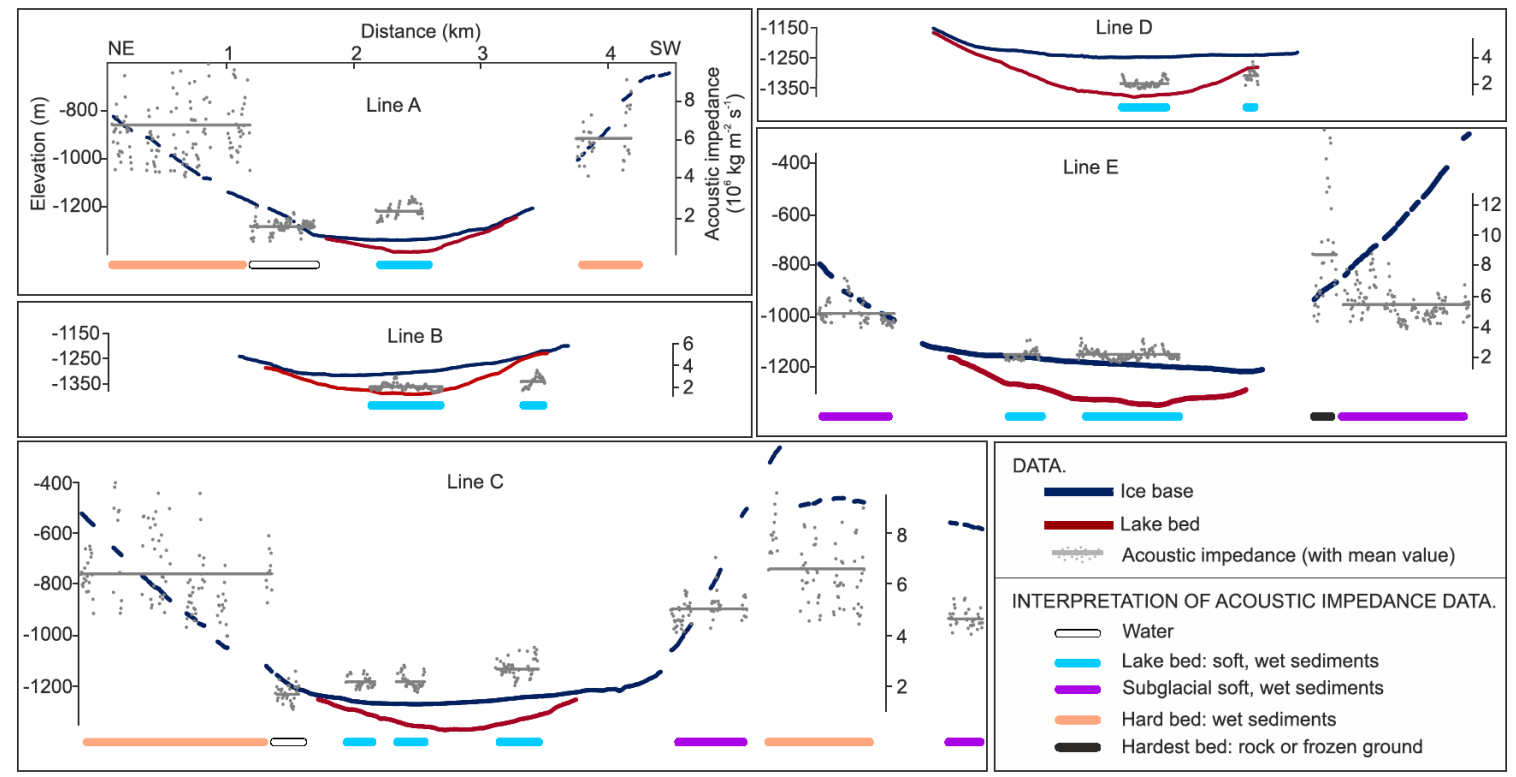

Fig. 1.9 Lake bed and subglacial material interpreted from seismic reflection strengths. The right axes show acoustic impedance determined from reflection strengths, and the left side axes the elevation. Gaps show where clear reflections from the bed are not identified, or their reflection strength is not able to be measured. From Smith and others (2018).

\subsection{Ice Sheet Models}

Numerical ice sheet models attempt to capture complex glaciological, geological, atmospheric, and oceanic processes and interactions to simulate the observed behaviour of ice sheets. Capturing the processes and interactions correctly can then allow past, present, and future behaviour to be investigated (Bindschadler et al., 2013). The modelling process can be designed to minimise differences between modelled and observed data, such as ice sheet velocities and thickness, but no model is likely to capture every aspect correctly (Bindschadler et al., 2013). Furthermore, models need to accommodate different timescales that characterise ice sheet processes. Section 3.1 discusses model components and modelling methodology.

\subsubsection{Development of Ice Sheet Models}

Early numerical ice sheet models utilised laboratory based flow law approximations to calculate ice velocities (Campbell \& Rasmussen,1969, 1970; Rasmussen \& Campbell,1973). After these initial developments, the creation of two-dimensional, dynamic glacier model equations subsequently led to the development of three-dimensional models (Mahaffy, 1976). These early models used a Glen-type ice flow rheology as well 
as shallow ice approximations (SIA; see Section 3.1.1 for a more detailed explanation). A more rigorous and consistent SIA for ice sheet models was later derived by Hutter (1983) and Morland (1984). Simultaneously, the first thermomechanically coupled model was applied to the Greenland Ice Sheet (Jenssen, 1977), and later to the AIS (Budd \& Smith, 1981, 1982; Budd et al 1984). Concurrently, Oerlemans (1982a, 1982b, 1982c, 1983) improved the computational efficiency of thermomechanically coupled ice-sheet models, as well as accounting for glacial isostatic bedrock adjustment, and a basic inclusion of ice shelves in the Antarctic model. Subsequently, Huybrechts and Oerlemans (1988) and Huybrechts (1990) developed the first comprehensive, 3-D, thermomechanically coupled ice-sheet model (i.e. accounts for variations in ice temperature and viscosity with depth), where the AIS included the earlier derived shallow shelf approximation (SSA; see Section 3.1.1). It also included basal sliding and an ice sheet to ice shelf transition model. Herterich (1988) and Bohmer and Herterich (1990) developed a similar model, which included a coupled ice sheet and ice shelf based on the SIA and SSA, respectively, as well as specific treatment of the transition zone. Other 3-D thermomechanically coupled ice-sheet models were developed in the 1990s, which led to the first model intercomparison project, the European Ice-Sheet Modelling Initiative (EISMINT; MacAyeal et al., 1996; Huybrechts et al., 1996; MacAyeal, 1997; Huybrechts, 1998; Oerlemans et al., 1998; Payne et al., 2000). From here, models using the full Stokes simulation of ice flow were developed (e.g. Gudmundsson, 1999; Luthi \& Funk, 2000; Zwinger et al., 2007; Jouvet et al., 2008), which are computationally more demanding than the SIA and SSA models, particularly if also applied to continental-scale ice sheets. A first order approximation of the full Stokes solution was implemented (Saito et al., 2003), as well as a similar model developed by Pattyn (2003). A concentrated effort to create higher-order and full Stokes models led to the Ice-Sheet Model Intercomparison Project (ISMIP; Pattyn et al., 2008), and the later Marine Ice Sheet Model Intercomparison Project (MISMIP; Pattyn et al., 2012).

Currently multiple models are in use in the ice sheet modelling community, with their own specific advantages and disadvantages. Some of the main ice sheet models will be described here, specifically in comparison to the Parallel Ice Sheet Model (PISM) which is used for this study (see Section 1.5.2). Figure 1.10 shows some of the increasing complexities of specific model examples. 


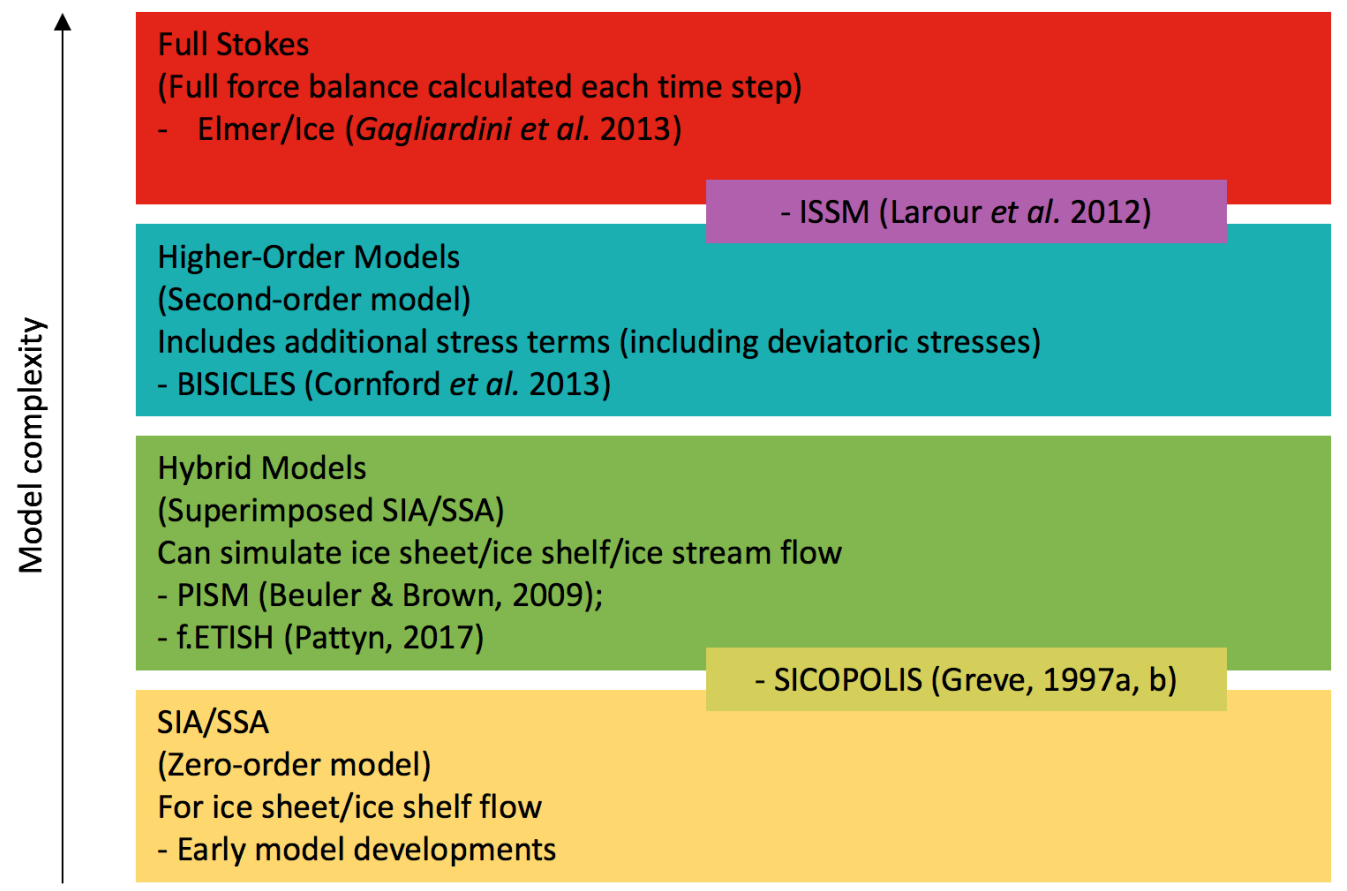

Fig. 1.10 Simplified diagram showing the different levels of ice sheet model complexities, with example models. Figure adapted from Davies (2015).

BISICLES is an adaptive mesh refinement ice-sheet model, with a polygon-based grid that can be resized as needed, allowing for finer resolution near the grounding line. This model has the distinct advantage that adaptive mesh refinement is able to resolve changes along complex boundaries, such as the grounding zone or ice stream margins, by increasing the resolution to capture changes at the correct scale (Cornford et al., 2013). BISICLES uses vertically integrated ice flow calculations that include longitudinal and lateral stresses and a simplified treatment of vertical shear stress (Schoof \& Hindmarsh, 2010), and is most suitable for ice streams and ice shelves.

The fast Elementary Thermomechanical Ice Sheet model (f.ETISH) is a vertically integrated thermomechanically coupled, hybrid ice sheet-ice shelf model. The model uses two different flux conditions for the marine boundary which are coherent with Coulomb basal friction and power-law basal sliding. It has an increased sensitivity of the grounding zone, and is represented by two different conditions, which are consistent with Coulomb basal friction and power-law basal sliding (Pattyn, 2017).

The Ice Sheet System Model (ISSM) is a coupled thermomechanical ice flow model that includes full Stokes approximation anisotropic mesh grids, higher-order stress components, a higher spatial resolution capability, and relies on a parallelised architecture. It utilises classical conservation laws for mass, momentum, and energy 
balances and combines these with material laws and boundary conditions (Larour et al., 2012). An advantage of the ISSM model is the higher-order treatment of complex boundaries (similar to BISICLES) which allows for a better treatment of these areas.

A distinct disadvantage of the above-mentioned models is that there is a lower level of user-controlled parameters for the subglacial environment (e.g. till friction angles) compared to PISM, which is the main focus of this study.

Representation of the grounding zone in ice sheet models has been the focus of multiple studies, and until the development of higher-order models this transition was not accurately captured in models, due to the utilisation of different approximations between the grounded and the floating ice components of the model. The abrupt change from shear dominated flow to flow dominated by longitudinal extension creates issues in modelling this transition, and as a result multiple studies have focused on solving the Stokes equations to better capture the grounding zone transition (e.g. Hindmarsh \& LeMeur, 2001; Hindmarsh, 2006; Pattyn et al., 2006). Vieli and Payne (2005) indicated that capturing this transition zone in ice sheet models is sensitive to grid resolution, which more recent ice sheet models address (e.g. BISICLES and ISSM). An analytical solution was obtained by Schoof (2007a, 2007b) which confirmed that marine ice sheets are susceptible to grounding zone instability, and that in areas of reversed bed slopes and in the absence of buttressing, there is no stable grounding zone position on reverse bed slopes. This model is a two dimensional solution rather than a realistic ice sheet, but it can nonetheless be utilised as a benchmark comparison for marine ice sheet models (e.g. The Marine Ice Sheet Model Intercomparison Project; Pattyn et al., 2012).

\subsubsection{The Parallel Ice Sheet Model}

The Parallel Ice Sheet Model (PISM, version 0.7) was initially developed at the University of Alaska Fairbanks, and is the numerical model used for this thesis. PISM uses a hybrid stress balance that heuristically combines velocity solutions of the SIA and SSA across the model domain (Bueler \& Brown, 2009). PISM simulates two main processes; the mass balance of an ice sheet (i.e. where the ice sheet is either losing or gaining mass) and the flow of the ice sheet. The flow of an ice sheet is a continuous process, represented in ice sheet models using a series of discrete steps where multiple equations are solved and the results are then used as the input for the next series of equations. PISM is a fixed grid, finite difference model with an applied sub-grid grounding zone scheme in this study. It is thermomechanically coupled, where the 
ice temperature is calculated simultaneously with the velocity field. Adaptive time stepping is used, so that the size of the time step changes as each set of calculations proceeds, in order to maintain stability. PISM has been widely used for modelling both the Greenland and the Antarctic Ice Sheets (e.g. Beyer et al., 2018; Colleoni et al., 2018; Golledge et al., 2019), and can simulate ice sheets at temporal scales ranging from decades to millennia. A key strength of PISM is the evolving basal substrate model which allows detailed investigation of basal sediment and hydrological conditions, some of which can be constrained by seismic data analysis. The higher level of user-controlled subglacial parameters will allow for more relevant parameter adjustments in respect to seismic data results.

\subsection{Thesis Structure}

Following the Introduction and Background, this study proceeds methodically, from smaller to larger scales of investigation, beginning with smaller spatial and temporal scale seismic survey results, increasing the temporal and spatial scale to both KIS flowline modelling and WAIS simulations, and lastly focuses on both the KIS and the West Antarctic Ice Sheet under changing climatic conditions over 1000 and 10,000 year scales.

Chapter 2: Kamb Ice Stream Seismic Surveys, reviews the theoretical background of seismic data processing, and describes, analyses, and interprets the results from active source seismology surveys in an effort to understand the subglacial sedimentary and hydrological conditions beneath the present day KIS. Data were collected during both the 2015/2016 and 2018/2019 austral summer Antarctic seasons. This chapter addresses Research Question 1.

Chapter 3: Kamb Ice Stream Flowline Simulations, outlines the theoretical background of numerical ice sheet modelling, and explores the controlling basal conditions, processes, interactions, and thresholds of the KIS and its catchment. This is achieved by using PISM to run a KIS ensemble experiment with differing subglacial conditions over 1000-year periods. This chapter addresses Research Questions 2 and 3.

Chapter 4: West Antarctic Ice Sheet Simulations, explores the basal conditions, processes, interactions, and thresholds of the WAIS, in order to understand the WAIS as a whole and the wider scale impacts of the subglacial environment explored in the previous two chapters. This chapter addresses Research Questions 2 and 3. 
Lastly, Chapter 5: Synthesis, and Chapter 6: Conclusions, discuss the key results from both the numerical modelling and the active source seismology in the context of the research questions, and identify both the key findings as well as areas where further research is required.

\section{Data Acquisition and Data Ownership}

The active source seismology section of this thesis relies on data collected on the Kamb Ice Stream during two austral summer field seasons, 2015/2016 and 2018/2019. The data collected during the 2015/2016 season are provided by Huw Horgan and his collaborators, and in part have been published under Horgan et al., (2017). However, the specific analyses that form part of this thesis have not been previously performed or published. The second data set was collected during the 2018/2019 field season by the author of this study and colleagues after two previous attempts to collect these data were unsuccessful. 



\section{Kamb Ice Stream Seismic Inves- tigation}

Here, active source seismic methods are used to image and characterise the Kamb Ice Stream's substrate near the grounding zone at the present time, and potentially utilise these in comparison to model results in the subsequent chapters. The seismic methodology, data acquisition, processing and analysis, are presented initially, followed by the results, interpretation, and discussion. Seismic data from two seismic surveys, KIS1516 and KIS1819, are processed to calculate the seabed acoustic impedance, providing quantitative constraints of the underlying material. The method produces mean acoustic impedance values for three seismic lines, of $3.5 \pm 2.0 \times 10^{6} \mathrm{~kg} \mathrm{~m}^{-2} \mathrm{~s}^{-1}$ for line KIS1819-1, $2.9 \pm 1.2 \times 10^{6} \mathrm{~kg} \mathrm{~m}^{-2} \mathrm{~s}^{-1}$ for line KIS1819-2, and $3.7 \pm 1.4 \times 10^{6} \mathrm{~kg} \mathrm{~m}^{-2}$ $\mathrm{s}^{-1}$ for line KIS1516-1, which indicate water-saturated, soft sediments. No acoustic impedance was able to be calculated for the grounded section of KIS1516-1 due to the low acoustic impedance contrast at the bed. However, this low contrast indicates a subglacial acoustic impedance similar to that of ice $\left(\sim 3.5 \times 10^{6} \mathrm{~kg} \mathrm{~m}^{-2} \mathrm{~s}^{-1}\right)$. Subglacial material with this acoustic impedance is likely to be dewatered till (Zechmann et al., 2018). Both seismic surveys are compared and contrasted to other ice streams around Antarctica (e.g. Luthra et al., 2016; Horgan et al., 2012; 2013a; 2013b; Brisbourne et al., 2017; Smith \& Murray, 2009; Smith et al., 2015) to characterise subglacial differences. Lastly, linking the porosity and effective pressure provides a method of comparison with observational data, as well as ice sheet modelling presented in Chapters 3 and 4. The KIS1516 seismic survey has been partially analysed and presented previously by Horgan and others (2017), however, the survey is processed using a different method in this study. The KIS1819 seismic survey is first presented in this study. 


\subsection{Methodology}

\subsubsection{Data Acquisition}

Tailored data acquisition techniques are essential for collecting high quality data in polar environments. Multiple studies on the collection and analysis of active source seismic data in ice environments inform data acquisition and analysis techniques for this study (e.g. Smith, 2007; Holland \& Anandakrishnan, 2009; Horgan et al., 2012; Luthra et al., 2017; Smith et al., 2018). Two active source seismic surveys are used in this study, KIS1516 collected in 2015/2016 and KIS1819, collected in 2018/2019 during the austral summers on the KIS, Antarctica (Figure 2.1). Both seismic surveys use explosive charge seismic sources, due to their wide frequency bandwidth and highly repeatable signal. As snow and firn efficiently dissipate seismic energy, charges must be buried to achieve the best energy input into the subsurface. A hot water drill was used to bury the Pentax explosive charges $\sim 25$ to $27 \mathrm{~m}$ into the ice (with an approximate density between 550 and $700 \mathrm{~kg} \mathrm{~m}^{-3}$; Ligtenberg, Helsen \& van den Broeke, 2011), which provides a better coupled seismic signal, and retains a consistent source amplitude for the entire survey (Luthra et al., 2016). Detonating the source at this depth also separates the primary reflection from the source ghost (short-path multiple between the source and receiver), which can contaminate the data. The geophones are buried up to approximately $0.5 \mathrm{~m}$ below the surface where they have a higher detection of the seismic signal, as the burial process provides better snow coupling and reduces the impact of wind noise.

The KIS1516 data set was collected prior to this study by Huw Horgan and others (2017). Table 2.1 summarises the acquisition parameters for KIS1516 and KIS1819 surveys discussed in this study. Figure 2.1 indicates the locations of three seismic lines, KIS1819-1, KIS1819-2, and KIS1516-1, as well as the Kamb Ice Stream flowline position (see Chapter 3), the grounding zone position, and the low ice velocities. The KIS1819 seismic lines were chosen due to KIS grounding zone proximity and imaging of potential pre-stagnation sediments, while the KIS1516 line was chosen as it crosses the KIS grounding zone, and also images subglacial sediments beneath the KIS. 
Table 2.1 Seismic survey acquisition parameters for the KIS1516 (Horgan et al., 2017) and KIS1819 seismic surveys.

\begin{tabular}{lc}
\hline & KIS1516 and KIS1819 \\
\hline Shot interval & $240 \mathrm{~m}$ \\
Shot-receiver near offset & $5 \mathrm{~m}$ \\
Shot-receiver far offset & $475 \mathrm{~m}$ \\
Number of live channels & 96 \\
Recording equipment & 4 Geometrics 24 -channel Geodes \\
Geophone depth & $0.5 \mathrm{~m}$ \\
Source type & $2.4 \mathrm{~kg}$ Pentax \\
Geophone spacing & $10 \mathrm{~m}$ \\
Geophone type & $40 \mathrm{~Hz}$ geophones \\
Sampling rate & $0.5 \mathrm{~ms}$ \\
Record length & $4 \mathrm{~s}$ \\
Shot depth & $\sim 25 \mathrm{~m}$ \\
\hline
\end{tabular}

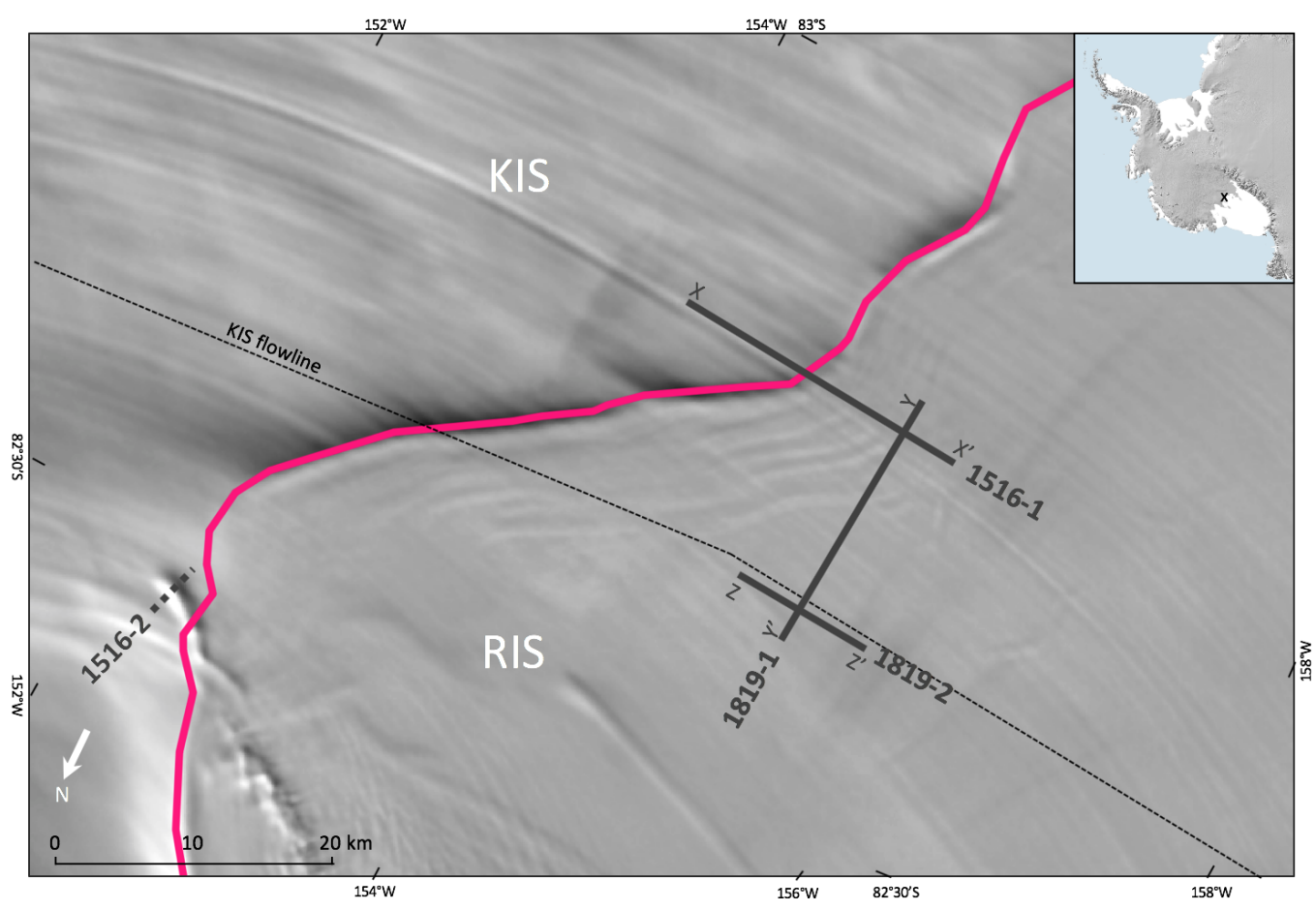

Fig. 2.1 Map of the KIS1516 and KIS1819 seismic survey line locations (grey). The grounding line position (pink) has been inferred from the MEaSUREs data (Rignot et al., 2011), and the MODIS MOA satellite imagery is used as the background to highlight the surface terrain (Haran et al., 2014). The KIS flowline model path (black) is also illustrated. Data from line KIS1516-2 are not analysed in this study. 


\subsubsection{Data Processing - Seismic Reflection Lines}

The seismic data are processed in GLOBE Claritas (Ravens, 2001), as well as MATLAB and Python using custom scripts, and standard seismic processing procedures are followed to produce final stacks. The seismic processing follows standard processing sequences which are described in depth in extensive literature (e.g. Drijkoningen \& Verschuur, 2003; Yilmaz, 2008; Sheriff, 2002). Figure 2.2 shows the key steps of seismic processing. The same processing sequence is applied to both KIS1516 and KIS1819 data to reduce variation introduced due to seismic processing. The final seismic stacks are used for qualitative interpretation such as seabed characteristics, potential internal sedimentary layering, and a potential deeper interface (see Section 2.3).

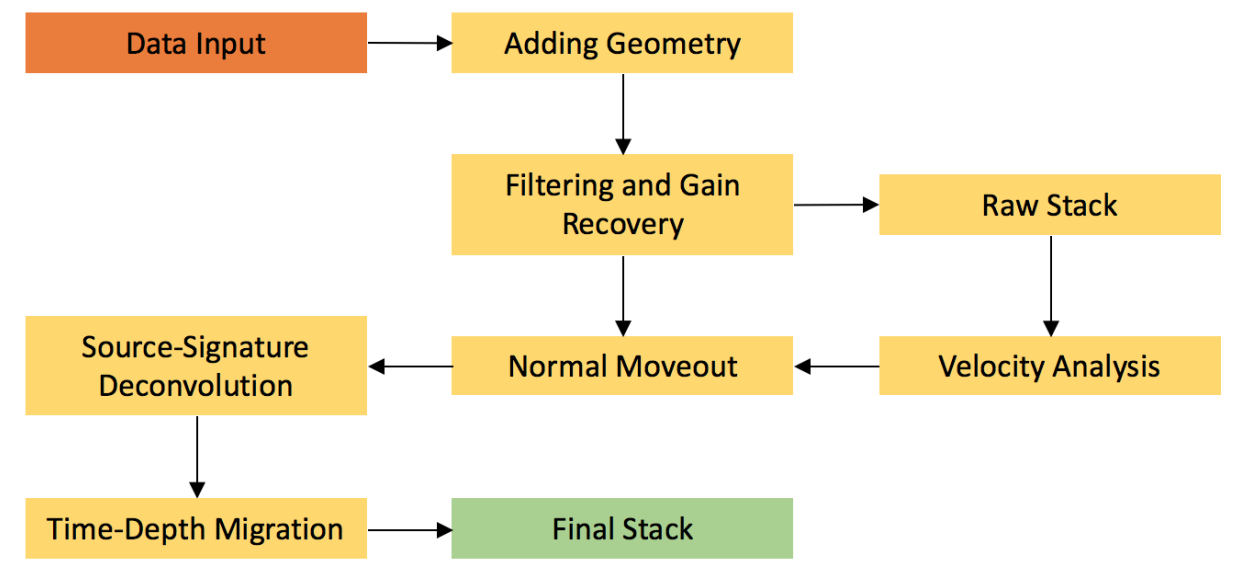

Fig. 2.2 Seismic survey processing sequence used in this study to produce the final seismic lines.

\section{Data Input}

Seismic shot records are collected in the field as SEG-D files, where each file contains a single shot record and the pertaining information, which is converted to SEG-Y file formats for both amplitude selection and further processing.

\section{Geometry}

The shot sorted data has geometry information added, consisting of GNSS shot locations and calculated geophone locations (provided courtesy of Andrew Gorman). The shot records are subsequently sorted into common depth-point (CDP) gathers, which increase the signal-to-noise ratio of seismic data. In this step of the processing sequence, field geometry (i.e. latitude, longitude) is incorporated into the headers of the SEG-Y files. Once the traces are sorted into CDPs, they are further ordered 
by increasing or decreasing offset, which contain information relating to the same subsurface points.

\section{Filtering and Gain Recovery}

Raw seismic traces contain both the seismic signal and introduced noise, and it is desirable to increase the signal-to-noise ratio. This is achieved through bandpass filtering, which is defined by four corner frequencies that filter data outside that range. Gain recovery in seismic data adjusts for energy decay between the source and the receiver. The greater energy close to the source resulted in higher amplitudes at the top of traces which can obscure lower amplitudes at depth, and gain recovery equalises the traces (Drijkoningen \& Verschuur, 2003). Automatic Gain Control (AGC), is an operator that scales a trace sample by sample, by normalising the amplitude of a sample by the average amplitude of a specified window $(250 \mathrm{~ms})$ centred on that window.

\section{Velocity Analysis and Normal Moveout}

Seismic wave velocities provide the means to link time and depth, and the velocity model is an important parameter in seismic processing (Drijkoningen \& Verschuur, 2003). The normal moveout (NMO) describes the effect that the distance between a seismic source and receiver, the offset, has on the return time of energy. This causes flat reflections appear approximately hyperbolic in shape. NMO velocity calculations for this hyperbolic moveout correct the velocity prior to stacking and are also used for accurate layer thickness calculations. This relationship is summarised in Equation 2.1

$$
t^{2}=t_{0}^{2}+\frac{x^{2}}{V^{2}}
$$

where $t$ and $t_{0}$ are the offset and zero offset, respectively, $x$ the distance between the source and the receiver, and $V$ the layer velocity.

\section{Source-Signature Deconvolution}

The source signature deconvolution goals are to compress the recorded wavelet and attenuate any reverberations. This increases resolution and creates a more accurate representation of subsurface reflections. Random noise removal can be achieved through the use of frequency-space ( $\mathrm{f}-\mathrm{x}$ ) deconvolution, which attenuates random noise using Wiener deconvolution in the $\mathrm{f}-\mathrm{x}$ domain. 


\section{Raw Stack}

To increase the signal-to-noise ratio of a seismic section, data are stacked. The raw stack consists of NMO corrected CDP traces which use a velocity model, and consists of one output trace for each CDP.

\section{Time-Depth Migration}

Migration attempts to return dipping reflections to their original and true locations within the subsurface, and to collapse any diffractions (Drijkoningen \& Verschuur, 2003). A basic velocity model is used as an input for migration processing. This process increases the spatial resolution of a seismic section and creates a more accurate seismic image of the subsurface. Post-stack, finite-difference migration is used on the KIS data, and is the last processing step on the KIS1516 and KIS1819 data before the final stack is produced.

\subsubsection{Data Processing - Amplitude Analysis}

Amplitude analysis follows the methodology outlined in Smith and others (2018) with extra parameters drawn from Holland and Anandakrishnan (2009).

\section{Acoustic Impedance and Reflection Coefficients}

The relationship between acoustic impedance $(\mathrm{Z})$ and reflection coefficients $(\mathrm{RC})$ can be used to obtain both qualitative and quantitative information about the subglacial bed and seabed properties, using both Equations 2.2 and 2.3.

$$
Z=V_{p} \rho
$$

where the acoustic impedance of a material is indicative of its material properties, and is the product of bulk density $(\rho)$ and the material $\mathrm{P}$-wave velocity $\left(V_{p}\right)$. This is related to the RC by Equation 2.3

$$
R_{i w}=\frac{\left(Z_{w}-Z_{i}\right)}{\left(Z_{w}+Z_{i}\right)}
$$

where $R_{i w}$ in this example is the $\mathrm{RC}$ of the ice-water interface, $Z_{i}$ the acoustic impedance of ice, $Z_{w}$ the acoustic impedance of water. The $\mathrm{RC}$ is a value between -1 and +1 , which is how much of the seismic energy is either reflected or transmitted at a seismic interface. A negative $\mathrm{RC}$ between -1 and 0 indicates a decrease in acoustic 
impedance, for example at an ice-water interface where ice overlays water. The RC value of the ice-water interface $\left(R_{i w}\right)$ is dependent on the angle of incidence at the ice base (Figure 2.3), and calculated for KIS1516 and KIS1819. Returns which are reflected at angles that exceed $10^{\circ}$ from the normal incidence are not used for amplitude analysis, following the methods of Holland and Anandakrishnan (2009). Figure 2.3 also shows the incidence angle and corresponding phase angles at the ice base calculated from Zoeppritz equations (Horgan et al., 2012), which are indicative of the reflection and refraction properties between two different interfaces.

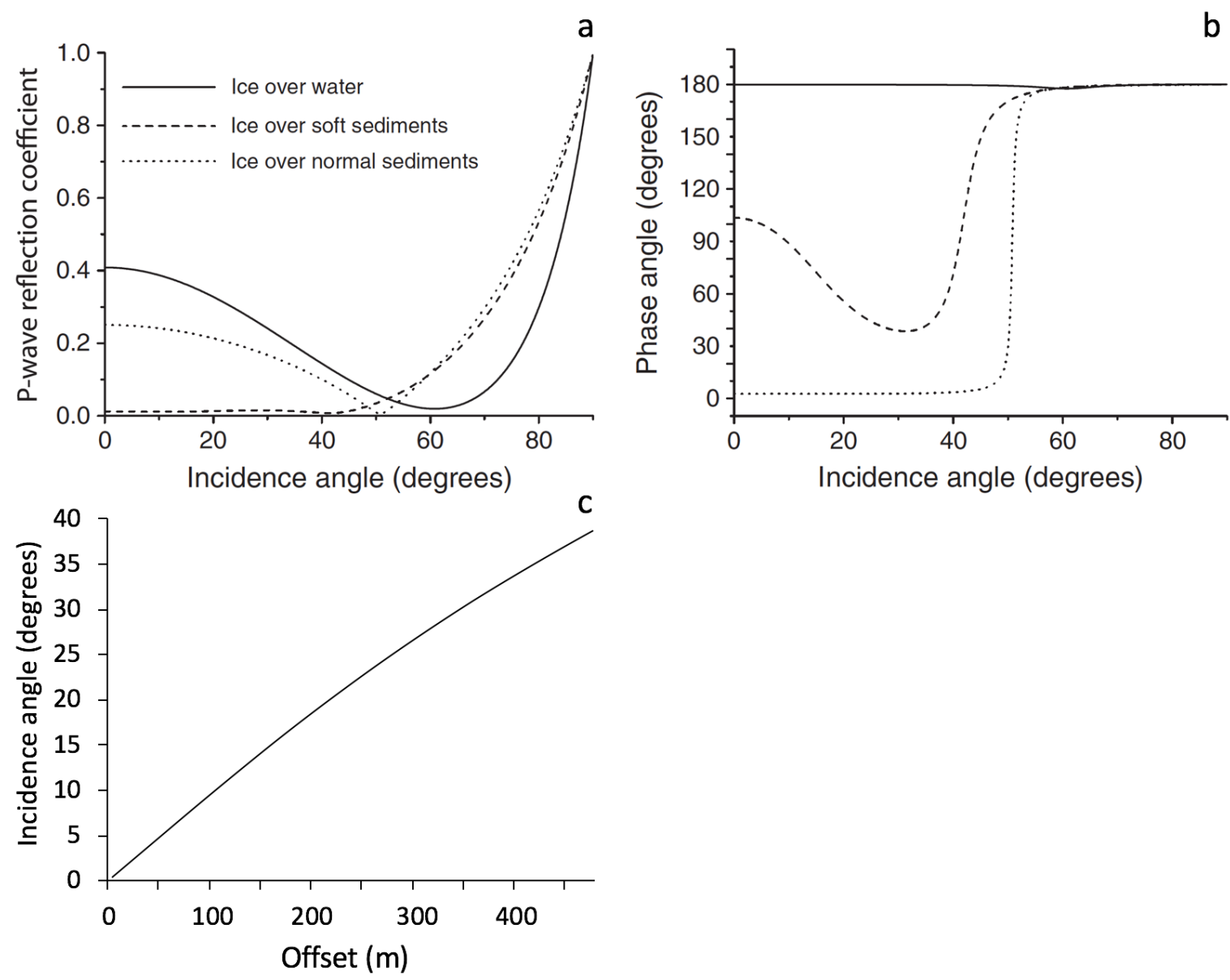

Fig. 2.3 Three potential bed scenarios and their corresponding P-wave reflection coefficients (a) and phase angles (b) are plotted against the seismic incident angles. Ice overlaying water (solid line), normal sediments (dotted line) and soft sediments (dashed line) are plotted. Panel (c) plots the incident angle at the ice base against offset from the seismic source for the KIS1516 and KIS1819 data sets. Modified from Horgan and others (2012).

The $\mathrm{RC}$ at the seabed is calculated as the difference in energy between the ice-water and water-seabed reflections (Equation 2.4). An advantage of using this method to calculate the seabed $\mathrm{RC}$, is that it uses variables calculated directly from the seismic 
shot records, as opposed to techniques that require estimations for attenuation and spreading losses, as an example (Holland \& Anandakrishnan, 2009).

$$
R_{w b}^{2}=\frac{E_{w b} R_{i w}^{2}}{E_{i w}\left(1-R_{i w}^{2}\right)^{2}}\left(1+\frac{V_{w} h_{w}}{V_{i} h_{i}}\right)
$$

where $V$ is the material $\mathrm{P}$-wave velocity, $h_{i}$ the ice thickness, and $h_{w}$ the water thickness. The amplitude energies at the water-seabed and ice-water interfaces, $E_{w b}$ and $E_{i w}$, are extracted from the seismic wavelet amplitude breaks. These are picked in GLOBE Claritas at consistent locations on the wavelets across all data sets, which allows for amplitude value comparison between the data sets. Panels (a) and (b) on Figure 2.4 illustrate the picked locations of the ice-water interface and the water-seabed interface, using KIS1516-1 as an example. The ice-water interface breaks are picked at the zero crossing of the normal polarity peak before the reverse polarity trough of the ice-water interface to capture the entire following wavelet. The water-bed interface is picked at the reverse polarity trough before the positive polarity peak. Panels (c) and (d) on Figure 2.4 illustrate wavelet signals where accurate amplitude selection is difficult (e.g. due to noise interference), and a pick is selected in relation to amplitude picks on adjacent channels, as otherwise the entire wavelet amplitude would not be captured. It is not possible to pick ice and water amplitudes on every shot, as interference with the wavelet does not allow for accurate selection. 


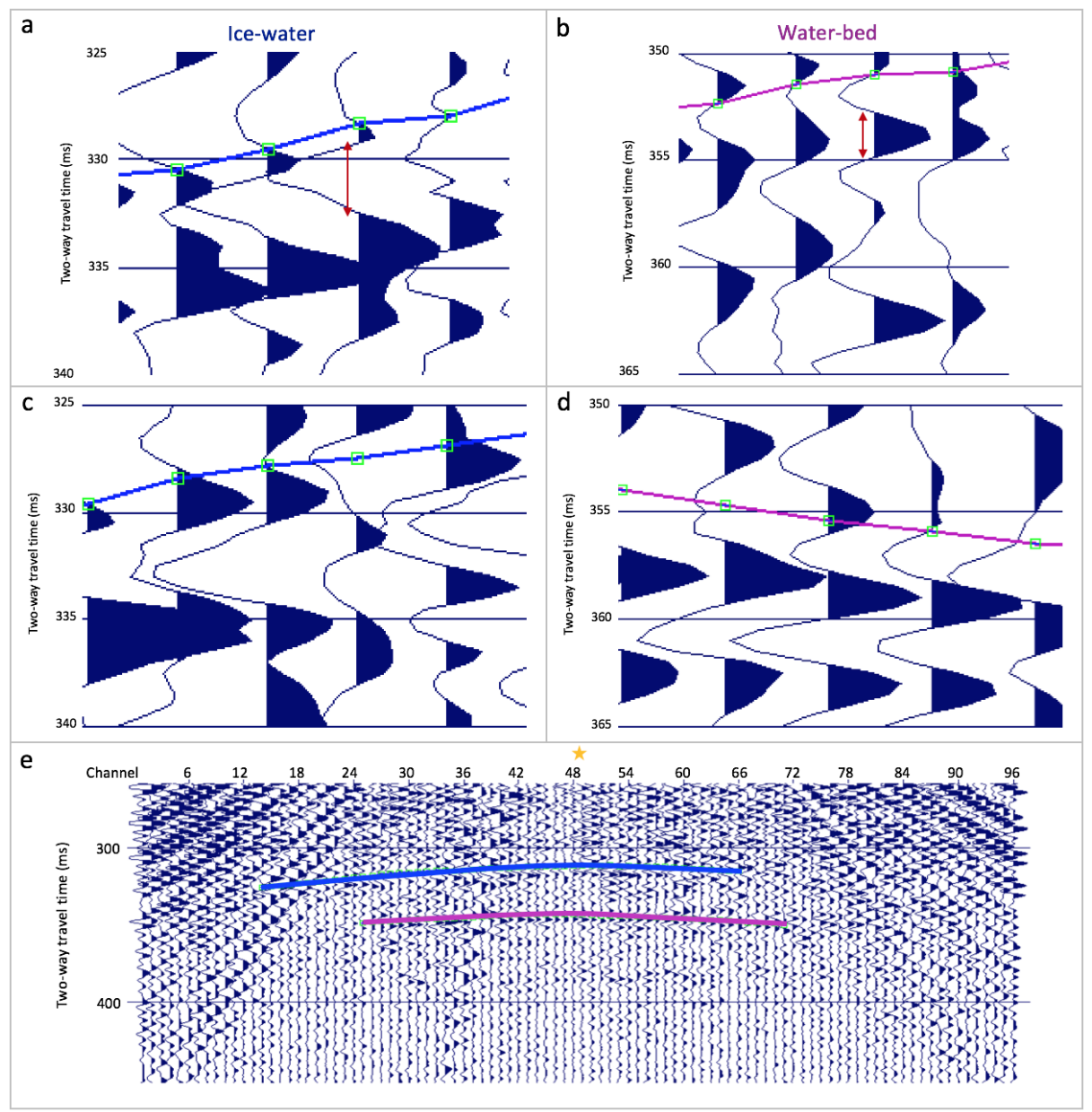

Fig. 2.4 Amplitude selection for the ice-water interface and the water-bed interface from seismic shot records on line KIS1516-1. Panels (a) and (b) show the preferred locations for break picking, which capture the entire following wavelet peak for either the ice base or sea bed. Panels (c) and (d) show sections of the ice base or sea bed where picking the preferred location is not possible. Pick locations are selected to retain the overall reflection horizon (e). The red arrow indicates the extent of an example time window used for amplitude extraction. The yellow star indicates the seismic source location.

Amplitudes are extracted using the pick locations in GLOBE Claritas, and the absolute peak amplitude values are extracted using the second and third zero wavelet crossings that follow the pick location. On shots where both ice-water and water-bed interfaces are picked, the amplitude energy $(E)$ is calculated for each channel using Equation 2.5, and the extracted amplitude values $(a)$.

$$
E=\sum_{i=1}^{N} a^{2}
$$


Subsequently, the thickness of the water column $\left(h_{w}\right)$ and ice $\left(h_{i}\right)$ is calculated using the shot-dependent RMS velocity $\left(V_{r m s}\right)$ and ice velocity $\left(V_{i}\right)$ with Equation 2.6 to NMO correct with offset. Equation 2.6 also uses the zero offset one-way travel times $\left(t_{i}\right)$ from the amplitude picks through the ice and water column.

$$
V_{r m s}=\sqrt{\frac{\sum_{i=1}^{N} V_{i}^{2} \triangle t_{i}}{\sum_{i=1}^{N} \triangle t_{i}}}
$$

Lastly, using the calculated water-bed RC from Equation 2.4, Equation 2.3 is used to calculate the $\mathrm{RC}$ and subsequently the acoustic impedance of the seabed material. Table 2.2 summarises $\mathrm{P}$-wave and $\mathrm{S}$-wave $\left(V_{s}\right)$ velocities, as well as material densities and resulting acoustic impedance values, of ice, ocean water, and likely sediments encountered in this study. The measured range of seismic velocities and densities are drawn from Zechmann and others (2018), Smith and others (2018, and references therein) and Peters and others (2006).

Table 2.2 Glaciomarine sediment, ice, and ocean water physical properties used throughout this study, and corresponding acoustic impedance values. Sediment values drawn from Zechmann and others (2018), Smith and others (2018), and Peters and others (2006).

\begin{tabular}{|c|c|c|c|c|}
\hline Sediment type & $V_{p}\left(\mathbf{m ~ s}^{-1}\right)$ & $V_{s}\left(\mathrm{~m} \mathrm{~s}^{-1}\right)$ & $\rho\left(\mathrm{kg} \mathrm{m} \mathbf{m}^{-3}\right)$ & 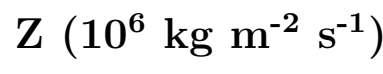 \\
\hline Ice & 3860 & 1930 & 917 & 3.5 \\
\hline Ocean water & 1440 & 0 & 1020 & 1.5 \\
\hline Dilatant till & $1500-1800$ & $0-500$ & 1700-2000 & $2.6-3.6$ \\
\hline Dewatered till & $1600-2000$ & $400-1100$ & $1900-2200$ & $3.0-4.4$ \\
\hline Consolidated till & $1900-2300$ & $1000-1200$ & $2100-2500$ & $4.0-5.8$ \\
\hline
\end{tabular}

\subsection{Results}

\subsubsection{Seismic Reflection Lines}

\section{KIS1819}

Figures 2.5 and 2.6 show both the uninterpreted and interpreted stacks of the KIS1819 seismic lines. The interpreted seismic lines have not been depth corrected for consistency when comparing to the non-interpreted lines. The seismically imaged ice-water interface (A) return is a strong, high amplitude, negative polarity reflection at an approximate two-way travel time (TWTT) between $310-330 \mathrm{~ms}$, and is imaged along the entire 
seismic line. Larger sections of lower amplitudes at both the seabed and below, are likely due to poor shot and receiver coupling, higher noise level during data acquisition, or due to incorrect seismic geometry and stacking during data processing. The next prominent reflection (B) is likely a ghost signal, which is similar in appearance to the ice-water interface reflection, and results from the short-path multiple of the ice base as a result of shot burial. Following the ghost signal, the seabed reflection (C) is imaged as a positive polarity, moderate amplitude reflection between a TWTT of 350-380 ms along the entire line, and shows a gentle normal slope towards the deeper end of the line (Y'/Z'). It has corresponding gaps to the ice-water interface, and displays a uniform seismic signal. Following this, the seabed ghost (D) is visible as a negative polarity reflection that follows a similar appearance of the seabed reflection at a TWTT of 380-400 ms. Deeper reflections (E) is imaged between a TWTT of 490-560 ms, with some possible associated layering. It displays positive polarity, high amplitude reflections along line 1 between $3-12 \mathrm{~km}$, with low amplitude reflections on either side. The reflection dips towards the deeper end ( $\left.Y^{\prime}\right)$ of the seismic line. In line 2 this reflection is imaged between a TWTT of 500-560 ms, displays positive polarity, low amplitudes, and becomes shallower towards the far offset (Z') of the seismic line. Reflection E also indicates that enough seismic energy is transmitted past the ice and water to image significant impedance contrasts in the deeper subsurface. 

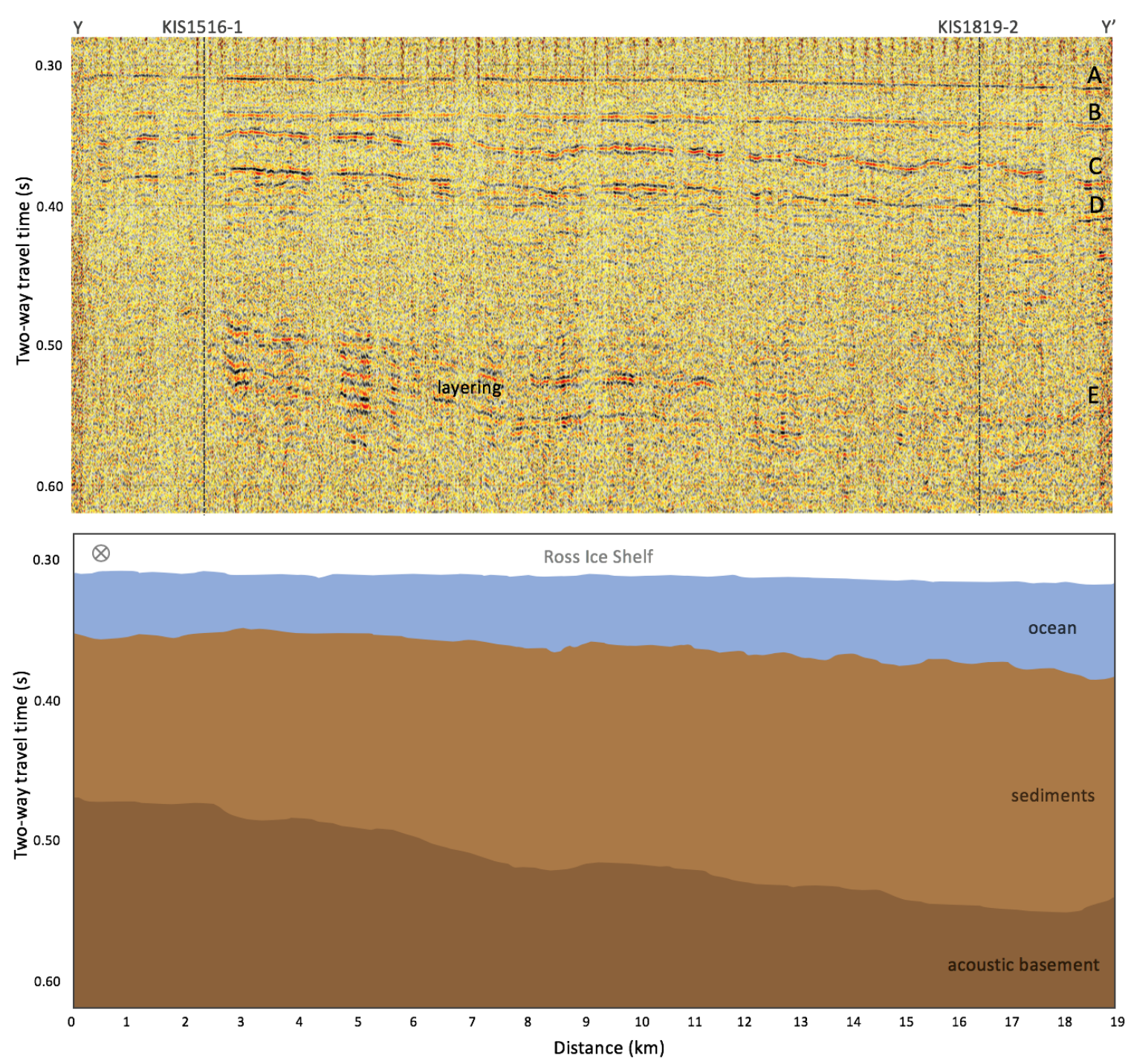

Fig. 2.5 Interpreted seismic survey line KIS1819-1. The top figure shows the uninterpreted final stack, with distance $(\mathrm{km})$ across the $\mathrm{x}$-axis, and two-way travel time (ms) along the $\mathrm{y}$-axis. The lower figure shows the interpreted environments of this seismic line, with ice at the top (white), followed by oceanic water (blue), interpreted till sediments (light brown), and an acoustic basement boundary in the subsurface (dark brown). Note that this line has not been depth converted, and intersections with other seismic lines are annotated. 

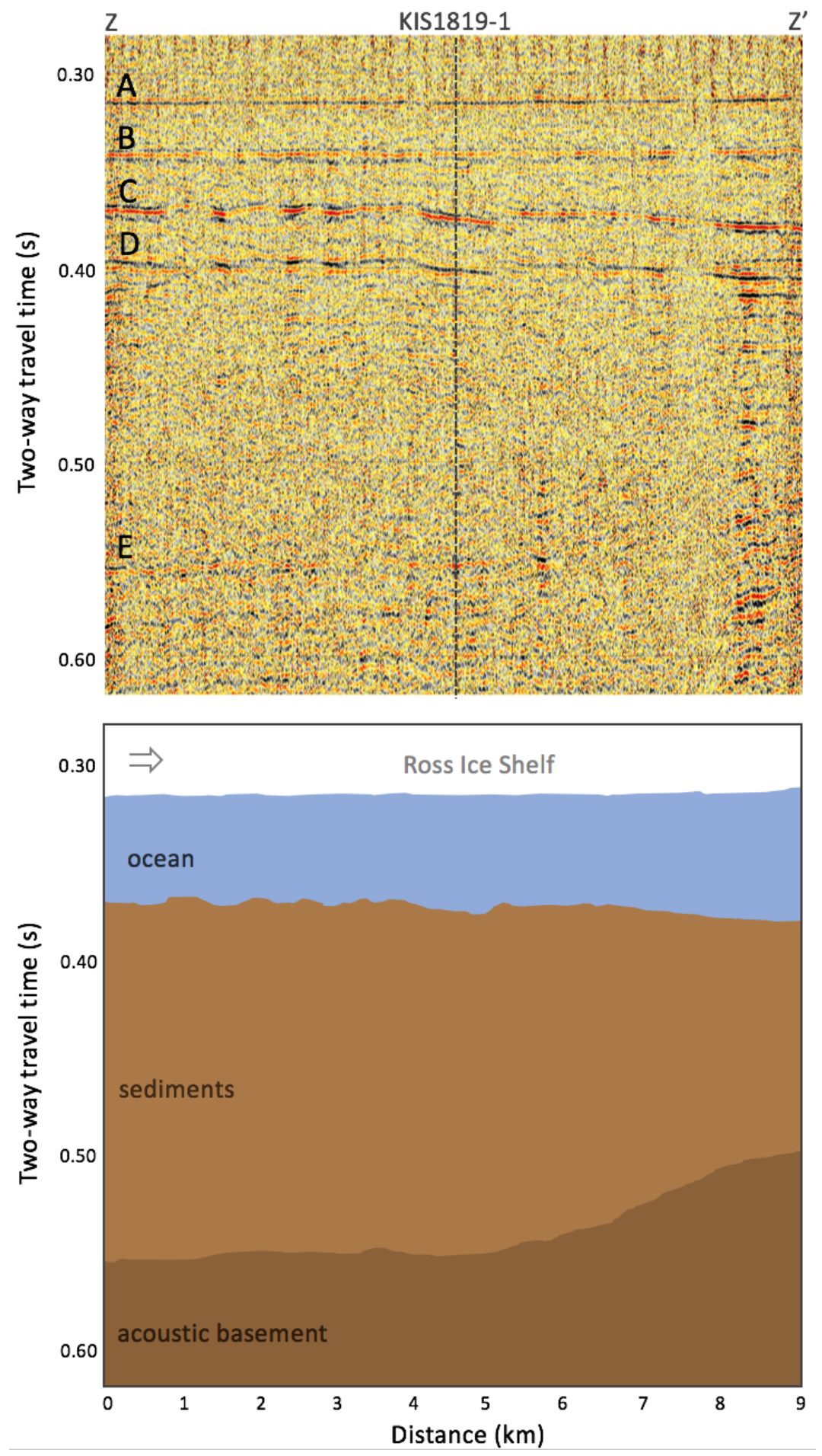

Fig. 2.6 Interpreted seismic survey line KIS1819-2. The top figure shows the uninterpreted final stack, with distance $(\mathrm{km})$ across the $\mathrm{x}$-axis, and two-way travel time $(\mathrm{ms})$ along the $\mathrm{y}$-axis. The lower figure shows the interpreted environments of this seismic line, with ice at the top (white), followed by oceanic water (blue), interpreted till sediments (light brown), and an acoustic basement boundary in the subsurface (dark brown). Note that this line has not been depth converted, and intersections with other seismic lines are annotated. 


\section{KIS1516}

The KIS1516-1 seismic line is described in Horgan and others (2017), and is briefly summarised in this study as a comparison to the KIS1819 seismic lines, with updated event labels (A-F) to reflect those of this study (Figure 2.7). The grounding line location is imaged at approximately $9 \mathrm{~km}$, corresponding to the onset of tidally induced vertical ice shelf motion (Horgan et al., 2017). The ice-water (A) and water-seabed (C) interfaces are imaged at similar TWTTs to the KIS1819 data, of approximately $310 \mathrm{~ms}$ and 350-380 ms, respectively. The ice-water interface is imaged as a high-amplitude, negative polarity bed return (A) and is identified from $\mathrm{km} \mathrm{9-23,} \mathrm{with} \mathrm{small} \mathrm{gaps} \mathrm{in} \mathrm{the}$ bed that likely indicate basal crevassing, for example as imaged at $16 \mathrm{~km}$ down the seismic line. The next reflection (B) is a ghost multiple of the ice base resulting from the buried shot. The water-seabed reflection $(\mathrm{C})$ is a moderate amplitude, positive polarity reflection from 9-23 km. Following this, the seabed short-path multiple is visible (D) as a negative polarity signal that follows a similar appearance of the seabed reflection at a TWTT of 380-400 ms. A deeper reflection (E) is visible in this seismic line, between a TWTT of approximately 450-550 ms, similar to that observed in the KIS1819 lines. Lastly, the ice basal return (F) is imaged as a low amplitude, positive polarity reflection from 0-9 km, at approximate TWTT of 350-330 ms, and radio echo sounding profiles indicate a slight reverse bed slope (Horgan et al., 2017). 

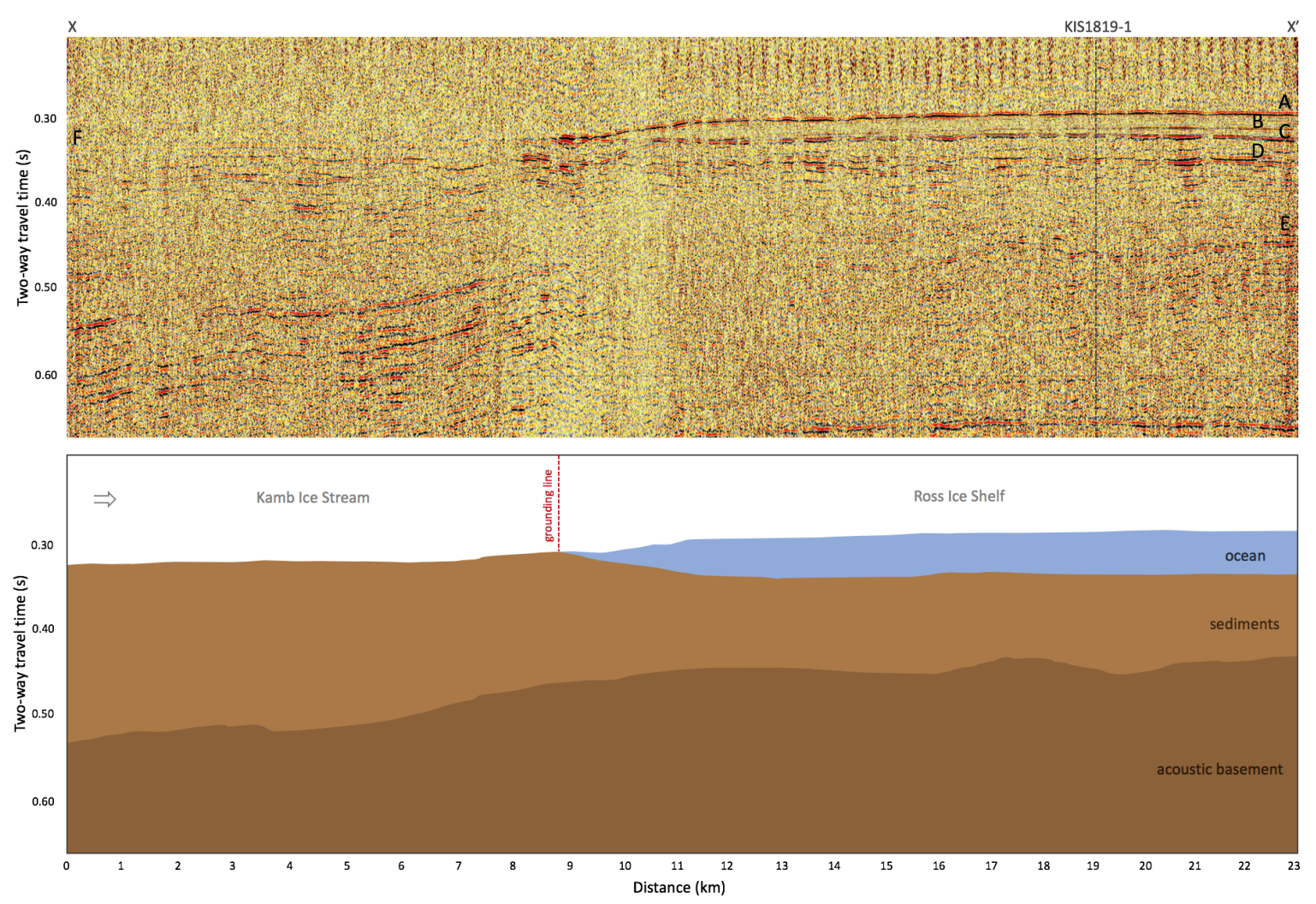

Fig. 2.7 Interpreted seismic survey line KIS1516-1. The top figure shows the uninterpreted final stack, with distance $(\mathrm{km})$ across the x-axis, and two-way travel time (ms) along the y-axis. The lower figure shows the interpreted environments of this seismic line, with ice at the top (white), followed by oceanic water (blue), interpreted till sediments (light brown), and an acoustic basement boundary in the subsurface (dark brown). Note that this line has not been depth converted, and intersections with other seismic lines are annotated.

\subsubsection{Acoustic Impedance of the Bed}

Figure 2.8 plots the offshore calculated acoustic impedance for KIS1516-1, KIS1819-1, and KIS1819-2, showing the mean absolute peak acoustic impedance. The average mean is calculated per seismic line, as the assumption is made that limited spatial variation exists in areas of no extracted amplitudes. Line KIS1516-1 has an average absolute peak mean acoustic impedance of $3.7 \times 10^{6} \mathrm{~kg} \mathrm{~m}^{-2} \mathrm{~s}^{-1}$ with a standard deviation (SD) of $\pm 1.4 \times 10^{6} \mathrm{~kg} \mathrm{~m}^{-2} \mathrm{~s}^{-1}$, KIS1819-1 an average acoustic impedance of $3.5 \times 10^{6} \mathrm{~kg}$ $\mathrm{m}^{-2} \mathrm{~s}^{-1}$ with a SD of $\pm 2.0 \times 10^{6} \mathrm{~kg} \mathrm{~m}^{-2} \mathrm{~s}^{-1}$, and KIS1819-2 an average acoustic impedance of $2.9 \times 10^{6} \mathrm{~kg} \mathrm{~m}^{-2} \mathrm{~s}^{-1}$ with a SD of $\pm 1.2 \times 10^{6} \mathrm{~kg} \mathrm{~m}^{-2} \mathrm{~s}^{-1}$. As the data display some distinct outliers, the upper and lower limits of plotted data are calculated using the first and third quartiles, and the inter-quartile range. Data outside of the calculated range between the upper and lower limits are rejected and not used for calculating the 
average acoustic impedance per line. A decision was made to reject values outside of a geologically probable range, in other words, below the acoustic impedance of ocean water $\left(1.5 \times 10^{6} \mathrm{~kg} \mathrm{~m}^{-2} \mathrm{~s}^{-1}\right)$ and below the acoustic impedance of dense, basement rock $\left(10 \times 10^{6} \mathrm{~kg} \mathrm{~m}^{-2} \mathrm{~s}^{-1}\right)$. Further analysis of the raw shot records shows no distinct difference between shots used to calculate the outlier acoustic impedance values and those within the accepted data range. It is suggested that slight variation within pick location could be a factor of the outlier presence. Using the methodology from Smith and others (2018), it is not possible to calculate the acoustic impedance for the grounded section of KIS1516-1 is not possible without a multiple reflection. This is not imaged on Figure 2.7, and the low amplitude reflections do not present a high enough amplitude peak in raw shot records to accurately pick. 

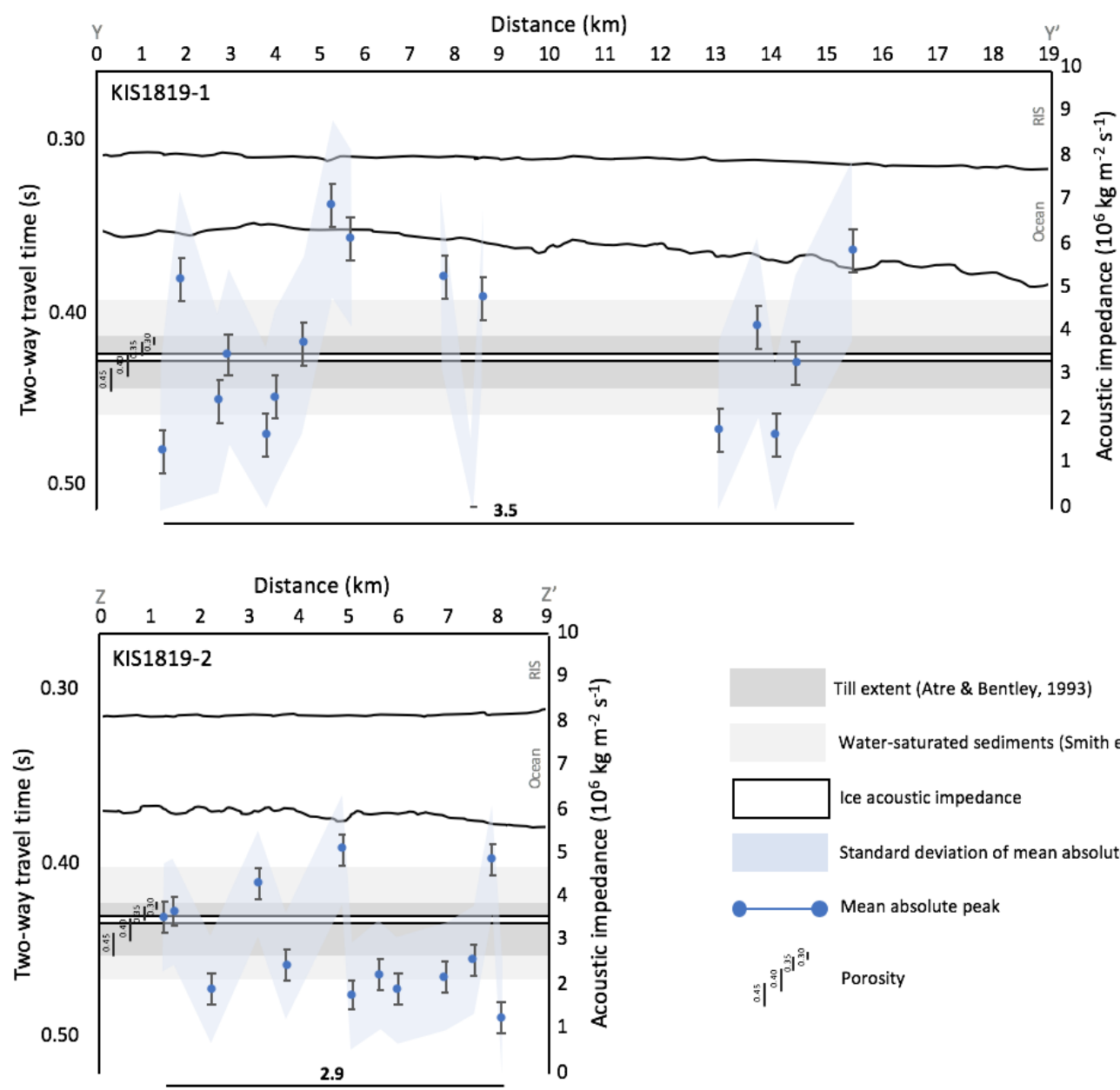

Till extent (Atre \& Bentley, 1993)

Water-saturated sediments (Smith et al. 2018)

Ice acoustic impedance

Standard deviation of mean absolute peak

Mean absolute peak

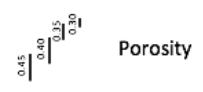

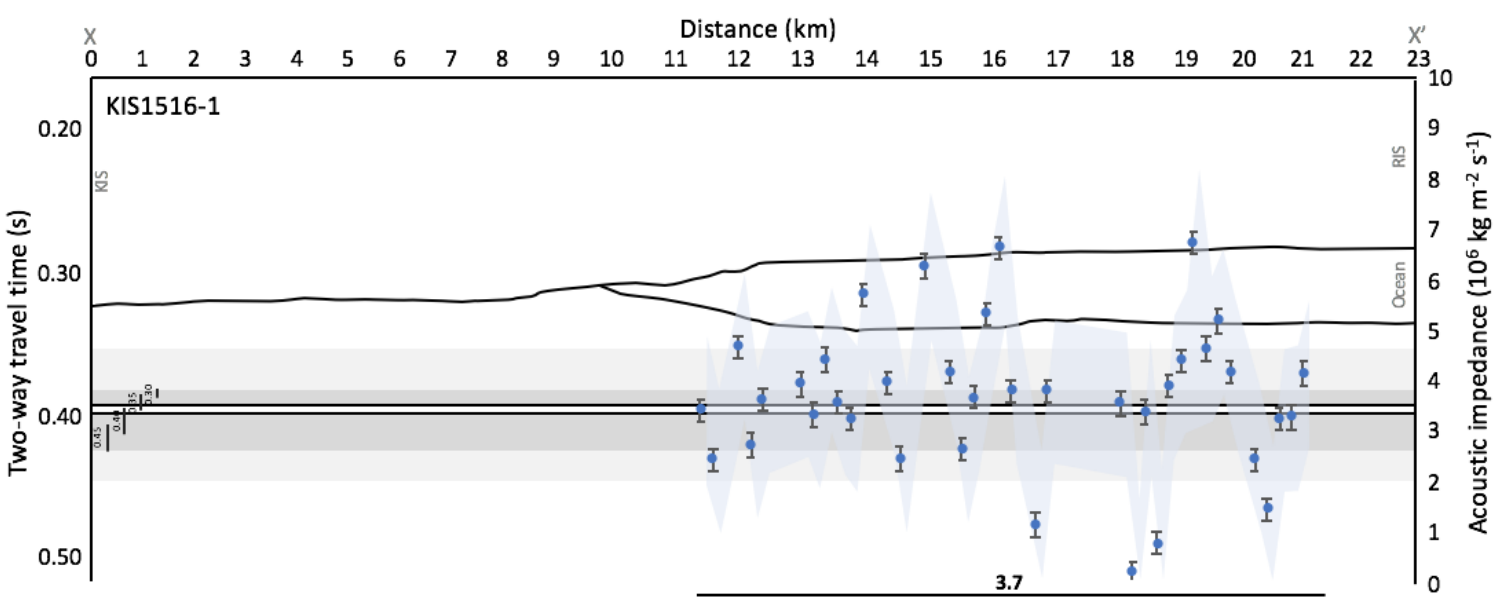

Fig. 2.8 Acoustic impedance for KIS1516-1, KIS1819-1, and KIS1819-2. The mean absolute peak acoustic impedance are plotted along the seismic line distance, with the upper and lower standard deviation range shown in light blue. The till acoustic impedance range described in Atre and Bentley (1993) is shown in dark grey, the upper and lower limits of water-saturated sediment acoustic impedance described in Smith and others (2018) denoted in light grey, and the ice acoustic impedance in white. Corresponding till porosity ranges, described by Atre and Bentley (1993), are plotted, as well as the average acoustic impedance value per seismic line. 


\subsection{Interpretation}

Figure 2.9 highlights the main processes and sediments at the grounding zone, and proximal to the grounding zone, which provides glaciological context for the seismic interpretations in the following sections (Smith et al., 2019). While limited information is able to be derived from below the grounded ice in the seismic lines, some first order assessments can be made when comparing the seismic interpretations with grounding zone and subglacial processes, such as the low amplitude reflections of the grounded portion showing no evidence of water presence.

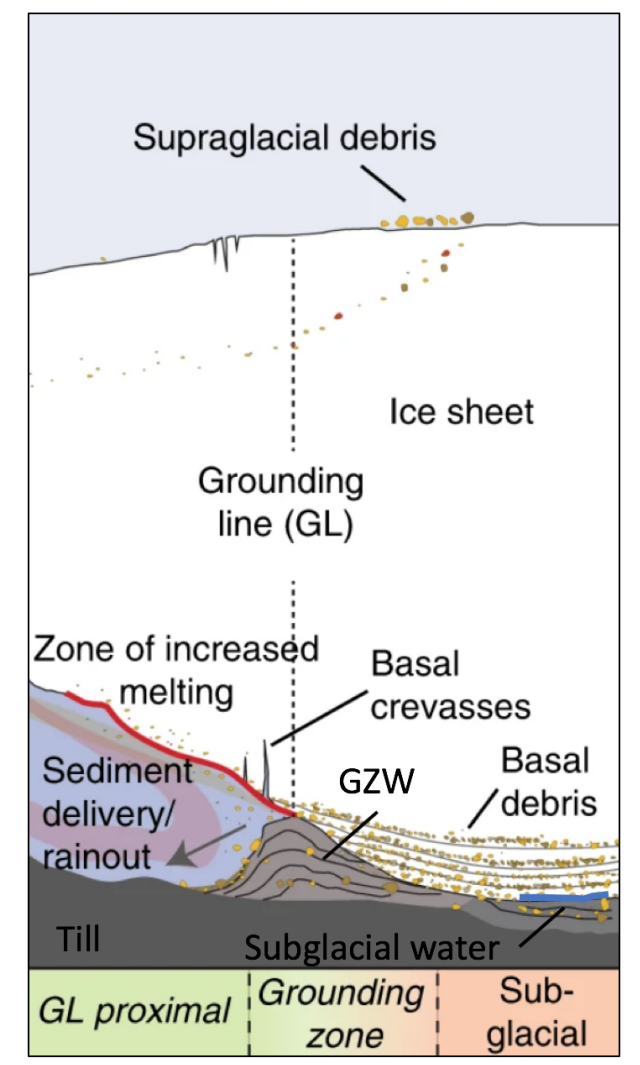

Fig. 2.9 Simplified view of the subglacial processes and sediments near and at the grounding line. The presence of subglacial debris, till, subglacial water and grounding zone wedges (GZW) are indicated on the schematic, as well as the position of the grounding line. Modified from Smith et al., 2019

\subsubsection{Subglacial Environment}

The ice basal contact with the subglacial sediments on KIS1516-1 is imaged as a faint, low amplitude, positive polarity reflection. Distinct amplitude peaks are not visible on the raw seismic shots and cannot be used for acoustic impedance calculations. Instead, the positive nature of the faint reflection, the lack of strong reflection amplitudes and 
impedance contrasts at this interface, and the imaging of deeper reflections, indicating that sufficient energy has reached this interface, implies a subglacial material with a similar acoustic impedance as the ice (Atre \& Bentley, 1993; Horgan et al., 2017). The subglacial acoustic impedance is therefore between $3.3 \times 10^{6} \mathrm{~kg} \mathrm{~m}^{-2} \mathrm{~s}^{-1}$ from Atre and Bentley (1993) and $3.5 \times 10^{6} \mathrm{~kg} \mathrm{~m}^{-2} \mathrm{~s}^{-1}$ using the P-wave velocity and densities in this study (Table 2.2). Atre and Bentley (1993) also show the relationship between differences in acoustic impedance values and porosity, with subglacial till ranging in porosity between 0.3 and 0.45 . This range includes non-deforming saturated sediment with a porosity of $\sim 0.3$ and lower, and deforming saturated sediments that are dilated with increased porosity of $\sim 0.4$ and greater (Boulton \& Dent, 1974; Boulton \& Paul, 1976; Alley et al., 1986; Alley et al., 1987). No other hydrological observations of the subglacial environment can be interpreted from the KIS1516 and KIS1819 lines, as the low amplitude reflections of the grounded portion show no evidence of water presence, which would be imaged as high amplitude, negative polarity reflections (Peters et al., 2007).

\subsubsection{Grounding Zone Position and Sediments}

The grounding zone position is visible on the KIS1516-1 seismic line, and its location is likely imaged at the first occurrence of a high amplitude, negative polarity bed reflection (Horgan et al., 2017), where there is an increased impedance contrast in comparison to the first $9 \mathrm{~km}$ of the seismic line. Grounding zone wedges (GZWs) typically form asymmetrical, wedge-shaped deposits (Dowdeswell \& Fugelli, 2012), with semi-transparent to chaotic acoustic characteristics (Ó Cofaigh et al., 2005; Dowdeswell \& Fugelli, 2012). At the grounding zone of KIS1516-1, no distinct grounding zone deposits are imaged (such as GZWs) which Horgan and others (2017) suggest indicates a lack of significant sediment flux due to melt out of englacial debris or subglacial deformation or a grounding line not present at that position for long. Provided the ice stream was flowing, they have estimated sediment depositional rates of approximately $2.5 \mathrm{~m}$ per 100 years, which makes it likely that a seismically resolvable unit would have been deposited subsequent to the stagnation of the KIS. In comparison to the WIS grounding zone, which migrated to its current position within the last 120 years (Marsh et al., 2016), a detectable seismic unit has resulted from englacial sediment melt out and deforming till (Horgan et al., 2013). Horgan and others (2017) provide a further in-depth discussion of the grounding zone position and lack of grounding zone deposits for this seismic line. Despite covering approximately $40 \mathrm{~km}$ of seafloor, no grounding zone deposits are imaged in the KIS1819 seismic lines. 


\subsubsection{Off-Shore Sediments}

Lines KIS1819-1, KIS1819-2, and part of KIS1516-1 are located offshore, and image subglacial till previously beneath the KIS. The material at the seabed has an acoustic impedance range between 2.9-3.7 $\times 10^{6} \mathrm{~kg} \mathrm{~m}^{-2} \mathrm{~s}^{-1}$, which is similar to acoustic impedance values of till and seabed sediments (Hamilton, 1971; Richardson \& Briggs, 1993; Smith, 1997 and references therein; Vardy, 2015). Figure 2.10 summarises the acoustic impedance range of different sediment types highlighted by Smith and others (2018), Atre and Bentley (1993), as well as the acoustic impedance range calculated in this study. Acoustic impedance values between $\sim 2.0 \times 10^{6} \mathrm{~kg} \mathrm{~m}^{-2} \mathrm{~s}^{-1}$ and $3.0 \times 10^{6} \mathrm{~kg} \mathrm{~m}^{-2} \mathrm{~s}^{-1}$ usually exhibit a similar seismic velocity as water $\left(\sim 1440 \mathrm{~ms}^{-1}\right)$ at the sediment surface, which increases gradually with depth. The variation within the acoustic impedance of these sediments is largely due to bulk density differences, such as the variation in porosity and sediment grain type (Smith et al., 2018). In the glaciomarine environment, sediments with acoustic impedance values of $>3 \times 10^{6} \mathrm{~kg} \mathrm{~m}^{-2} \mathrm{~s}^{-1}$ are likely to be sandy, seabed sediments (Smith et al., 2018). In contrast, silt-and clay-dominated sediments typically have impedance values of $\leq 2.7 \times 10^{6} \mathrm{~kg} \mathrm{~m}^{-2} \mathrm{~s}^{-1}$.
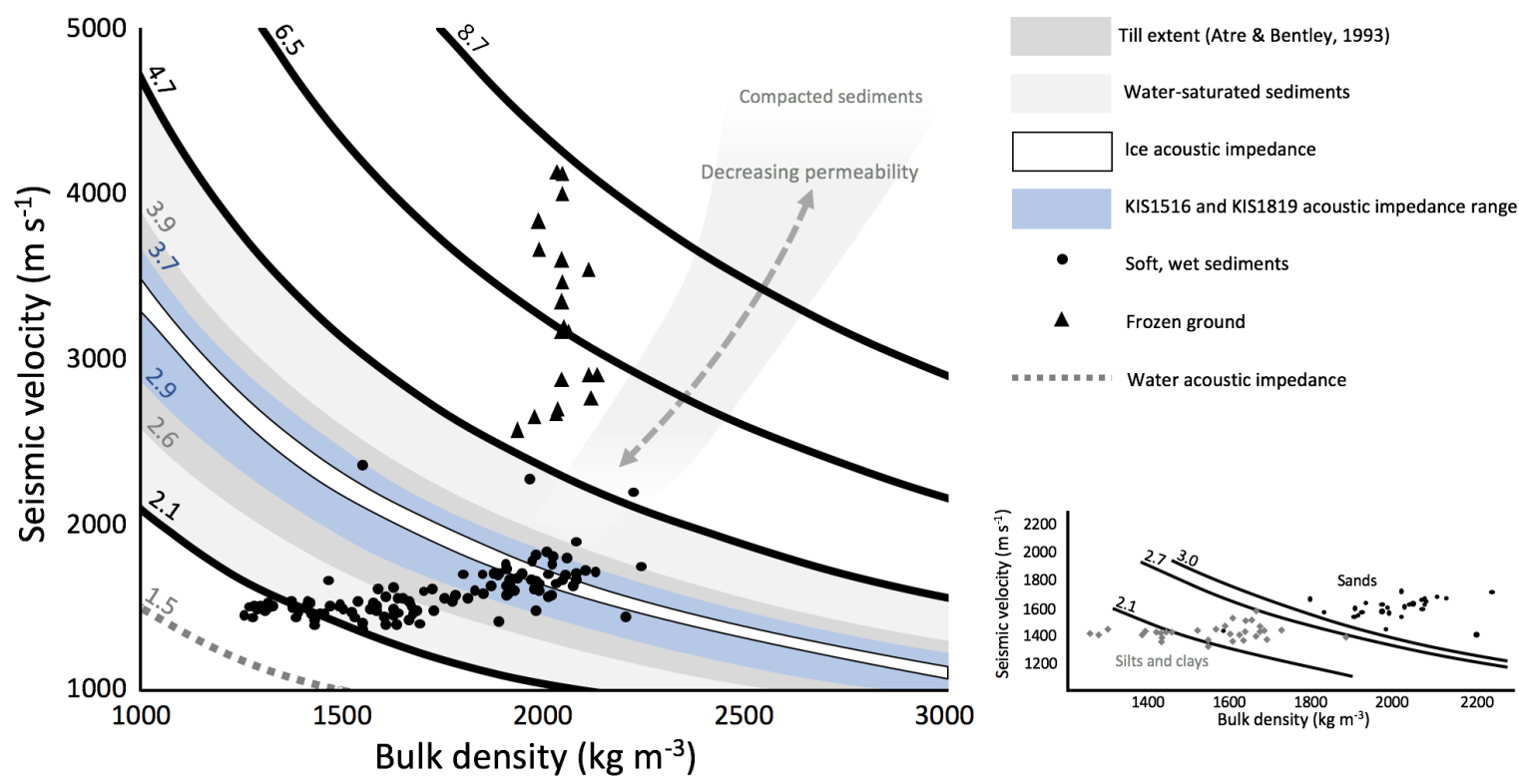

Fig. 2.10 Potential seabed and subglacial sediment scenarios, with corresponding P-wave acoustic impedance values. Modified from Smith and others (2018) and references therein. 


\subsubsection{Acoustic Basement}

Six Ross Sea Unconformities (RSU) are observed within multiple seismic surveys collected in the Ross Sea, as well as the Deep Sea Drilling Project (DSDP) cores 270-272 (Anderson et al., 1992; Brancolini et al., 1995; De Santis et al., 1995; De Santis et al., 1999; Robesco et al., 2006), and these regional unconformities are separated by differing sedimentary units. The RSUs are observed in both the Western and the Eastern Ross Sea margins, as well as likely on a wider continental scale (Robesco et al. 2006; Halberstadt et al., 2016; Kim et al., 2018). They are thought to date from the late Oligocene-early Miocene to the mid Plio-Pleistocene (De Santis et al., 1995; De Santis et al., 1999; Robesco et al., 2006). Deeper reflections imaged on KIS1516-1, KIS1819-1, and KIS1819-2 likely indicates an acoustic basement, and the positive polarity, high amplitude reflections indicate that there is a significant impedance contrast between this unit and the overlying unit. It is suggested that the acoustic basement imaged in this study is likely an extension of a RSU; however, it is currently unknown which RSU this may correspond with, and it is outside of the scope of this study to further investigate the relationship.

\subsection{Discussion}

This Chapter evaluate the utilisation of off-shore sediments as a means to provide extra information about sediments previously thought to be beneath the KIS, as well as discussing the limitations of the seismic studies and the assumptions made (i.e. to address research question 1). The seismic surveys presented in this study image the ice-bed contact and the underlying ocean cavity and sediments, consistent with expectations. Quantitative analysis of the sea bed acoustic impedance values indicate dilatant subglacial tills and soft, water-saturated glaciomarine sediments. The low impedance contrast beneath the grounded ice stream indicates KIS is underlain by dewatered till. There is also enough evidence to calculate a minimum seabed sediment thickness. A lack of seismic multiples in the data, and a lack of a clear interface, did not allow for more extensive acoustic impedance calculations of the subglacial material. This study suggests that due to this lack of strong contrast, and lack of negative polarity, the acoustic impedance of the subglacial material is likely higher than that of ice (Atre \& Bentley, 1993; Horgan et al., 2017). 


\subsubsection{Grounding Zone Location}

The grounding zone of the KIS has retreated towards the continent since its stagnation approximately 160 years ago (Horgan et al., 2017), and Horgan and others (2017) provide an in-depth discussion of the modern day grounding zone position of the KIS, and the implications of no imaged grounding zone deposits. The stagnation of the KIS halted the ice flux upstream, and due to a change in mass balance, among other processes, the downstream sector of the KIS continued to thin post-stagnation (Horgan et al., 2017; Moholdt et al., 2014). This resulted in ice flotation and eventually grounding zone retreat. Horgan and others (2017) place the start of this grounding zone retreat less than 150 years ago, and it likely ceased more than 30 years ago, according to satellite imagery evidence. They also calculate potential retreat rates of at least $0.2 \mathrm{~km} \mathrm{y}^{-1}$, which could signify up to a total of $\sim 24 \mathrm{~km}$ grounding zone retreat since the stagnation of the KIS, over the 120 year period of migration. This may indicate that all three seismic lines in this study image subglacial material that was under the KIS less than 120 years ago. Reactivation and re-advance of the KIS grounding zone would see this material again at the ice-bed contact. Figure 2.11 shows the locations of the three seismic lines, similar as seen in Figure 2.1; however, it has a potential pre-stagnation grounding zone extent indicated. This also demonstrates that future characterisation of the current off-shore sediments on seismic lines can provide insights into current subglacial sediments. 


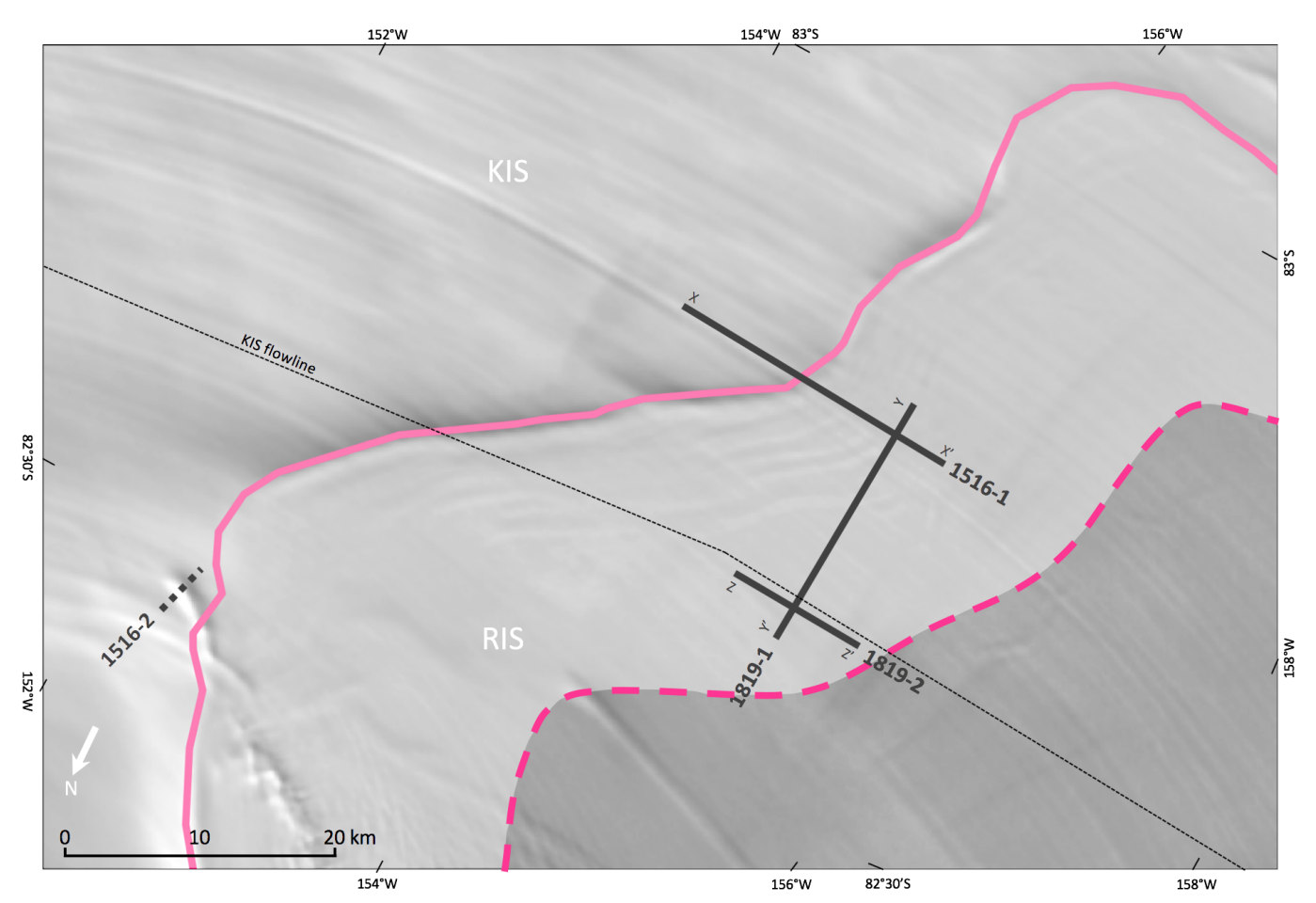

Fig. 2.11 Map of the KIS1516 and KIS1819 seismic survey line locations in relation to an extended KIS (white), pre-stagnation grounding zone position (pink dashed). The current inferred grounding zone position (pink solid) is inferred from the MEaSUREs ice velocity data (Rignot et al., 2011) and the KIS flowline model path (black) are also illustrated. The MODIS MOA (Haran et al., 2014) surface morphology is shown in the background.

\subsubsection{Subglacial Properties}

\section{Acoustic Impedance Sediment Thickness}

The length of the seismic reflection wavelet at the seabed can be used to estimate the minimum sediment thickness $(d)$ used to calculate the acoustic impedance values. The recorded wavelet length (in time, $t$ ) of approximately $3 \mathrm{~ms}$ is equivalent to $\sim 4.5 \mathrm{~m}$ in the sediments, using a P-wave velocity $\left(V_{P}\right)$ of $1500 \mathrm{~m} \mathrm{~s}^{-1}$ for water saturated till and Equation 2.7.

$$
V_{P}=\frac{d}{t}
$$

There are sections of no observed wavelet distortion in multiple shots for all three seismic lines, which allows for the minimum thickness calculation. Previously collected borehole data upstream on the KIS (Kamb, 2001) recorded minimum till thicknesses of 0.3 to $0.7 \mathrm{~m}$, with other seismic surveys inferring till thicknesses up to an average of 
$6.5 \mathrm{~m}$ (Rooney et al., 1987). The minimum till thickness calculated from the seabed wavelets in this study fall well within range of these results.

\section{Sedimentary Unit Thickness}

A likely maximum thickness of the imaged sediment package can be calculated using the seabed and the deeper imaged reflection to represent the boundaries of this sedimentary section. Using the thickest section observed on the seismic lines, which is seen at the near continent side of the line KIS1819-2, an approximate maximum thickness of 145 $\mathrm{m}$ is calculated, using an average P-wave velocity of $1600 \mathrm{~m} \mathrm{~s}^{-1}$ (where the top third is implied to have an approximate velocity of $1500 \mathrm{~m} \mathrm{~s}^{-1}$, the middle third of $1600 \mathrm{~m}$ $\mathrm{s}^{-1}$, and the bottom third $1700 \mathrm{~m} \mathrm{~s}^{-1}$ to represent increasing seismic till velocities with depth; Zechmann et al., 2018).

\section{Estimates of Porosity}

Comparison of the derived acoustic impedance values to known and expected materials gives an indication of subglacial properties. Two key, related, properties of the seabed and subglacial material are the porosity and effective pressure beneath the ice stream, and it is possible in some cases to discriminate between deforming and non-deforming subglacial sediment (Davison et al., 2019). The acoustic impedance and effective pressure are related, namely through this porosity, mineral composition, elastic moduli (bulk modulus, both dry and wet, and shear modulus, both dry and wet) of both the dry framework and saturated sediments, and seismic velocity (Luthra et al. 2016). Data summarised by Atre and Bentley (1993) compares acoustic impedance values of water-saturated sediments, and the associated levels of porosity, which range between 0.3 to 0.45 . The porosity is a reasonable value for subglacial sediments and sediments that may have previously been beneath an ice stream; however, it does not uniquely identify subglacial sediments. Till porosity can serve as a proxy for the rheology of till beneath ice streams to allow for differentiation between non-deforming and deforming sediments (Alley et al., 1986; Alley et al., 1987). Non-deforming, lodged sediment generally has a porosity of 0.3 or lower, and can also be referred to as 'dewatered' tills (Zachmann et al., 2018). Higher porosities, 0.4 to 0.45 , are likely a result from either shear deformation of saturated sediments or marine sediments, which increases dilation and porosity (Boulton \& Dent, 1974; Boulton \& Paul, 1976). Figure 2.8 demonstrates the acoustic impedance and interpreted range of basal conditions from the KIS1516-1, KIS1819-1 and KIS1819-2 seismic lines, together with the till acoustic impedance range from Atre and Bentley (1993) and the saturated sediment zone 
from Smith and others (2018 and references therein). The calculated seismic acoustic impedance values, 2.9, 3.5 and $3.7 \times 10^{6} \mathrm{~kg} \mathrm{~m}^{-2} \mathrm{~s}^{-1}$ from the seismic lines correspond to medium to high porosity values of 0.41-0.45 for KIS1819-2, 0.32-0.38 for KIS1819-1, and 0.3-0.33 for KIS1516-1, respectively, which are located on Figure 2.12. Figure 2.12 summarises the relationship between acoustic impedance and porosity, and plots the acoustic impedance and porosity range of till, ice and the seismic lines discussed in this study. It is hypothesised that prior to the retreat of the KIS grounding zone, both lines KIS1516-1 and KIS1819-1 indicate subglacial areas that are associated with non-deforming sediments. Line KIS1819-2 has a higher porosity range, which indicates that subglacial deformation was possible at this location prior to the migration of the KIS grounding zone. Previous studies have estimated mean porosities over the KIS to be approximately 0.4 ; however, the KIS shows larger porosity variations than measured in other ice streams, such as the WIS or the BIS (Kamb, 2001). Measured porosities from borehole cores upstream on the KIS indicate a porosity range between 0.28 to 0.6 , with mean porosities of $0.42 \pm 0.015$. Data upstream from the KIS sticky spot indicate areas of no deformation. It is possible that line KIS1819-2 captures an area of more easily deformable sediment compared to lines KIS1516-1 and KIS1819-1. While limited subglacial information is available from the grounded section of line KIS1516-1 using the techniques within this study, it is suggested that the till beneath this section likely consists of dewatered till. As previously discussed, the low amplitude reflections likely indicate a lack of contrast between the ice base and the substrate, and dewatered till occurs beneath slow moving ice (Alley et al., 1987; Peters et al., 2008; Christianson et al., 2013; Luthra et al., 2016). 


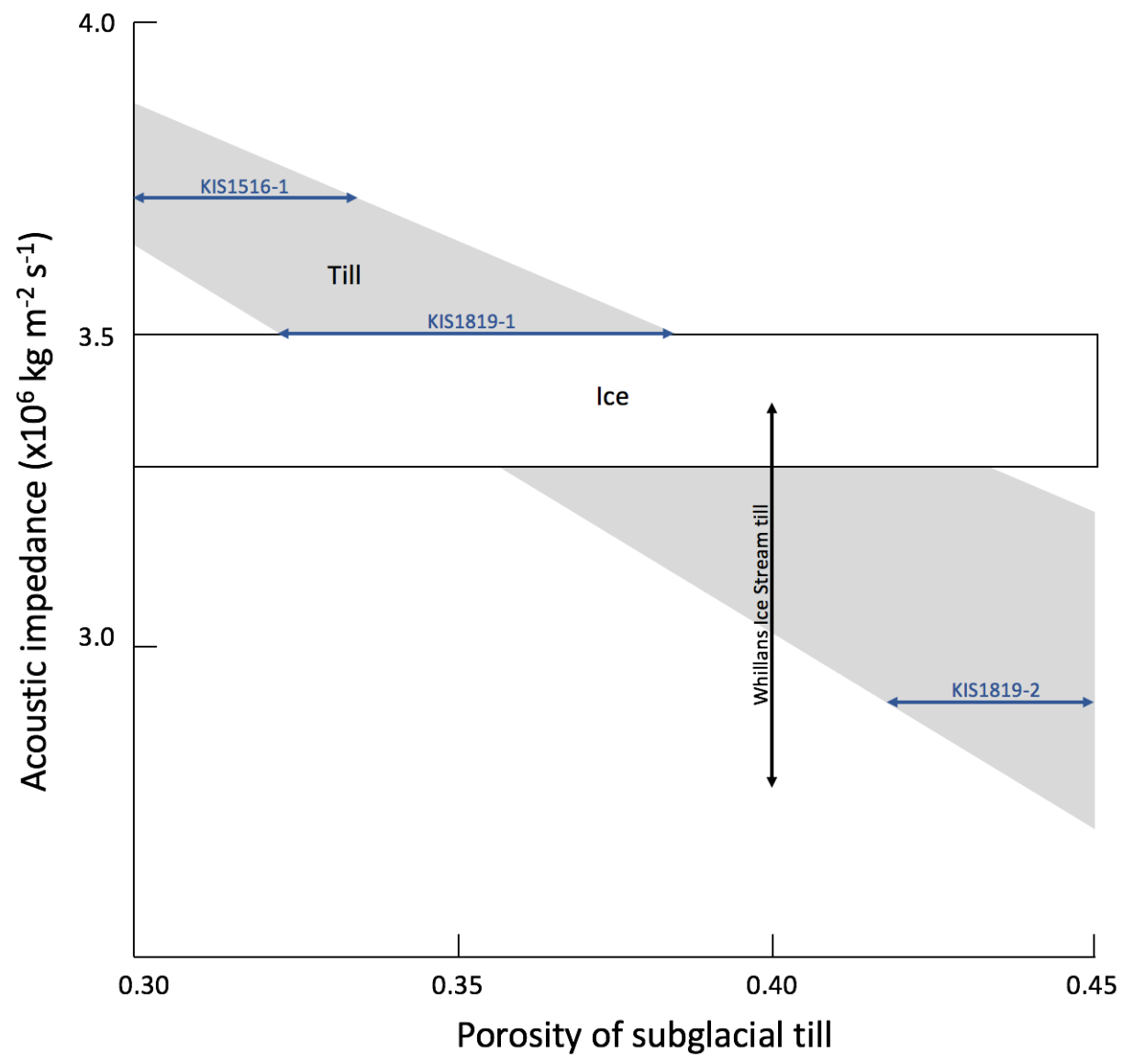

Fig. 2.12 Till and ice acoustic impedance values plotted against porosity, with corresponding acoustic impedance values from lines KIS1516-1, KIS1819-1, KIS1819-2, and Whillans Ice Stream (Atre \& Bentley, 1993). Modified from Atre and Bentley (1993) and references therein.

\subsubsection{Comparison to Adjacent Ice Streams}

Comparing the KIS to the WIS provides insights into the similarities and differences of the two ice streams systems, and why they display different behaviours. Seismically resolvable water is imaged beneath the WIS (Horgan et al., 2012; Horgan et al., 2013a; Horgan et al., 2013b), is contrast to the KIS. Some seismic reflection experiments on the WIS report estimates of basal porosity of approximately 40\%, with corresponding effective pressures of $50 \pm 50 \mathrm{kPa}$, i.e. that the pore pressure in the basal layer is $99 \%$ of the overburden pressure (Blankenship et al., 1987). Further seismic profiling across a wide area showed the basal layer was almost universally present in the survey area, with thickness ranging from $2 \mathrm{~m}$ or less (i.e. too small to be resolved) to $12 \mathrm{~m}$ (Rooney et al., 1987). Alley and others (1987) concluded from theoretical studies that the basal layer under the WIS is probably deforming and hypothesised that a basal deforming till is the cause of the high velocity of ice movement observed the upper extent of the 
WIS (450 m year-1 ; Whillans et al., 1987). A dilatant layer (40\% porosity, density 1.99 $\mathrm{Mg} \mathrm{m}^{-3}$ ), with an effective pressure in the range of $30 \pm 100 \mathrm{kPa}$, was indeed found at the bed in the boreholes (Engelhardt et al., 1990).

\subsubsection{Utilisation in Model Studies}

The overarching aim of this study is to utilise seismic surveys to provide quantitative constraints for ice sheet modelling, and vice versa, to use model outputs to provide a qualitative insight into seismic survey observations. While this has not been achieved, this chapter has provided valuable insight into the present-day state of the KIS at the locations imaged. Chapter 3 provides modelling insights into the surface and subglacial environment of the KIS in regards to basal stresses, temperatures, hydrological controls, and basal and surface velocities, as well as some preliminary effective pressure values. Seismic data, model results, and observed data from borehole studies on the KIS, provide three different types of data to quantitatively integrate effective pressure measurements, key observations, and results of the subglacial conditions. Some studies (e.g. Siegert et al., 2005; Smith et al., 2013; Ashmore et al., 2014; Kyrke-Smith, Gudmundsson \& Farrell, 2017) argue that there is currently no accurate physical theory which directly relates the acoustic impedance to basal shear stress or utilises the acoustic impedance as a parameter in a physical sliding law. However, this study suggests that effective pressure and porosity are useful parameters for comparison.

\subsubsection{Limitations and Assumptions}

The data presented in this study provide a picture of the likely subglacial and offshore subglacial sediment characteristics. However, multiple assumptions have been made in the processing and interpretation of this data set and the methods have some inherent limitations.

\section{Seismic data resolution and uncertainty}

The vertical resolution of interfaces of a layer in seismic data, is limited by the Rayleigh resolution criterion, which states that in most instances layers of a thickness of approximately a quarter of the wavelength $(\lambda)$ can be resolved. This is calculated using Equation 2.8, which uses the dominant frequency $(f)$ of the seismic data and the $\mathrm{P}$-wave velocity $\left(V_{p}\right)$ to calculate the dominant wavelength of the data set.

$$
\lambda=\frac{V_{p}}{f}
$$


Using a root mean squared (RMS) velocity of $3654 \mathrm{~m} \mathrm{~s}^{-1}$ calculated from the KIS ice and water velocities and thicknesses, and a dominant frequency range between 100 and $250 \mathrm{~Hz}$ (which is consistent across all three seismic lines), the minimum vertical resolution of the data is between $\sim 4$ to $9 \mathrm{~m}$.

The horizontal resolution is limited in sections of the seismic lines where no acoustic impedance values can be calculated due to the lack of amplitude picks on the shot records. The KIS1516-1 line displays the best horizontal resolution in the floating ice section of the line compared to the KIS1819 seismic lines. The shot records display less interference of the basal ice and bed returns and allow for better amplitude picking. The assumption has been made that between areas of calculated acoustic impedance values, particularly on KIS1819-1, the seabed shows limited spatial variation and the gaps with no data are unlikely to contain different acoustic impedance results. While it is possible that there is more spatial variability between the separate seismic lines than is currently assumed, it is argued that this would have limited impact on the interpretation of the modelling results in the following chapters. With the longest seismic line in this chapter covering an area of just over $23 \mathrm{~km}$, this represents less than $0.02 \%$ of the KIS flowline modelled in the subsequent chapter. So whilst the implications of spatial variability are important to consider at the seismic survey scale, as this chapter does between lines KIS1819-1 and KIS1819-2, it is suggested that this does not have a significant impact on the interpretation of the modelling results.

Lastly, the uncertainty surrounding the exact material beneath the ice sheet and at the seabed can also introduce errors into the velocity calculations. The seismic velocity of a material is also dependent on its porosity (Drijkoningen \& Verschuur, 2003), which, while estimated from the acoustic impedance, does not provide enough certainty to fully constrain the velocity model. With the data collected and presented in this thesis it is difficult to estimate the uncertainty introduced to the seismic velocity through variation of material porosities, and it is recommended that with the collection of additional data more extensive porosity calculations are performed.

\section{Subglacial material}

The interpretation of the subglacial material beneath the KIS on line KIS1516-1 relies on the assumption that the low amplitude reflection between the two interfaces indicates a low impedance contrast and $\mathrm{RC}$ between the ice and the subglacial material. It is likely that the acoustic impedance of the material beneath the ice stream is similar to, or slightly higher than, that of ice due to the positive nature of the polarity. This ranges between 3.3 and $3.5 \times 10^{6} \mathrm{~kg} \mathrm{~m}^{-2} \mathrm{~s}^{-1}$ using the P-wave velocities from this study, as well as 
Atre and Bentley (1993). Atre and Bentley (1993) also give a likely range of till acoustic impedance values between approximately 2.7 to $3.8 \times 10^{6} \mathrm{~kg} \mathrm{~m}^{-2} \mathrm{~s}^{-1}$, which would result in suitably low impedance contrasts to potentially describe what is happening beneath the KIS, and RC values of between -0.13 and 0.07 (using the upper and lower limits of the till, as well as both acoustic impedance values of the ice). The interpretation of the subglacial material is limited to this, as no direct porosity estimation can be made.

\section{Basal ice seismic velocity}

A significant limitation of the seismic reflection data is the inability to directly measure seismic velocities, particularly at the ice-sediment interface. When interpreting the seismic data, both seismic velocity and material density are sensitive to porosity, hence why acoustic impedance can be used as a proxy for porosity and sediment deformation (Blankenship et al., 1987). As such, incorrect estimations of seismic velocity can result in incorrect estimations of porosity and subglacial conditions. Acoustic impedance calculations would be better constrained with direct seismic velocity measurements (i.e. using borehole seismic), and result in better constrained acoustic impedance values. However, direct basal ice (lowermost $10 \mathrm{~m}$ of the ice sheet column) velocity measurements are difficult to obtain, and this uncertainty is likely to remain, unless other techniques that utilise the relationship between ice temperature and seismic velocity are explored; however, this is outside of the scope of this study.

\section{Source repeatability and geophone coupling}

The analysis presented in this study assumes limited to no variation between seismic source shots or between geophone coupling. It is important that shots are repeatable, and care has been taking during the acquisition of the KIS1516 and KIS1819 surveys to achieve the same source shot conditions by using the same seismic source and geophone burial. Geophone coupling is also important in the shot records. It has less of an ultimate effect on the final stack as the traces are averaged over the same location to reduce variation; however, it does matter for acoustic impedance estimates. Shot source repeatability is difficult to measure, but parameters such as wavelet amplitude, shape, duration, frequency content and travel time appear consistent between the shot records of both surveys, and are likely to be a good indicator of shot repeatability. 



\section{Kamb Ice Stream Flowline Simu- lations}

This Chapter summarises the results of the Kamb Ice Stream flowline numerical ice sheet modelling, which consist of simulations over a 1000 year period to better characterise and quantify the present-day and future behaviour of the Kamb Ice Stream. This Chapter addresses components of all three Research Questions, by initially simulating the present-day Kamb Ice Stream configuration and characterising the subglacial processes acting on the ice stream. This ensemble set of simulations yields 1746 different modelled variations of the Kamb Ice Stream, with changing shallow ice approximation, shallow shelf approximation, and till friction angles combined to provide a close match to the present-day state of the Kamb Ice Stream. Observed surface elevation, ice thickness, and surface ice velocities are compared statistically and visually to the modelled simulations to select three final model simulations that have a best-fit to the observed and measured data. As there is no significant variation between the three simulations, one simulation was selected to be used for the further simulations. This Chapter investigates how the modelled Kamb Ice Stream responds to changing hydrological conditions, by simulating either higher or lower amounts of water stored in the subglacial till, and by using a range of water decay rates. Lastly, a comprehensive set of future scenario simulations is analysed. This set of simulations incrementally perturbs the oceanic temperatures by $0.25^{\circ} \mathrm{C}$, the atmospheric temperatures by $1.0^{\circ} \mathrm{C}$, or a combination of both. This set of simulations is intended to provide a comprehensive analysis of changing responses and processes under a changing climate.

\subsection{Theoretical Background}

This study uses the Parallel Ice Sheet Model whose components are well documented in the PISM manual (Bueler \& Brown, 2009; Winkelmann et al., 2011). This is a comprehensive document that outlines the usage as well as theoretical background and 
calculations used in PISM. It is the main reference used for this section, and will not be referenced again separately. External references and references within the manual will be cited.

\subsubsection{Ice Dynamics}

\section{Stress Balance}

The stress balance equations are solved using temperature, basal strength, and geometry to determine the ice velocity. A full Stokes model (see Section 1.5.1) is computationally time consuming, and instead PISM solves two shallow approximations in parallel, the Shallow Ice Approximation (SIA) and the Shallow Shelf Approximation (SSA). The SIA describes ice as flowing by shear in planes parallel to the geoid, implying a strong connection of the ice base to frozen bedrock, without basal sliding, and is used for most of the grounded ice (Hutter, 1983). For most of the grounded ice sheet the SIA is an appropriate approximation of the full Stokes model, and the SIA equations use a local function of the driving stress to describe the vertical stress (Paterson, 1994).

The SSA provides an approximation of membrane-type flow of floating ice which has a smaller depth-to-width ratio, and limited basal resistance and basal stress, which better represents ice shelf flow speeds that are frequently an order of magnitude higher than in the non-sliding, grounded parts of ice sheets (Morland \& Zainuddin, 1987; Weis, Greve \& Hutter, 1999; Morland, 1987). This different representation of the basal stress conditions, with limited basal resistance and basal drag, can also be used to describe faster flowing areas of the grounded ice sheet, such as the formation and flow of ice streams, as these calculations require more than the non-sliding SIA (Bueler \& Brown, 2009; Winkelmann et al., 2011). Where different amounts of basal resistance act on adjacent columns of ice, either spatially or temporally, strong membrane or longitudinal stresses are exerted on each other that are better solved using the SSA (Schoof, 2006). This sliding law role for the SSA is in addition to its more obvious role in ice shelf modelling. The combination of both the SIA and the SSA serves as a hybrid model approximation of the full Stokes model, which is used in this study. The -stress_balance ssa+sia parameter in PISM combines the calculated SSA velocity, using a pseudo-plastic till, with the calculated SIA velocity for the ice flow of the ice sheet (Bueler \& Brown, 2009). 


\subsubsection{Mass Conservation}

\section{Surface Mass Balance}

This study uses a positive degree day (PDD) model to control the surface mass balance of the model simulations. This PDD model assumes that for each $1^{\circ} \mathrm{C}$ over $0^{\circ} \mathrm{C}$, a certain depth of snow (measured in millimetres water equivalent, mm w.e.) will be melted. The PDD model uses time-stepping solutions of the mass conservation and energy conservation equations (Equation $\mathrm{x}$ and $\mathrm{x}$ ). These use the ice velocity for advection, and can be incorporated in the SIA, SSA or SIA+SSA hybrid stress balances. The mass conservation can also be switched off in the model (option -no_mass) where the ice geometry does not evolve. This option is used in the setup no mass phase of the model simulations. The mass balance is calculated on a weekly basis in the simulations, where the PDD model tracks the current snow depth which is necessary to determine whether melt is calculated. A fraction of the melt is allowed to refreeze in the PDD model (using option -pdd_refreeze_ice_melt). PISM also does not have a separate firn model, and the snow depth is calculated from zero at the start of the model simulations.

\section{Ice and Ocean Interface}

In PISM, the components of the ocean model choice (Section 3.1.5) calculate a sub-shelf ice temperature and sub-shelf mass flux to the ice dynamics core. This sub-shelf ice temperature is used as a boundary condition (i.e. a condition that is specified for the solution to a set of differential equations at its boundary) in the energy and mass conservation code, where a positive flux corresponds to ice loss and a negative flux to ice gain. This equates the sub-shelf mass flux to a melt rate. The ocean model derives the basal melt rate and basal temperatures from thermodynamics at the basal ice shelf boundary layer (Ritz, 1997; Payne et al. 2000). Calculated melt water is not returned to the surrounding ocean, as no ocean circulation is modelled, and thus not conserved.

\subsubsection{Ice Rheology}

\section{Flow Laws}

Some ice rheology models can be considered isotropic, such as the one used in PISM, and can be described by flow laws, which are functions of ice temperature, liquid water fraction, ice overburden pressure, grain size and a stress tensor. In PISM, the GlenPaterson-Budd-Lliboutry-Duval flow law is also the only flow law choice in the model 
that calculates the softening of pressure-melting ice as the liquid fraction increases. This is the default flow law and is the one used for this study as it provides the most comprehensive flow law taking the liquid water fraction into account and is defined by Equation 3.1.

$$
A(T, \omega)=A_{C}(T)\left(1+C_{\omega}\right)
$$

where $A(T)$ is the temperature-dependent ice softness, $\omega$ the liquid water fraction, and $C$ a configuration parameter (default value of 181.25). This law is an extension of the Paterson-Budd flow law, which relies on different Arrhenius terms for pressure adjusted temperatures either above or below 263 K (Paterson \& Budd, 1982), and does not include a liquid water fraction.

\section{Enhancement Factors}

For any variations of strain rate not explained by either stress or temperature in ice creep, enhancement factors can provide a way to adjust modelled velocities. The enhancement factors are not physical variables (i.e. a factor that can be changed), however, these might represent unknown or unrepresented physical properties, and provide a way to "fine-tune" the ice sheet model to more closely resemble present-day conditions. An enhancement factor can be applied to both the SIA (-sia_e) and the SSA (-ssa_e) to adjust the flow law and ice flow behaviour. This study uses both the -sia_e and the -ssa_e to produce model simulations that closely match present-day observed data.

\section{Driving Stress}

The model calculates surface gradients to determine the gravitational driving stress, which is used for the SIA and the SSA stress balances equations, using Equation 3.2.

$$
\tau_{d, x}, \tau_{d, y}=-\rho H \nabla h
$$

where $H$ is the ice thickness, $\rho$ the ice density, and $h=H+b$ ( $b$ the bed elevation) the ice surface elevation. In the SIA the driving stress is calculated on a staggered grid that retains the coupling of pressure and velocity, while in the SSA the basal driving stress is calculated on a regular grid that uses centred differencing where the coupling of pressure and velocity is not necessary for the stress balance equations and more computationally efficient. The-gradient haseloff option is the default option, 
which also alters the slope formula in ice margin areas where an adjacent bedrock surface elevation is above the ice elevation.

\section{Conservation of Energy}

An enthalpy-based scheme is used for the ice and the subglacial layer, which allows for energy conservation even when the temperature is at the pressure-melting point. When ice is at the melting point, it is classified as temperate ice and part of its thermal energy is in the liquid water stored between the temperate ice crystals. The enthalpy-based scheme calculates this thermal energy, and allows for polythermal ice sheets to be modelled.

\subsubsection{Subglacial Environment}

\section{Basal Strength}

The option -stress_balance ssa+sia requires a basal resistance model, which is based on the assumption that the ice sheet is underlain by a layer of till. Three components of the basal resistance can be controlled: the sliding law, which links the basal shear stress to the ice base velocity, the model which relates the effective pressure on the till to the yield stress, and the model that links the amount of water stored in the till to the effective pressure on the till (Clarke, 2005). The basal shear stress is a function of the thickness of the ice, as well as the slope of the bed, the sliding law choice made and the threshold velocity, whereas the basal driving stress is a function of the thickness of the ice, as well as the slope of the bed, and the material density, and are typically around $10^{5} \mathrm{~Pa}$ at the base (Cuffey \& Paterson, 2010).

\section{Sliding Laws}

In this study a power sliding law is used, frequently called a pseudo-plastic law, which is commonly used for glaciological studies (Cuffey \& Paterson, 2010). Equation 3.3 describes the pseudo-plastic sliding law, with a power of $q$ and threshold velocity $u_{\text {threshold}}$. At the threshold velocity the basal shear stress, $\tau_{b}$, has the same magnitude as the yield stress $\left(\tau_{c}\right)$. The power $q$ is controlled by -pseudo_plastic_q (default 0.25 ), and $u_{\text {threshold }}$ is controlled by -pseudo_plastic_uthreshold (default $110 \mathrm{~m}$ $\left.\mathrm{y}^{-1}\right)$.

$$
\tau_{b}=-\tau_{c} \frac{\mathrm{u}}{u_{\text {threshold }}^{q}|\mathrm{u}|^{1-q}}
$$




\section{Yield Stress}

The yield stress $\left(\tau_{c}\right)$ represents the strength of the subglacial material at the base of an ice sheet that can resist sliding, and can be compared to the basal driving stress, which makes it a useful parameter (i.e. a measurable factor forming one of a set that defines a system) to characterise the subglacial environment. When using the -stress_balance ssa+sia option, a yield stress lower than a driving stress will likely result in basal sliding (Schoof, 2006).

The option -yield_stress mohr_coloumb calculates the yield stress using till friction angles ( $\phi$, tillphi) and effective pressure $\left(N_{t i l}\right)$ on the saturated till, and is also partially determined by subglacial hydrology, such as the amount of till pore water. The till friction angle is the internal friction angle which is the net result of the ice sheet mass acting on the subglacial bed and the frictional force, and above which material failure occurs. In this study tillphi was determined as a function of bed elevation, which has been found to be an effective way to modify the value, and is heuristically based on the hypothesis that basal material with a marine history is weaker (Huybrechts \& de Wolde, 1999; Martin et al., 2011; Winkelmann, et al., 2011; Aschwanden, Adalgeirsdottir \& Khroulev, 2013). The option -topg_to_phi was used to determine the best till friction angles (minimum and maximum angle) and bed elevation (minimum and maximum elevations) combinations, together with changing the -sia_e and -ssa_e, to most accurately replicate a present-day KIS configuration.

The yield stress is calculated using Equation 3.4.

$$
\tau_{c}=c_{0}(\tan \phi) N_{t i l}
$$

where $c_{0}$ is the till cohesion (default $=0$ ), but can be changed by using the option -till_cohesion. Studies summarised by Cuffey and Paterson (2010) suggest that the true effect of cohesion in deforming tills is probably small enough to be neglected in most problems and refer to this as the apparent cohesion. This approach is also used in this study.

\section{Effective Pressure}

The effective pressure on the till $\left(N_{t i l}\right)$ is determined by the modelled amount of water in the till, and is a component of a material's yield stress. With a lower effective pressure, more of the ice weight is carried by the pressurised water in the till and the ice can slide more easily as a result. The yield stress equation, Equation 3.5 calculates $N_{t i l}$, which is an important component of the yield stress equation (Equation 3.4). It 
is defined as

$$
N_{t i l}=\delta P_{o} 10^{\left(e_{0} / C_{c}\right)\left(1-\left(W_{t i l} / W_{t i l}^{\max }\right)\right)}
$$

where $P_{o}$ is the ice overburden pressure, which is determined by ice thickness and density. $W_{t i l}$ is equal to the parameter tillwat, and is the effective thickness of water in the till. $W_{t i l}^{\max }$ is equal to the parameter hydrology_till_max which is the maximum amount of water stored in the till. The remaining parameters are constants, with default values of 0.69 for $e_{0}$ (till void ratio), 0.12 for $C_{c}$ (till compressibility coefficient), and 0.02 for $\delta$ ( till effective fraction overburden).

\section{Subglacial Hydrology}

In the -hydrology null model (not mass-conserving, Section 3.1.2; default) a specific amount of water is stored in the till, set by the option -hydrology_tillwat_max, and any water that exceeds this is lost permanently. This hydrology model is based on the undrained plastic bed concept of Tulaczyk, Kamb and Engelhardt (2000). Equation 3.6 calculates the evolution of effective thickness of water stored in the till

$$
\frac{\partial W_{t i l}}{\partial t}=\frac{m}{\rho_{w}}-C
$$

where $m$ is equal to the basal melt rate (bmelt), $\rho_{w}$ is the density of fresh water, and $C$ is equal to the decay rate (hydrology_tillwat_decay_rate), where water accumulates in the till at the basal melt rate bmelt, minus this rate. It is argued that for the exploratory purposes of this thesis, that the -hydrology null model sufficiently replicates a subglacial hydrological scheme that shows the effect of increased amounts of water stored within the till on the ice velocity. This scheme is also two orders of magnitude less expensive computationally than the mass-conserving -hydrology routing model, and allows for a larger set of simulations.

\section{Earth Deformation Model}

This study uses the Lingle and Clarke (lc) model option, which is based on an improvement of the Elastic Lithosphere Relaxing Asthenosphere (ELRA) model (Lingle \& Clarke,1985; Bueler, Lingle \& Kallen-Brown, 2007), and allows purely-elastic deformation missing from the ELRA model to be calculated. This option is not active by default, however, and the model version used here is known to contain a code bug in the calculation of this elastic component. This is not thought to have a significant effect on the model results at the timescales that models are run in this study. 


\section{Bed Roughness}

Altering the stress balance model to allow for flow over rough bedrock topography requires calculating the amount by which the rough topography lowers the SIA diffusivity (Schoof, 2003). This allows for better handling of bed roughness, as it controls the effects of stresses that act on the ice as it flows over rougher areas. In this study a half width value of $10 \mathrm{~km}$ was used as recommended by Schoof (2003), to reduce the effect of bed roughness on the ice flow. The half width is the resolution of the basal smoothing parameter used in PISM. The application of this smoothing parameter is largely due to computational efficiency, which parameterises the effects of higher-order stresses which act on the ice as it flows over bumps and decreases the time needed for model runs.

\subsubsection{Calving}

Ice shelf calving fronts are controlled by different physics to the rest of the ice sheet, as their flow is very different from the SIA flow. The physics at the calving front is better described by using boundary condition changes to the SSA and vertically integrating force balance equations (Equation 3.7)

$$
\int_{z_{s}-\frac{\rho_{i}}{\rho_{\omega}} H}^{z_{s}+\left(1-\frac{\rho_{i}}{\rho_{w}}\right) H} \sigma \cdot \mathbf{n} d z=\int_{z_{s}-\frac{\rho_{i}}{\rho_{\omega}} H}^{z_{s}} \rho_{\omega} g\left(z-z_{s}\right) \mathbf{n} d z
$$

where $\mathbf{n}$ is the horizontal, ocean-ward vector, $H$ the ice thickness, $\rho_{\omega}$ and $\rho$ the densities of seawater and ice respectively, and $\sigma$ the stress tensor, for a sea level of $z_{s}$. When using the ice flow law, Equation 3.7 is rewritten in terms of strain rates, similar to the SSA. The option - cfbc replaces stress balance terms according to Equation 3.7 in any fully filled ice boundary grid cells, which then applies the correct stresses at the calving front (Albrecht et al., 2011; Winkelmann et al., 2011). The right hand side of Equation 3.7 accounts for the below sea level ice shelf component and the ocean pressure exertion.

To correctly model the ice shelf calving front movement on a finite difference grid, the tracking of any partially-filled cells is required (Albrecht et al., 2011). A moving calving front will add (or remove) ice from the adjacent cell, resulting in a partially filled cell with comparable ice thickness to its filled neighbour. The option -part_grid adds the ice to the partially filled cell, and calculates the coverage of the cell depending on the ice thickness of adjacent filled cells. When a cell becomes fully filled, the remaining ice is redistributed to adjacent cells using option -part_redist. The stress balance 
equations only use velocities from fully filled cells. The adaptive time stepping scheme and the Courant-Friedrichs-Lewy (CFL) condition (i.e. that the time steps length between calculations must be lower than the model resolution and that calculations are only applied to the immediate neighbouring cells) applied limit ice front propagation so that a maximum of one adjacent cell is filled or emptied per time step.

Options -cfbc, -part_grid, -part_redist, -no_subgl_basal_melt as well as -subgl and -kill_icebergs are all used in this study as the most comprehensive calving scheme and are defined below.

\section{Calving Mechanisms}

Multiple calving mechanisms are available in the model. The-calving eigen_calving is a physically based calving process that has calving rates $c$ which are proportional, $K$, to the horizontal strain rates components $\dot{\epsilon}_{ \pm}$(Winkelmann et al., 2011). This proportional value is set by -eigen_calving_K, and takes the material properties of ice at the calving front into account, and the relationship is described by Equation 3.8

$$
c=K \dot{\epsilon}_{+} \dot{\epsilon}_{-} \text {and } \dot{\epsilon}_{ \pm}>0
$$

The thickness calving process -thickness_calving calves any ice thinner than a specified ice thickness $H_{c r}$ at the calving front, which is set using -thickness _calving_threshold option. The -calving ocean_kill option removes any floating ice in sections selected as ice free ocean. This study applies all above discussed calving mechanisms to capture a comprehensive scheme for ice removal.

\section{Iceberg Removal}

The presence of a calving mechanism can create isolated ice patches outside the region of continuous ice in the model, which can produce either ice filled or partially filled cells, as well as patches of floating ice (i.e. icebergs). As the ocean applies no resistance to these icebergs to balance the driving stress, the SSA stress balance fails. Instead, icebergs are removed in the simulations (-kill_icebergs).

\subsubsection{Grounding Zone}

The option -subgl turns on the sub-grid grounding zone scheme, which uses a linear interpolation approach described in Gladstone, Payne and Cornford (2010). When using this option, an extra flotation mask is calculated, which corresponds to the 
fraction of the cell that is grounded versus floating. Fully floating, or ice free, cells are assigned the value 0 , and fully grounded cells the value 1 . Cells that are partially floating receive a value between 0 and 1 . By using this grounding zone scheme, abrupt changes in basal friction are avoided, and the basal melt rates $(M)$ are interpolated across cells that span the grounding zone, according to Equation 3.9

$$
M_{b, \text { adjusted }}=\lambda M_{b, \text { grounded }}+(1-\lambda) M_{b, \text { shelf-base }}
$$

where $\lambda$ is the value of the flotation mask.

\subsection{Methodology}

\subsubsection{Input Data Sets}

The coordinates of the KIS flowline are picked manually in QGIS (version 2.16, utilising the MEaSUREs data from Rignot et al., 2013 and Quantarctica data sets; Matsuoka, Skoglund, \& Roth, 2018) and follow the centre line of the KIS catchment. Figure 3.1 illustrates the flowline location, which is initially divided into $1 \mathrm{~km}$ equidistant points. Surface elevation and topographical data from BEDMAP2 (Fretwell et al., 2013) are used as input values for the topography and ice thickness, and the MEaSUREs data (Rignot et al., 2013) for the surface ice velocity. The MEaSUREs ice velocity data is also used to help define a line of best representation of the KIS surface ice flow. Data interpolated to the flowline are re-gridded to $10 \mathrm{~km}$ intervals, as a higher resolution is not computationally viable for this study. This study uses the same atmospheric and oceanic input data as Golledge and others (2015), which are sourced from Comiso (2000) and Lenaerts and others (2012) and used as boundary conditions for this model study. Table 3.1 shows the data input parameter choices for the model set-up, as well as those for the different sets of simulations. 
Table 3.1 Input options and parameter choices for the flowline model simulations, comparing the smoothing, evolution and spin-up simulations of the model, as well as the different sets of subsequent simulations.

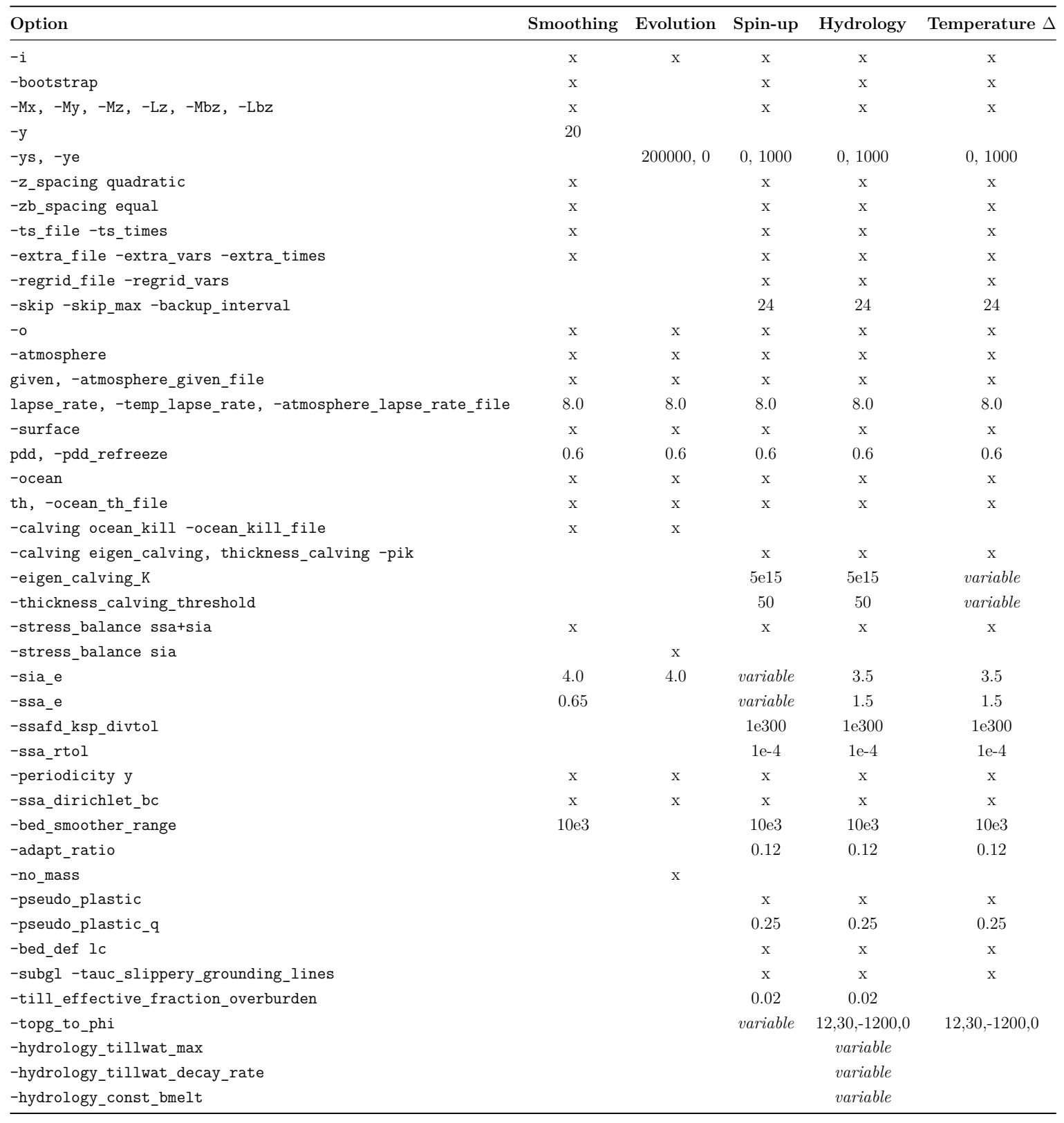




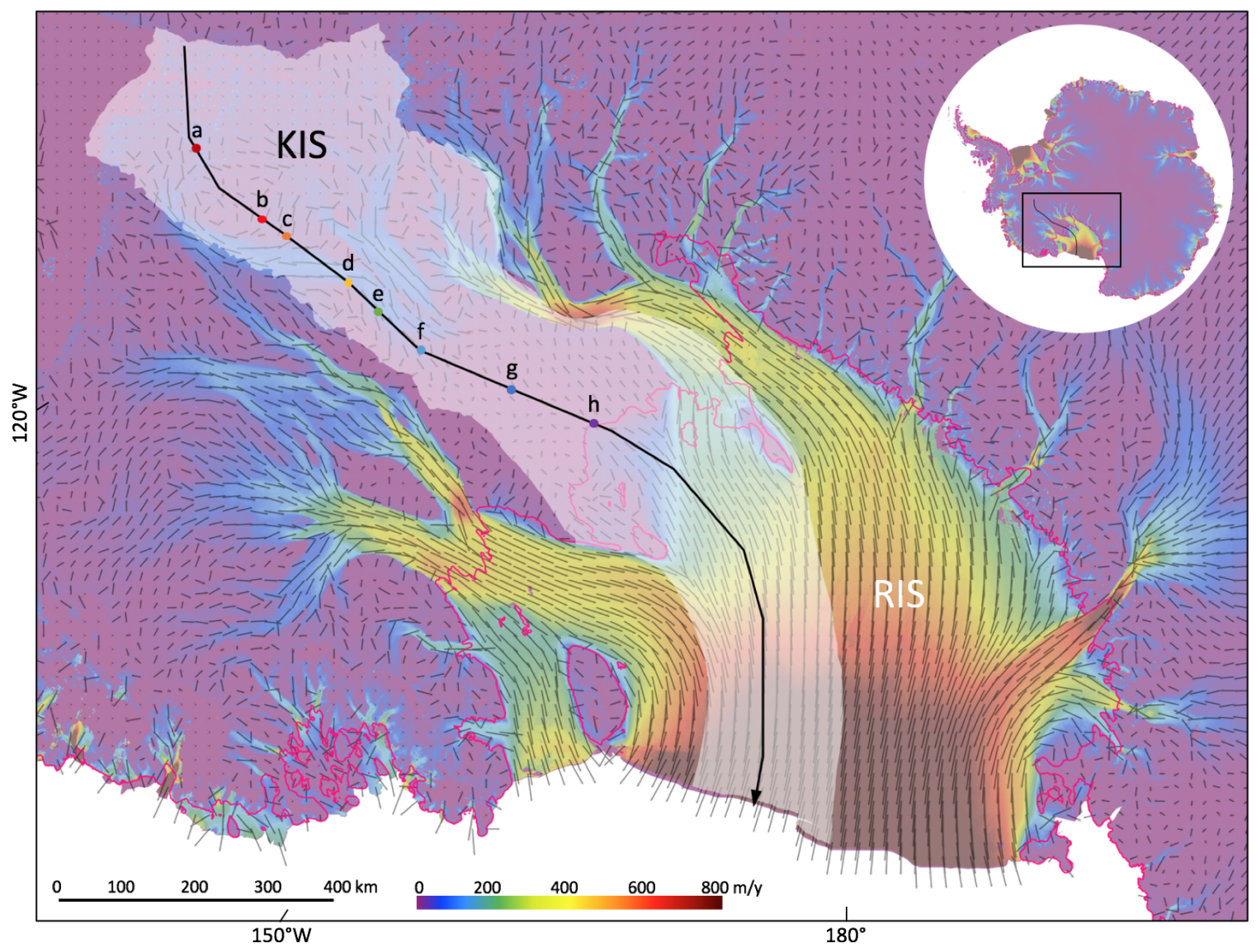

Fig. 3.1 Flowline location used for the model simulations, which follows the surface ice velocity (MEaSUREs ice velocity data, Rignot et al., 2011; background colours), the ice flow orientation (small black arrows), and is within the bounds of the KIS drainage area (white). The grounding line (pink) is inferred from the MEaSUREs ice velocity data (Rignot et al., 2011). The flowline (black arrow) also shows the locations selected for data comparison ( $a$ - $h$, shown in different colours) which are used in this study. The pink line indicates the inferred grounding zone from satellite imagery.

Figure 3.2 illustrates the KIS flowline at the start of the model ensemble simulations. The till friction angle is also plotted, as even though this is not a constant in the ensemble simulations, it remains constant for the following hydrological and temperature simulations. The ice thickness, surface elevation, and surface flow velocity are used at the analysis stage to ensure visual and statistical best fit of the ensemble simulations to present-day KIS conditions. 


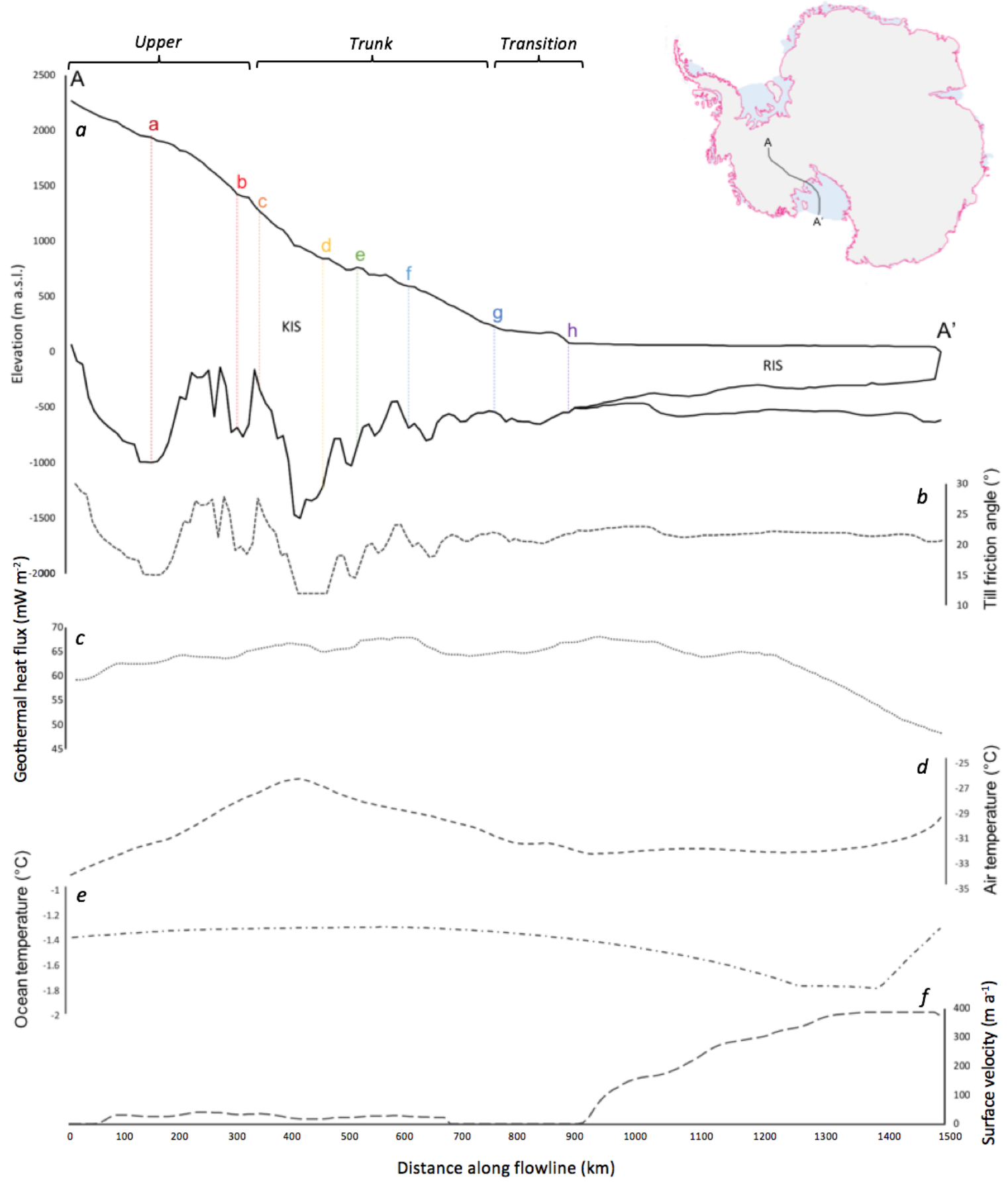

Fig. 3.2 Original values and parameters for the ice surface elevation, bed topography, ice thickness (subplot $a$; BEDMAP2; Fretwell et al., 2013), ice surface flow velocity (subplot $f$; MEaSUREs; Rignot et al., 2013), geothermal heat flux (subplot $c$; Shapiro \& Ritzwoller, 2004), atmospheric temperature, and oceanic temperature fields (subplots $d$ and $e$; Comiso, 2000; Lenaerts et al., 2012). The till friction angle is also plotted (subplot $b$ ), which is not a constant in the ensemble simulations, however, it remains constant for the following hydrological and temperature simulations. Eight locations $(a-h$, top figure) are chosen along the flowline for further in-depth analysis. 


\subsubsection{Smoothing and Evolution}

The initial stages of model set-up follow a similar approach to Golledge and others (2015). After the input data have been extracted and combined into raw input file, a 20 -year smoothing simulation is performed to remove steep gradients in the data and to set up the system for the evolution simulation. The evolution simulation allows the ice temperatures to evolve within a fixed geometry over a 200,000 year period to reach thermal equilibrium with the initial climate conditions. Both steps are necessary to ensure a stable starting state. Table 3.1 shows the options and values utilised for the smoothing and evolution simulations, as well a more detailed explanation in Section 3.1 .

\subsubsection{Model Spin-up}

On completion of the 200,000 year evolution simulation, a nudging procedure is used, described by Golledge and others (2019), where the bed topography and modelled ice thickness are reset to present day values. The model spin ups are performed over a 1000 year period, and use the full, evolving model physics, including the SIA and SSA, grounding zone movement, calving, bed deformation, and model boundaries. An ensemble approach is used, as opposed to an iterative simulation procedure, to produce a model simulation close to present-day observations. This produces a wide range of simulations that can provide a first order characterisation and understanding of the effect of parameter choices on the KIS configuration. The ensemble simulations explore a range of SIA and SSA enhancement factors, as well as a range of till friction angles (minimum till friction angle - Phimin and maximum till friction angle - Phimax) and till friction angle depths (minimum till friction angle depth - Phitopmin and maximum till friction angle depth - Phitopmax). The flow enhancers and till friction parameters are chosen as they provide a comprehensive degree of control on the subglacial environment to simulate a best-fit scenario. Table 3.2 shows the ensemble parameters and values, of the 1746 combinations employed. 
Table 3.2 Ensemble parameter options combined to produce 1746 model simulations that are compared to present-day observed values, which allows selection of the best-fit present-day configuration.

\begin{tabular}{|c|c|c|c|c|c|}
\hline SIA Enhancement Factor & SSA Enhancement Factor & Phimin & Phimax & Phitopmin & Phitopmax \\
\hline 1.0 & 0.25 & 2 & & -200 & \\
\hline 1.5 & 0.5 & 4 & & -400 & \\
\hline 2.0 & 0.75 & 6 & & -600 & \\
\hline 2.5 & 1.0 & 8 & 30 & -800 & 0 \\
\hline 3.0 & 1.25 & 10 & & -1000 & \\
\hline 3.5 & 1.5 & 12 & & -1200 & \\
\hline 4.0 & & & & -1400 & \\
\hline
\end{tabular}

\subsubsection{Analysis}

Both visual and statistical comparisons are used to determine the model simulation that best fits the observed KIS configuration. Three plots are produced to assist in the analysis and determine the optimal model simulation (Figure 3.3). Final values of ice thickness, surface ice elevation, and surface ice velocity are plotted against the KIS observed data to visually assess model fit to constraints. Subsequently, differences of ice thickness, surface elevation, and surface ice velocity between the model simulation and observed values is plotted. This shows where the model simulations differ the most, or least, from the observed data and is more indicative of best-fit. In particular, the models do not adequately replicate the observed data between 300 to $600 \mathrm{~km}$ along the flowline (i.e. the KIS trunk), as well as the floating ice immediately downstream of the grounding zone (Figure 3.3). The standard deviation (SD) and the mean absolute error (MAE) of the percentage difference between the model simulations and the observed values are also calculated and plotted on Figure 3.4. The calculations are performed separately for the total flowline, the grounded ice section of the flowline, and the floating ice section of the flowline. For both the total flowline and grounded ice, multiple model simulations have a similar best fit profile to the observed KIS configuration. The floating ice section is not captured as accurately as the grounded section, particularly near the grounding zone, which is likely due to the ocean melting component of the model not capturing all the processes occurring beneath the present-day ice shelf. As this study largely focuses on the grounded section of the ice stream and the subglacial environment, model simulations of best fit are chosen that best represent the total and grounded ice sections of the present-day KIS configuration. Three model simulations (KIS-1, KIS-2, KIS-3) are determined to have both visual and statistical best-fit to the observed KIS configuration, with the lowest overall standard deviation and mean 
absolute errors for all three comparison variables, and are plotted on Figure 3.3 and 3.4 .
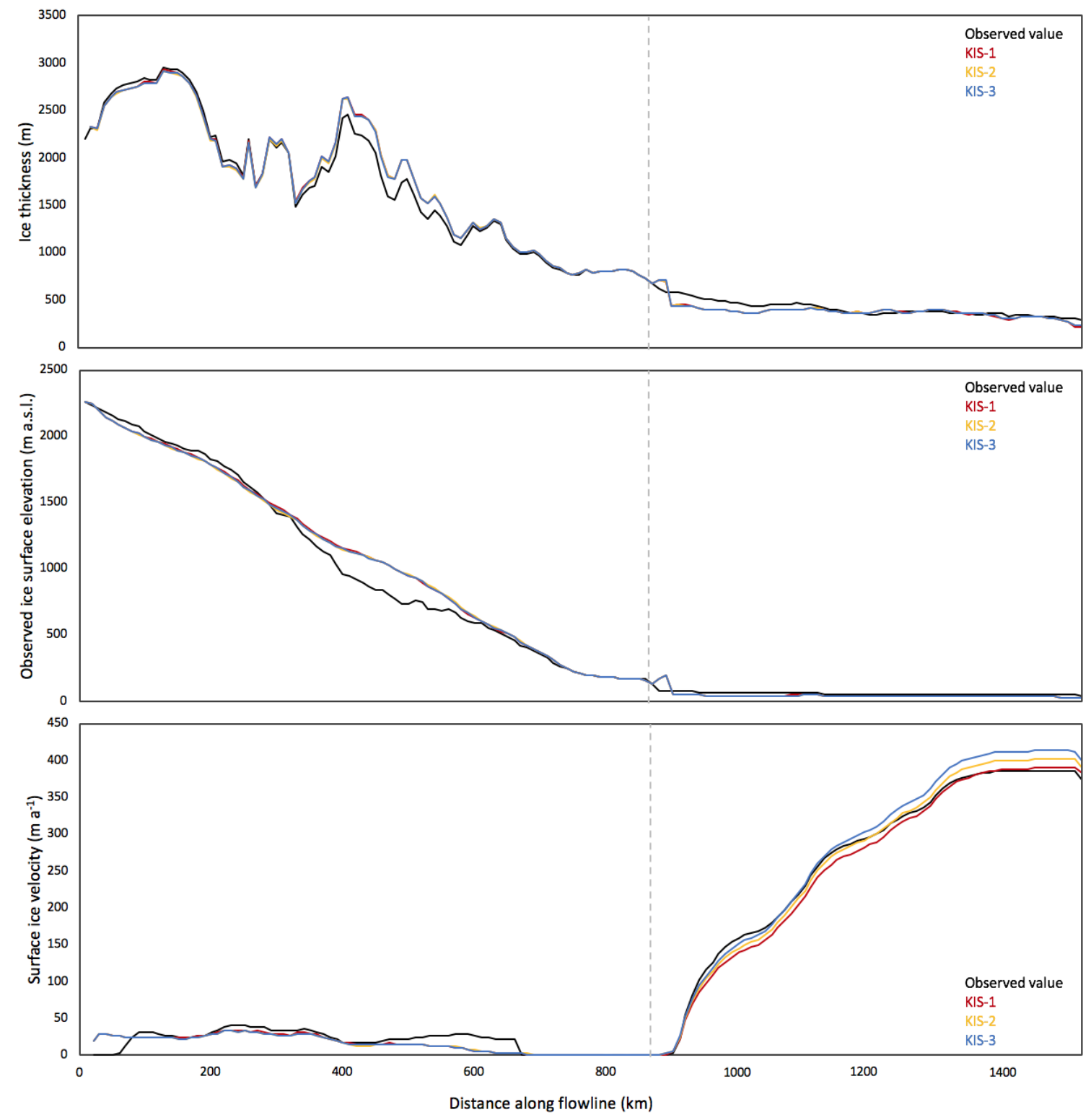

Fig. 3.3 Three final model simulations, KIS-1 (red), KIS-2 (yellow), and KIS-3 (blue) plotted against observed values (black) to show similarities and differences. The model simulations are most inaccurate between 300 to $600 \mathrm{~km}$ along the flowline, as well as immediately downstream of the observed grounding zone (grey dashed line at 900-1000 km along flowline). The top panel plots the observed and modelled ice thicknesses, the centre panel the observed and modelled ice surface elevations, and the bottom panel the measured and modelled surface ice velocities. Note, the different y-axis values for each plot. 


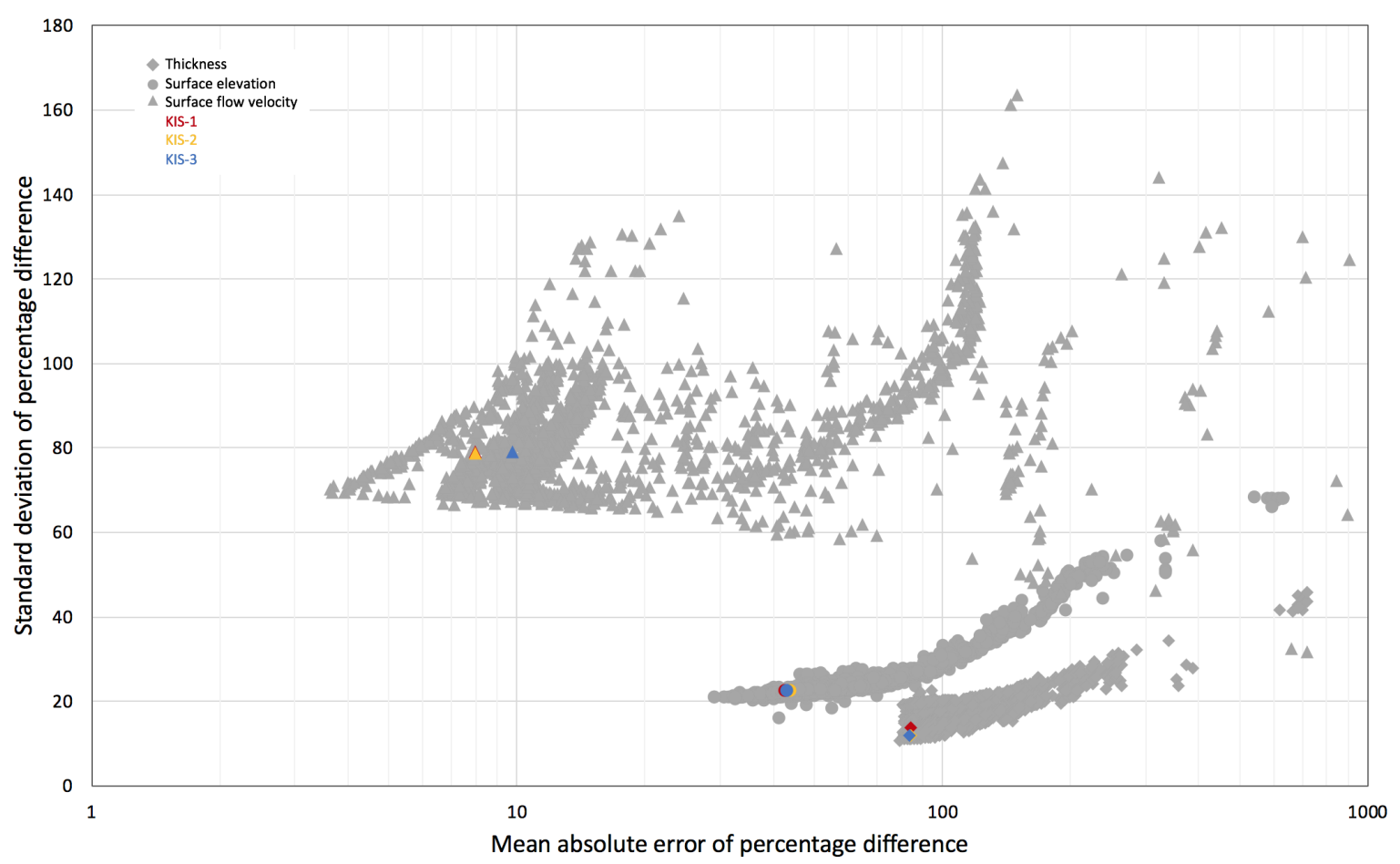

Fig. 3.4 Standard deviation against mean absolute error of the ice surface velocity (triangles), ice thickness (circles) and ice surface elevation (diamonds) percentage differences compared to the observed values. The three best-fit model simulations, KIS-1 (red), KIS-2 (yellow), and KIS-3 (blue) are shown.

These simulations do not have the smallest possible combination of SD and MAE values, but nonetheless represent the best-fit intersection of all three variables. Lastly, the mask variable is analysed to determine whether any change in grounding zone position occurred. Out of the 1746 ensemble simulations, in nine simulations the grounding zone position moved inland by either 10 or $20 \mathrm{~km}$, and in fifteen simulations the grounding zone extended ocean-ward past the present-day grounding zone. For the three simulations of best fit, the grounding zone position has not changed from its assumed present-day position. As there is limited visual or statistically significant difference between the three simulations of best-fit, the KIS-3 simulation is chosen as the starting point for further flowline simulations (Figure 3.3). It is suggested that the differences between the three model runs do not significantly effect further model result outcomes. The parameters for this final simulation, as well as the KIS-1 and KIS-2 simulations, are summarised in Table (3.3). 
Table 3.3 Final simulation parameters for KIS-1, KIS-2, and KIS-3. The KIS-3 simulation is chosen for further experiments.

\begin{tabular}{lccc}
\hline & KIS-1 & KIS-2 & KIS-3 \\
\hline SIA Enhancement & 3.5 & 3.5 & 3.5 \\
SSA Enhancement & 1.0 & 1.25 & 1.5 \\
Till Friction Angle Min. & $12^{\circ}$ & $8^{\circ}$ & $12^{\circ}$ \\
Till Friction Angle Max. & $30^{\circ}$ & $30^{\circ}$ & $30^{\circ}$ \\
Till Friction Depth Min. (m) & -1400 & -1400 & -1200 \\
Till Friction Depth Max. (m) & 0 & 0 & 0 \\
\hline
\end{tabular}

\subsubsection{Hydrological Controls}

The first set of simulations explores the characterisation of the subglacial environment and the KIS response to changing hydrological controls, by changing the amount of effective water stored in the till, and the decay rate at which the water is removed from the subglacial environment (i.e. the water accumulates in the till at the basal melt rate, minus the specified decay rate). This explores the influence of changing hydrological conditions on the resultant ice velocity and ice thickness, as well as basal stresses and temperatures. The spin-up uses a default maximum value of $2 \mathrm{~m}$ of effective water stored in the till, and a default decay rate of $1 \mathrm{~mm} \mathrm{y}^{-1}$. For the hydrology simulations, maximum water depths of $0.1,1.0,2.0,3.0$, and $3.9 \mathrm{~m}$ are used to characterise a range of responses and maximum water stored in till. These values effectively bracket the 1.4 $m$ water stored in the KIS till measured in borehole data on the upper KIS (Kamb, 2001), whilst also exploring higher and lower values that could occur as a response to changing hydraulic pathways or climatic changes. Five decay rates are also simulated, in combination with the effective thickness, to produce an ensemble of 25 simulations, with changing decay rates of $0.1,0.5,1$ (default), 1.5, and $2.0 \mathrm{~mm} \mathrm{y}^{-1}$.

\subsubsection{Future Projections and Impacts}

The second set of simulations explores the changes to the KIS under changing climatic conditions. A range of increasing atmospheric and oceanic temperature perturbations at the start of the run are simulated, to produce projections of changes along the KIS. First, surface air temperatures are incrementally increased by $1.0^{\circ} \mathrm{C}$ to a maximum atmospheric temperature anomaly of $8.0^{\circ} \mathrm{C}$ (chosen to be inline with the RCP8.5 scenario; Church et al., 2013). The second set of simulations varies ocean temperatures, 
with incremental perturbations of $0.25^{\circ} \mathrm{C}$ to a maximum anomaly of $2.0^{\circ} \mathrm{C}$ above the control simulation. Lastly, an ensemble of 81 combinations combines perturbations of ocean and surface air temperatures.

\section{Atmospheric Temperature and Precipitation Changes}

Separating atmospheric temperature changes, from changes in oceanic temperatures, provides a useful insight into the relative importance of each set of boundary conditions. In realistic scenarios the change in atmospheric temperatures is intrinsically linked to the change in oceanic temperature; however, as the ocean has a slower response time than the atmosphere (Bigg et al., 2003), characterising atmospheric effects on the KIS separately provides insight into decadal-scale forcing changes. Nine different atmospheric temperature increases are simulated, where the input atmospheric temperature variable is uniformly increased by $1.0^{\circ} \mathrm{C}$ incremental steps to $8.0^{\circ} \mathrm{C}$, starting with a $0.0^{\circ} \mathrm{C}$ control simulation. The change in this atmospheric temperature anomaly also corresponds to a change in precipitation rate, with a precipitation increase of $7.3 \%$ for every one degree Celsius of atmospheric temperature increase (Huybrechts, 2002). The simulations are run over a 1000 year period, to capture decadal and centennial temporal changes, as well as spatial changes.

\section{Oceanic Temperature Changes}

Similarly, the effect of isolated oceanic warming on the KIS is also useful to explore, as the slower response time affects changes at the centennial- to millennial-scale. Nine different oceanic temperature changes are simulated, where the input oceanic temperature is uniformly increased in increments of $0.25^{\circ} \mathrm{C}$, up to $2.0^{\circ} \mathrm{C}$, starting with a $0.0^{\circ} \mathrm{C}$ control simulation. The simulations are again run over a 1000 year period.

\section{Combined Temperature Scenarios}

While it is useful to model the oceanic and atmospheric temperature change components separately to understand their individual roles, the two are intrinsically linked. The changing of atmospheric temperatures results in a change of oceanic temperatures, and the combined scenarios with both changes in atmospheric and oceanic temperatures are run over a period of 1000 years, to simulate 81 possible climate change scenarios and their influence on the KIS. These simulations combine the same atmospheric and oceanic temperature changes as discussed in Sections 3.2.6 and 3.2.6, which are within 
the modelled ranges of the Representative Concentration Pathway (RCP) scenarios (Church et al., 2013).

\subsection{Results}

Flowline simulation results are analysed in terms of changes along the entire flowline, and by comparing discrete locations along the grounded ice section of the ice stream. Eight locations are selected along the flowline ( $a-h$, shown in Figures 3.1 and 3.2), which capture the spatial variation. Locations $a, b, d, f$, and $g$ are selected at regular $150 \mathrm{~km}$ intervals, locations $c$ and $e$ are selected as they display different temporal behaviour compared to the previous locations, and lastly, location $h$ is selected due to its proximity to the inferred MODIS MOA grounding zone (Haran et al., 2014).

\subsubsection{Till Water Storage and Decay Rates}

\section{Effect on Grounded Ice Volume}

The rate change of ice volume over the grounded section of the ice stream gives a first order assessment of the influences of changing the total availability of maximum effective water stored in the till on the entire KIS. The ice volume rate of change is derived and plotted against time to demonstrate the evolution of the grounded ice volume over the 1000 year simulation (Figure 3.5), using a constant basal water decay

rate of $1 \mathrm{~mm} \mathrm{y}^{-1}$. Changing the maximum amount of effective water stored in the till to $0.1 \mathrm{~m}$ produces an initial rapid increase in grounded ice volume rate of change over a 50 year period, which reduces rapidly over the following 150 years. The rate of change decreases in a more linear manner over the remaining 800 years. A change of maximum amount of effective water stored in the till to $1.0 \mathrm{~m}$ also produces an increase in ice volume growth rate, albeit slower than the $0.1 \mathrm{~m}$ simulation. The ice volume rate of change increases over a 125 year period, and then steadily reduces over the remaining 875 years. The maximum amounts of effective water stored in the till of 2.0, 3.0 and $3.9 \mathrm{~m}$ show similar responses over the 1000 year period, with a very slight, steady decline in ice volume rate of change. Since all five simulations have a similar ice volume rate of change at the end of the simulation, this may indicate that a steady state of the KIS is reached. As the end values are also similar to the starting values, this may indicate that an increase or decrease of the maximum amount of effective water stored in the till by $\pm 1.9 \mathrm{~m}$ from the default of $2.0 \mathrm{~m}$ does not cross a threshold in ice dynamics. The maximum response of the KIS is reached within the first 150 
years of the simulation, and the decay is likely diffusion driven subsequent to this (Benn \& Evans, 2010). Changing the basal water decay rate while keeping the maximum amount of effective water stored in the till constant, responds to the ice volume rate of change. The lower decay rates $\left(0.1\right.$ and $\left.0.5 \mathrm{~mm} \mathrm{y}^{-1}\right)$ retained a slightly larger ice volume at the end of the 1000 year period, where the maximum amount of effective water stored in the till was higher than $2.0 \mathrm{~m}$, and also stabilised the rate of change earlier than the higher decay rates. The return of the KIS to near original conditions after the 1000 year simulation, implies that these changes are transient and reversible at this scale, and that the KIS is self regulating at the level of changes applied to it in this study.

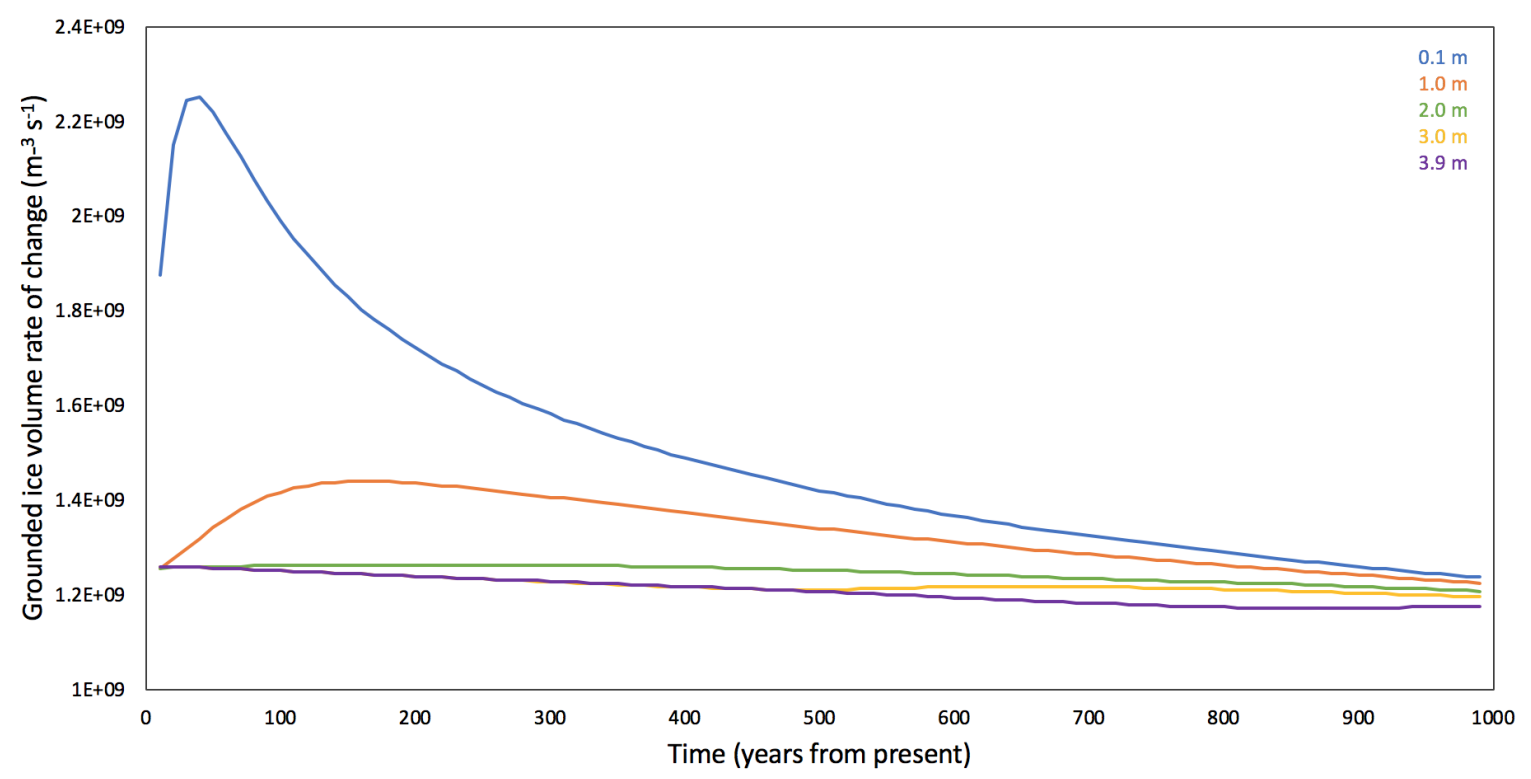

Fig. 3.5 Grounded ice volume rate of change under different maximum amounts of effective water stored in the till $(0.1 \mathrm{~m}=$ blue; $1.0 \mathrm{~m}=$ orange; $2.0 \mathrm{~m}=$ green; $3.0 \mathrm{~m}=$ yellow; and $3.9 \mathrm{~m}=$ purple $)$ and a constant decay rate $\left(1 \mathrm{~mm} \mathrm{y}^{-1}\right)$.

\section{Surface and Basal Velocity}

The variations of the basal and surface ice velocities along the KIS flowline provide a high-level characterisation of the effects of changing the maximum amounts of effective water stored in the till. Increases in ice velocity can be indicative of higher rates of sliding at the basal interface due to enhanced lubrication as a result of the availability of liquid water (Shannon et al., 2013; Nienow et al. 2017). If the subglacial water pressure is sufficiently high in the ice stream, the formation of cavities at the basal interface is possible, which can result in bed separation sliding, and subsequently reduces basal friction and allows faster ice flow (Jiskoot et al., 2011). The surface and 
basal velocities are plotted in Figure 3.6 along the flowline locations. The basal velocity reflects a similar velocity pattern as the surface; however, at approximately an order of magnitude lower than the surface flow. The KIS exhibits the highest sensitivity to changes of maximum amounts of effective water stored in the till of 0.1 and $1.0 \mathrm{~m}$, in comparison to 2.0, 3.0, and $3.9 \mathrm{~m}$. The upper zone of the KIS, as well as locations $d$ and $f$ in the trunk zone (Figure 3.1 and Figure 3.6d and 3.6f), demonstrate an initial lowering of ice velocities with the 0.1 and $1.0 \mathrm{~m}$ simulations, which likely indicates a lack of available water for basal sliding. Locations $c$ and $e$ in the trunk zone potentially demonstrate "sticky spot" locations along the flowline, for example as discussed by Luthra and others (2017), where rapid reductions of surface velocity from 100-60 to 20-10 $\mathrm{m} \mathrm{y}^{-1}$ and basal velocity from 20-10 to $2 \mathrm{~m} \mathrm{y}^{-1}$. In a real world scenario, increases of upstream melt water draining along the base of the ice is routed around the sticky spot, and results in the relatively stable ice velocities at this location (Luthra et al., 2016; Luthra et al. 2017). In the model the hydrological parameter does not re-route the water around a sticky spot, and is instead removed from the simulation. Instead, these sections of lowered basal ice velocities could be viewed as analogous to a sticky spot type scenario rather than the exact capturing of a sticky spot in the flowline. Lastly, locations $g$ and $h$ in the transition zone exhibit minimal change in surface and basal ice velocities, indicating that processes such as the influence of sea water availability govern the ice flow motion at these locations (Padman, Siegfried \& Fricker, 2018). It is suggested that the transition zone is potentially affected by the low slope angle, which creates a more dynamically moving grounding zone location (Padman, Siegfried \& Fricker, 2018), compared to the upper and trunk zones. 

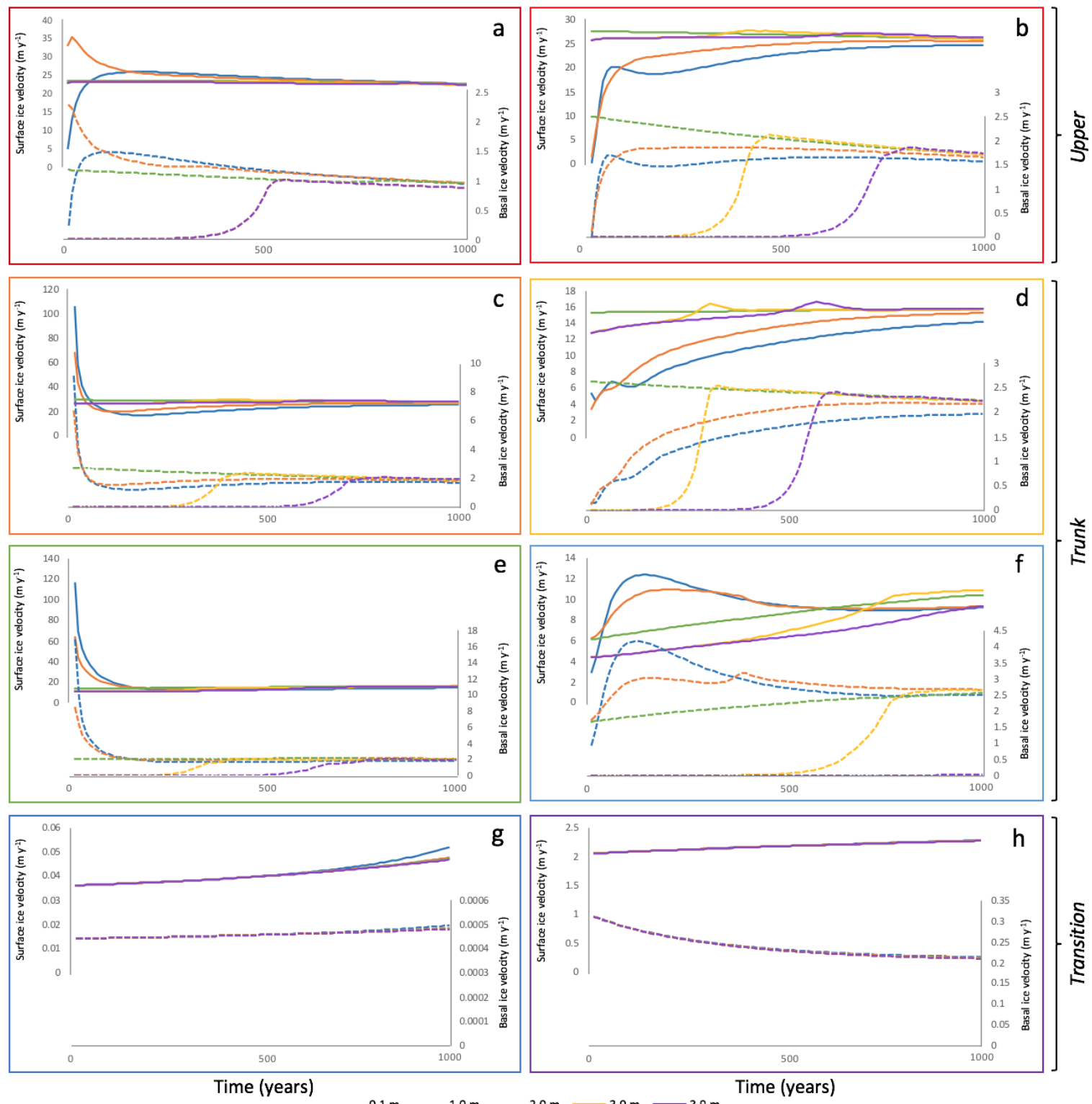

Fig. 3.6 Surface (solid) and basal (dashed) ice velocities under different maximum amounts of effective water stored in the till and a constant decay rate $\left(1 \mathrm{~mm} \mathrm{y}^{-1}\right)$. Each graph $(a-h)$ corresponds to the previously described locations of the KIS (Figure 3.1). Note the changing y-scale for each graph.

\section{Effect on Basal Stresses}

It is important to characterise the processes that govern the temporal and spatial variation of basal stresses in order to better understand the behaviour of ice streams (Sergienko, Creyts \& Hindmarsh, 2014), as well as project their future evolution under changing climates. The gravitational driving stress, basal shear stress, basal yield stress, and effective pressure are important components of the ice stream, and it is 
important to assess their individual roles on ice stream flow. The gravitational driving stress is the result of ice thickness and surface slopes, and is calculated using the ice density, gravitational acceleration, ice thickness, ice surface elevation, and the slope gradient (Sergienko, Creyts \& Hindmarsh, 2014). Typically around $10^{5} \mathrm{~Pa}$ at the base (Patterson, 1994), glacier driving stresses tend to be relatively uniform due to the ice rheology. Figure 3.7 plots changes in the modelled basal shear stress regime acting upon the KIS flowline. The variable response of the basal shear stress closely reflects the changes observed in the surface ice velocity, showing the intrinsic link between the gravitational driving force and resultant ice flow and stresses acting on the bed. As the basal shear stress represents the driving force acting upon the bed, and glacial ice typically can support basal shear stresses of approximately $10^{5} \mathrm{~Pa}$, an observed change in the ice flow is also exhibited. The ice thickening that produces basal shear stresses in excess of this leads to increased ice flow and as a result, ice thinning (Marshall et al., 2011).

This study's modelled yield stress of the KIS flowline is similar in both the upper and the trunk zones (Figure 3.7a-f), implying similar substrates beneath these sections of the KIS flowline. Higher yield stresses are observed for the 3.0 and $3.9 \mathrm{~m}$ maximum amounts of effective water stored in the till in the first $~ 500$ years of the simulations, indicating a stronger substrate, as yield stress represents the strength of the subglacial material at the base of an ice sheet that resists sliding (Bueler \& Brown, 2009; Winkelmann et al., 2011). At values dependent on the yield strength of the substrate, subglacial material begins to deform in a plastic manner as the yield stress is approached, and at stresses equal or higher to the yield stress the deformational change is instantaneous and irreversible. Generally, the glacial ice yield strength is higher than that of till, $\sim 100 \pm 50 \mathrm{kPa}$ and 2-90 kPa, respectively (Paterson, 1994; Murray, 1997).

The sliding velocity of an ice stream is in part controlled by basal shear stress and effective pressure which is the difference between ice overburden pressure $\left(P_{o}=\rho h g\right)$ and water pressure (Jiskoot et al., 2011). Sediment deformation occurs if the basal shear stress is greater than the yield stress of the till (Davies et al., 2012). Figure 3.7 plots the calculated effective pressure along the modelled KIS flowline, which shows limited spatial variation in the upper and trunk zones of the flowline. The 0.1 and 1.0 $\mathrm{m}$ maximum amounts of effective water stored in the till showing the most variable behaviour, ranging between $4.18 \times 10^{4}$ to $1.73 \times 10^{5} \mathrm{~Pa}$. The overall linearly increasing trend of calculated effective pressure observed in each panel (Figure 3.7a-h) illustrates the increasing resistance to basal sliding along the flowline. The transition zone displays an apparent lack of sensitivity to changes in the different maximum amounts of effective 
water stored in the till, with lower observed basal shear, and yield stresses, as well as effective pressures. This low effective pressure occurs with high water pressure or low ice thicknesses, and results in higher rates of basal sliding, and vice versa (Blankenship et al., 1987; Blankenship et al., 1986; Kamb, 2001).
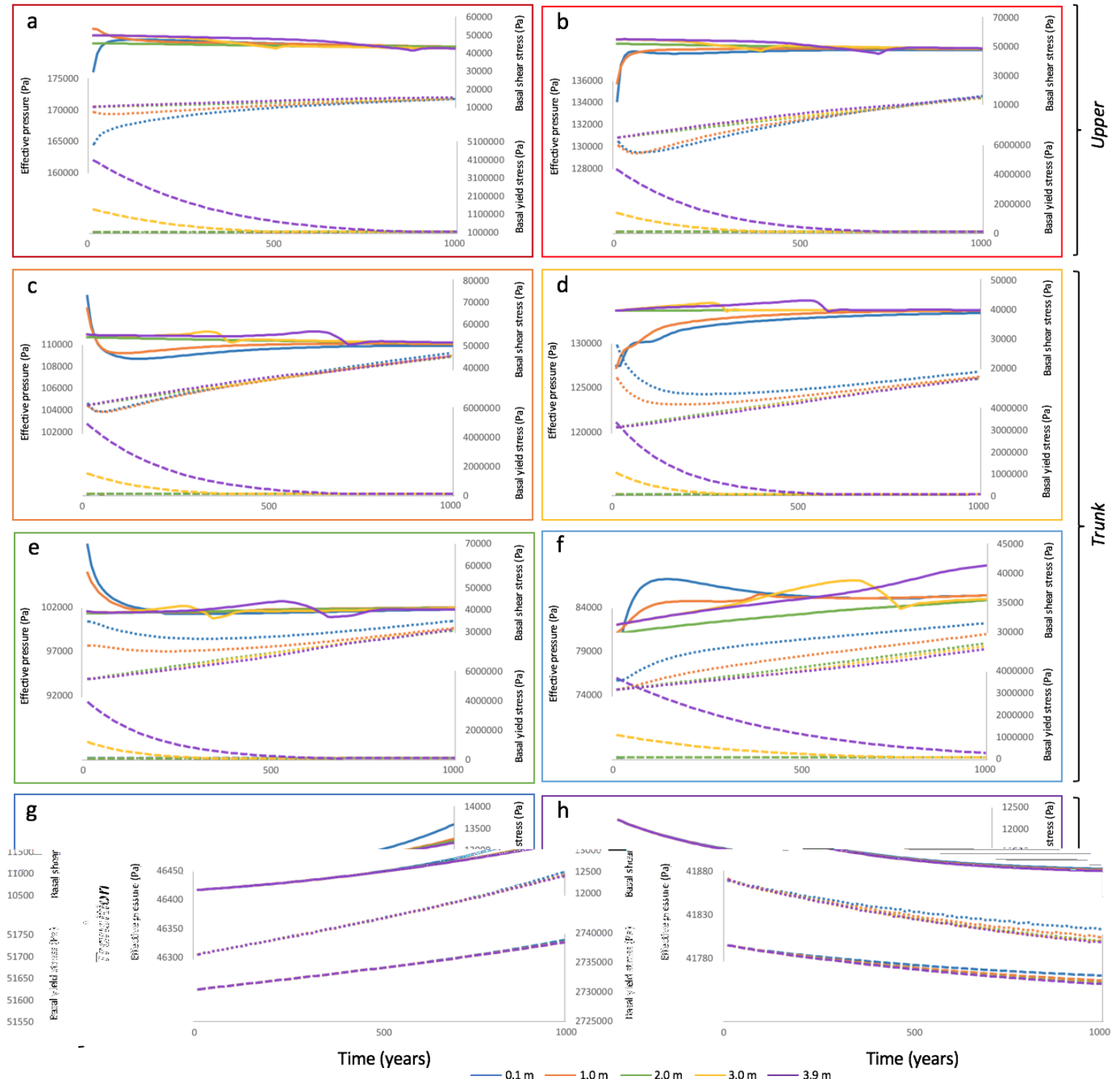

Fig. 3.7 Basal shear stress (solid), basal effective pressure (dotted), and basal yield stress (dashed) under different maximum amounts of effective water stored in the till and a constant decay rate (1 $\mathrm{mm}^{-1}$ ). Each graph $(a-h)$ corresponds to the previously described locations of the KIS (Figure 3.1). Note the changing $\mathrm{y}$-scale for each graph. 


\section{Basal Water Production, Temperature and Friction Heating}

The velocity of ice flow and sources of heat beneath an ice stream are intrinsically linked, as increases of basal heat provide the means to produce water beneath an ice sheet in the form of basal melt, which plays an important role in the lubrication of the basal interface. Both geothermal heat flux (explored in Chapter 4) and basal frictional heating play a role in basal melting, or the refreezing of water beneath the ice sheet (Feldmann \& Levermann, 2017). Higher frictional heating can increase the basal melt beneath the ice stream, and subsequently, migration of the water can saturate sediments downstream and enhance ice flow (Benn \& Evans, 2010). As a result of increased ice flow, more frictional heat is produced, leading to further increases of ice flow speeds. As such, a positive feedback can amplify an initial perturbation to the ice stream and contribute towards unstable glacier acceleration. However, this feedback can also be self-regulating at longer timescales due to decoupling from the bed (van Pelt \& Oerlemans 2012).

Figure 3.8 shows the observed changes in basal temperature, basal frictional heating, and basal melt along the KIS flowline. Given the intrinsic link between ice velocity and basal frictional heating, the basal frictional heating patterns closely follow those of the basal ice velocities, as observed in Figure 3.6. Limited basal melt rate variation is observed between the five simulations in the upper section of the KIS (Figure 3.8a-b), with all simulations increasing steadily over the 1000 year simulation. The exception is the first 100 years of the $0.1 \mathrm{~m}$ simulation at location $a$, which exhibits a rapid increase in basal melt over the first 125 year period from $2.0 \times 10^{-3}$ to $3.6 \times 10^{-3} \mathrm{~m} \mathrm{y}^{-1}$, before increasing in a similar fashion to the other simulations. In reality, the topography beneath the KIS is a likely factor in the accumulation of basal melt water in these two locations, as they are located within topographic low points; however, in our model melt water would remain local in the substrate. Locations $c$ and $e$ demonstrate similar behaviour where in the $0.1 \mathrm{~m}$ simulation initial basal melt rates rapidly drop over a 50 year period from $9.0 \times 10^{-3}$ to $3.5 \times 10^{-3} \mathrm{~m} \mathrm{y}^{-1}$ and $1.4 \times 10^{-2}$ to $4.0 \times 10^{-3} \mathrm{~m} \mathrm{y}^{-1}$, respectively, at which it is stable for approximately 100 years. After this, the basal melt rate reduces rapidly again over a 10 to 20 year period, at which point it linearly increases over the remaining simulation. Simulation 1.0 m reduces from the first 100 years from $6.0 \times 10^{-3}$ to $3.0 \times 10^{-3} \mathrm{~m} \mathrm{y}^{-1}$ and $6.0 \times 10^{-3}$ to $4.0 \times 10^{-3} \mathrm{~m} \mathrm{y}^{-1}$, respectively, after which it increases linearly over the remaining 950 year period to $4.5 \times 10^{-3} \mathrm{~m} \mathrm{y}^{-1}$ for both. The remaining simulations all increase linearly, and reach near identical end values of approximately $4.5 \times 10^{-3} \mathrm{~m} \mathrm{y}^{-1}$, similar to the 0.1 and $1.0 \mathrm{~m}$ simulations. The transition zone displays distinct behaviour from the upper and trunk zones, and an apparent lack of sensitivity 
to changes in the different maximum amounts of effective water stored in the till. This observed basal frictional heating at the bed of a glacier is directly proportional to the product of the shear stress and strain rate (or basal motion; Meyer et al., 2018). Thus, even if basal velocities are very large, frictional heating will not occur if there is no traction between the glacier and its bed. This means that frictional heating shuts down when ice decouples from the bed, preventing runaway basal melting, which is potentially observed in Figure 3.8. A (second) feedback between ice velocities and ice thickness exists, where downstream acceleration increases ice extension and produces dynamic thinning of the ice (Hulbe \& Fahnestock, 2004). In cold environments this increases the heat diffusion away from the basal interface, thus decreasing the basal temperature and likely the ice velocities, which can stabilise the ice flow (Hulbe \& Fahnestock, 2004; Cuffey \& Paterson, 2010). However, in the upper sectors of the ice stream, acceleration of ice can lead to dynamic thickening down glacier, which inhibits heat diffusion. 

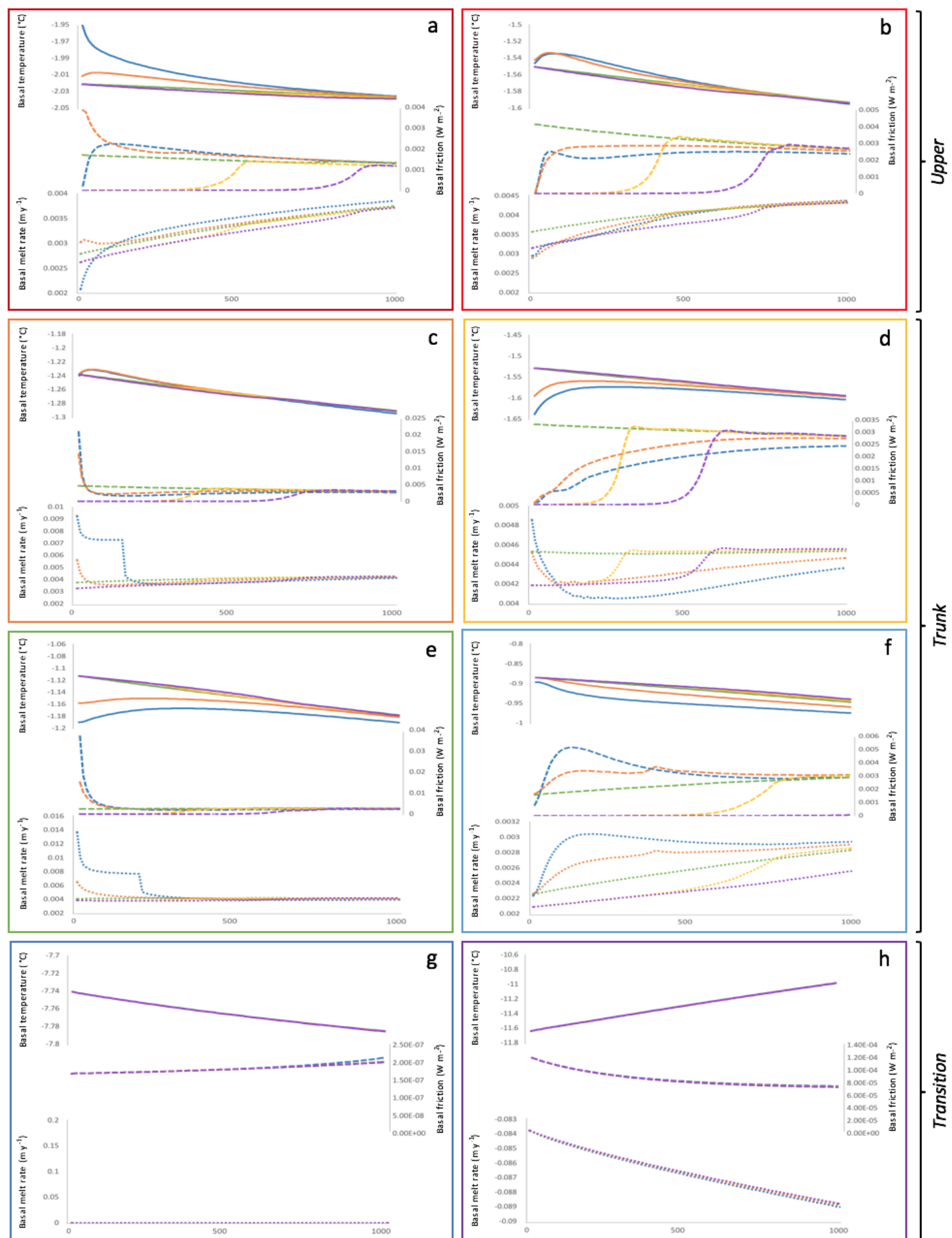

Time (years)

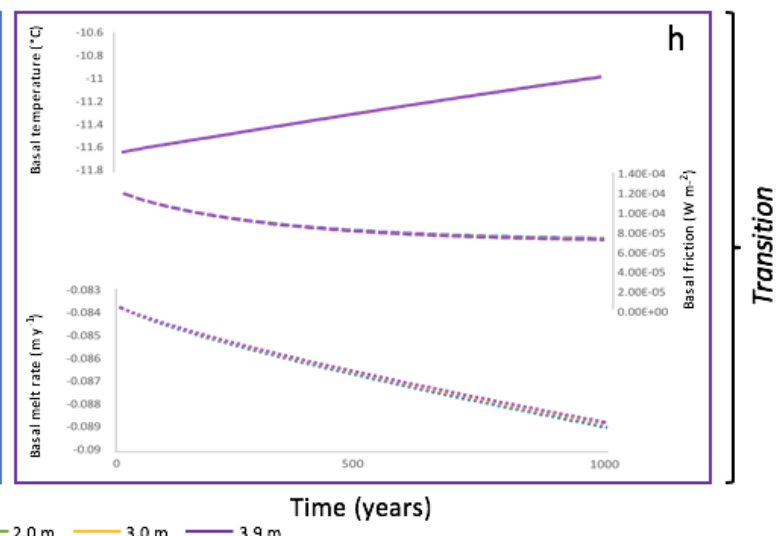

Fig. 3.8 Basal temperature, basal melt rates and basal friction under different maximum amounts of effective water stored in the till and a constant decay rate $\left(1 \mathrm{~mm} \mathrm{y}^{-1}\right)$ which shows the effect on basal temperatures (solid), basal melt rate (dotted) and basal friction (dashed). Each graph $(a-h)$ corresponds to the previously described locations of the KIS (Figure 3.1). Note the changing y-scale for each graph. 


\subsubsection{Atmospheric Temperature and Precipitation Changes}

\section{Ice Thickness}

As increases of atmospheric temperatures increase levels of moisture in the air, the resultant higher levels of precipitation on the Antarctic Ice Sheet are projected to negatively contribute towards changes in the sea level if the climate warms (Church et al., 2013). However, it is important to note that this will be smaller than the corresponding ice loss from basal melt. By changing ice thickness and surface mass balance, increased precipitation can have consequences for ice flow and the subglacial environment (Benn \& Evans, 2010; Winkelmann et al., 2012).

In this study, however, the increased atmospheric temperature forcing on the KIS flowline results in minimal change over a 1000 year period, and no grounding zone retreat or ice shelf reduction is observed. A small, consistent increase of the rate of change of ice thickness is observed in the trunk zone of the KIS flowline for the control simulation; however, between the two end members of the atmospheric temperature forcing $\left(0.0\right.$ and $\left.8.0^{\circ} \mathrm{C}\right)$ limited change is observed. Figure 3.9 exhibits these two end members, and plots the absolute values of ice thickness rate of change of the control simulation $\left(0.0^{\circ} \mathrm{C}\right)$ on the left and the difference between the control and the $8.0^{\circ} \mathrm{C}$ simulation on the right. Some observable rates of ice thickness change are present in the first 100 years of the simulation on the floating section of the flowline. This is attributed the initial stabilisation after the applied atmospheric temperature forcing. Limited observable changes in the ice thickness rate of change are also visible in the grounded section of the flowline. This rate of change propagates from the upper zone of the flowline down stream over the 1000 year period, but does not reach the transition zone of the flowline. It is proposed that the propagation of the ice thickness rate of change downstream is the result of initial upstream ice thickening due to increased accumulation, where the resultant increase in ice thickness subsequently increases ice flow (Benn \& Evans, 2010; Winkelmann et al., 2012). 


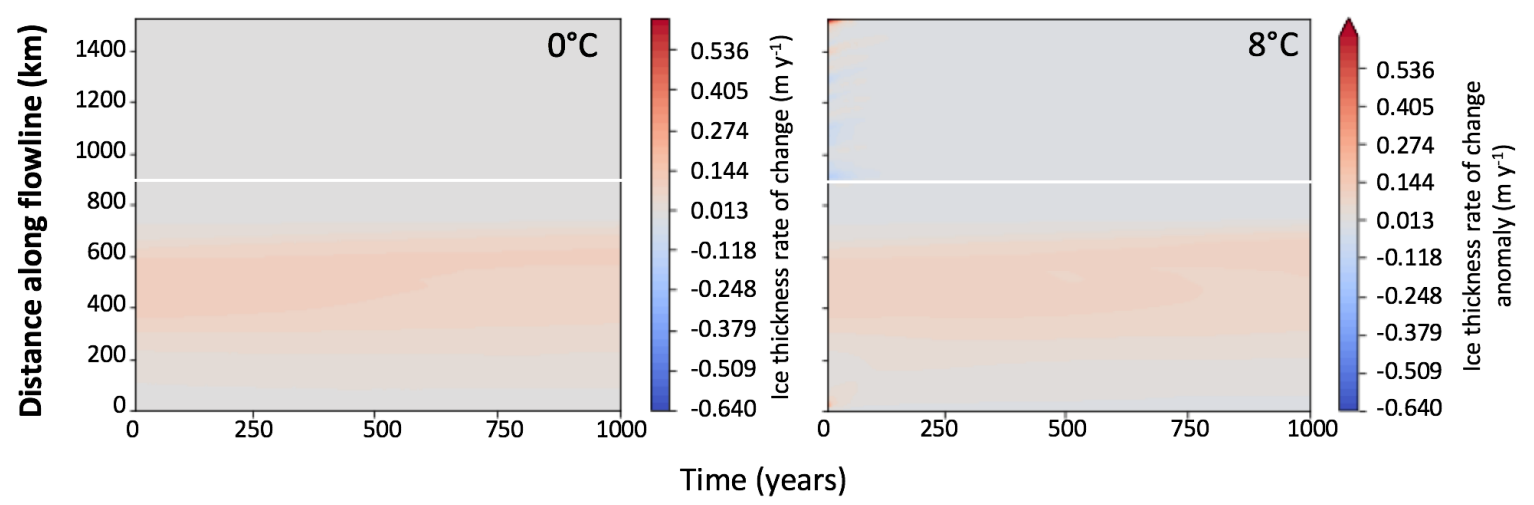

Fig. 3.9 Ice thickness rate of change with increasing atmospheric temperatures over a 1000 year period. The control simulation $\left(0.0^{\circ} \mathrm{C}\right)$ and the difference in ice thickness rate of change between the control and $8.0^{\circ} \mathrm{C}$ are plotted. The panels show time on the $\mathrm{x}$-axis, the distance along the flowline on the y-axis (which is grounded on the lower half of the panel, and floating near the top). The solid white line indicates the grounding zone.

\section{Ice Velocity}

An increase in ice velocity due to increased ice thickness is observed in Figure 3.10, where the change in basal ice velocity between the control simulation and the $8.0^{\circ} \mathrm{C}$ increase in atmospheric temperature is plotted. This simulated temporal and spatial change in the basal ice velocity partially coincides with the propagation of the ice thickness rate of change, and accumulation at approximately $600 \mathrm{~km}$ downstream of the flowline. The simulated basal ice velocity at this location coincides with a topographic high, where a potential pinning point of the KIS exists. This increased change in basal ice velocity rapidly reduces at the onset of the transition zone, indicating that different basal controls regulate this zone, potentially the influx of ocean water with grounding zone retreat (Padman, Siegfried \& Fricker, 2018). Initial basal velocity increases in the first 50 to 100 years of the simulation are attributed to the initial response to a new perturbation and the subsequent reduction to the stabilisation of the ice stream. It is suggested that the increases in ice velocity are indicative of higher rates of sliding at the basal interface due to enhanced lubrication as a result of the availability of liquid water due to increased atmospheric temperatures (Nienow et al. 2017). 

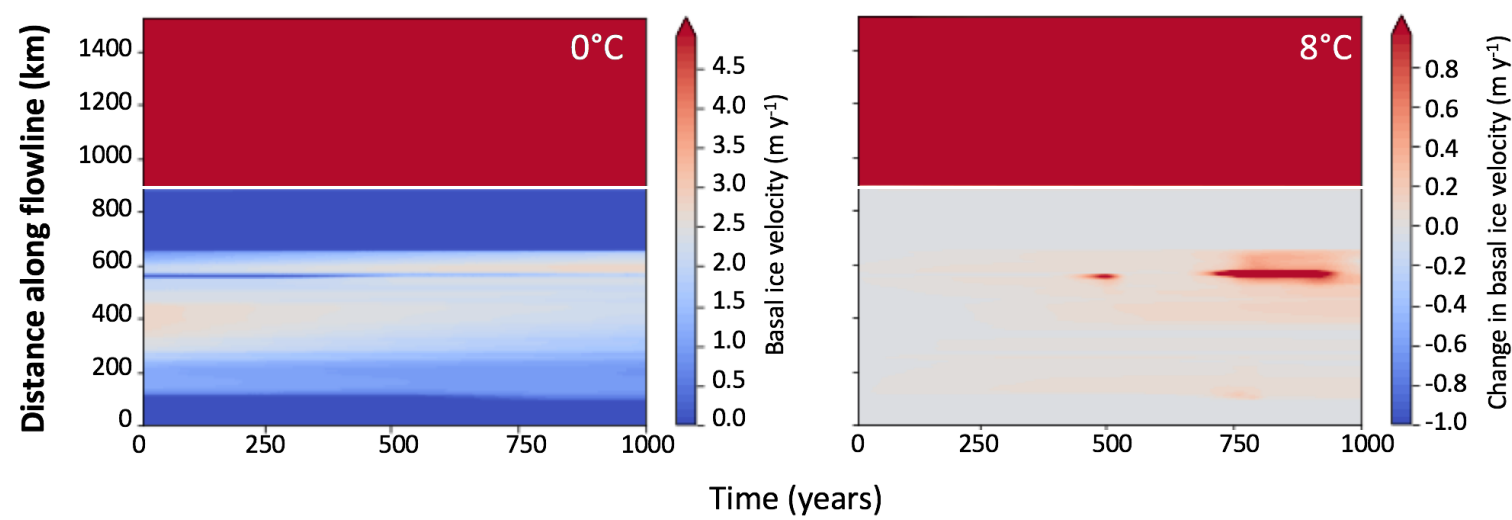

Fig. 3.10 Basal ice velocity $\left(\mathrm{m} \mathrm{y}^{-1}\right)$ with increasing atmospheric temperatures over a 1000 year period. The control simulation $\left(0.0^{\circ} \mathrm{C}\right)$ and the difference in basal ice velocity between the control and $8.0^{\circ} \mathrm{C}$ are plotted. The panels show time on the $\mathrm{x}$-axis, the distance along the flowline on the $\mathrm{y}$-axis (which is grounded on the lower half of the panel, and floating near the top). The solid white line indicates the grounding zone.

\section{Basal Stresses}

Section 3.3.1 discussed the role of basal shear and yield stresses on basal sliding. The increase in basal ice velocity coincides with a reduction in the basal shear stress, and a reduction in the basal yield stress (Howat et al., 2008; Jiskoot et al. 2011). The effects of increases in atmospheric temperatures on basal stresses, such as the basal shear stress and basal yield stress, are illustrated in Figures 3.11 and 3.12, which show the limited changes observed on the basal regime. This lower basal shear stress is observed with higher atmospheric temperature increase of $8.0^{\circ} \mathrm{C}$ (Figure $3.12 \mathrm{~b}$ ), which indicates a weaker substrate (Bueler \& Brown, 2009; Winkelmann et al., 2011). 


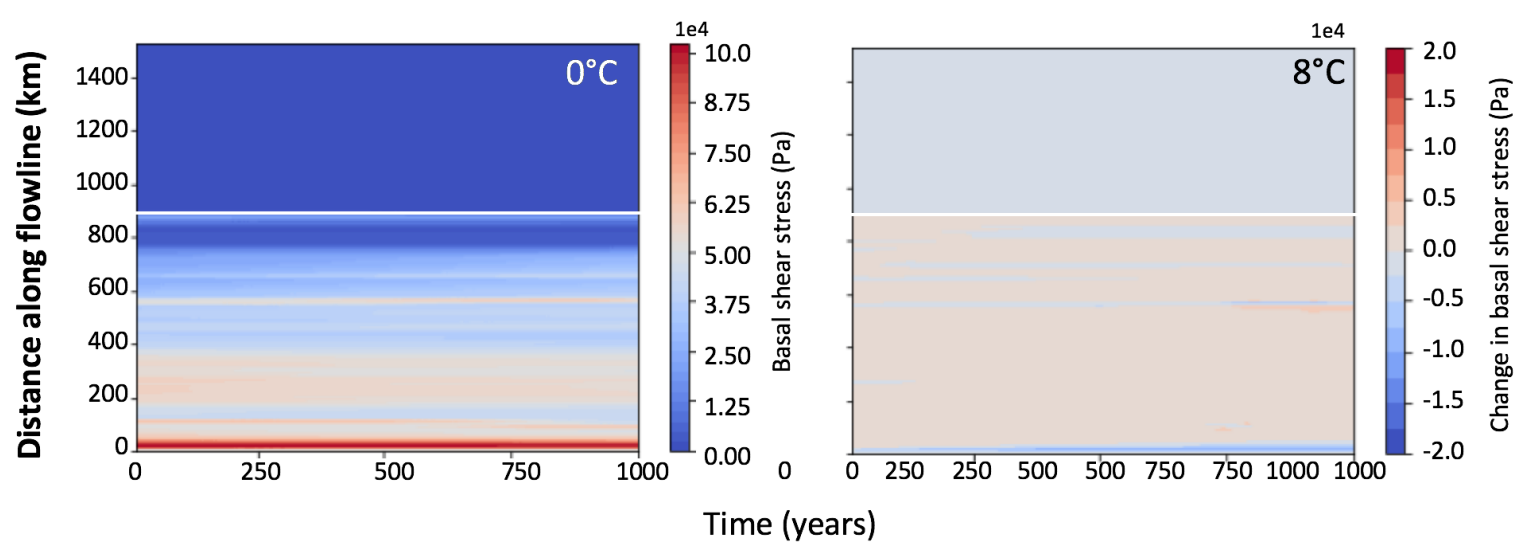

Fig. 3.11 Basal shear stress $(\mathrm{Pa})$ with increasing atmospheric temperatures over a 1000 year period. The control simulation $\left(0.0^{\circ} \mathrm{C}\right)$ and the difference in basal shear stress between the control and $8.0^{\circ} \mathrm{C}$ are plotted. The panels show time on the x-axis, the distance along the flowline on the y-axis (which is grounded on the lower half of the panel, and floating near the top). The solid white line indicates the grounding zone.

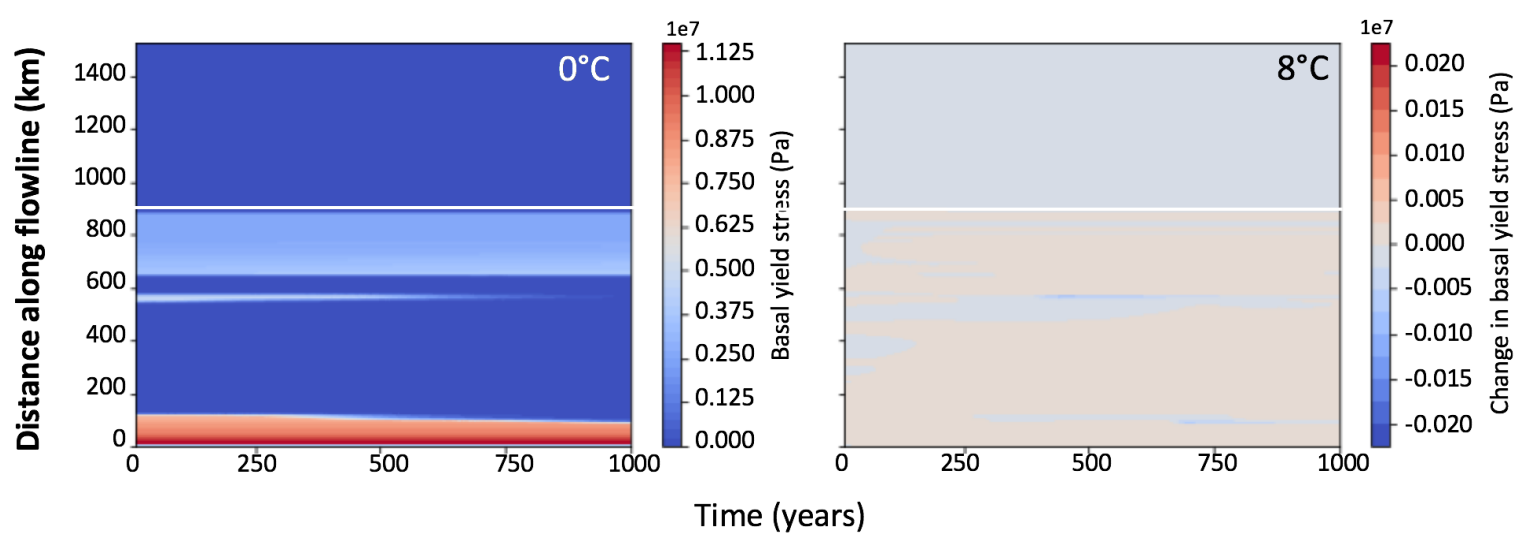

Fig. 3.12 Basal yield stress $(\mathrm{Pa})$ with increasing atmospheric temperatures over a 1000 year period. The control simulation $\left(0.0^{\circ} \mathrm{C}\right)$ and the difference in basal yield stress between the control and $8.0^{\circ} \mathrm{C}$ are plotted. The panels show time on the x-axis, the distance along the flowline on the $\mathrm{y}$-axis (which is grounded on the lower half of the panel, and floating near the top). The solid white line indicates the grounding zone.

\section{Basal Temperatures}

Figure 3.13 exhibits the changes in basal frictional heating with increased atmospheric temperatures. The main observed increases in basal frictional heating occurs approximately $600 \mathrm{~km}$ downstream of the flowline, and coincides with the increase of basal ice velocity, decrease in basal shear stress and the preceding decrease in basal yield stress. Section 3.3.1 discussed the link between increases of basal frictional heating and ice velocity increases. However, with the increases in atmospheric temperatures, the resultant increase in ice velocity and basal frictional heating are inferred to be 
due to both increases of ice thickness, as well as the warming and softening of the ice (McCarthy, Savage \& Nettles, 2017). Glacial ice will soften with increases of temperature, whether climatic driven, or driven due to the increased temperature gradients as a result of ice thickening (Paterson \& Cuffey, 2010; Larour et al., 2012).

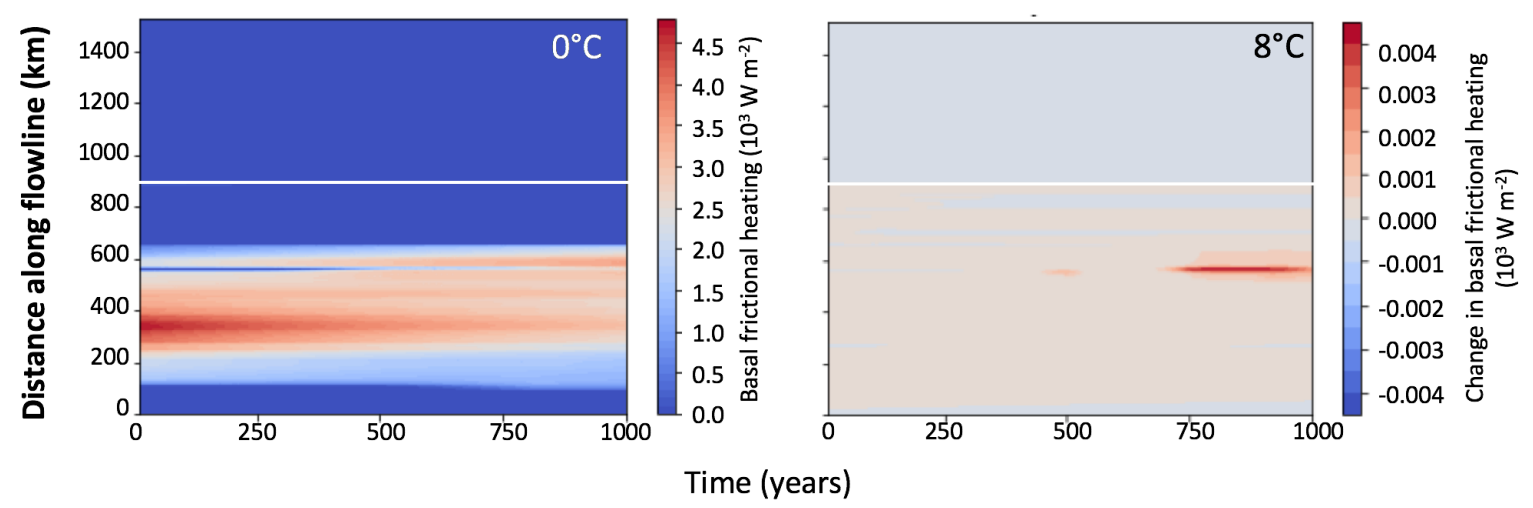

Fig. 3.13 Basal frictional heating $\left(10^{3} \mathrm{~W} \mathrm{~m}^{-2}\right)$ with increasing atmospheric temperatures over a 1000 year period. The control simulation $\left(0.0^{\circ} \mathrm{C}\right)$ and the difference in ice thickness rate of change between the control and $8.0^{\circ} \mathrm{C}$ are plotted. The panels show time on the $\mathrm{x}$-axis, the distance along the flowline on the y-axis (which is grounded on the lower half of the panel, and floating near the top). The solid white line indicates the grounding zone.

\subsubsection{Oceanic Temperature Changes}

Eight different oceanic temperature anomalies are explored in this study, incrementally increasing by $0.25^{\circ} \mathrm{C}$ up to $2.0^{\circ} \mathrm{C}$. Figures 3.14 to 3.19 illustrate the changing properties of the KIS along the grounded flowline over the 1000 year period. These show ice velocities, ice thickness rate of change, basal temperatures, basal friction, basal melt rates, and basal stresses.

\section{Grounded Ice and Ice Shelf Extent}

Incremental increases of oceanic temperatures produce substantial changes in grounding zone location and ice shelf extent. The control simulation, with no change in oceanic temperatures, illustrates a constant grounding zone location, and no change in ice shelf extent. With an oceanic temperature increase of $0.25^{\circ} \mathrm{C}$, the grounding zone location remains constant, however, incremental losses of the ice shelf are observed. A gradual retreat of the calving margin by $\sim 150 \mathrm{~km}$ occurs over the first 250 years, with a rapid reduction of $\sim 50 \mathrm{~km}$ within a decade (Figure $3.14 \mathrm{a}$ ). This new ice shelf extent remains constant for $\sim 400$ years, until a rapid reduction of a few kilometres is seen. The ice shelf extent remains relatively constant during the rest of the simulation. 
With a $0.50^{\circ} \mathrm{C}$ increase of oceanic temperatures (Figure 3.14c), a rapid loss of $400 \mathrm{~km}$ of ice shelf extent occurs after $\sim 100$ years. The ice shelf extent increases again over $\sim 100$ years, after which it reduces over a 50 year period, and remains constant until an increase $\sim 700$ years after the start of the simulation. Subsequently, rapid loss of the ice shelf is observed after 50 years, with almost no ice shelf remaining. The grounded ice sheet has two periods of retreat, the first from 0 to 200 years, reducing extent by $\sim 300 \mathrm{~km}$ and then remaining at a constant location, followed by a second reduction at $\sim 625$ years, reducing the ice sheet extent by another $\sim 200 \mathrm{~km}$. A similar pattern of rapid ice shelf reduction, stabilisation, followed by a short period of ice shelf growth, and another rapid ice shelf reduction is seen with the remaining oceanic temperature increases. However, the period of stability and ice shelf growth occur earlier in each simulation with a decreasing period of stability as the magnitude of the temperature forcing increases. Ice shelf extent also remains larger in lower oceanic temperature changes. The grounded ice sheet displays similar step-wise decreases in extent as described in the $0.5^{\circ} \mathrm{C}$ simulation, but these occur earlier in the simulation period, and after oceanic temperature changes of $1.25^{\circ} \mathrm{C}$ the grounding zone position appears to not reduce any further in its extent. The simulations suggest that the patterns of grounding zone retreat and ice shelf reduction are the result of topographic pinning points, which provide a control on the retreat of these ice streams (Schoof, 2007).

\section{Ice Thickness}

Longitudinal propagation of ice thinning can be observed in Figure 3.14, which illustrates key areas of relatively large ice thickness rates of change across the KIS flowline. The large changes in grounding zone location induce localised velocity responses that propagate upstream and produce a thinning response in the trunk zone of the KIS flowline. A dynamic response to ice shelf growth is observed as a retreat in grounding zone position, also inferred to be due to the additional thinning of the ice and the longitudinal extension (Goldberg, Holland \& Schoof, 2009). The control $\left(0.0^{\circ} \mathrm{C}\right)$ and the $0.25^{\circ} \mathrm{C}$ panels (Figure 3.14a and 3.14b) demonstrate limited change in ice thickness rates, with a slight reduction of the ice shelf thickness rate observed in the first 125 years of the simulation. At an increase of $0.5^{\circ} \mathrm{C}$ (Figure 3.14c), the increases of positive ice thickness rate of change are seen between 50 to 250 years and 650 to 750 years on the ice shelf, which initially lead to an increase of ice shelf extent, before it is followed by accelerated thinning and ice shelf retreat. A similar pattern is followed for the remaining panels (Figure 3.14d-i), where rapid thickening precedes growth of the ice shelf, and accelerated thinning precedes grounding zone retreat, as well as inland 
thinning. Rignot and others (2011) note that enhanced flow $\left(>25-30 \mathrm{~m} \mathrm{a}^{-1}\right)$ can result in significant ice motion far into the interior of the ice sheet. Viscous deformation that causes ice sheet flow does not respond as rapidly to environmental perturbations compared to sliding (Schoof, 2006; Nick et al., 2009). Consequentially, perturbations to the ocean system will only cause rapid changes if the ice sheet rapidly propagates the changes inland (Hindmarsh \& Le Meur, 2001). In ice streams and shelves, these perturbations can rapidly propagate inland due to the dominant membrane stresses (Nick et al., 2009; Hindmarsh, 2006; Schoof, 2007), which is observed within this study where ice sheet thinning is observed to propagate inland after the removal of the buttressing ice shelf.

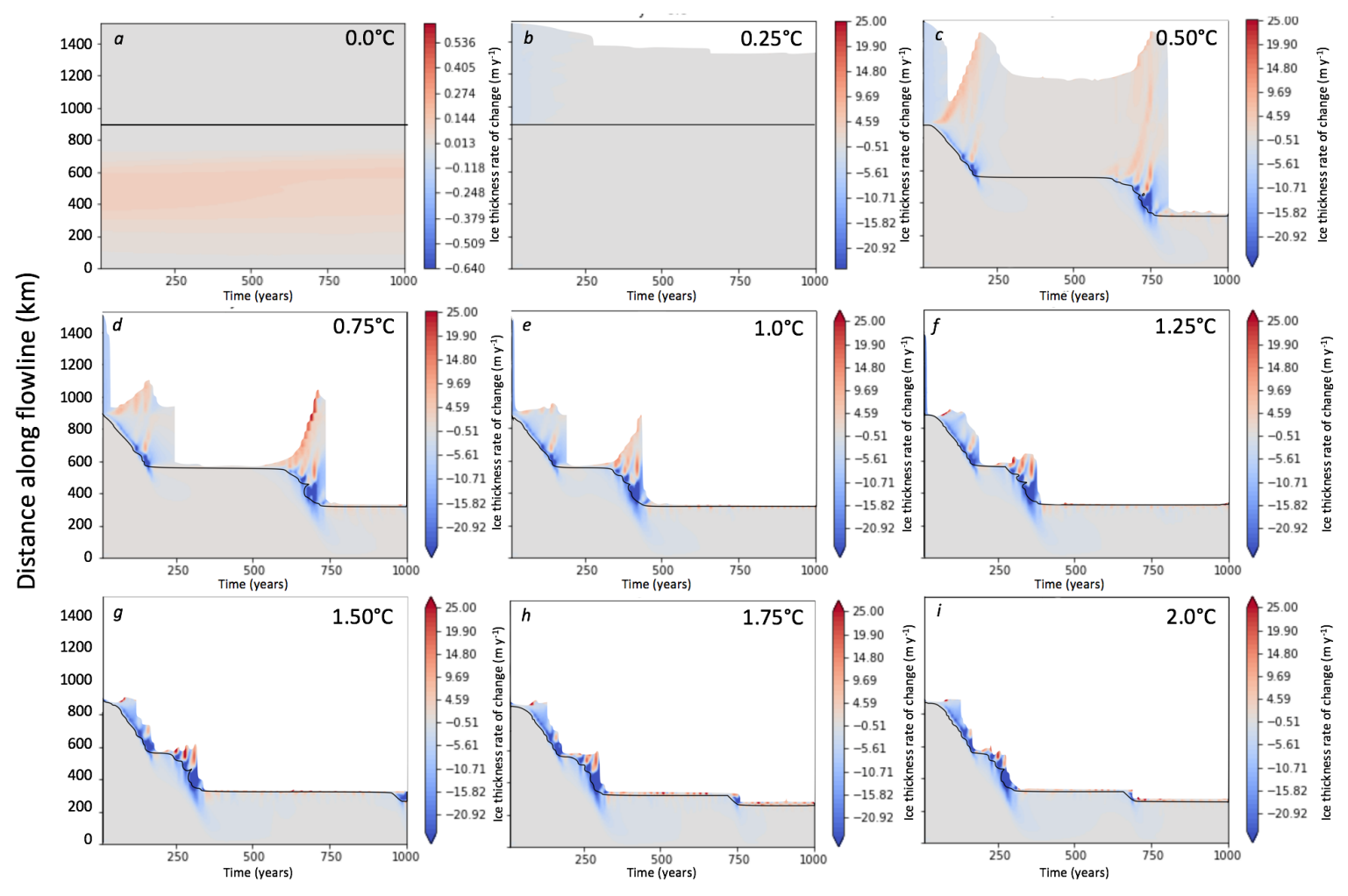

Fig. 3.14 Ice thickness rate of change with increasing oceanic temperatures over a 1000 year period. Each panel illustrates an increase in oceanic temperature by $0.25^{\circ} \mathrm{C}$. The panels show time on the $\mathrm{x}$-axis, the distance along the flowline on the $\mathrm{y}$-axis (which is grounded on the lower half of the panel, and floating near the top). The solid black line indicates the grounding zone, and the white background indicates open ocean. Note the changing y-scales.

\section{Basal Ice Velocity}

Figure 3.15 illustrates basal ice velocities $\left(\mathrm{m} \mathrm{y}^{-1}\right)$. The control simulation $\left(0.0^{\circ} \mathrm{C}\right)$ has temporally consistent grounded and floating basal ice velocities, with limited change seen over the 1000 year period. The increase of oceanic temperatures by $0.25^{\circ} \mathrm{C}$ (Figure 
3.15b) demonstrates an increase in basal velocity within the first 50 years on the ice shelf, and after approximately 750 years at approximately $600 \mathrm{~km}$ downstream of the flowline. The following panels (Figure 3.15c-i) illustrate the rapid grounded basal ice velocity following the removal of the ice shelf, with large sections of the grounded ice sheet flowing in excess of $45 \mathrm{~m} \mathrm{y}^{-1}$ after approximately 250 years. The ice shelf basal velocities increase rapidly on the remaining sections, with some areas flowing in excess of $3200 \mathrm{~m} \mathrm{y}^{-1}$. Other studies have demonstrated that the removal of buttressing ice shelves increases the velocity at which ice is delivered from the continent to the ocean (e.g. Scambos et al., 2004), and this is suggested as the likely explanation as to the increased ice flow in the increased oceanic temperature change simulations.

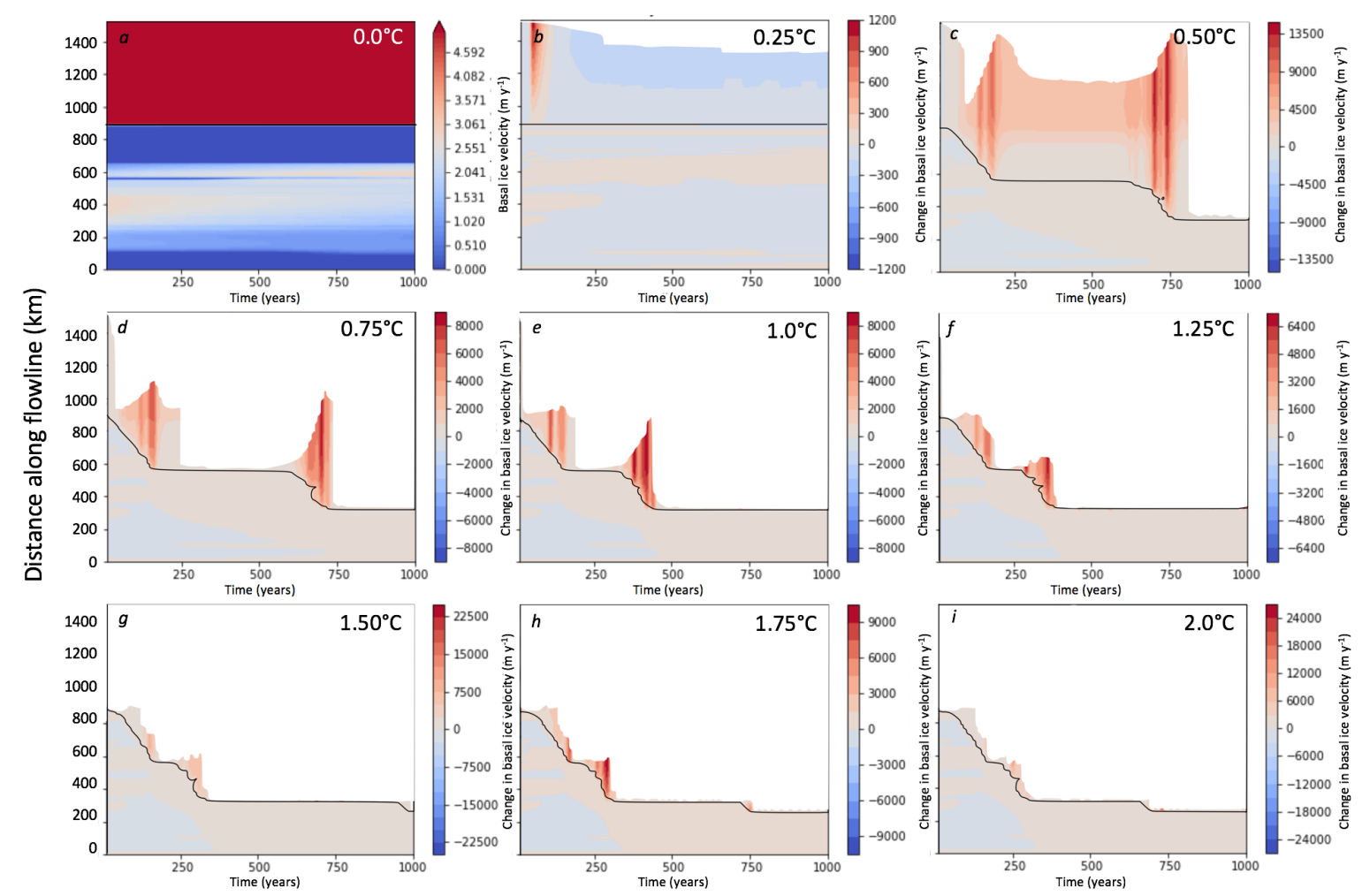

Fig. 3.15 Basal ice velocity $\left(\mathrm{m} \mathrm{y}^{-1}\right)$ with increasing oceanic temperatures over a 1000 year period. Each panel illustrates an increase in oceanic temperature by $0.25^{\circ} \mathrm{C}$. The panels show time on the $\mathrm{x}$-axis, the distance along the flowline on the y-axis (which is grounded on the lower half of the panel, and floating near the top). The solid black line indicates the grounding zone, and the white background indicates open ocean. Note the changing y-scales.

\section{Basal Stresses}

The basal shear stress shows limited temporal variation for both the control $\left(0.0^{\circ} \mathrm{C}\right)$ and the $0.25^{\circ} \mathrm{C}$ simulations as seen in Figure 3.16 . For the 0.5 to $2.0^{\circ} \mathrm{C}$ simulations, the highest basal shear stress is observed in proximity to the grounding zone, subsequent 
to its retreat. High basal shear stress is also observed near the ice divide (0 to $50 \mathrm{~km})$, and increases occur earlier with each increase in oceanic temperature. This variable response of the basal shear stress closely reflects the changes observed in the surface ice velocity, showing the intrinsic link between the gravitational driving force and resultant ice flow and stresses acting on the bed. As the basal shear stress represents the driving force acting upon the bed, and glacial ice typically can support basal shear stresses of approximately $10^{5} \mathrm{~Pa}$, an observed change in the ice flow is also exhibited. The ice thickening that produces basal shear stresses in excess of this leads to increased ice flow and as a result, ice thinning (Marshall et al., 2011). This ice thinning is also observed in the simulations, particularly in Figure 3.14c-i.
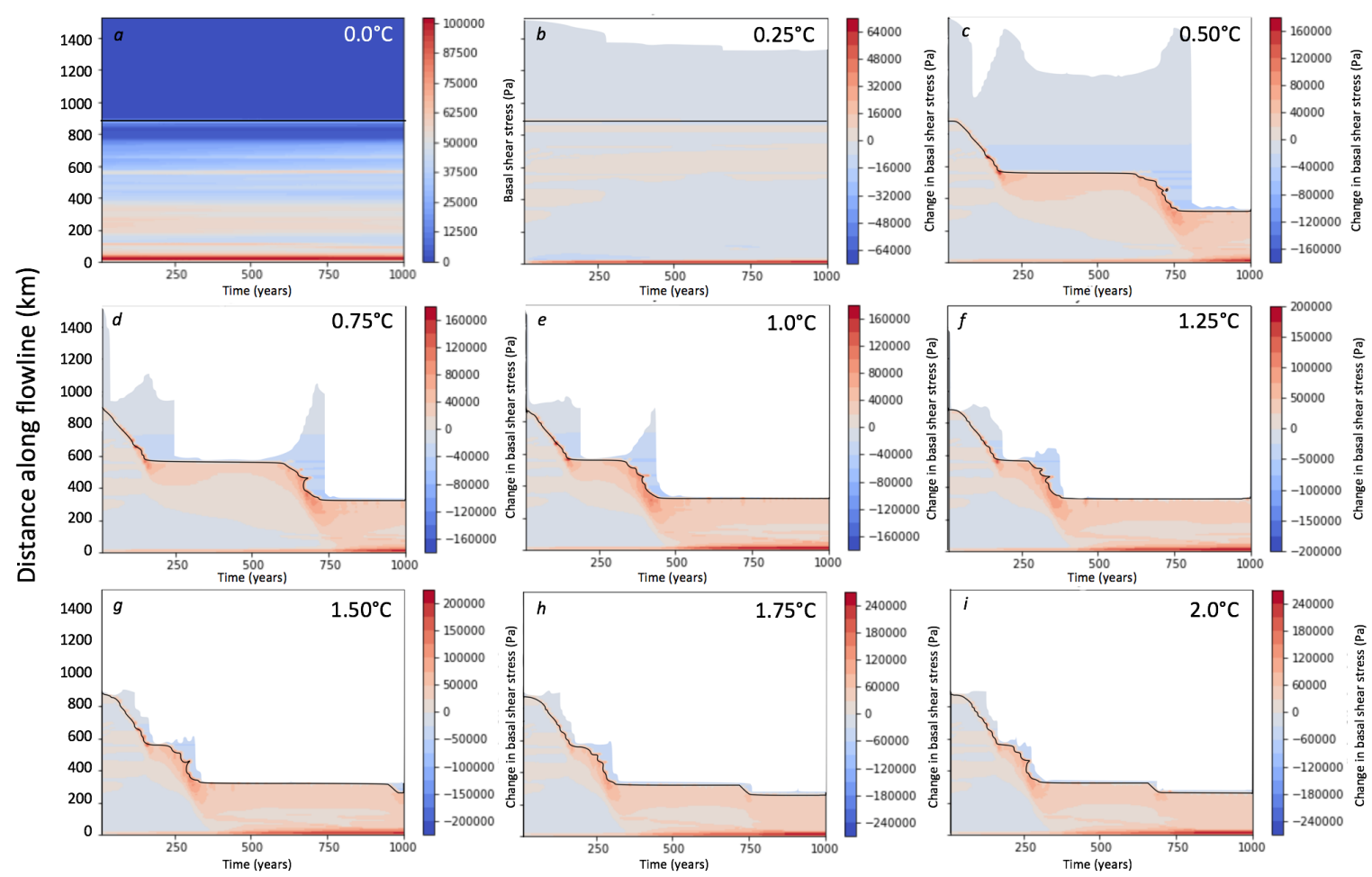

Fig. 3.16 Basal shear stress $(\mathrm{Pa})$ with increasing oceanic temperatures over a 1000 year period. Each panel illustrates an increase in oceanic temperature by $0.25^{\circ} \mathrm{C}$. The panels show time on the $\mathrm{x}$-axis, the distance along the flowline on the y-axis (which is grounded on the lower half of the panel, and floating near the top). The solid black line indicates the grounding zone, and the white background indicates open ocean. Note the changing y-scales.

Figure 3.17 illustrates the basal yield stress, which shows limited variation across all increases of oceanic temperatures, with some decrease in basal yield stress observed from 50 to $100 \mathrm{~km}$ from 1.25 to $2.0^{\circ} \mathrm{C}$. Lower yield stresses are observed with higher oceanic temperature increases (Figure 3.17d-i), indicating a weaker substrate, as yield stress represents the strength of the subglacial material at the base of an ice sheet 
that resists sliding (Bueler \& Brown, 2009; Winkelmann et al., 2011). It is suggested that the increased oceanic temperatures and subsequent availability of water in the subglacial substrate, has decreased the yield strength of the substrate.
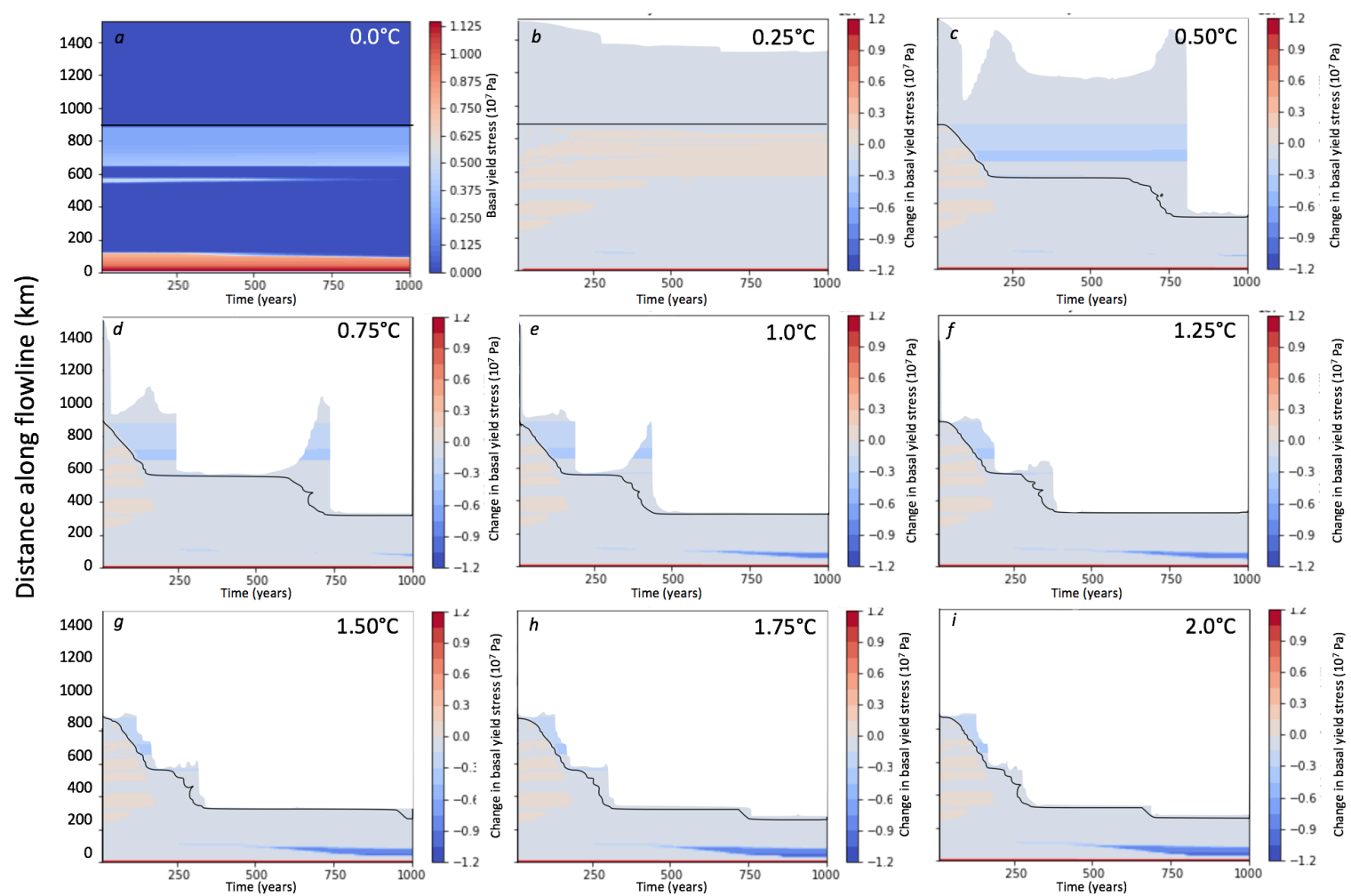

Fig. 3.17 Basal yield stress (Pa) with increasing oceanic temperatures over a 1000 year period. Each panel illustrates an increase in oceanic temperature by $0.25^{\circ} \mathrm{C}$. The panels show time on the $\mathrm{x}$-axis, the distance along the flowline on the y-axis (which is grounded on the lower half of the panel, and floating near the top). The solid black line indicates the grounding zone, and the white background indicates open ocean. Note the changing y-scales.

\section{Hydrology}

The ice shelf basal melt rate is illustrated in Figure 3.18, where the control $\left(0.0^{\circ} \mathrm{C}\right)$ and the $0.25^{\circ} \mathrm{C}$ simulations show limited ice shelf basal melt. At $0.5^{\circ} \mathrm{C}$ the ice shelf shows increased basal melt as the grounding zone moves up the KIS flowline. From the 0.75 to $1.25^{\circ} \mathrm{C}$ simulations, increases of ice shelf basal melt are observed subsequent to the reduced extent of the grounded ice sheet. The last three simulations show similar ice shelf basal melt patterns, as well as increased basal melt along the entire grounding zone from approximately 300 years onward. From 0.5 to $2.0^{\circ} \mathrm{C}$ areas of decreased basal melt, or increased ice growth, can be observed around the area of the the original grounding zone, which is potentially an artefact of the ice sheet model as opposed to a response of the KIS. It is suggested that an incorrect basal melting scheme at the 
grounding zone and too coarse a resolution are potentially the cause of this artefact. Golledge and others (2019) suggest that recent observations of both the Antarctic and Greenland Ice Sheets indicate ice loss at accelerating rates as a response to increased oceanic temperatures forcings. A large component of the mass loss occurs on the ice shelves, and observations show a clear relationship between increasing oceanic heat to the margin of the ice sheet and the increasing amounts of mass loss (Joughin, Alley \& Holland, 2012). This is observed in this study's mass loss of the ice shelves and the increased basal melt rates at the grounding zone. Other recent studies have also emphasised the sensitivity of the ice sheets to increases of oceanic temperature perturbations (e.g. Golledge et al., 2015; Rintoul et al., 2016; Webber et al., 2017; Wood et al., 2018).
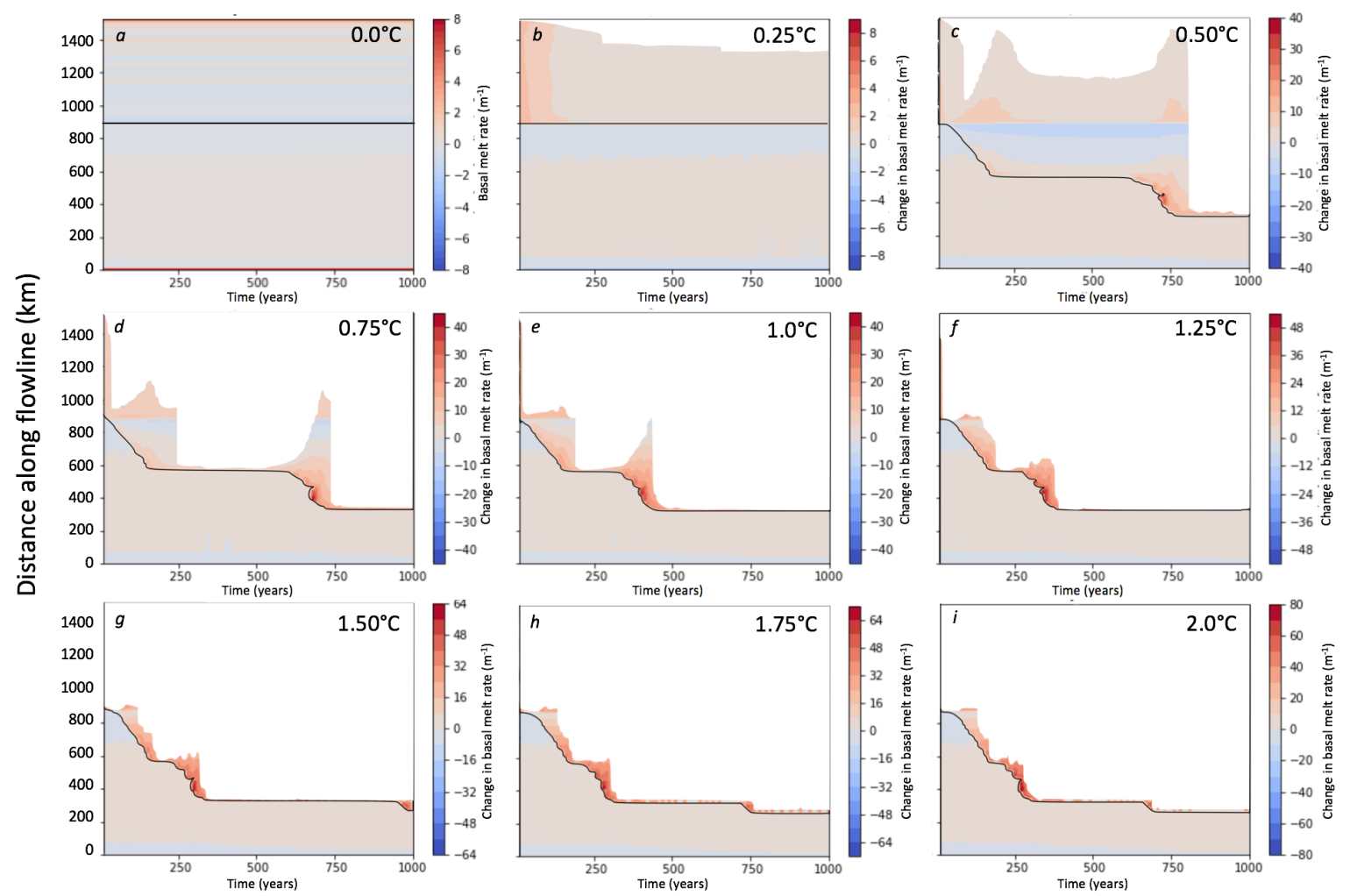

Fig. 3.18 Ice shelf basal melt rate (m) with increasing oceanic temperatures over a 1000 year period. Each panel illustrates an increase in oceanic temperature by $0.25^{\circ} \mathrm{C}$. The panels show time on the $\mathrm{x}$-axis, the distance along the flowline on the $\mathrm{y}$-axis (which is grounded on the lower half of the panel, and floating near the top). The solid black line indicates the grounding zone, and the white background indicates open ocean. Note the changing y-scales. 


\section{Basal Frictional Heating}

Figure 3.19 illustrates basal frictional heating, and neither the control $\left(0.0^{\circ} \mathrm{C}\right)$ or $0.25^{\circ} \mathrm{C}$ simulations show any obvious increase. Simulations of 0.5 to $1.25^{\circ} \mathrm{C}$ display increased basal frictional heating, subsequent to the retreat of the grounding zone. The last three simulations, 1.5 to $2.0^{\circ} \mathrm{C}$, also show increases in basal frictional heating at the stable sections of the grounding zones of up to $90 \mathrm{~W} \mathrm{~m}^{-2}$. As previously mentioned, frictional heating resulting from ice flow can warm or melt basal ice, perhaps enhancing flow. Observed increases in basal friction at the grounding zone precede areas of increased basal melt, and coincide with increases of velocity of the ice shelves, as well as increases in basal shear stress (Krabbendam, 2016). As the frictional heating at the bed of a glacier is directly proportional to the product of the shear stress and strain rate (Benn \& Evans, 2010), the linked increases observed beneath the KIS indicate a sensitivity to oceanic temperature perturbations.

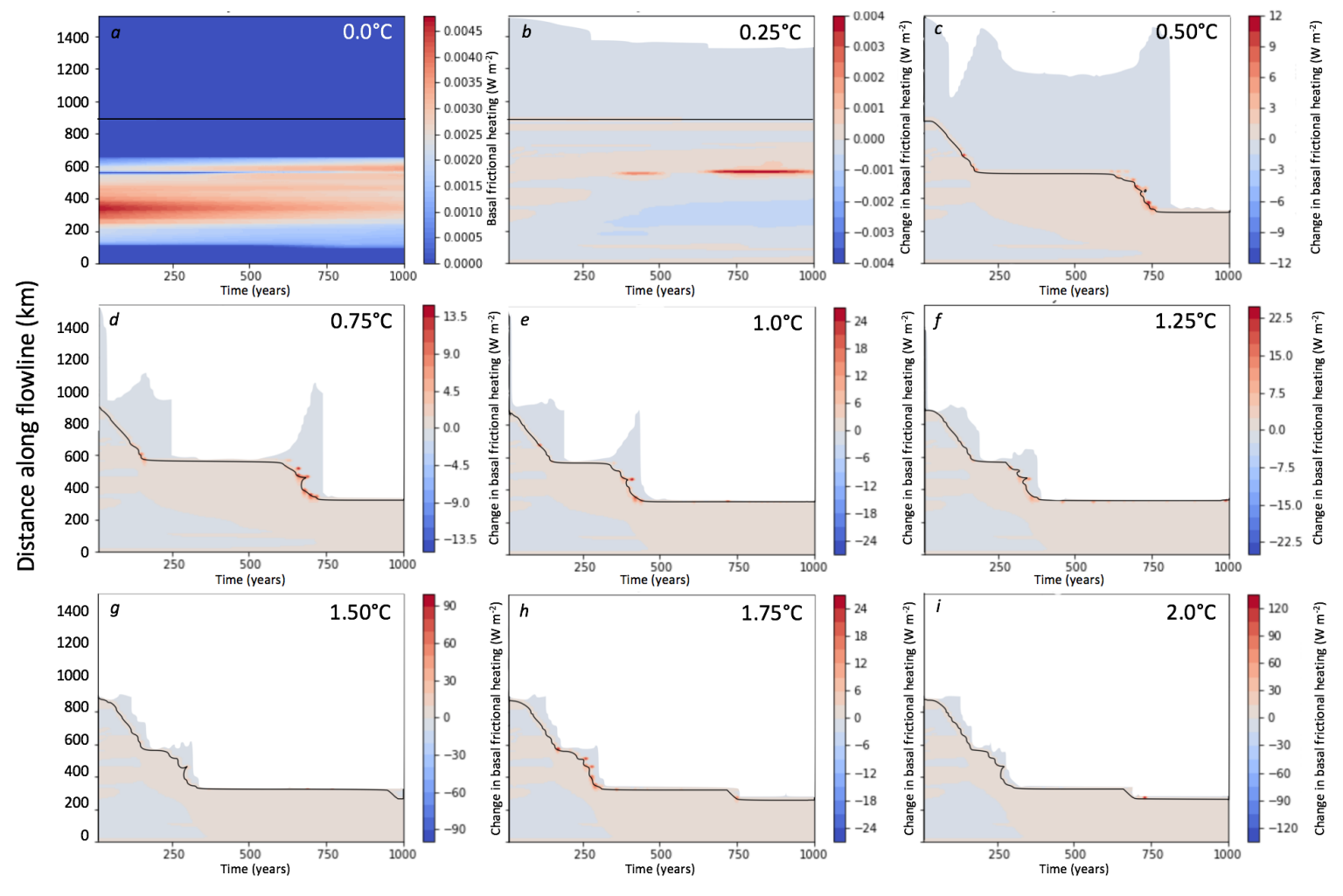

Fig. 3.19 Basal frictional heating $\left(\mathrm{W} \mathrm{m}^{-2}\right)$ with increasing oceanic temperatures over a 1000 year period. Each panel illustrates an increase in oceanic temperature by $0.25^{\circ} \mathrm{C}$. The panels show time on the $\mathrm{x}$-axis, the distance along the flowline on the y-axis (which is grounded on the lower half of the panel, and floating near the top). The solid black line indicates the grounding zone, and the white background indicates open ocean. Note the changing y-scales. 


\subsubsection{Combined Scenarios}

By combining atmospheric and oceanic temperature changes, 81 simulations are run to capture a wide range of climate change scenarios. Figures 3.20 and 3.21 show the changing ice thickness at 100, 500, and 1000 years. Changes in atmospheric temperatures are plotted along the $\mathrm{x}$-axis, changes in oceanic temperatures along the $\mathrm{y}$-axis, changes in ice thickness along the z-axis of the block diagrams. Figure 3.20 shows the relative stability of the upper and trunk zones of the KIS (locations $a$ - $d$ ) after 100, 500, and 1000 years into the simulations, with limited ice thickness changes occurring regardless of the increase of oceanic or atmospheric temperatures. Figure 3.21 shows the ice thickness for locations $e$ - $h$ at 100, 500, and 1000 years into the simulations. An increased loss of ice with $0.25^{\circ} \mathrm{C}$ ocean warming is observed in the upper zone, and the trunk and transition zones have lost the majority of the ice after 500 years and an increase of $0.75^{\circ} \mathrm{C}$ of oceanic temperatures. Lastly, after 1000 years, the trunk and transition zones have lost the majority or all the ice after oceanic temperature increases of $0.25^{\circ} \mathrm{C}$. Large ice losses are observed in the upper zone after 1000 years; however, some ice remains at these locations. A distinct threshold for change is observed in the KIS at an oceanic temperature increase of $0.25^{\circ} \mathrm{C}$. The transition zone (locations $g$ and $h$ ) shows greater response to increased oceanic and atmospheric temperatures, with a rapid loss of grounded ice above a $0.25^{\circ} \mathrm{C}$ oceanic temperature increase after 100 years, and increasing ice losses with increasing ocean and atmospheric temperatures. This is consistent with other studies, such as Golledge and others (2017) and Golledge and others (2019). 


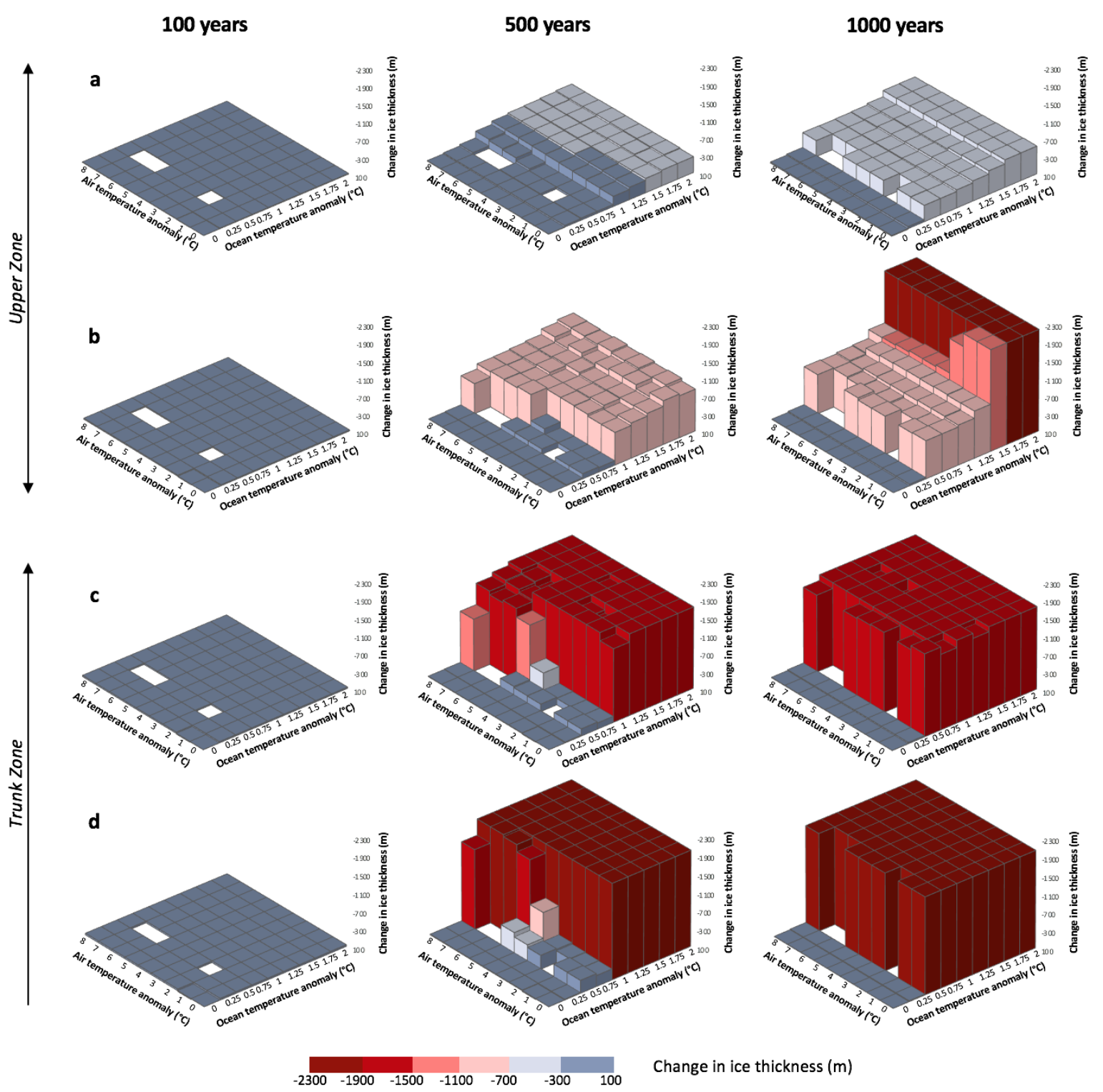

Fig. 3.20 Changes in ice thickness after 100 (solid) and 1000 (transparent) years for the combined scenario atmospheric and oceanic temperature increases. Each graph (a-d) correspond to the previously described locations of the KIS. 


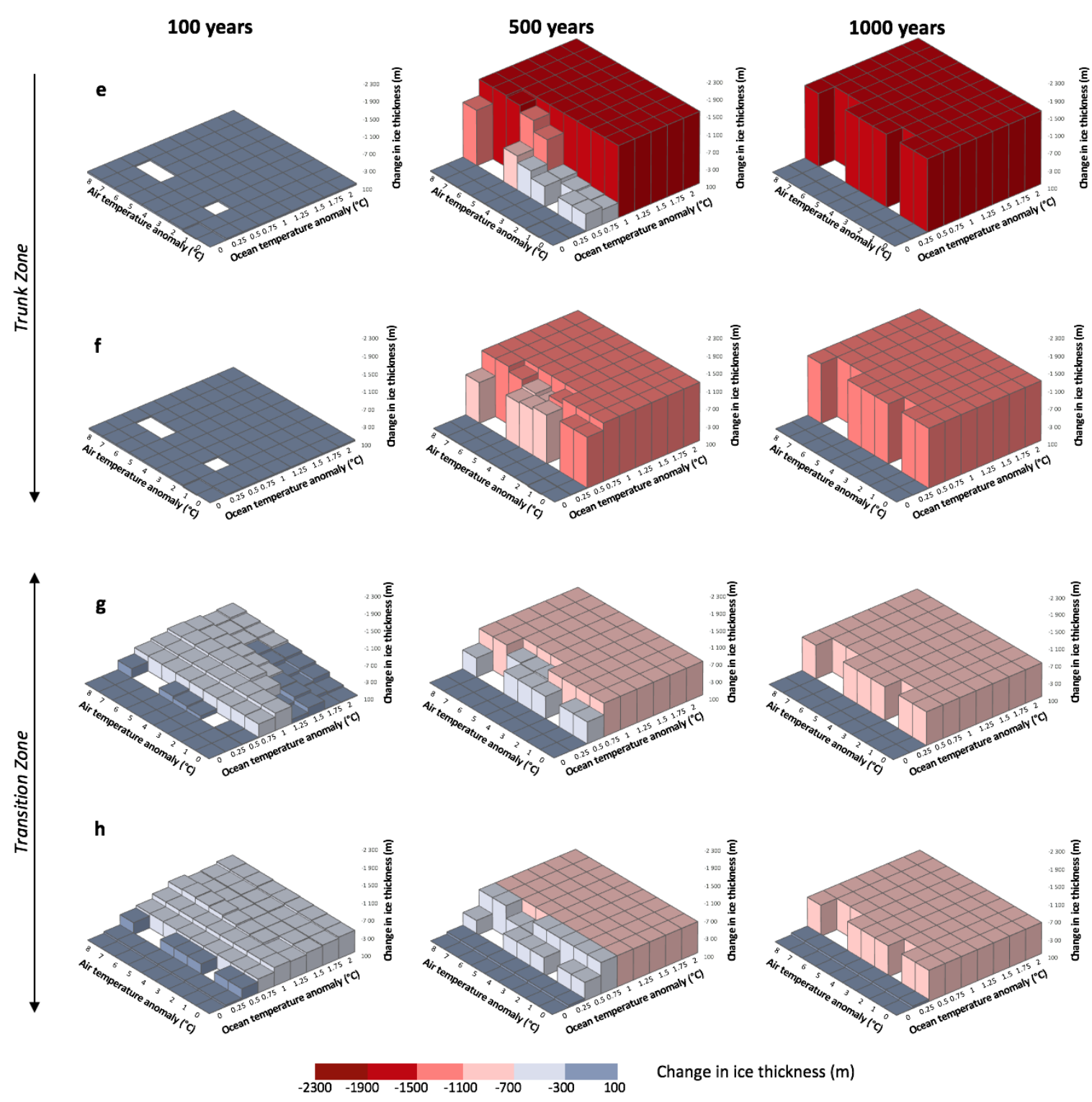

Fig. 3.21 Changes in ice thickness after 500 (solid) and 1000 (transparent) years for the combined scenario atmospheric and oceanic temperature increases. Each graph (e-h) correspond to the previously described locations of the KIS.

Figure 3.22 illustrates changes in ice surface elevation and the reduction of the ice shelf with increased oceanic and atmospheric temperatures. It particularly shows the retreat of the grounding zone with increased oceanic temperatures, to two pinning points (see Section 3.5.1), and the limited retreat that arises under increasing atmospheric temperatures. Between an oceanic temperature increase of 0.25 and $0.5^{\circ} \mathrm{C}$, a substantial reduction in ice surface elevation and ice thickness is observed from $300 \mathrm{~km}$ downstream the flowline onward. With a $0.5^{\circ} \mathrm{C}$ increase the grounding zone has retreated inland to a pinning point between 340 to $360 \mathrm{~km}$ downstream. The increases in oceanic 
temperature between 0.5 to $1.5^{\circ} \mathrm{C}$ are largely grounded at this location, with retreat to a new pinning location occurring after the $1.5^{\circ} \mathrm{C}$ increase to between 280 to $310 \mathrm{~km}$ downstream. The ice surface elevation at the start of the flowline has not reduced over the 1000 year period. This is due to the imposed boundary conditions of the model domain as opposed to ice stream behaviour. A consequence of this imposed anchoring at approximately 2250 m.a.s.l., is the effect of a lower atmospheric temperature at this location to if this point evolved to a lower elevation. This would potentially lead to greater melt which is not included in this scenario.

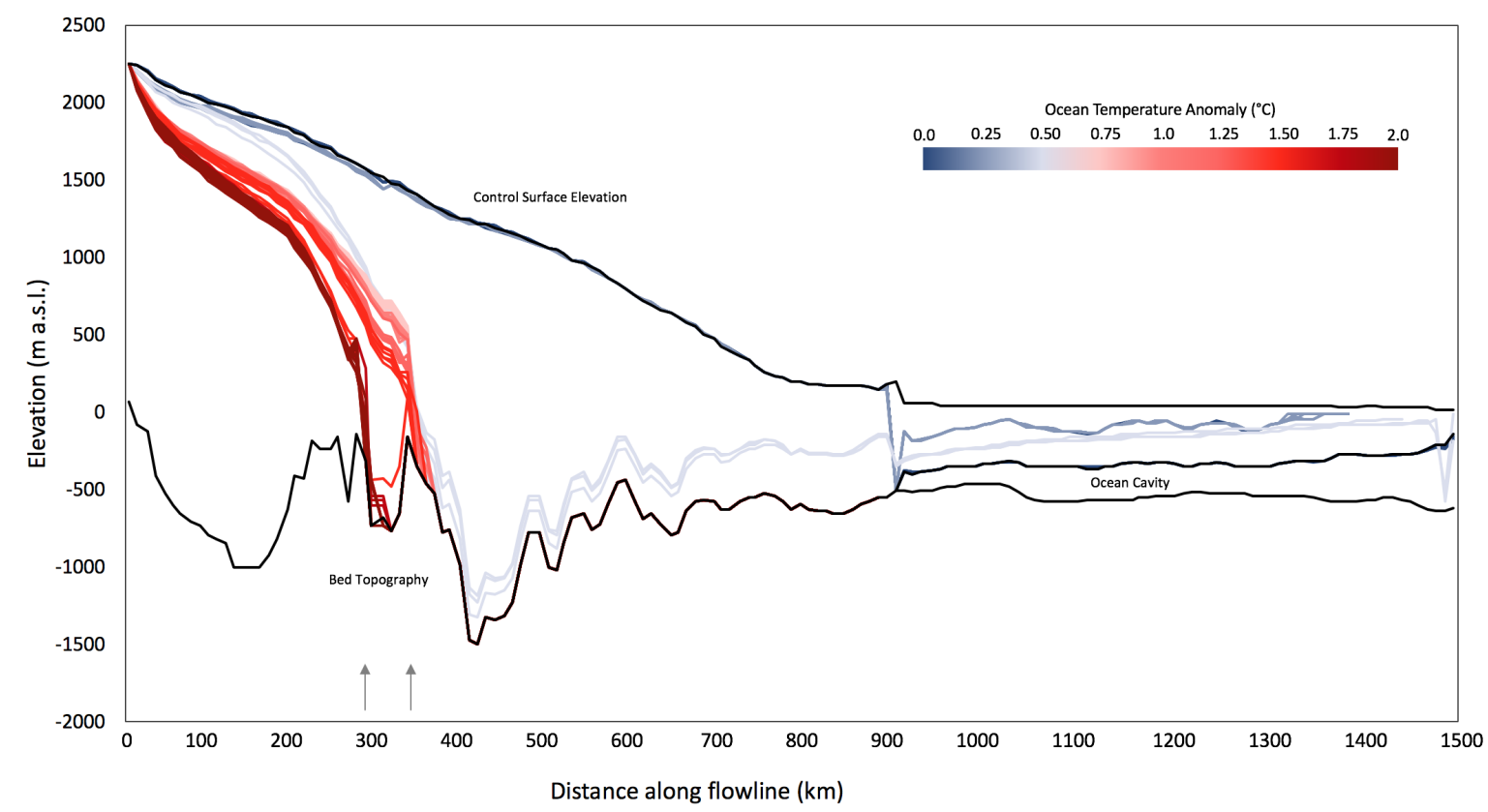

Fig. 3.22 Ice surface elevations under warming oceanic conditions. The nine different oceanic temperature anomalies are plotted $\left(0.0^{\circ} \mathrm{C}\right.$ to $2.0^{\circ} \mathrm{C}$ with $0.25^{\circ} \mathrm{C}$ increments $)$ and within each oceanic temperature increase, nine plots of atmospheric temperature increases are plotted. The oceanic temperatures are plotted in different colours $\left(0.0^{\circ} \mathrm{C}\right.$ as dark blue through to dark red for $\left.2.0^{\circ} \mathrm{C}\right)$. The atmospheric changes are coloured according to the oceanic changes, as these show higher variation. Two arrows (grey) indicate potential pinning points.

\subsection{Discussion: Hydrological Changes in the Sub- glacial Environment}

\subsubsection{Temporal Responses of the Subglacial Environment}

The five different simulations of total maximum effective water stored in the till show three distinct temporal responses. Within the initial $\sim 250$ years of the simulations, the 0.1 and $1.0 \mathrm{~m}$ simulations show large scale variation in the KIS responses at locations 
$a$ to $f$ in contrast to the 2.0, 3.0 and $3.9 \mathrm{~m}$ simulations (Figures 3.6-3.8). After the initial $\sim 250$ year period, between 250 and 500 years, the 3.0 and 3.9 m simulations frequently exhibit a rapid increase in the shown parameter, often to a similar value as the 0.1 and $1.0 \mathrm{~m}$ simulations. Lastly, between 500 and 1000 years into the simulation, the ice stream appears to stabilise and, for most variables, each simulation of total maximum effective water stored in the till has near identical end values. It is inferred from these data that large, instantaneous changes in the total maximum effective water stored in the till perturb the KIS on a centennial scale; however, the ice stream returns to a steady state on the millennial scale, often at near similar values as the start state. The increase of maximum effective thickness of water stored in the till by $\pm 1.9 \mathrm{~m}$ from $2.0 \mathrm{~m}$ does not cross a threshold of the system, which implies that the changes are transient and reversible. At the millennial-scale the KIS appears to self regulate and be reversible with changing amounts of water in the till; however, at longer time scales modelled oscillatory behaviour of ice velocity is found to occur (i.e. the stagnation and reactivation of ice streams, potentially due to changes in the basal hydrology), which may not be evident in this study's shorter-term simulations (van Pelt \& Oerlemans, 2012).

\subsubsection{Spatial Variation}

A key feature of the KIS are the highly variable subglacial conditions, particularly when compared with other ice streams, such as the Whillans Ice Stream (WIS) (e.g. Kamb, 2001; Luthra et al., 2017; Atre \& Bentley, 1993; Bentley et al., 1998; Catania et al., 2003). Seismic and borehole data from the WIS show the stronger homogeneity observed beneath the ice stream (Kamb, 2001). The data in this study strongly agree with results of KIS variation, as shown particularly in Figures 3.6 to 3.8, which show intrinsically different responses along the KIS flowline in the ice velocities, basal stresses, basal temperatures and basal hydrology.

\subsection{Discussion: Projecting Future Change}

The future projection simulations show the importance of understanding how presentday processes and thresholds will impact the reaction of the KIS and the wider WAIS to changing climatic temperatures and conditions. Global mean surface temperatures (GMSTs) are projected to warm up to $2.6^{\circ} \mathrm{C}$ by $2046-2065$, and up to $4.8^{\circ} \mathrm{C}$ by $2081-2100$ relative to 1985-2005 average temperatures (Collins et al., 2013). The Representative 
Concentration Pathways (RCPs) are four scenarios where $\mathrm{CO}_{2}$ concentrations are higher in 2100 relative to present-day as a result of further increase of cumulative emissions of $\mathrm{CO}_{2}$ to the atmosphere during the $21^{\text {st }}$ century (Church et al., 2013). This study presents 81 simulations of increasing atmospheric, oceanic, or combined temperatures that show large scale effects on the KIS, both on the surface and subglacially. This comprehensive set of simulations encompasses the changes outlined by the RCP scenarios, and beyond.

\subsubsection{Pinning Points and Grounding Zone Retreat}

The inland bed deepening of some marine-based ice streams is thought to render these sectors of the ice sheet inherently unstable, whereas the presence of topographical pinning points provide a control on the retreat of these ice streams (Weertman, 1974; Schoof, 2007). Satellite observations of rapid ice-stream thinning and recession seem consistent with this theory (Joughin, Smith \& Holland, 2010; Rignot, 2008; Pritchard et al., 2009). However, the retreat patterns of palaeo-ice streams show high regional inconsistencies, which could indicate that local controls such as basin geometry can provide an important modulation on ice stream retreat in addition to climate and oceanic temperature forcings (Ó Cofaigh et al., 2008; Livingstone et al., 2012). Jamieson and others (2012) also show the consistent slowdowns of grounding zone retreat rates at locations of topographic highs. This study provides evidence that the KIS has three potential topographic pinning points, 300, 500 and $600 \mathrm{~km}$ upstream of the present-day grounding zone, which provide locations of stabilisation under increased oceanic temperature forcings. These are presented in Figure 3.22, which shows the stabilisation of retreat at two topographical pinning points. With oceanic temperature forcing increases of $0.25^{\circ} \mathrm{C}$, the modelled ice stream displays a rapid retreat of the grounding zone to the first pinning point, and a subsequent rapid retreat to the second pinning point. Higher temperature simulations show a similar pattern of rapid retreat to the first and second pinning point positions over 1000 year simulations. With oceanic temperature forcing of $1.5^{\circ} \mathrm{C}$ and above, the KIS retreats back to the highest topographical pinning point. Increased atmospheric temperature forcings have limited effect on the retreat of the grounding zone; however, it is argued that the first potential pinning point provides a different basal stress and frictional heating regime with the increases of atmospheric temperatures that likely increased the ice velocity in this area. Grounding zone dynamics may also be affected by the pinning points, where the unpinning of the grounding zone changes the force balance, changing the ice thickness 
and flow velocities (Still, Campbell \& Hulbe, 2019; Goldberg et al., 2009; Favier et al., 2012; Favier \& Pattyn, 2015).

\subsubsection{Ice Stream Sensitivity}

This study investigates the sensitivity of the KIS to climate-related thresholds, through increases in oceanic and atmospheric temperature perturbations. Figure 3.23 captures the changes of ice volume with increasing oceanic and atmospheric temperature perturbations (panels 3.23a and 3.23b), as well as ice stream sensitivity (panels 3.23c and $3.23 \mathrm{~d}$ ) for the grounded and floating sections of the KIS flowline. Panel 3.23a illustrates the oceanic temperature threshold at which large decreases of grounded ice volume are observed from 500 years onward. This increased ice loss occurs between temperature increases of 0.25 and $0.5^{\circ} \mathrm{C}$, as was observed in Section 3.3. Overall decreases and final total loss of the ice shelf after 1000 years are also observed. Panel $b$ shows the limited change in total ice volume with increasing atmospheric temperatures, for either the grounded or the floating ice over the 1000 year period. The grounded ice shows a strong sensitivity to oceanic temperature perturbations of $0.25^{\circ} \mathrm{C}$ after a 1000 years, where the ice volume rate of change rapidly reduces. At the 100 and 500 year time intervals a sensitivity to an oceanic temperature perturbation of $0.25^{\circ} \mathrm{C}$ is also observed. Further oceanic temperature perturbations above $0.75^{\circ} \mathrm{C}$ also highlight ice stream sensitivity to oceanic warming. The rapid removal of the ice shelves in the simulations above $0.25^{\circ} \mathrm{C}$ also shows the high sensitivity of floating ice shelves to increased ocean warming. This highlights that the grounded ice sheet is more sensitive to increases of oceanic temperatures at the centennial and millennial scales, and the floating ice at decadal scales. However, while it is useful to model the oceanic and atmospheric temperature change components separately to understand their individual roles, the two are intrinsically linked, and it is suggested that future work should asses the sensitivity of the ice stream with combined atmospheric and oceanic temperature increases. These results are in line with the large body of work that has been conducted over the recent years which demonstrate the sensitivity of the Antarctic (and Greenland) Ice Sheets to increases in oceanic temperatures (e.g. Golledge et al., 2015; Christianson et al., 2016; Golledge et al., 2017; Tabone et al., 2018; Golledge et al., 2019; Levy et al., 2019). Lastly, panel $d$ shows the limited sensitivity of the KIS to atmospheric temperature perturbations of $1.0^{\circ} \mathrm{C}$ and $3.0^{\circ} \mathrm{C}$, while the floating ice shelf displays minimal sensitivity to atmospheric temperature perturbations. It is also noted that the anchoring of the ice sheet elevation at the start of the flowline likely aids to underestimate the role of increased atmospheric temperatures on future evolution of 
KIS than the flowline model results currently suggest. It is suggested that this be further investigated in subsequent studies to quantify the impact of the anchoring.
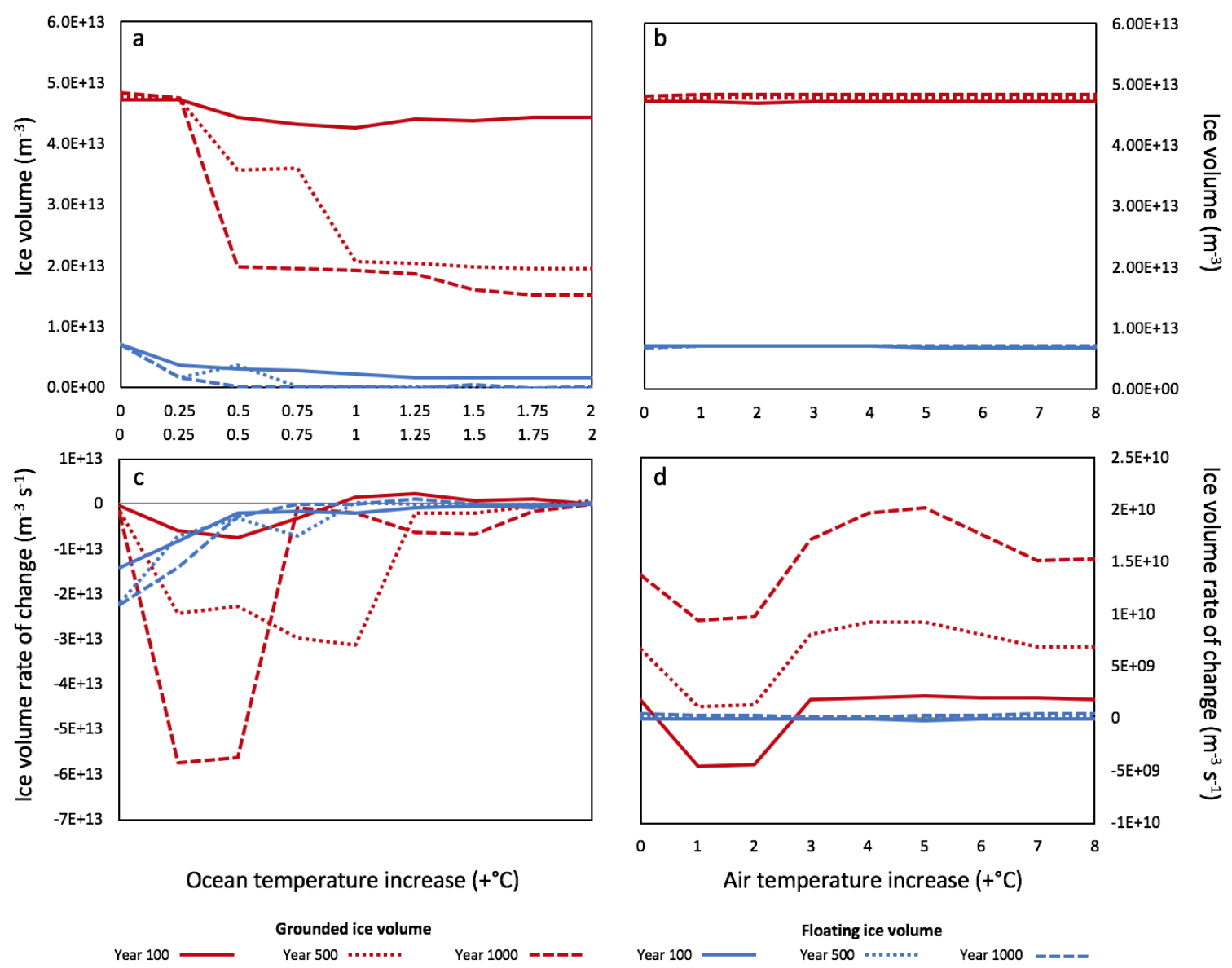

Fig. 3.23 Total domain ice volume changes, and rates of change, with increasing oceanic or atmospheric temperatures. Panels (a) and (b) illustrate the total KIS ice volume for either the grounded (red) or floating (blue) section of the flowline at increasing temperatures. These are plotted after 100 years (solid), 500 years (dotted) and 1000 years (dashed) of the model simulations. Panels (c) and (d) show the ice stream sensitivity with increasing ocean or atmospheric temperatures. Note the different y-scales.

\subsubsection{Reactivation of the Kamb Ice Stream}

The removal of the buttressing effect of ice shelves results in increased ice velocities, such as observed after the partial collapse of the Larsen B ice shelf (Scambos et al., 2004). The buttressing effect of the RIS is also thought to play an important role in restraining the outflow of upstream grounded ice on the SCIS (Fürst et al., 2016). While most of the RIS provides active buttressing, sections have been labelled as "passive" where the removal of the ice shelf until this point results in minimal increase in ice velocity (Fürst et al., 2016). Figure 3.24 shows the Ross Sea sector and the 
RIS buttressing effects in relation to the KIS flowline in this study. Data presented in this study show the possibility of ice stream reactivation with increases of oceanic temperatures above $0.25^{\circ} \mathrm{C}$, where large sections of the ice shelf have melted and been removed past the "passive" line of buttressing. Removal of the ice shelf therefore likely resulted in increased basal and surface velocities, and thinning on the ice stream likely arose from this increased rate of ice loss. This study, however, does not take into account the buttressing effect that the Ross Ice Shelf provides upon the KIS, with studies indicating that the RIS provides the highest ratio of buttressing on the KIS in respect to the other SCIS (Reese, Winkelmann, \& Gudmundsson, 2018). The minority of ice discharges into unconfined, or mostly unconfined, ice shelves, and these provide limited influence on the upstream ice flow (Schoof, 2007). The majority of ice flow, is discharged into confined ice shelf embayments, which exert a control on the upstream ice flow and discharge from the grounded ice sheet (Fürst et al., 2015). In this study's flowline simulations, the grounding zone retreat likely occurs at a faster rate, than if it is discharging into an buttressing ice shelf.
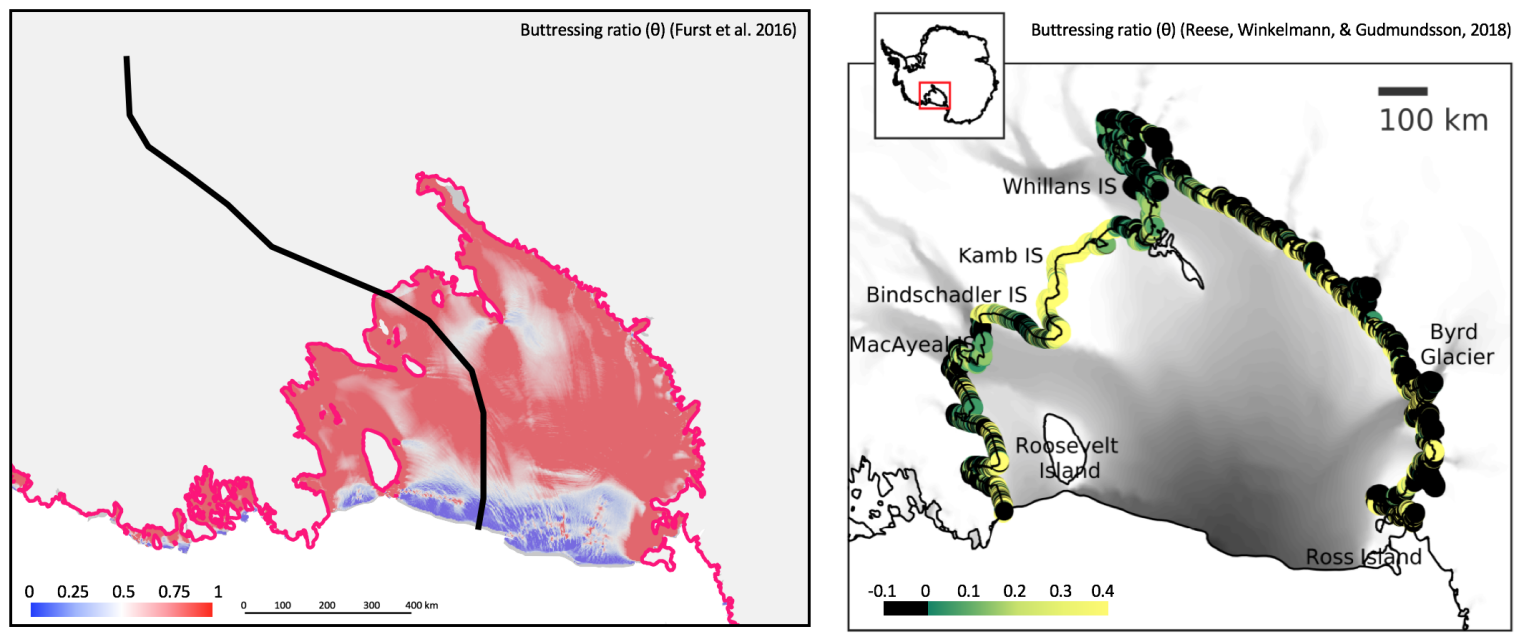

Fig. 3.24 Ross Ice Shelf buttressing effects, where the Fürst and others (2016) data in the left panel shows the 'passive' buttressing section of the RIS coloured in blue, and the 'active' buttressing in red. The Kamb Ice Stream flowline is indicated in black. The right hand panel shows the buttressing ratio $\theta 1$ along the Ross Ice Shelf grounding zone by Reese, Winkelmann and Gudmundsson (2018), which indicates high levels of buttressing along the Kamb Ice Stream grounding zone. Modelled ice velocity is plotted in grey ranging up to $1500 \mathrm{~m} \mathrm{y}^{-1}$. Modified from Fürst et al., (2016) and Reese, Winkelmann \& Gudmundsson (2018).

\subsubsection{Model Limitations and Assumptions}

\section{Resolution}

Due to the computational constraints of this study, the flowline simulations are at 
a horizontal resolution of $10 \mathrm{~km}$, as opposed to a higher resolution of either 1 or 5 $\mathrm{km}$. This resolution is unable to capture finer detail, and it would be desirable for future work to consider replicating the simulations at higher resolutions and comparing the simulations to the lower $10 \mathrm{~km}$ resolution flowline. A higher resolution of bed topography could also be desirable. Secondly, the flowline is limited to two dimensional resolution, any three dimensional lateral variation is ignored within the flowline simulations. Chapter 4 partially aims to address a more three dimensional extent of the KIS in comparison to the flowline simulations.

\section{Model response versus ice stream response.}

An important component of this study is the characterisation of the subglacial environment as a response to changing parameters of the flowline model. A limitation is the consideration of which modelled responses are glaciological and geological responses, and which responses are due to the choice of model parameters. It would not be accurate to present all the results in this Chapter without a consideration as to what extent the model choice and model parameter choices have influenced the results. The model used is a comprehensive SIA and SSA hybrid model, as previously discussed, which aims to capture the complex understanding of glaciological, geological and climatological processes (Bueler \& Brown, 2009). This study suggests that the comprehensive 1746 ensemble simulations in combination with a robust ice sheet model, provide some certainty that the modelled results presented are indeed responses of the ice stream, as opposed to a responses inherent to the model.

\section{Oceanic and atmospheric components}

The oceanographic component of the model used for the KIS may not capture in its entirety the complex oceanographic processes occurring beneath the RIS, such as basal melt rates (De Rydt \& Gudmundsson, 2016), and likely led to incorrect ice geometry at and near the grounding zone. It is suggested that an incorrect basal melting scheme at the grounding zone and too coarse a resolution are potentially the cause of this artefact. It is outside of the scope of this study to modify the ocean component of the model, and it is recommended for future work that extra simulations are performed which test different oceanographic models to better capture the grounding zone transitions.

As suggested earlier in this chapter, the imposed anchoring of the ice surface at $0 \mathrm{~km}$ on the modelled profile likely affected the impact of increased oceanic temperatures in this location. The upper trunk of the KIS flowline was artificially kept at lower atmospheric temperatures due to this anchoring, and this likely underestimated the response of the 
KIS to increased atmospheric temperatures in this section of the profile. While it is outside of the scope of this study to perform an ensemble of simulations to assess the impact of this anchoring, it is suggested that this could be included in future research to better refine the impact of atmospheric temperature increase on this sector of the KIS.

\section{Model issues}

An issue that occasionally occurs in PISM is failure of the stress balance calculations, and a simulation unable to finish under certain parameter combinations. This issue can frequently be solved by changing the adaptive time step used in the model; however, this strategy did not work for this study. In this study, three model simulations (combinations of oceanic temperatures of $0.5^{\circ} \mathrm{C}$, and atmospheric temperatures of 2.0, 6.0 and $7.0^{\circ} \mathrm{C}$ ) which combined increases in oceanic and atmospheric temperatures had a stress balance failure, and were not able to run the simulation for the full 1000 year period. When changing the adaptive timestepping ratio other model simulations resulted in the same issue. The decision was made that out of the 81 model simulations, the three simulations that failed would not be included in the results. This study argues that this does not have a significant impact on the presentation and interpretation of results. 



\section{West Antarctic Ice Sheet Simula- tions}

This Chapter aims to characterise the larger-scale West Antarctic Ice Sheet subglacial environment, both in the context of the Kamb Ice Stream, as well as wider, continental changes. Another aim of this chapter is to assess the robustness of the parameter choices made for the KIS flowline simulations at a continental scale, and whether the parameter choices were a function of resolution and model complexity. Two sets of whole continent simulations are performed, where the first set uses the same parameters as the KIS flowline simulations (Chapter 3) and investigates changes in subglacial hydrology. Replication of KIS parameters at a continent level allows for the assessment of parameter choices made at a flowline level, and whether these are appropriate at larger scales. The second set of simulations uses different parameters than the KIS flowline simulations, which better capture the present-day state of the whole continent, and explore atmospheric temperature perturbations, as well as precipitation changes, and changing geothermal heat fluxes (GHF). The KIS parameter-based simulations are run over a 1000 year period, while the AIS parameter based simulations are run over a 10,000 year period to allow for stabilisation of the ice sheet. Both sets of simulations provide insights into the behaviour of the West Antarctic Ice Sheet, as well as more focused responses of the Ross Sea Sector and the Kamb Ice Stream.

\subsection{Methodology}

The methodology of the whole continent simulations closely follows the KIS flowline methodology, which is comprehensively discussed in Chapter 3. This section aims to report differences from the main methodology. The initial stages of model smoothing, evolution, and the spin-up are identical to the KIS flowline simulations; however, they are performed at the entire Antarctic continent scale. Table 3.1 records the parameter choices for the model smoothing and evolution, while Table 4.1 records the 
parameter choices for both the KIS-based whole continent simulations, as well as the longer, AIS-based whole continent simulations. These two subsets of whole continent simulations explore ice sheet response and behaviour at different temporal scales, as well as quantifying which parameter choices capture the present-day KIS, Ross Sea Sector, and WAIS. The initial KIS-based, whole-continent simulation uses the same SIA enhancement, SSA enhancement, till phi, atmospheric, and oceanic parameters as the KIS flowline simulations (Table 4.1), and is run over a 1000 year period. Using the same parameter choices allows for both the seismic survey results and the flowline model results to be applied in a wider context. The second set of whole-continent simulations explores different SIA and SSA enhancement combinations, to produce a 25 simulation ensemble that aims to best capture present-day surface ice velocity, elevation, and ice extent. These simulations are run over a 10,000 year period, and at a $30 \mathrm{~km}$ resolution, to allow for longer stabilisation and changes of the ice sheet. 
Table 4.1 PISM input options and parameter choices for whole continent simulations, comparing the KIS and AIS focused spin-ups, and hydrological, temperature increase $\left({ }^{\circ} \mathrm{C}\right)$, and geothermal heat flux (GHF) change simulations.

\begin{tabular}{|c|c|c|c|c|}
\hline PISM option & KIS Spin-up & KIS Hydrology & AIS Spin-up & AIS ${ }^{\circ} \mathrm{C} ; \mathrm{GHF}$ \\
\hline -bootstrap & $\mathrm{x}$ & $\mathrm{x}$ & $\mathrm{x}$ & $\mathrm{x}$ \\
\hline$-y$ & 20 & & & \\
\hline -ys, -ye & 0,1000 & 0,1000 & $0,10,000$ & $0,10,000$ \\
\hline -z_spacing quadratic & $\mathrm{x}$ & $\mathrm{x}$ & & \\
\hline -ts_file -ts_times & $\mathrm{x}$ & $\mathrm{x}$ & $\mathrm{x}$ & $\mathrm{x}$ \\
\hline -extra_file -extra_vars -extra_times & $\mathrm{x}$ & $\mathrm{x}$ & $\mathrm{x}$ & $\mathrm{x}$ \\
\hline -regrid_file -regrid_vars & $\mathrm{x}$ & $\mathrm{x}$ & & \\
\hline -skip -skip_max -backup_interval & 24 & 24 & 100 & 100 \\
\hline-0 & $\mathrm{x}$ & $\mathrm{x}$ & $\mathrm{x}$ & $\mathrm{x}$ \\
\hline anomaly, -atmosphere_anomaly_period, -atmosphere_anomaly_file & & & 1 & 1 \\
\hline paleo_precip, -atmosphere_paleo_precip_file & & & & $\mathrm{x}$ \\
\hline -surface & $\mathrm{x}$ & $\mathrm{x}$ & $\mathrm{x}$ & $\mathrm{x}$ \\
\hline pdd, -pdd_refreeze & 0.6 & 0.6 & 0.6 & 0.6 \\
\hline delta_T -surface_delta_T_file & & & $\mathrm{x}$ & $\mathrm{x}$ \\
\hline -ocean & $\mathrm{x}$ & $\mathrm{x}$ & $\mathrm{x}$ & $\mathrm{x}$ \\
\hline th, -ocean_th_file & $\mathrm{x}$ & $\mathrm{x}$ & $\mathrm{x}$ & $\mathrm{x}$ \\
\hline -calving ocean_kill -ocean_kill_file & $\mathrm{x}$ & $\mathrm{x}$ & $\mathrm{x}$ & $\mathrm{x}$ \\
\hline -calving eigen_calving, thickness_calving -pik & $\mathrm{x}$ & $\mathrm{x}$ & $\mathrm{x}$ & $\mathrm{x}$ \\
\hline -eigen_calving_K & $5 \mathrm{e} 15$ & $5 \mathrm{e} 15$ & $1 \mathrm{e} 16$ & $1 \mathrm{e} 16$ \\
\hline -ssa_dirichlet_bc & $\mathrm{x}$ & $\mathrm{x}$ & & \\
\hline -bed_smoother_range & $10 \mathrm{e} 3$ & $10 \mathrm{e} 3$ & $25 \mathrm{e} 3$ & $25 \mathrm{e} 3$ \\
\hline -pseudo_plastic & $\mathrm{x}$ & $\mathrm{x}$ & $\mathrm{x}$ & $\mathrm{x}$ \\
\hline -pseudo_plastic_q & 0.25 & 0.25 & 0.25 & 0.25 \\
\hline -subgl -tauc_slippery_grounding_lines -no_subgl_basal_melt & $\mathrm{x}$ & $\mathrm{x}$ & $\mathrm{x}$ & $\mathrm{x}$ \\
\hline -no_subgl_basal_melt & & & $\mathrm{x}$ & $\mathrm{x}$ \\
\hline -till_effective_fraction_overburden & 0.02 & 0.02 & 0.02 & 0.02 \\
\hline -topg_to_phi & $0,12,-1200,0$ & $0,12,-1200,0$ & & \\
\hline -hydrology_tillwat_max & & variable & & \\
\hline
\end{tabular}

\subsubsection{Analysis}

Both sets of exploratory simulations are visually compared to the observed AIS surface elevation (BEDMAP2; Fretwell et al, 2013), surface ice velocity (MEaSUREs; Rignot et al., 2013), and ice extent (SCAR Antarctic Digital Database) in Figure 4.1. This visual comparison aims to identify whether the results of the set-up simulations appear similar to observed values at the first order. Whilst the two sets of simulations are run 
for different lengths of time, they are initially compared after both have run for 1000 years, to allow for direct comparison. The simulations are plotted next to the observed data to assist in the visual analysis and determine the optimal model parameters (Figure 4.1). This allows for a comparison to establish which model simulations are most similar to the observed data. From the AIS scale ensemble simulations, a SIA enhancement of 4.0 and a SSA enhancement of 0.65 have the best visual comparison to the present-day observations, and are plotted alongside the KIS-parameter simulations. The AIS simulation better captures the extent of the present-day ice shelves and grounding zone locations than the KIS-based simulation, as seen in Figure 4.1. The KIS-based simulation has overestimated the modelled ice shelf extents; however, has better captured the ice surface elevations, particularly near the TAM and the Victoria Land Sector. However, since this aim of this simulation is to assess the viability of the flowline parameter choices on a wider continental scale, these simulations remain included and are not changed, even with the incorrect ice shelf extents. Some grounding zone location mismatch is observed at the base of the FRIS on both the KIS and AIS simulations. Surface ice velocities (top panels) are similarly captured in both the KIS and AIS simulations; however, the KIS-based simulations have better captured the overall SCIS velocities. Basal velocities do not have directly observed data, but are included for comparison between the two types of simulations. 

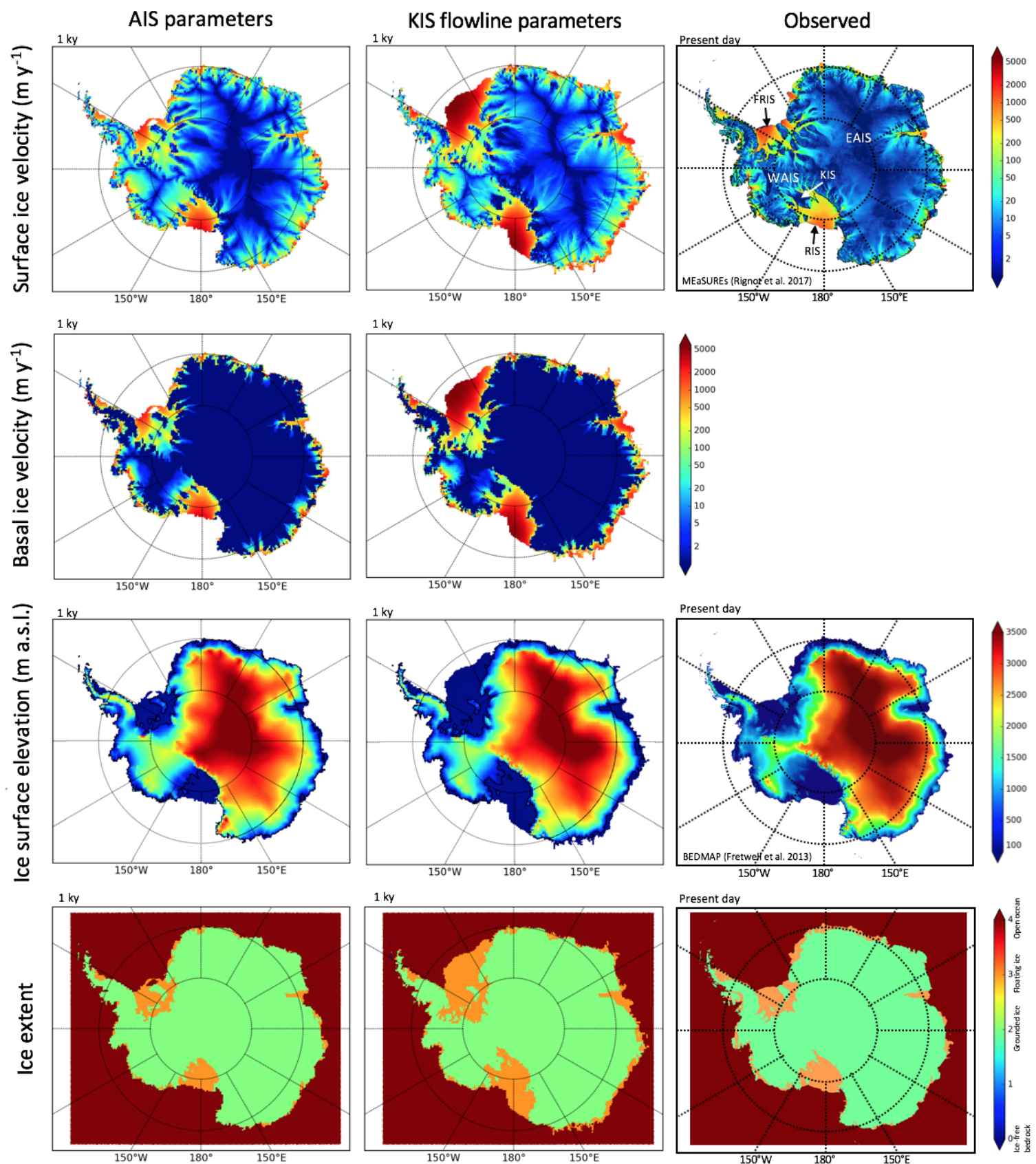

Fig. 4.1 Surface and basal ice velocities, ice surface elevation, and ice extent of the whole-continent simulations based on the KIS flowline parameters (middle) and the final selection of the AIS ensemble simulations (left) after 1000 years. The right-hand column has the observed surface ice velocity, ice surface elevation, and ice extent. The Ross Ice Shelf (RIS), Kamb Ice Stream (KIS), Filchner-Ronne Ice Shelf (FRIS), West Antarctic Ice Sheet (WAIS) and East Antarctic Ice Sheet (EAIS) locations are annotated on the observed surface ice velocity panel. 


\subsubsection{Hydrological Controls}

The hydrological simulations explore the same parameters as the KIS flowline simulations (see Section 3.2.5), by changing the maximum amount of effective water stored in the till to $0.1,1.0,2.0$ (default), 3.0, and $3.9 \mathrm{~m}$ to characterise a range of responses over the entire Antarctic continental scale, focussing on the WAIS and Ross Sea Sector. This explores the result of changing hydrological conditions on ice velocities and ice thickness, as well as ice extent. The range of decay rates as simulated in the KIS flowline simulations are not explored in the whole continent simulations, as they have been shown to have limited impact in the flowline simulations.

\subsubsection{Atmospheric Temperature and Precipitation Perturba- tions}

The second set of simulations characterises the responses of the whole AIS under longer-term changing climatic conditions, and this is explored using the AIS-based parameters as opposed to the KIS flowline parameters. The KIS flowline parameters have been chosen to best represent the subglacial environment of the KIS, whereas the AIS simulation parameter choices better represent the present-day state of the entire AIS. Two atmospheric temperature and precipitation perturbations are explored, as opposed to eight different temperature perturbations in the KIS flowline. This is done to explore the longer-term, higher increases of atmospheric warming, as opposed to the shorter term, smaller changes in atmospheric temperature. Perturbations of 5 and $10^{\circ} \mathrm{C}$ are applied to the atmospheric temperature to encompass different RCP scenario values, and the model is then run over a 10,000 year period. The atmospheric component of the model is modified for the precipitation experiments to include the paleo_precip choice, which incorporates a $7.3 \%$ change of precipitation rate for every one degree Celsius of atmospheric temperature change (Huybrechts, 2002). The precipitation change experiments are also performed at atmospheric temperature perturbations of 5 and $10^{\circ} \mathrm{C}$.

\subsubsection{Geothermal Heat Flux Changes}

Lastly, four different GHF simulations are explored as a means to characterise the timescales at which changing GHF affects the subglacial hydrology. This study explores a range of GHF values that deviate from the Shapiro and Ritzwoller (2004) model, to capture the wide range of measured and inferred GHF (e.g. Pollard et al., 2005; 
Shapiro \& Ritzwoller, 2004; Fox Maule et al., 2005; Purucker, 2013; An et al., 2015; Martos et al., 2017). Reductions by both 25 and $50 \%$, as well as increases by 25 and $50 \%$ are simulated over a 10,000 year period to explore the effects of increased or decreased basal heat on the KIS and the WAIS. The changes in GHF are simulated over a 10,000 year period as opposed to a 1000 year period to capture longer temporal changes.

\subsection{Results}

This section aims to provide insights into the response of the WAIS to changing hydrological, temperature and GHF parameters, and allows the KIS to be understood in a wider context. Visually comparing the ice surface elevation, basal and surface ice velocities, and the basal melt to the control simulations, provides comprehensive characterisation of both temporal and spatial changes of the WAIS.

\subsubsection{Hydrological Changes}

\section{Ice Surface Elevation}

Figure 4.2 shows the change in WAIS ice surface elevation, at 100, 500, and 1000 year intervals. Very limited changes are observed, both spatially and temporally, with increases and decreases of changing maximum amounts of effective water stored in the till on the ice surface elevation. The changes in the maximum amounts of effective water stored in the till do not provide a sufficient modification to the subglacial environment to result in change. This is different from the response observed in the flowline simulations, where the changes in maximum amounts of effective water stored in the till are more concentrated along the KIS, and show larger scale changes along the KIS. The values used in the KIS flowline simulation for the hydrological simulations are sufficiently different from the default of $2.0 \mathrm{~m}$ to result in change, but in a continent-wide simulation do not provide a sufficient modification to the subglacial system to result in change. It is suggested that the whole continent simulations may be missing a significant response to the hydrological changes, or that the flowline simulations are more sensitive to changes in the hydrology. 

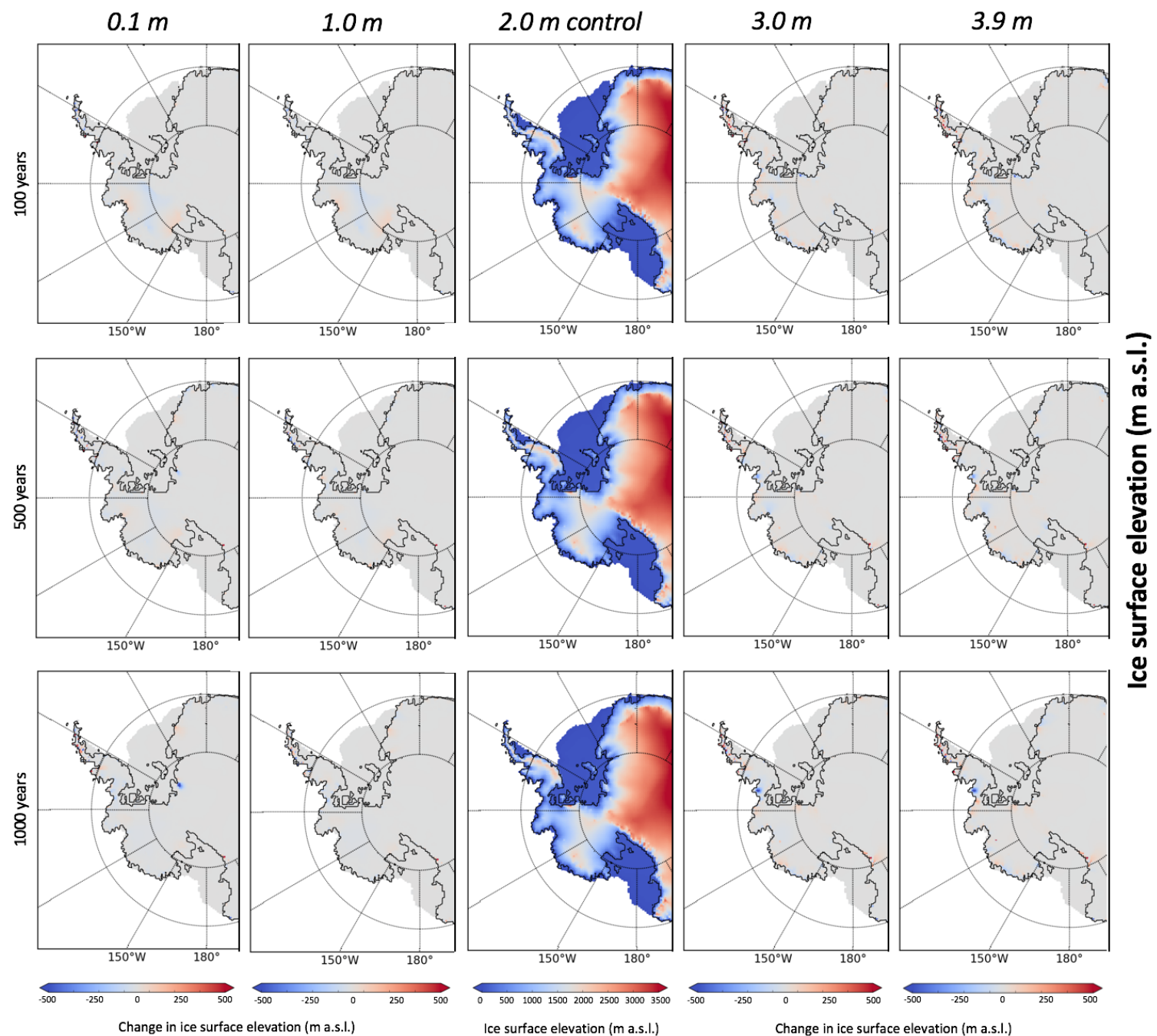

Fig. 4.2 Ice surface elevation (m a.s.l.) with changing amounts of effective water stored in the till after a 1000 year simulation. The response of the WAIS to changing the amount of effective water stored in the till to $0.1,1.0,3.0$ and $3.9 \mathrm{~m}$ is captured at 100,500 , and 1000 year intervals, and are plotted relative to a control of $2.0 \mathrm{~m}$ water storage. The modelled grounding zone is outlined in black.

\section{Surface and Basal Ice Velocities}

Limited variation, $\pm 50 \mathrm{~m} \mathrm{y}^{-1}$, in basal and surface ice flow is simulated under changing maximum amounts of effective water stored in the till, as seen in Figures 4.3 and 4.4, with changes concentrated on the FRIS and the RIS, and within the first 500 years of the simulation. As suggested in the previous paragraph, the values used in the KIS flowline simulation for the hydrological simulations are sufficiently different from the default of $2.0 \mathrm{~m}$ to result in change, but in a continent-wide simulation do not provide a sufficient modification to the subglacial system to result in change. This is evidenced 
in the lack of change in basal and surface ice flow, and likely a result of the whole continent simulations missing a significant response to the hydrological changes.
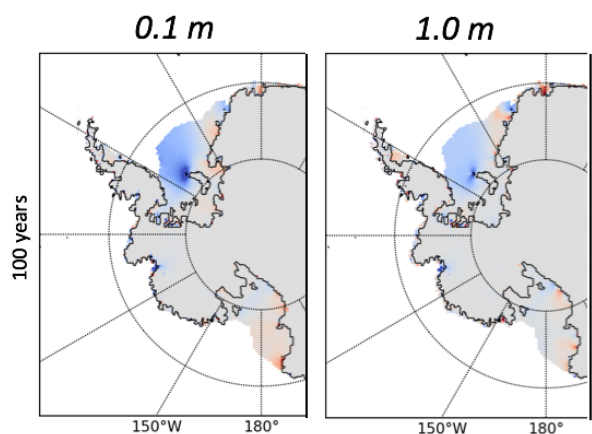

$2.0 \mathrm{~m}$ control
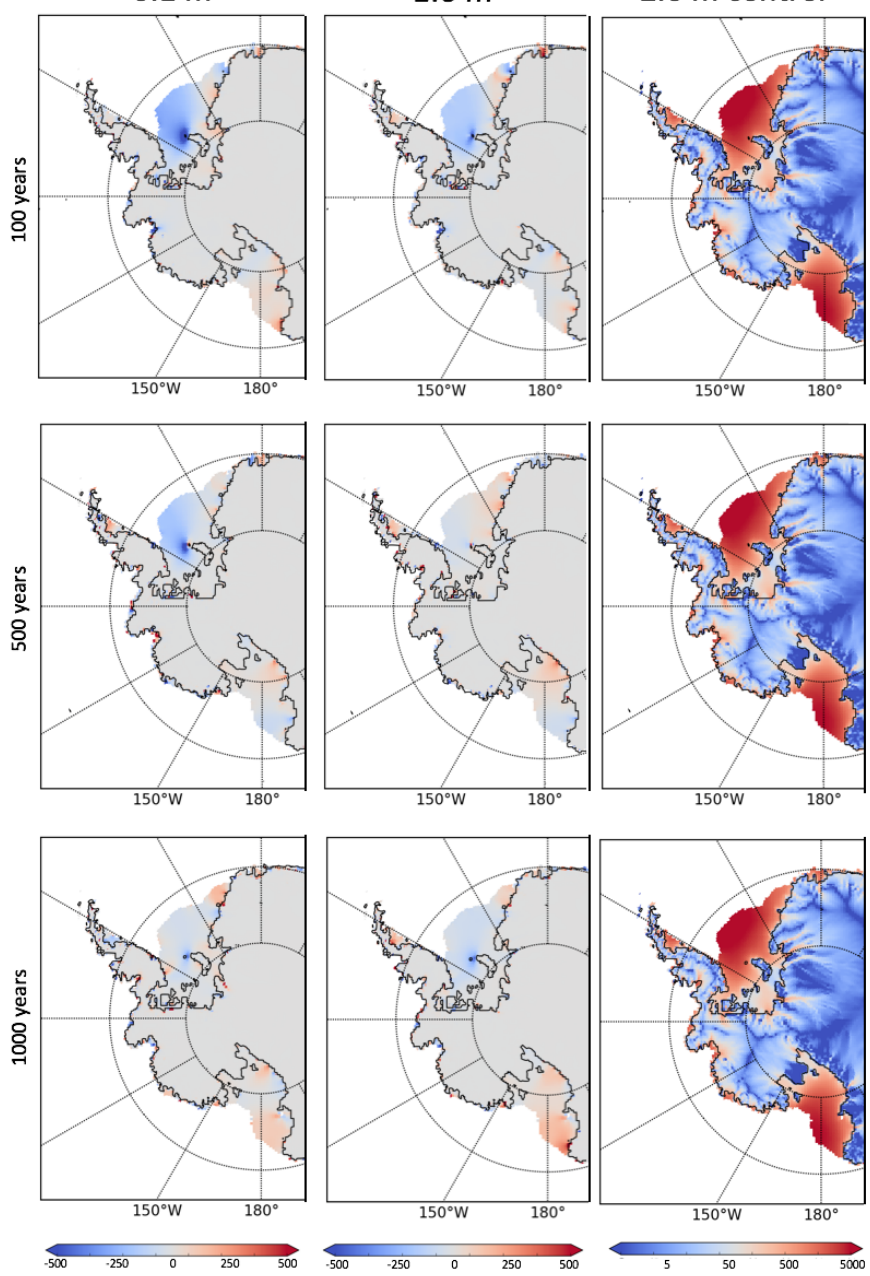

Change in surface ice velocity $\left(\mathrm{m} \mathrm{v}^{-1}\right)$
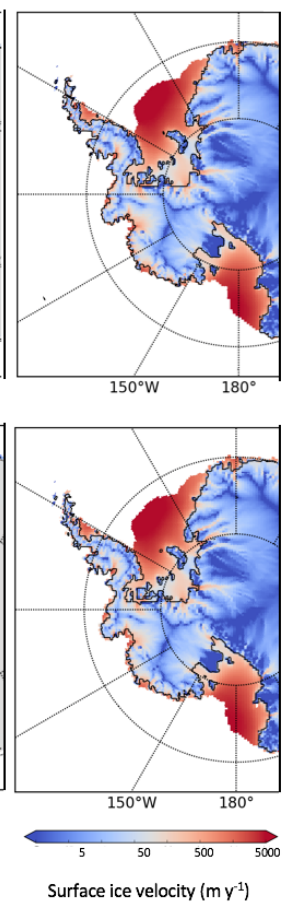
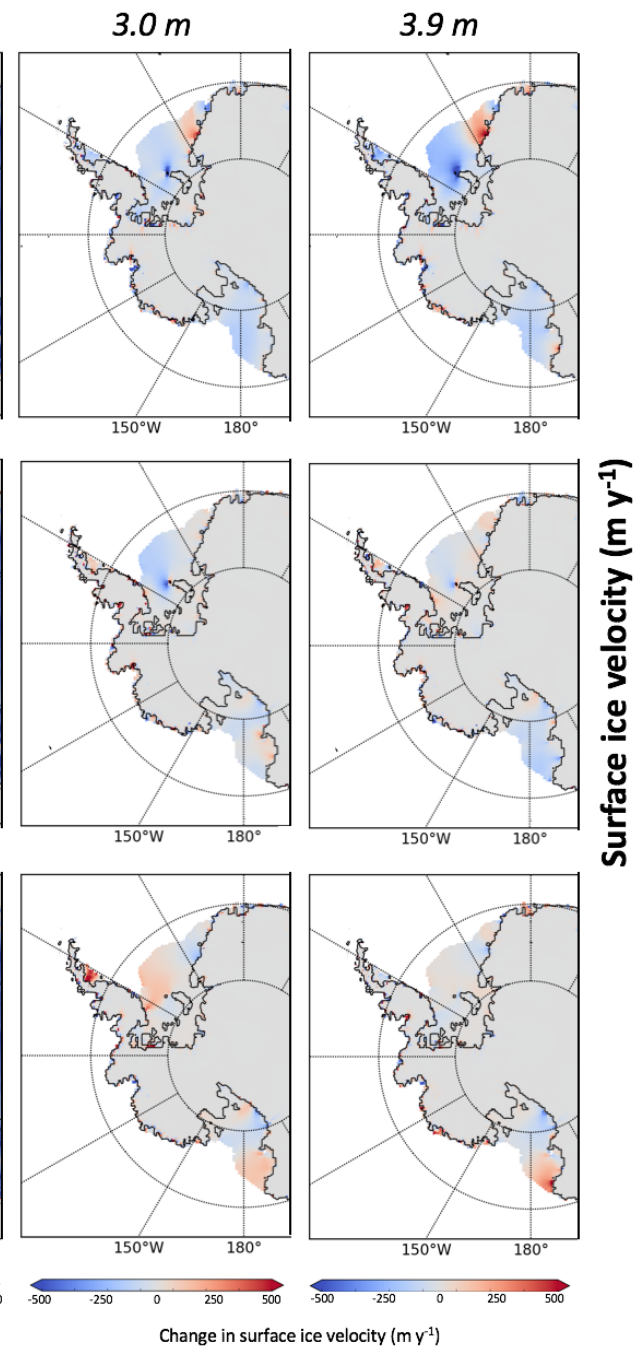

Fig. 4.3 Surface ice velocity $\left(\mathrm{m} \mathrm{y}^{-1}\right)$ with changing amounts of effective water stored in the till after a 1000 year simulation. The response of the WAIS to changing the amount of effective water stored in the till to $0.1,1.0,3.0$ and $3.9 \mathrm{~m}$ is captured at 100, 500, and 1000 year intervals, and are plotted relative to a control of $2.0 \mathrm{~m}$ water storage. The modelled grounding zone is outlined in black. 

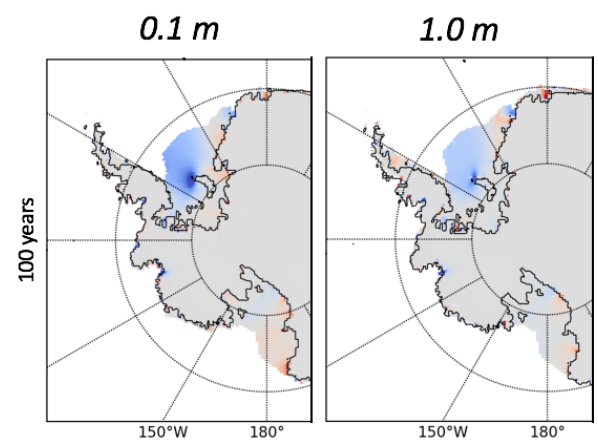

2.0 m control
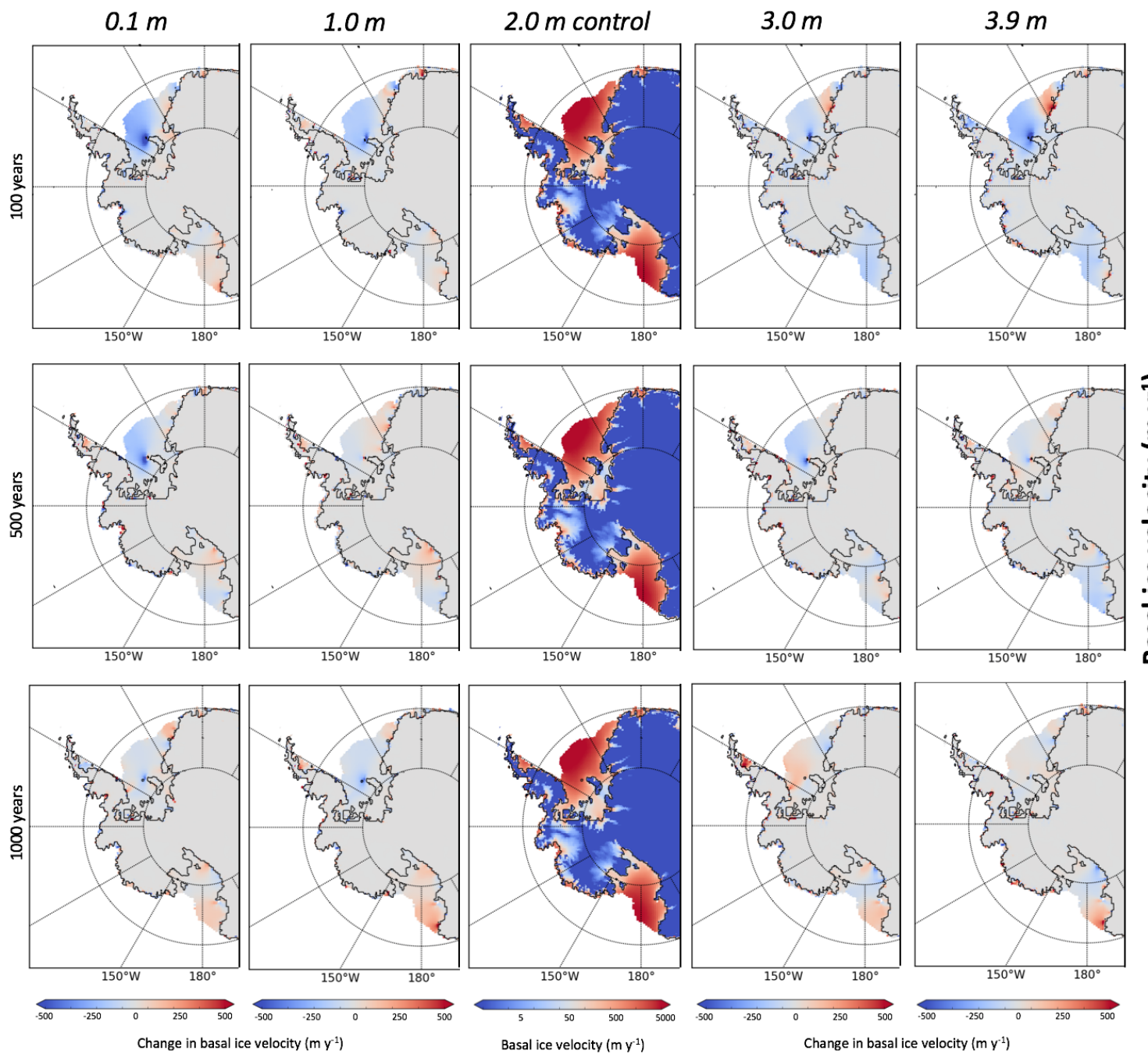

Fig. 4.4 Basal ice velocity $\left(\mathrm{m} \mathrm{y}^{-1}\right)$ with changing amounts of effective water stored in the till after a 1000 year simulation. The response of the WAIS to changing the amount of effective water stored in the till to $0.1,1.0,3.0$ and $3.9 \mathrm{~m}$ is captured at 100, 500, and 1000 year intervals, and are plotted relative to a control of $2.0 \mathrm{~m}$ water storage. The modelled grounding zone is outlined in black.

\section{Basal Melt}

Similar to ice velocities, basal melt shows minimal change, $\pm 2 \mathrm{~m} \mathrm{y}^{-1}$, between different maximum amounts of effective water stored in the till (Figure 4.5) as opposed to the changes simulated in the KIS flowline. Changes in basal melt are not observed until the 1000 year completion of the simulation, where increased basal in excess of, or reduction of, $2 \mathrm{~m} \mathrm{y}^{-1}$ is largely concentrated between the FRIS, the Pine Island Glacier (PIG), and Thwaites Glacier (TG). The KIS shows no observed change with different amounts of effective water stored in the till at this scale, in contrast to the flowline simulations. This is attributed to a likely insensitivity of the model to this 
level of subglacial hydrological change, and further investigation is recommended to the thresholds at which the whole continent responds to subglacial hydrological changes.
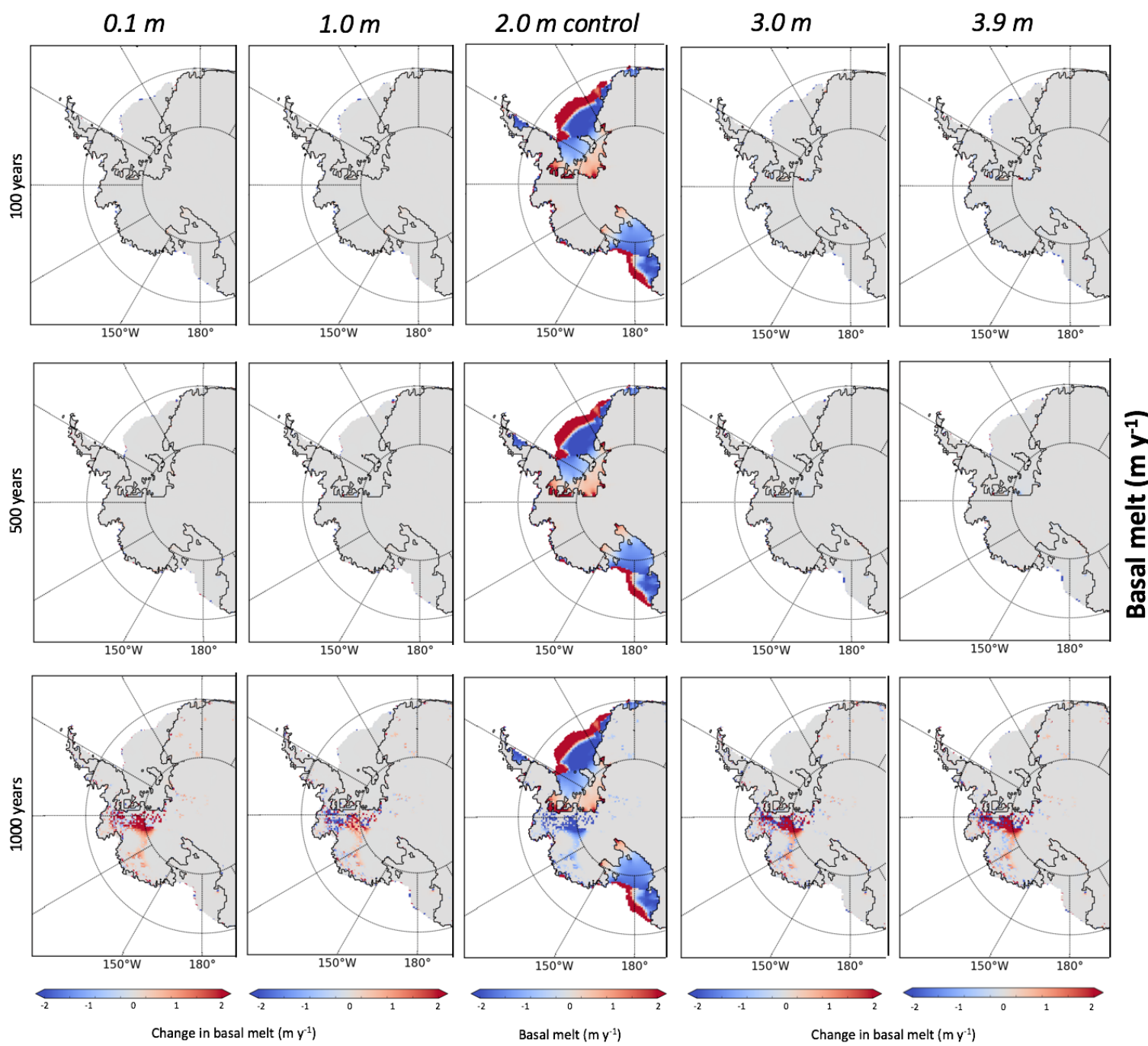

Fig. 4.5 The basal melt $\left(\mathrm{m} \mathrm{y}^{-1}\right)$ with changing amounts of effective water stored in the till after a 1000 year simulation. The response of the WAIS to changing the amount of effective water stored in the till to $0.1,1.0,3.0$ and $3.9 \mathrm{~m}$ is captured at 100, 500, and 1000 year intervals, and are plotted relative to a control of $2.0 \mathrm{~m}$ water storage. The modelled grounding zone is outlined in black.

\subsubsection{Atmospheric Temperature and Precipitation Perturba- tions}

\section{Ice Surface Elevation, Ice Extent and Basal Melt}

Response of the WAIS to increasing atmospheric temperatures, compared to the control simulation, is largely evident in the retreat of grounding zone positions and the ice 
surface elevation changes of the FRIS, TG, and PIG, as observed in Figure 4.6. Limited grounding zone retreat, approximately $50 \mathrm{~km}$ inland in some areas such as the TG and PIG basins, is observed with the $5^{\circ} \mathrm{C}$ atmospheric temperature perturbation; however, large scale grounding zone retreat, in excess of $900 \mathrm{~km}$ inland, has occurred in the $10^{\circ} \mathrm{C}$ simulation, with the FRIS, TG and PIG subglacial basins connecting and allowing the through flow of ocean water. The SCIS show minimal grounding zone retreat in the $10^{\circ} \mathrm{C}$ simulation, with the retreat of the TG and PIG grounding zone reaching the upper sector of the KIS drainage basin.

Reductions in ice surface elevation are also observed with an atmospheric temperature perturbation of $10^{\circ} \mathrm{C}$. This is again evident in the Amundsen and Weddell Sea Sectors; however, a large reduction exceeding $500 \mathrm{~m}$ in ice surface elevation is also observed between the Ross and Amundsen Sea Sectors, reducing by $\sim 500 \mathrm{~m}$ over the 10,000 year period with increased temperature and precipitation. Increased precipitation leads to different behaviour of the WAIS, with increases of ice surface elevation by up to $1 \mathrm{~km}$, are observed for both the 5 and $10^{\circ} \mathrm{C}$ precipitation increases. This additional precipitation could reduce and offset some of the projected WAIS loss under increasing atmospheric temperatures (Joughin et al., 2014; DeConto \& Pollard, 2016; Medley et al., 2018); however, is likely only significant without an increase in oceanic temperatures. Some grounding zone advance is observed on the FRIS with both precipitation increases, as well as a relative stability of the RIS, TG and PIG grounding zones. Increased ice surface elevation is also observed in the KIS drainage basin. The changes in basal melt simulated in Figure 4.6 show the reduction of basal melt beneath the ice shelves with atmospheric temperature changes, and the increase of basal melt beneath the ice shelves with increases of precipitation. This increase of ice shelf basal melt likely reflects the thickening of ice shelves with increased precipitation, and the depth dependent melt rate scheme used in the model (Hellmer, Jacobs \& Jenkins, 1998; Holland \& Jenkins, 1999). This is analogous to the presence of colder, High Salinity Shelf Water (HSSW) beneath the larger ice shelves. This aids the refreezing of ice on the thinner ice shelf and the increased melting of the ice shelf when it is thicker and the base sits deeper in the thermocline, with warmer water available to melt the base of the ice shelf (Holland, Jenkins \& Holland, 2008; Webber et al., 2017). The increase of precipitation and atmospheric temperature perturbation by $10^{\circ} \mathrm{C}$ show significant increases of basal melt beneath the grounded ice sheet, which is largely concentrated between the FRIS, TG, and PIG, with some basal melt increases occurring in the trunk sector of the KIS drainage area. A perturbation of atmospheric temperatures by $10^{\circ} \mathrm{C}$ 
without increased precipitation shows large scale increases of basal melt beneath the newly formed ice shelf in the Amundsen Sea Sector. 

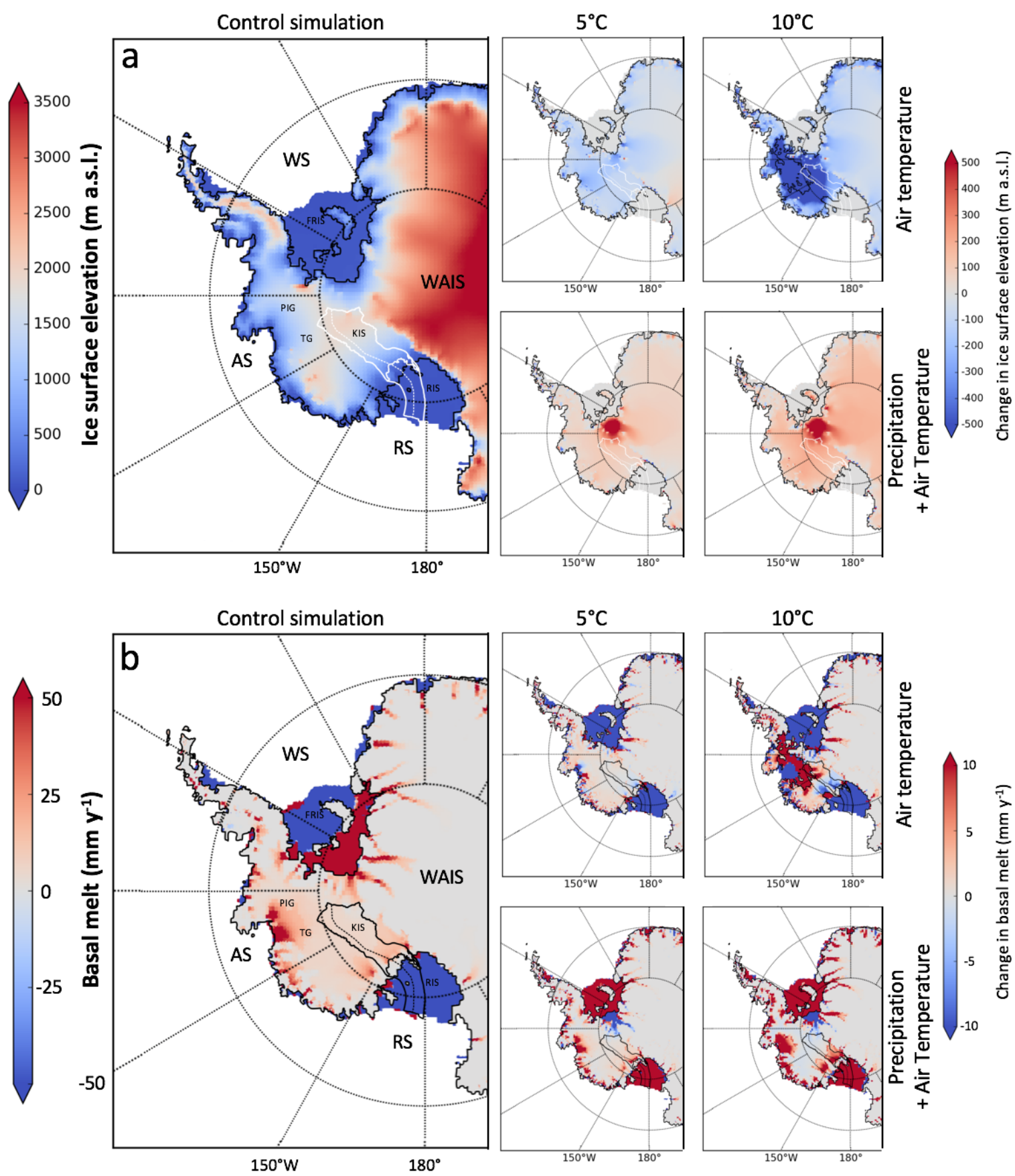

Fig. 4.6 Ice surface elevation (a) and basal melt (b) with atmospheric temperature and precipitation perturbations after a 10,000 year simulation. The control simulation with no changing atmospheric temperature perturbation or precipitation is shown on the left, while the changes in atmospheric temperature and corresponding precipitation are illustrated in the adjacent panels. The Ross Sea (RS), Amundsen Sea (AS), and Weddell Sea (WS) Sectors are annotated, as well as the Thwaites Glacier (TG), the Pine Island Glacier (PIG), Filchner-Ronne Ice Shelf (FRIS), Ross Ice Shelf (RIS), and the Kamb Ice Stream (KIS). The KIS drainage area is outlined in white (solid) and the KIS flowline modelled in Chapter 3 is shown by a white dashed line. 


\section{Surface and Basal Ice Velocities}

Surface and basal velocity changes under atmospheric temperatures and increasing precipitation are plotted in Figure 4.7. Compared to the control simulation, the response of the WAIS to increasing atmospheric temperatures is largely evident in velocity changes of the ice shelves. With increases of atmospheric temperature by $5^{\circ} \mathrm{C}$, the FRIS and RIS show large increases ice velocity in the order of $\sim 300-500 \mathrm{~m} \mathrm{y}^{-1}$, and with the perturbation of atmospheric temperature by $10^{\circ} \mathrm{C}$, large ice velocity increases are also observed on the PIG and TG. Increased precipitation shows a more spatially variable pattern of velocity increases and decreases, largely concentrated on the RIS and FRIS. The KIS is also observed to vary in both surface and basal ice velocities, where an increase is observed near the grounding zone with increases of precipitation, and a decrease is observed with atmospheric temperature increases. It is suggested that the increase in ice thickness is due to increased accumulation, which results in an ice thickness increase and increased ice flow. The reduction of ice thickness due to surface melt under warmer atmospheric temperatures results in lower ice velocities (Benn \& Evans, 2010; Winkelmann et al., 2012). 


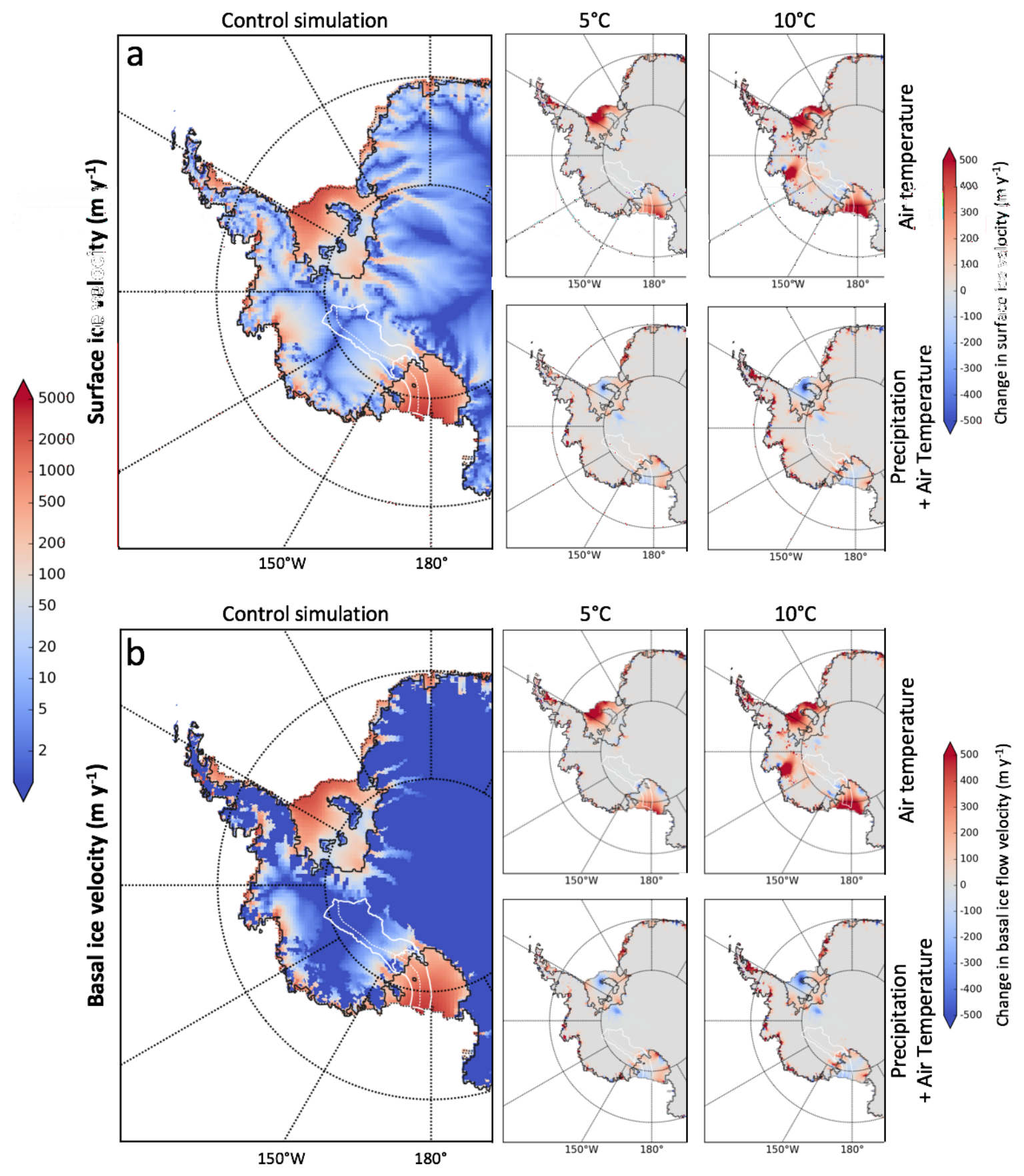

Fig. 4.7 Surface (top) and basal (bottom) ice velocities $\left(\mathrm{m} \mathrm{y}^{-1}\right)$ with changing atmospheric temperatures and precipitation after a 10,000 year simulation. The control simulation with no changing atmospheric temperature or precipitation is shown on the left, while the changes in atmospheric temperature and corresponding precipitation are illustrated in the adjacent panels. The Ross Sea (RS), Amundsen Sea (AS), and Weddell Sea (WS) Sectors are annotated, as well as the Thwaites Glacier (TG), the Pine Island Glacier (PIG), Filchner-Ronne Ice Shelf (FRIS), Ross Ice Shelf (RIS), and the Kamb Ice Stream (KIS). The KIS drainage area is outlined in white (solid) and the KIS flowline modelled in Chapter 3 is shown by a white dashed line. The modelled grounding zone and ice shelf extents are outlined in grey. 


\subsubsection{Geothermal Heat Flux Sensitivity}

This study explores the effect of increasing and decreasing the GHF beneath the WAIS, as a means to characterise the timescales at which changing GHF affects the subglacial hydrology and to partially assess the effects of GHF model choice. No high heat flux anomalies are observed within the Shapiro and Ritzwoller (2004) data on which this study's GHF simulations are based, in contrast to more recent GHF models (e.g. An et al., 2015; Martos et al., 2017). The high anomalies likely have a larger influence on the ice sheet at a local, rather than continental scale. Figure 4.8 shows the change in basal melt around the WAIS with GHF increases and decreases. Change in basal melt is observed for the 10,000 year simulations, whether decreasing or increasing the GHF by up to $50 \%$ which is captured within the variation we see in the different GHF models.
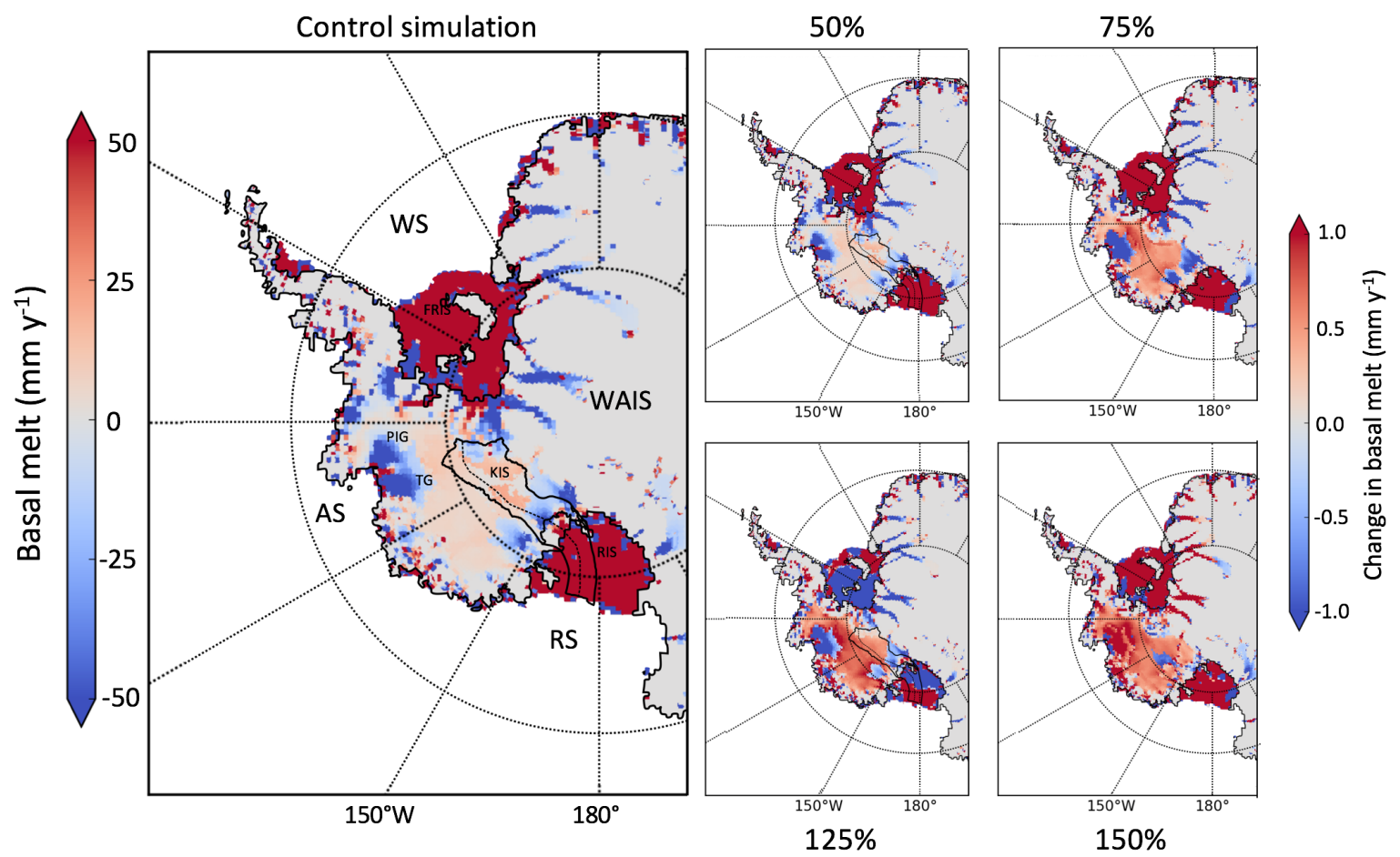

Fig. 4.8 Changes in basal melt with changing geothermal heat flux after a 10,000 year simulation. The control simulation with no changing geothermal heat flux is shown on the left, while the changes resulting from changes in geothermal heat flux are illustrated in the adjacent panels. The Ross Sea (RS), Amundsen Sea (AS), and Weddell Sea (WS) Sectors are annotated, as well as the Thwaites Glacier (TG), the Pine Island Glacier (PIG), Filchner-Ronne Ice Shelf (FRIS), Ross Ice Shelf (RIS), and the Kamb Ice Stream (KIS). The KIS drainage area is outlined in white (solid) and the KIS flowline modelled in Chapter 3 is shown by a white dashed line. 


\subsection{Discussion}

\subsubsection{Kamb Ice Stream Responses}

The KIS shows a relatively consistent stability in the whole continent simulations, throughout the changing hydrological, atmospheric temperature, and precipitation perturbations, with the exception of a $10^{\circ} \mathrm{C}$ atmospheric temperature change. In the $10^{\circ} \mathrm{C}$ atmospheric temperature perturbation simulations the entire WAIS is observed to have largely reduced in volume. Whole continent simulations provide a more complex replication of the present-day AIS, as opposed to the more isolated KIS flowline. However, the whole continent simulations are run at a coarser resolution $(30 \mathrm{~km})$ and smaller scale processes are likely not captured as well at this resolution as that of the KIS flowline $(10 \mathrm{~km})$. With the exception of the $10^{\circ} \mathrm{C}$ atmospheric temperature increase simulation, the KIS appears to be less sensitive to wider scale changes than it is to highly local changes as explored in Chapter 3. The grounding zone also does not display retreat and sensitivity to atmospheric temperature changes or changes in the subglacial hydrology. However, as previously discussed, the KIS system likely experienced grounding zone retreat as a result of its stagnation (Horgan \& Anandakrishnan, 2006). While this is outside of the scope of this study, it is suggested that in future simulations potential retreat of the grounding zone is modelled to confirm retreat rates discussed in Chapter 2.

\subsubsection{Subglacial Variation}

A key feature of the SCIS are the highly variable subglacial conditions among the ice streams (Kamb, 2001; Luthra et al., 2017; Atre \& Bentley, 1993; Bentley et al., 1998; Catania et al., 2003), which show intrinsically different responses to basal ice velocities and basal melt rates in the SCIS. Whole continent simulations also illustrate the subglacial variation beneath the entire WAIS, with large differences observed between the Ross, Weddell, and Amundsen Sea Sectors. High basal melt and basal ice velocity differences are observed beneath the ice streams within these sectors, both under changes in atmospheric temperature and precipitation. Increasing subglacial variation is observed with an atmospheric temperature increase of $10^{\circ} \mathrm{C}$ in the Amundsen and Weddell Sea Sectors, where basal ice velocities and basal melt rates between ice streams display higher variation than at lower temperature increases. This is a potential indicator of a more stable RIS, where limited grounding zone retreat is observed with increasing atmospheric temperature and precipitation anomalies and likely indicates 
that at pure atmospheric temperature increases up to $10^{\circ} \mathrm{C}$ the RIS does not cross a threshold that results in large scale changes. Changes in hydrological parameters, as seen in Figures 4.3 to 4.5, show the inter-ice stream subglacial variation, spatially and temporally, and a lack of temporal variation intra-ice stream.

\subsubsection{Adjacent Ice Streams}

It has been hypothesised that the WIS has contributed to "water piracy" from the KIS, where subglacial water from beneath the KIS has been redirected to the WIS and that this played a role in the stagnation of the KIS (e.g. Anandakrishnan \& Alley, 1997; Joughin, Tulaczyk \& Engelhardt, 2003; Carter, Fricker \& Siegfried, 2013). Currently still actively flowing, the WIS has been observed by GPS to have decelerated between 1973 to 1997, as well as between 2003 and 2004 (Joughin et al., 2005). It is also hypothesised that the WIS may become completely stagnant, similar to the KIS, if current widespread basal freezing estimates beneath much of WIS are correct (Joughin et al., 2004). Basal freezing in turn may dewater and strengthen the till beneath the WIS (Tulaczyk, Kamb \& Engelhardt, 2000), and result in stagnation if insufficient water is produced or distributed beneath the ice stream (Bougamont et al., 2003). By potentially contributing to the subglacial water of the WIS, changes in the KIS hydrology could affect ice flow of the WIS. However, in both sets of the whole continent simulations, limited change of the WIS is observed, specifically a lack of stagnation or further deceleration. It is possible that with increased temperatures and changing hydrological parameters, the KIS continues to provide sufficient subglacial water into the WIS to sustain its current ice flow and prevent further deceleration or stagnation, similar the "water piracy" hypothesis of (Anandakrishnan \& Alley, 1997). It is also likely that the WIS itself has an increased amount of subglacial water generation, which aids in the continuous ice flow over the 1000 and 10,000 year simulations.

\subsubsection{Wider Implications on the Ross Sea Sector}

\section{Atmospheric Temperature Increases}

This study shows a more limited response of the Ross Sea Sector to atmospheric temperature changes than the more extensive grounding zone and basal melt changes observed in other of oceanic-forced modelling studies. Martin and others (2019) present a useful comparison study, where high levels of oceanic melting are applied to different sectors of the AIS, and simulations are run over 1000 year periods. When applied 
to the Amundsen, Weddell, East Ross and West Ross Sea Sectors, the higher melt levels produce extensive grounding zone retreat toward the interior of the ice sheet, as shown in Figure 4.9. In this study's $10^{\circ} \mathrm{C}$ atmospheric temperature perturbation simulations, similar levels of grounding zone retreat are observed in the Weddell and Amundsen Sea Sectors (Figure 4.9). A comparable amount of grounding zone retreat is not observed in the Ross Sea Sector, which shows a lesser sensitivity to increased atmospheric temperatures in the absence of increased oceanic temperatures, with more stable grounding zone positions. Other useful comparison studies, such as Golledge and others (2015) and Golledge and others (2017), increase both the oceanic and atmospheric temperatures according to the four RCPs from the Fifth Assessment Report of the Intergovernmental Panel on Climate Change, to assess the impact on the AIS over both centennial and millennial time scales. The inclusion of oceanic warming shows a similar response in grounding zone retreat in the Weddell and Amundsen Sea Sectors as both this study and Martin and others (2019), as well as extended retreat of the grounding zone in the Ross Sea Sector. Other studies with coupled increases of both atmospheric and oceanic temperatures (e.g. DeConto \& Pollard, 2016; Winkelmann et al., 2015), show similar grounding zone retreat patterns in the Amundsen and Weddell Sea Sectors as observed in this study with an atmospheric temperature increase of $10^{\circ} \mathrm{C}$. This study concludes that over millennial time scales, both the Amundsen and Weddell Sea Sectors exhibit a significant vulnerability to atmospheric temperature increases without additional oceanic temperature increases. However, the Ross Sea Sector has shown a limited sensitivity to increases of atmospheric temperature without coupled oceanic temperature increases. While the increases in atmospheric and oceanic temperatures are intrinsically linked, oceanic temperature increases occur at slower timescales (millennial) than atmospheric timescales (decadal to centennial). This suggests that the effects of climatic changes on heating the atmosphere will not be observed in the Ross Sea Sector until the oceans have increased in temperature significantly. 

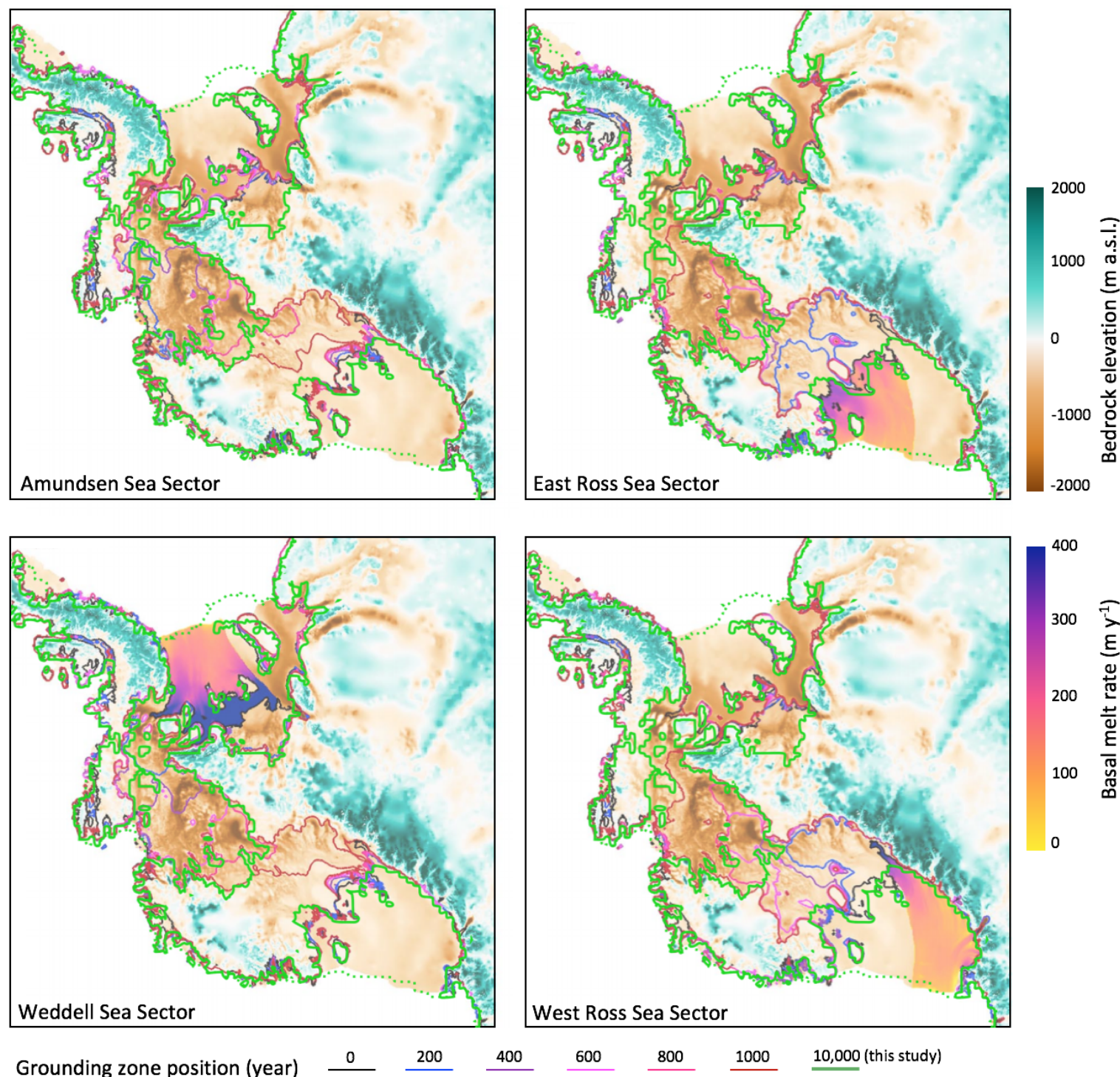

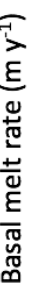

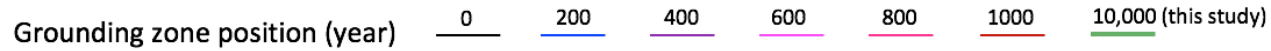

Fig. 4.9 Grounding zone evolution illustrated with contours every 200 years for for the Amundsen, Weddell, East Ross, and West Ross Sea Sectors (Martin et al., 2019), with the addition of the grounding zone position of this study's $10^{\circ} \mathrm{C}$ atmospheric temperature increase after a 10,000 year simulation (grey). The colour map shows initial melt distribution for each sector. Modified from Martin and others (2019).

\section{Precipitation Increases}

The ability of warmer air to hold higher levels of moisture and increase precipitation, is expected to contribute positively to the surface mass balance of the AIS in future projections (Church et al., 2013). Due to a strong dominance of natural variation, observations have been unable to appropriately constrain the relationship between temperature and accumulation changes (Bromwich, Nicolas, \& Monaghan, 2011; Lenaerts 
et al., 2012). However, models consistently predict increasing accumulation on the AIS with increasing temperatures (Monaghan, Bromwich \& Schneider, 2008; Krinner et al., 2008; Ligtenberg et al., 2013). This study is in agreement with other model studies, where increased precipitation with either an atmospheric temperature increase of 5 or $10^{\circ} \mathrm{C}$ leads to increased accumulation and ice surface elevation. However, the increase of precipitation and accumulation is spatially variable, with the largest increases observed on the FRIS. The Antarctic Peninsula and TAM show a more limited pattern of accumulation. This spatial variation is likely a result of regional patterns of surface topography, with lower precipitation rates over the higher elevation inner plateau and large increases in precipitation at the lower elevation coastal regions (Lenaerts et al., 2012; Van de Berg et al., 2006; Palerme et al., 2014). In this study, the increase of precipitation also has the effect of increasing ice velocities near ice shelf grounding zones, inferred to be a result of ice thickening (Marshall et al., 2011; Jiskoot, 2011).

\subsubsection{Geothermal Heat Flux}

This study explores a range of GHF values that deviate from the Shapiro and Ritzwoller (2004) model, to capture the wide range of measured and inferred GHF. Both increases and decreases of the GHF by 25 and $50 \%$ are modelled in this study, and these show a significant effect of GHF on changing the subglacial melt in the simulations. Ice sheet sensitivity experiments conducted by Pollard and others (2005) vary the GHF beneath the Cenozoic extent of the AIS. They vary the GHF either by a uniform 37.7 or 75.4 $\mathrm{mW} \mathrm{m}^{-2}$ over the entire Antarctic continent, or a spatially variable distribution ranging between $41 \mathrm{~mW} \mathrm{~m}^{-2}$ in East Antarctica to $70 \mathrm{~mW} \mathrm{~m}^{-2}$ in West Antarctica, similarly to the Siple Dome measurement. Conclusions from the Pollard and others (2005) study indicate similar results to this study's simulations, where reasonable changes of the GHF have limited effect on overall ice volume, extent, and flow velocities; however, larger changes in the overall location and volume of basal melt are observed in the sensitivity experiments, which is also observed in other model studies (e.g. Pattyn, 2010), as well as this study. These low levels of basal melt, less than $10 \mathrm{~mm} \mathrm{y}^{-1}$, are also captured with this study's changes of GHF. As a result, this study concludes that changing the magnitude of GHF available beneath the ice sheet, has a significant impact on the subglacial environment beneath the Kamb Ice Stream at millennial and continent scales using the parameters of this study and that our model choice of the GHF is an important parameter choice. 

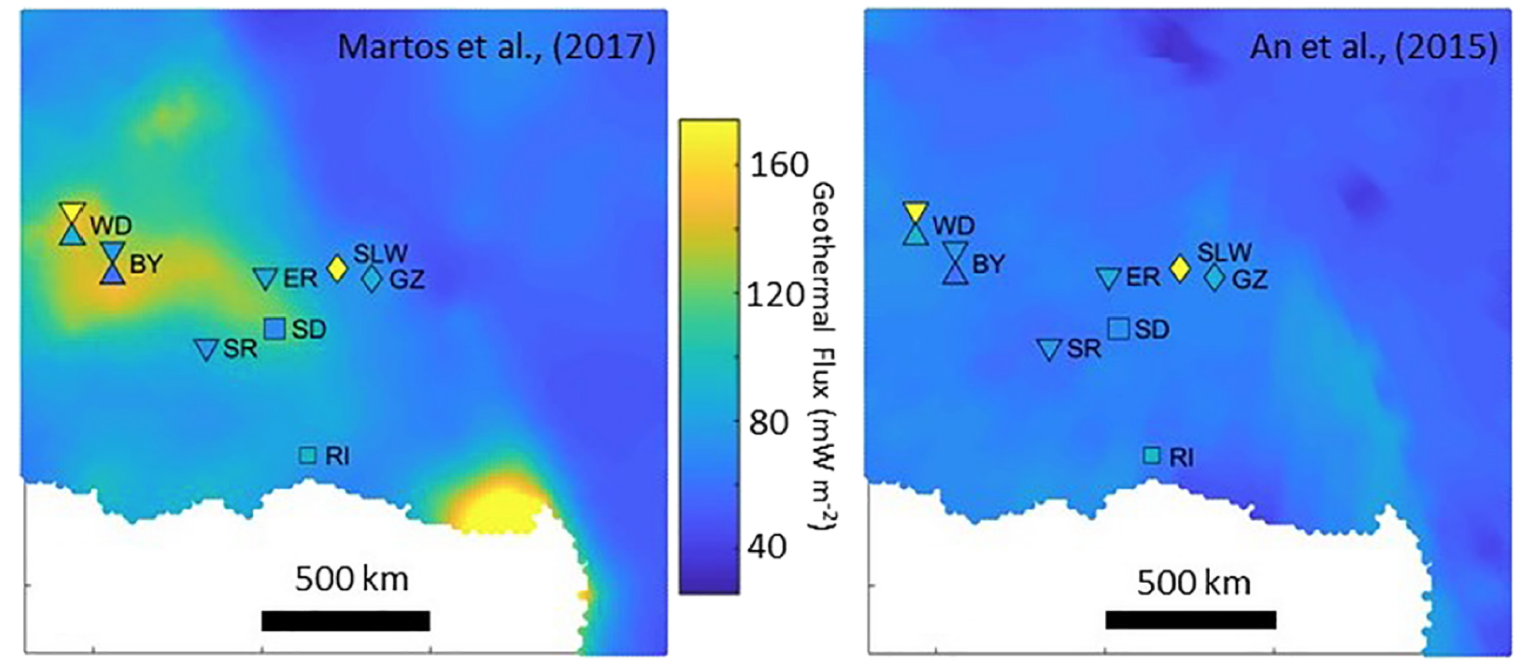

Fig. 4.10 The Ross Sea Sector of the West Antarctic Ice Sheet (WAIS), showing remotely sensed estimates of geothermal heat flux with direct measurements. Maximum and minimum estimates (triangles), values from ice-core sites with measured basal temperatures below freezing (square), and measurements in subglacial sediments (diamonds; Begeman et al., 2017; Fisher et al., 2015). SD = Siple Dome; ER= Engelhardt Ridge; SR = Shabtaie Ridge; RI = Roosevelt Island; WD = West Antarctic Ice Sheet divide ice core; BY =Byrd ice core; SLW = subglacial Lake Whillans; GZ = grounding zone. From Fudge and others (2019).

\subsubsection{Model Limitations and Assumptions}

\section{Resolution.}

Due to the computational constraints for this study, the whole continent simulations are at a horizontal resolution of $30 \mathrm{~km}$, as opposed to higher resolutions. This resolution is unable to capture all detail within the simulations, and it would be desirable for future work to consider replicating some of the simulations at higher resolutions and comparing the simulations to the lower $30 \mathrm{~km}$ resolution simulations.

\section{Model response versus glaciological response.}

As was the case in Chapter 3, characterising the glaciological and geological response versus the response inherent to the model due to parameter choice, has limitations. PISM is a comprehensive SIA and SSA hybrid model, which aims to capture the complex understanding of glaciological, geological and climatological processes (Bueler \& Brown, 2009), and the results in this Chapter are presented in this robust framework. Through using the same parameters from the KIS flowline simulations, as well as the 25 ensemble simulations, in combination with a robust ice sheet model, some certainty is provided that the modelled results presented are indeed glaciological responses, as 
opposed to model parameter choice.

\section{Model complexity}

Another limitation of this study is the complexity of the processes that it aims to characterise and simulate. By increasing both the spatial and temporal scale in the whole continent simulations, the scale of process complexity is also increased. The scope of this study does not allow for the capturing of all smaller scale glaciological, geological and climatological processes, and instead focuses on replicating the present-day, larger scale processes and observations, for example the surface ice velocity. 


\section{Synthesis}

This study uses numerical ice sheet modelling and active source seismic data to characterise the subglacial conditions of the Kamb Ice Stream and its response to environmental change at different temporal and spatial scales. The work contained in this study encompasses detailed analyses of two active source seismic surveys conducted on the Kamb Ice Stream, which specifically focus on the present-day, transient subglacial conditions, as well as two separate ice sheet model studies that investigate responses to perturbations over millennial scales. The results presented have given insight to the sensitivity of the KIS to specific subglacial hydrology controls, as well as the large impacts of oceanic and atmospheric temperature perturbations. This Chapter aims to initially address the use of two types of methods to characterise the KIS, then the combined results from both methods, and lastly any limitations to the methods used and results presented.

\subsection{Combined Use of Seismic and Model Data}

A key aspect of this study is the combined use of active source seismic surveys and numerical ice sheet modelling. This approach allows a comprehensive study of the present-day KIS, at different temporal and spatial scales. The seismic data analysed in this study contains detailed acoustically imaged information about the till that is previously inferred to have been beneath the pre-stagnated KIS, approximately 160 years ago. The numerical ice sheet modelling has provided an in depth analysis of the KIS and wider WAIS in response to subglacial hydrology changes, and temperature perturbations. The variable subglacial environment is captured at both scales of modelling, as well as in the seismic data.

The range of temporal and spatial scales that are analysed and modelled in this study allows for investigations of centennial- to millennial-scale behaviour, as well a more instantaneous, present-day state that is captured by the seismic data. Due to 
large gaps in observational data and high spatial variation, many estimates of Antarctic processes, such as surface mass balance, have inherently large errors associated with them (Richardson et al., 1997; Genthon \& Krinner, 2001; Frezzotti et al., 2004; Frezzotti et al., 2005). This spatial variation is evident at both large and small scales, for example in the captured variation of acoustic impedance of the seismic lines, and the glacial behaviour of the KIS at the flowline scale at different locations along the ice stream. However, at the whole continent scale, this variation is still evident but at larger scales than resolved in the seismic and flowline studies.

While numerical ice sheet models can provide a continuous and spatially diverse picture of an ice sheet, there are some inherent scale-based limitations (Åkesson et al., 2018). For example, grounding zone dynamics are one of the most important physical processes at the ice sheet/stream and ice shelf interface (Schoof, 2007), which require higher spatial resolution for more accurate representation in ice sheet models (Vieli \& Payne, 2005; Seroussi et al., 2014; Gagliardini et al., 2016). Flowline models can resolve grounding zone motion at higher resolutions than is computationally efficient for whole continent studies, particularly over longer timescales (Åkesson et al., 2018), and are largely used in ice stream and outlet glacier studies (Jamieson et al., 2012; Nick et al., 2013; Vieli \& Nick, 2011).

While flowline models provide useful characterisation of physical processes, complex geometries and the interactions between neighbouring drainage basins, such as the WIS and KIS drainage basins, are not suitably modelled purely using flowline simulations (Åkesson et al., 2018). This scaling of investigation also provides a better characterisation of the extent to which either site specific processes or external perturbations dominate the ice stream behaviour (Åkesson et al., 2018). For example, in this study we see a larger hydrological control on the KIS behaviour at the flowline scale in comparison to the whole continent scale, where changing subglacial hydrological parameters result in limited change to the KIS drainage basin and wider Ross Sea Sector. This study has captured the grounding zone dynamics and other physical processes at a diverse range of scales, from tens of metres in the seismic data, to 10 and $30 \mathrm{~km}$ resolutions in the flowline, and whole continent simulations, respectively, which has allowed for multiple levels of process investigations. 


\subsection{Subglacial Conditions}

\subsubsection{Kamb Ice Stream Subglacial Conditions}

This topic is investigated using active source seismology surveys, which provide remote observations of the subglacial environment. Analysis of the seismic data allows an insight to the subglacial environment, specifically the sedimentary, deformational and hydrological aspects. Analyses from other ice streams are also compared, to better understand what similarities and differences are observed and inferred between the different ice streams.

\section{Effective Pressure}

The modelled effective pressure values along the KIS flowline depict variable subglacial conditions across the wider KIS drainage area, particularly in comparison with other ice streams (Kamb, 2001; Luthra et al., 2016; Luthra et al., 2017). While estimates of effective pressure are a useful parameter by which modelled data can be related to seismic survey data (Luthra et al., 2016), due to the more limited subglacial information available beneath the grounded section of KIS1516-1, an effective pressure is not able to be calculated at this location. Luthra and others (2016) calculate the effective pressure of the WIS sticky spot from seismic data using the rock-physics procedure described by Dvorkin and others (1999). However, their sediment material properties are better constrained than available from the KIS1516-1 used in this study.

Currently, bore hole data from the KIS provide the most comprehensive effective pressure measurements on the KIS (Kamb, 2001). The thirteen bore hole measurements contribute evidence of subglacial effective pressure variation, and range between -1.0 to $1.1 \times 10^{5} \mathrm{~Pa}$, calculated as a result of the ice overburden pressure $(P=\rho g h)$ minus the pore water pressure. Figure 5.1 presents the effective pressures along the KIS flowline, as well as the values presented in Kamb (2001). The effective pressure values plotted on Figure 3.7 show that despite varying the maximum effective amount of water stored in the till, effective pressures are all near identical at the end of the 1000 year simulation. Location $f$ from this study is the closest in proximity to the bore hole data and the KIS sticky spot falls within the measured data range (Luthra et al., 2016). This provides some confidence that the modelled data capture the main subglacial processes of the KIS. 
Low effective pressure in a basal water system is typically associated with fast ice stream flow and is observed on both the WIS and BIS (Blankenship et al., 1987; Blankenship et al., 1986; Kamb, 2001). Observational data from the base of mountain glaciers, as well as theoretical work, suggests that increased basal water pressure reduces the effective pressure at the bed of the glacier by reducing the ice bed contact area (Bindschadler, 1983; Boulton \& Hindmarsh, 1987). With the presence of sediments, low rates of effective pressure can also increase subglacial sediment deformation and increase basal flow rates (Engelhardt et al., 1978; Hodge, 1979; Iken \& Bindschadler, 1986; Fowler, 1987; Iverson et al., 1999; Bingham et al., 2008). An understanding of effective pressure at the base of the KIS is important to potentially identify areas of fast ice flow in the future.

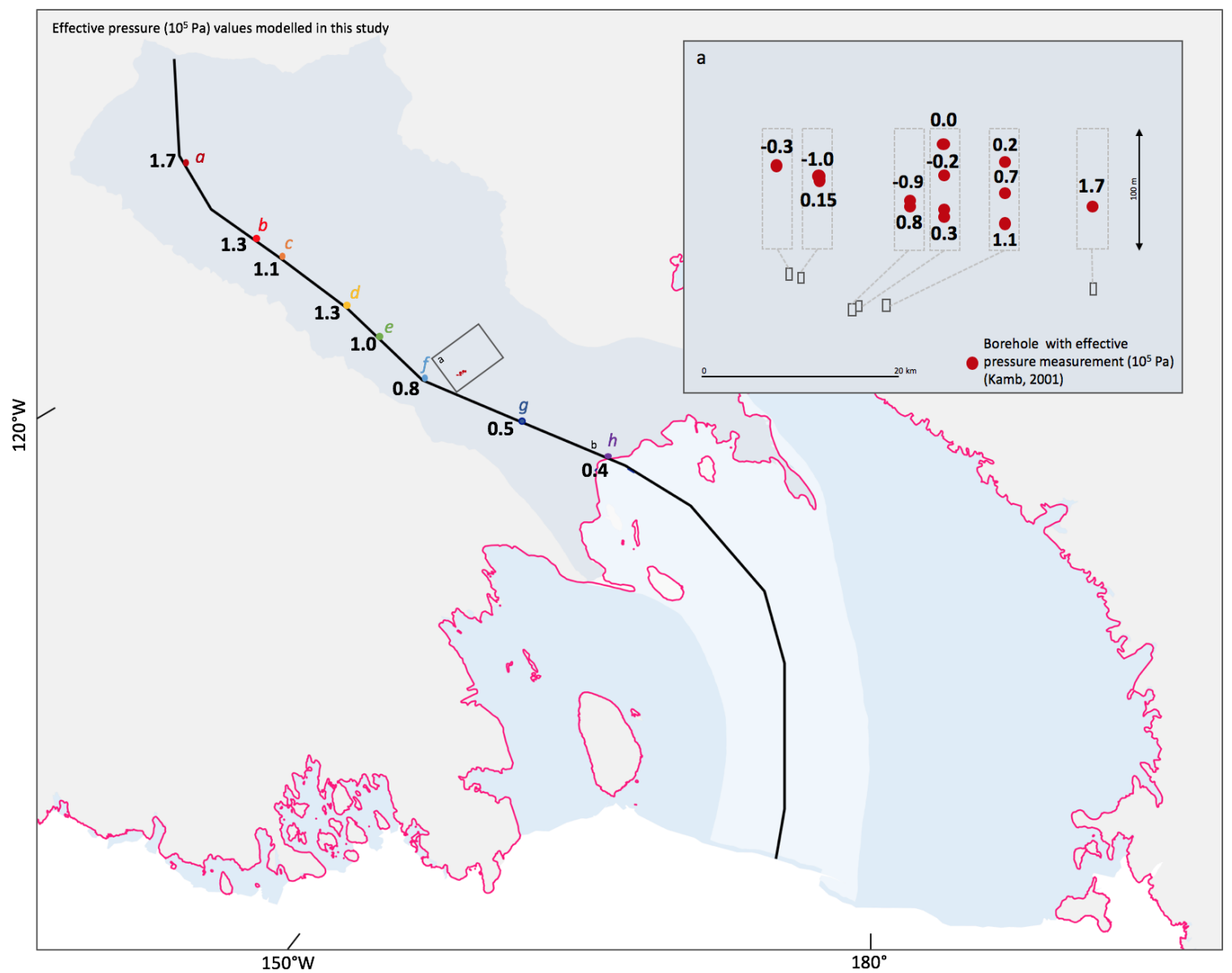

Fig. 5.1 Modelled effective pressure $\left(10^{5} \mathrm{~Pa}\right)$ estimates along the KIS flowline, as well as from the KIS1516-1 seismic line and bore hole data (Kamb, 2001). The current inferred grounding zone position (pink) is inferred from the MEaSUREs ice velocity data (Rignot et al., 2011). 


\subsubsection{Kamb Ice Stream Responses and Thresholds}

\section{Hydrology}

This study shows a minimal impact of changing amounts of maximum effective water stored in the till on the reactivation of the KIS in flowline simulations, or the reorganisation of SCIS flow in the whole continent simulations. While the hydrological simulations of 0.1 and $1.0 \mathrm{~m}$ maximum effective water stored in the till show initial perturbations to the KIS ice velocity, basal stresses, effective pressure, and basal friction, over the 1000 year simulations no permanent thresholds of the system are crossed. All five simulations show a return to pre-perturbation conditions, with no observable permanent change. At the whole continent scale, minimal change is observed that can be attributed to changes of maximum effective water stored in the till in this study. It is suggested that the changing amounts of maximum effective water stored in the till simulated in this study, are not sufficient enough to perturb the system permanently, counter to results found in studies such as Bougamont and others (2015), Kyrke-Smith, Katz and Fowler (2015) and Goeller and others (2015). At longer timescale simulations, Van Pelt and Oerlemans (2012) have shown the sensitivity of ice flow to changes in the basal sliding and hydromechanical conditions, where oscillatory behaviour is found to occur. It is suggested that similar behaviour could be present in this study's simulated KIS and SCIS under longer run time conditions, and that the modelled self regulation of the KIS is timescale dependent.

In contrast, combined with the existence of subglacial till, subglacial hydrology is shown elsewhere to be a key controlling factor on the regulation of ice streams (e.g. Schoof, 2004; Joughin \& Alley, 2011; Beem et al., 2014; Kyrke-Smith, Katz \& Fowler, 2015). Using coupled basal hydromechanical processes and ice flow, Bougamont and others (2015) show variable ice stream reactivation and stagnation of the SCIS due to water "piracy" beneath neighbouring ice streams with water influxes beneath the modelled Siple Coast domain. They highlight that the weak basal resistance of the KIS tributaries are a key influence on regional instability and the reactivation of the KIS (Kamb, 2001; Catania et al., 2003).

\section{Temperature Perturbations}

The effects of atmospheric and oceanic temperature perturbations on the AIS and potential sea level rise are extensively studied (e.g. Golledge et al., 2015; DeConto \& Pollard, 2016; Golledge et al., 2017; Martin et al., 2019; Golledge et al. 2019). 
This study shows that with larger magnitude atmospheric and oceanic temperature perturbations, and increased precipitation, the present-day conditions of the KIS and RIS are susceptible to climatic change. The subglacial mechanical processes, such as basal friction, beneath the KIS in the flowline simulations show an increased susceptibility to increases of oceanic temperature anomalies. A distinct threshold for change is observed in the KIS at an oceanic temperature increase of $0.25^{\circ} \mathrm{C}$. Minimal change is observed on the KIS flowline with increased atmospheric temperature perturbations, and no thresholds of permanent change are modelled in this study. In whole continent simulations, the WAIS shows a susceptibility to atmospheric temperature increases in the Weddell and Amundsen Sea Sectors, where atmospheric temperature anomalies of $10^{\circ} \mathrm{C}$ cross a threshold and cause extensive grounding zone retreat. While the effects of increased oceanic temperatures at the whole continent scale were not simulated in this study, it is suggested that this will have a significant impact on the ice sheets and shelves, and that a similar response will be observed as that of the flowline simulations.

\subsection{Model Limitations}

While this study uses an ensemble approach in the attempt to accurately model both the present-day KIS and the WAIS, the intrinsic limitations of a lack of observational data does increase the chance of error and inaccuracies in the modelled results. Misfits between observed surface ice velocities, ice surface elevation, and ice thickness are presented in both Figures 3.3 and 4.1, and these show that our model has not correctly captured the entire KIS and WAIS and that certain glaciological processes are missing.

A study presented by Bernales and others (2017) also shows the differences between different hybrid model schemes, where simulations with the same input data are run over a 400,000 year period. Figure 5.2 shows an example of the modelled differences between the four different hybrid schemes (Bernales et al., 2017). In the context of this study, the results presented in Bernales and others (2017) show that while the four different hybrid schemes produce comparable fits to observational ice surface elevations and surface ice velocities, inferred values of basal sliding coefficients show large discrepancies between the schemes. While this study has demonstrated through the use of extensive ensemble simulations and the fit of modelled results to observed data, that it replicates the present-day KIS conditions, the intrinsic variation that exists between numerical ice sheet models needs to be taken into account. 
Hybrid ice sheet models enable the simulation of ice sheets on continental scales over hundreds of thousands of years, and perform well in intercomparison tests when compared to full stokes type ice sheet models (Pattyn et al., 2013; Feldmann et al., 2014). The combination of the SIA and SSA in a hybrid model is heuristically based, and different models have a different approach to this combination, which range from a summation over the entire model domain to weighted averages of both velocity solutions (Bernales et al., 2017). Despite the differences between the hybrid models, common limitations to the modelling of the present-day AIS exist. Errors in the modelled data can be introduced due to a shortage of observational data to constrain model parameters and boundary conditions, such as geothermal heat flux, glacial isostatic adjustments, the introduction of flow enhancement factors, and water saturated sediment distribution (Bernales et al., 2017). In particular, the distribution of water saturated sediments and its ability to initiate or increase basal sliding, is still thought to be a large source of misfit between modelled and observed AIS elevations (de Boer et al., 2015). While recent inverse method studies endeavour to quantify these misfits, especially in ice velocities, discrepancies between the modelled and observational data still exist (Joughin et al., 2009; Arthern \& Gudmundsson, 2010; Arthern, Hindmarsh \& Williams, 2015). 

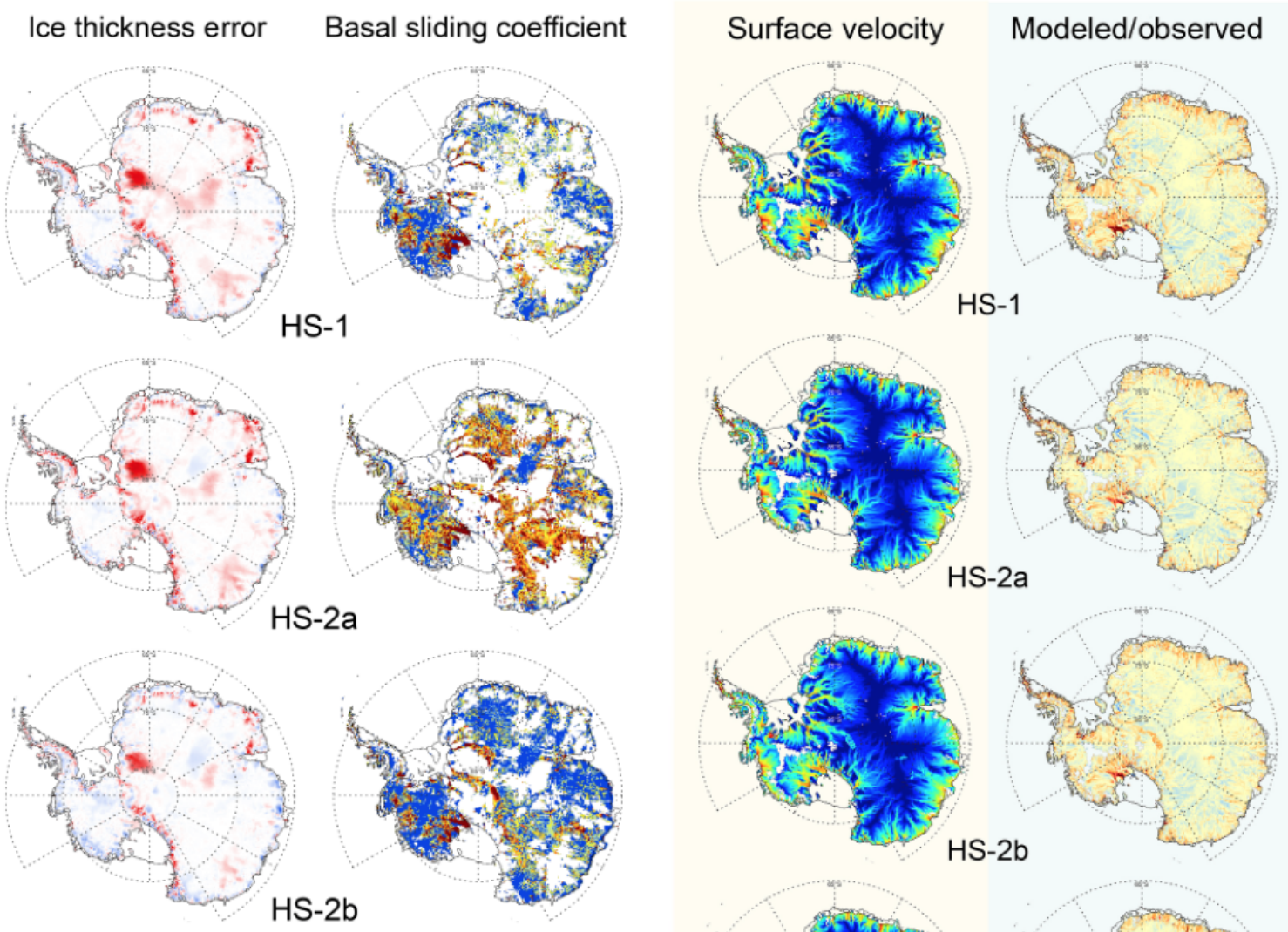

$\mathrm{HS}-2 \mathrm{~b}$

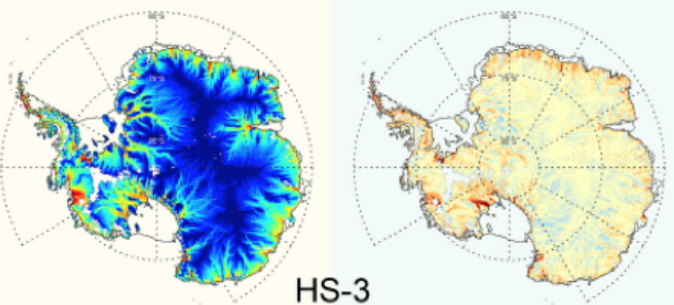

HS-3

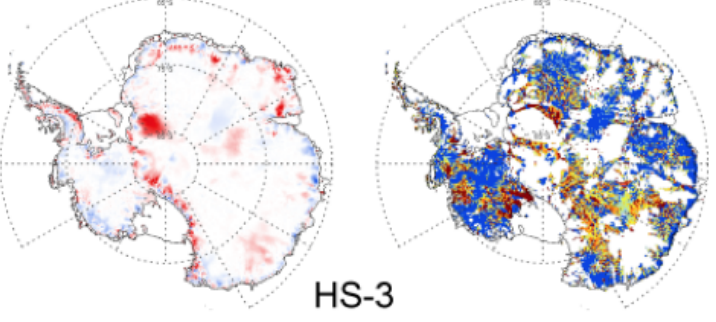

HS-3
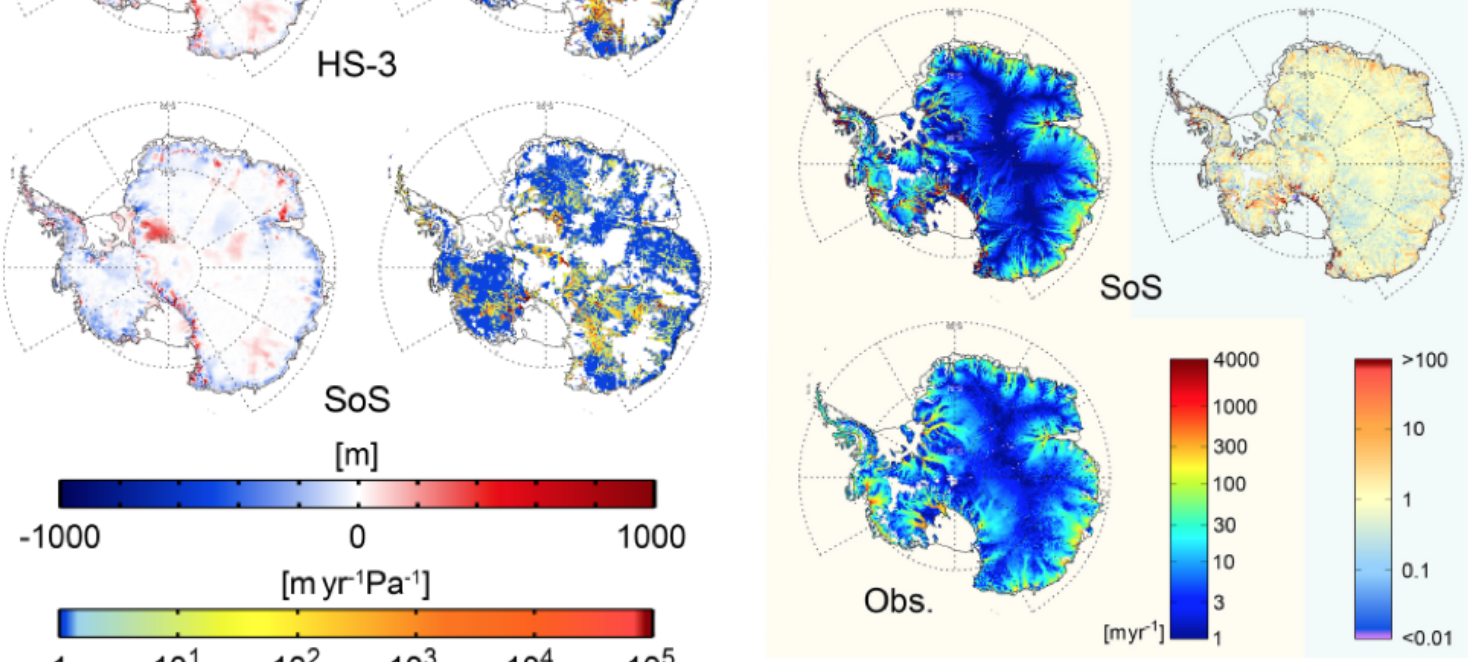

Fig. 5.2 Ice sheet state comparison derived from different hybrid model schemes at the end of the equilibrium simulations. From left to right, the differences between the modelled and observed ice thickness, distributions of basal sliding coefficients, surface velocities across the grounded ice, and ratios of the modelled to observed surface velocities are plotted for the four different hybrid schemes presented in Bernales and others (2017). 


\section{Conclusions}

\subsection{Chapter Summaries}

\section{Kamb Ice Stream Seismic Surveys:}

1. Calculated acoustic impedance values between 2.9 and $3.7 \times 10^{6} \mathrm{~kg} \mathrm{~m}^{-2} \mathrm{~s}^{-1}$ of the offshore sections of the KIS1516-1, and the KIS1819-1 and KIS1819-2 lines indicate a likely saturated till or sandy sediment environment.

2. Estimates of acoustic impedance between 3.3 and $3.8 \times 10^{6} \mathrm{~kg} \mathrm{~m}^{-2} \mathrm{~s}^{-1}$ beneath the grounded section of the Kamb Ice Stream likely indicate a dewatered till, which is supported by retreat rates of the Kamb Ice Stream grounding zone post-stagnation.

3. No thin water bodies are evident beneath the grounded section of line KIS1516-1, providing limited hydrological information.

4. The acoustic basement imaged beneath all three lines likely corresponds to a Ross Sea Unconformity.

\section{Kamb Ice Stream Flowline Model:}

1. Adjustments of the maximum amount of effective water stored in the subglacial till below $2.0 \mathrm{~m}$ initially have large impacts on the Kamb Ice Stream flow regime in the simulations, after which the system self-regulates to a steady-state.

2. Changing subglacial water decay rates has limited impacts on the flow regime and subglacial conditions of the Kamb Ice Stream in the simulations.

3. Increases of oceanic temperature perturbations above $0.25^{\circ} \mathrm{C}$ have large-scale impacts on the Kamb Ice Stream and its subglacial conditions in comparison to atmospheric temperature perturbations, potentially triggering a reactivation of 
the Kamb Ice Stream. Ice shelf extent is also reduced, as well as rapid grounding zone retreat to topographic pinning points with increasing oceanic temperatures perturbations.

4. Pure atmospheric temperature anomaly increases, without increases of oceanic temperature anomalies, have limited effect on the extent and flow regime of the Kamb Ice Stream, nor the subglacial conditions.

\section{West Antarctic Ice Sheet:}

1. Continental scale simulations show a decreased sensitivity to changing hydrological parameters, where very limited changes in the flow regimes of the West Antarctic Ice Sheet are observed.

2. Large sections of the West Antarctic Ice Sheet are lost with atmospheric temperature increases of $10^{\circ} \mathrm{C}$, particularly near the Filchner-Ronne Ice Shelf, and the Thwaites and Pine Island Glaciers. The Ross Ice Shelf and Siple Coast Ice Streams show limited change.

3. Precipitation increases due to atmospheric temperature perturbations offset mass ice loss that is observed with purely atmospheric temperature increase, with up to $1 \mathrm{~km}$ of increased ice thickness in the Weddell Sea Sector.

4. Geothermal heat flux increases and decreases significantly impact the basal melt production beneath the West Antarctic Ice Sheet, particularly beneath grounded sectors not associated with ice streams and outlet glaciers.

\subsection{Key Conclusions}

\section{Hydrological simulations of the Siple Coast and Kamb Ice Stream ap- pear to be self regulating, with high reversibility.}

As shown in the hydrological simulations at both the flowline and whole continent scales, the hydrological perturbations appear to have limited impact on the long term state of the KIS and SCIS, and these appear to be self regulating. Decreases of the maximum amount of effective water stored in the till initially show perturbations to the KIS ice velocity, basal stresses, effective pressure and basal friction, over a 1000 year period. The KIS shows a reversibility, where the initial perturbations on the ice stream hydrology return the KIS to a steady-state that is similar to the start state of the KIS. These perturbations of the KIS occur at different temporal scales depending 
on the maximum amount of effective water stored in the till. In the whole continent simulations, minimal changes to the KIS and WAIS are observed, and it is therefore suggested that the hydrological perturbations do not permanently cross a threshold that results in irreversible change under the parameters of this study. This differs from what previous studies have found, at it is suggested that while the results of this study are presented within its parameters, the model may not capture all glaciological processes.

2. Ocean forcing is the key driver of change of the Kamb Ice Stream, and is susceptible to topographic pinning points and lateral drag.

While atmospheric temperature perturbations up to $8^{\circ} \mathrm{C}$ show minimal effects on the KIS subglacial conditions or flow regime, a smaller temperature perturbation of $0.25^{\circ} \mathrm{C}$ to oceanic temperatures initiates large scale changes of the KIS. Ice shelf loss is initially observed, and with additional oceanic temperature perturbations large scale retreat of the grounding zone is also observed. The main constraints on the grounding zone retreat are shown to be topographical pinning points, where two main pinning points are identified beneath the ice stream in close proximity to each other. Oceanic temperature perturbations up to $1.5^{\circ} \mathrm{C}$ remain stable at the first pinning point, while perturbations up to $2.0^{\circ} \mathrm{C}$ remain stable at the second pinning point. Lastly, the KIS is also shown to be susceptible to lateral drag of the ice shelf. In the flowline simulations no lateral drag has been applied to the simulations, and rapid grounding zone retreat and ice shelf losses are observed. However, in the whole continent simulations where a more realistic "real-world" ice shelf with full stresses is used, it is possible that the lateral drag of the RIS potentially prevents the large scale retreat of the grounding zone and large ice shelf losses. This study largely suggests lateral drag as the main factor due to its high impact in ice shelf systems.

\section{Continent-wide precipitation increases offset the effect of atmospheric temperature perturbations and influence subglacial conditions.}

In this study, the increases of continent-wide precipitation largely offset the effects of pure atmospheric temperature perturbations, by up to $1 \mathrm{~km}$ of ice thickness in the Weddell Sea Sector. The simulations with pure atmospheric temperature perturbations demonstrate large scale losses of ice thickness of the WAIS, as well as grounding zone retreat and increases in ice velocity in the Amundsen and Weddell Sea Sectors. However, the simulations with the inclusion of precipitation show more dynamic ice stream behaviour on the Siple Coast. Even though the increases in ice thickness have 
partially offset the mass loss observed with pure atmospheric temperature perturbations, increases of ice velocity, as well as increased basal melt beneath the SCIS are observed.

\subsection{Further Research}

\subsubsection{Ice Stream Velocity Changes}

The present-day KIS is not fully dormant, and some of the upper sections still reach ice velocities of between 60 to $120 \mathrm{~m} \mathrm{y}^{-1}$ (Engelhardt \& Kamb, 2013). At the convergence between slower ice and this section of faster flowing ice, a thickening ice bulge is formed, with thickening rates of approximately $0.55 \mathrm{~m} \mathrm{y}^{-1}$ (Price et al., 2001; Joughin \& Tulaczyk, 2002b). Often the movement of ice bulges can form glacier surging, which may separate the actively flowing section of the ice stream from the stagnant section (Engelhardt \& Kamb, 2013). The KIS shows typical characteristic of glacier surging, larger accumulation areas, water storage, basal sliding, and a restricted water drainage in the lower sections of the glacier (Engelhardt \& Kamb, 2013). Understanding the variation of the ice velocities, and the ramifications increasing velocities have further downstream, the first set of further research that is recommended by this study is the exploration between the increase of uniform ice velocities, grounding zone position, and ice thickness. As discussed in Section 2.4, the KIS grounding zone is inferred to have been located approximately $24 \mathrm{~km}$ downstream prior to its stagnation. This study recommends a set of simulations which explore changes in boundary climatic conditions, where the ice dynamics are allowed to evolve, but the ice geometry is kept constant. The potential resultant grounding zone movement and associated subglacial processes can provide insight into the till conditions beneath seismic lines KIS1819-1, KIS1819-2, and KIS1516-1 prior to grounding zone retreat. Secondly, increasing the ice velocity at variable rates across the ice stream can assess the impact of select basal sliding on the ice stream control, ice accumulation and grounding zone movement. A flowline model, ensemble approach is recommended, where a similar split of the KIS as used in this thesis is recommended (upper, trunk and transition zones) and incrementally increasing the ice velocities in these sectors by $100 \mathrm{~m} \mathrm{y}^{-1}$ increments to maximum ice velocities of $800 \mathrm{~m} \mathrm{y}^{-1}$, which would allow for comparisons to the uniform velocity increase simulations. 


\subsubsection{Effects of Model Resolution}

The chosen model resolution has a large effect on the modelled results, as observed in Figure 6.1 (Bueler \& Brown, 2009). It is suggested that the impact of model resolution on this study's results be investigated, both by scaling up the resolution and scaling it down. Currently the KIS flowline is modelled at a resolution of $10 \mathrm{~km}$, and the whole continent at $30 \mathrm{~km}$. While both these resolutions are used due to their computational efficiency for the scale of simulation, they may not accurately capture the detailed physical processes that effect the subglacial environment, particularly near the grounding zone where different behaviour could be observed. An intercomparison of multiple model resolutions is recommended to asses the validity of our results at different scales. For the KIS flowline it is recommended that the final selected model used (KIS-3) is run at the spin-up stage at 20,5, and $1 \mathrm{~km}$ resolutions to assess the impact this has on the results. The whole continent simulations are recommended to be re-run at the spin-up stage at resolutions of both 50 and $10 \mathrm{~km}$, to assess the same impact.
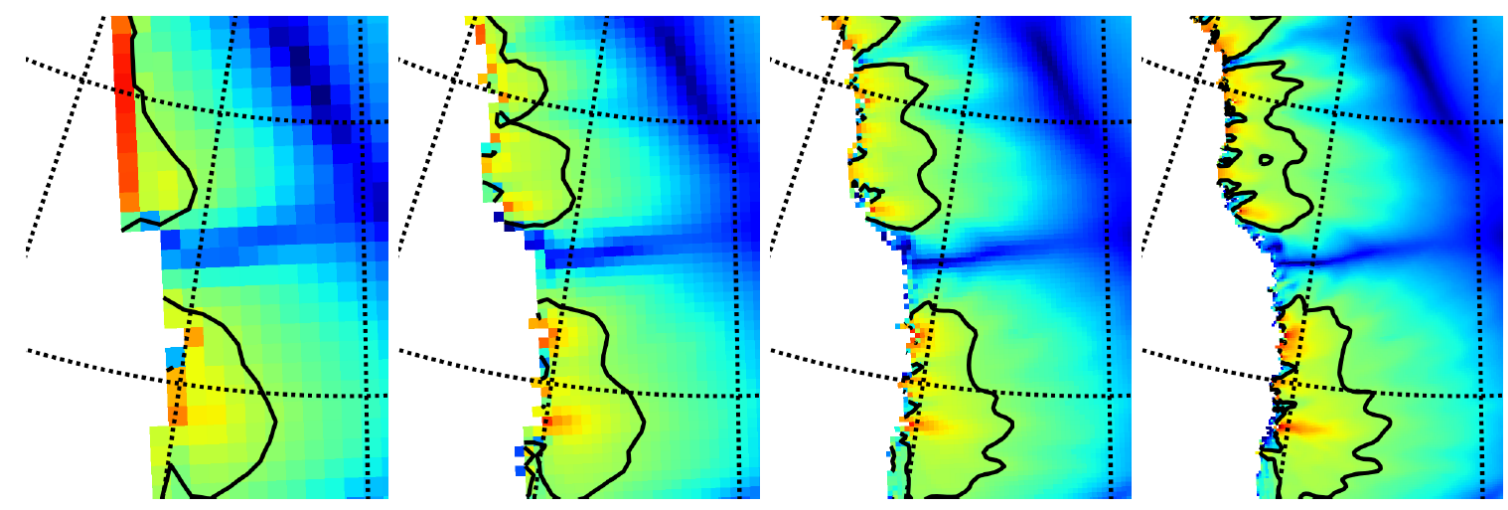

Fig. 6.1 Detailed comparison ice surface velocity of the west coast of Greenland, including Jakobshavn Isbrae, with different model resolutions of $40,20,10,5 \mathrm{~km}$, from left to right. These panels show the variation within results due to resolution, particularly in the faster flowing margin areas (Bueler \& Brown, 2009).

\subsubsection{Till Beneath Seismic Line KIS1516-1}

Lastly, this study recommends further investigation of the material properties of the likely dewatered till inferred to be present beneath the grounded section of seismic line KIS1516-1, as the lack of strong reflection beneath the grounded zone of the seismic line makes it difficult to reach an accurate conclusion in regard to the material properties. While it is outside of the scope of this study to collect more seismic data, a current 
programme led by New Zealand scientists, "The Vulnerability of the Ross Ice Shelf", has collected more active source seismic data on the grounded section of the KIS. Processing and analysis of the collected seismic data may provide further characterisation of the possibly dewatered till beneath this section of the KIS. The results from these seismic lines will provide additional context to the current interpretations of the offshore seismic lines used in this study. 


\section{References}

Åkesson, H., Morlighem, M., Nisancioglu, K. H., Svendsen, J. I., and Mangerud, J. (2018). Atmosphere-driven ice sheet mass loss paced by topography: Insights from modelling the south-western Scandinavian Ice Sheet. Quaternary Science Reviews, 195:32-47.

Albrecht, T., Martin, M., Haseloff, M., Winkelmann, R., and Levermann, A. (2011). Parameterization for subgrid-scale motion of ice-shelf calving fronts. The Cryosphere, $5: 35-44$.

Alley, K. E., Scambos, T. A., Siegfried, M. R., and Fricker, H. A. (2016). Impacts of warm water on Antarctic ice shelf stability through basal channel formation. Nature Geoscience, 9:290-293.

Alley, R. B. (1989). Water-pressure coupling of sliding and bed deformation:I. Water system. Journal of Glaciology, 35:108-118.

Alley, R. B., Anandakrishnan, S., Dupont, T. K., Parizek, B. R., and Pollard, D. (2007). Effect of Sedimentation on Ice-Sheet Grounding-Line Stability. Science, 315:1838-1841.

Alley, R. B., Blankenship, D. D., Bentley, C. R., and Rooney, S. T. (1986). Deformation of till beneath ice stream B, West Antarctica. Nature, 322:57-59.

Alley, R. B., Blankenship, D. D., Rooney, S. T., and Bentley, C. R. (1987). Continuous till deformation beneath ice sheets. The Physical Basis of Ice Sheet Modelling, 170:81-91.

Alley, R. D. and Bindschadler, R. A. (2001). The West Antarctic Ice Sheet and sealevel change. In Alley, R. D. and Bindschadler, R. A., editors, The West Antarctic Ice Sheet: Behaviour and Environment. Antarctic Research Series, pages 201-213. American Geophysical Union, Washington, DC. 
An, M., Wiens, D. A., Zhao, Y., Feng, M., Nyblade, A., Kanao, M., Li, Y., Maggi, A., and Lévêque, J. (2015). Temperature, lithosphere-asthenosphere boundary, and heat flux beneath the Antarctic Plate inferred from seismic velocities. Journal of Geophysical Research: Solid Earth, 120(12):8720-8742.

Anandakrishnan, S. and Alley, R. B. (1997). Stagnation of Ice Stream C, West Antarctica by water piracy. Geophysical Research Letters, 24(3).

Anandakrishnan, S., Alley, R. B., Jacobel, R. W., and Conway, H. (2001). The Flow Regime of Ice Stream C and Hypotheses Concerning Its Recent Stagnation. The West Antarctic Ice Sheet: Behavior and Environment, 77:283-296.

Anandakrishnan, S., Catania, G. A., Alley, R. B., and Horgan, H. J. (2007). Discovery of Till Deposition at the Grounding Line of Whillans Ice Stream. Science, 315:18351838 .

Anderson, J. B. and Bartek, L. R. (1992). Cenozoic glacial history of the Ross Sea revealed by intermediate resolution seismic reflection data combined with drill site information. The Antarctic Paleoenvironment:A Perspective on Global Change, Antarctic Research Series, 56:231-263.

Anderson, J. B., Shipp, S. S., Lowe, A. L., Wellner, J. S., and Mosola, A. B. (2002). The Antarctic Ice Sheet during the Last Glacial Maximum and its subsequent retreat history: a review. Quaternary Science Reviews, 21:49-70.

Arthern, R. J. and Gudmundsson, G. H. (2010). Initialization of ice-sheet forecasts viewed as an inverse Robin problem. Journal of Glaciology, 56(197):527-533.

Arthern, R. J., Hindmarsh, R. C. A., and Williams, C. R. (2015). Flow speed within the Antarctic ice sheet and its controls inferred from satellite observations. Journal of Geophysical Research: Earth Surface, 120(7):1171-1188.

Aschwanden, A., Adalgeirsdóttir, G., and Khroulev, C. (2013). Hindcasting to measure ice sheet model sensitivity to initial states. The Cryosphere, 7:1083-1093.

Ashmore, D. W., Bingham, R. G., Hindmarsh, R. C. A., Corr, H. F. J., and Joughin, I. R. (2014). The relationship between sticky spots and radar reflectivity beneath an active West Antarctic ice stream. Annals of Glaciology, 55:29-38.

Ashmore, D. W., Hubbard, B., Luckman, A., Kulessa, B., Bevan, S., Booth, A., Munneke, P. K., O'Leary, M., Sevestre, H., and Holland, P. R. (2017). Ice and firn 
heterogeneity within Larsen C Ice Shelf from borehole optical televiewing. Journal of Geophysical Research: Earth Surface, 122(5).

Atre, S. R. and Bentley, C. R. (1993). Laterally varying basal conditions beneath ice Streams B and C, West Antarctica. Journal of Glaciology, 39(133):507-514.

Bamber, J. L., Alley, R. B., and Joughin, I. (2007). Rapid response of modern day ice sheets to external forcing. Earth and Planetary Science Letters, 257:1-13.

Bamber, J. L., Ferraccioli, F., Joughin, I., Shepherd, T., Rippin, D. M., Siegert, M. J., and Vaughan, D. G. (2006). East Antarctic ice stream tributary underlain by major sedimentary basin. Geology, 34(1):33-36.

Bamber, J. L., Riva, R. E. M., Vermeersen, B. L. A., and LeBrocq, A. M. (2009). Reassessment of the Potential Sea-Level Rise from a Collapse of the West Antarctic Ice Sheet. Science, 324:901-903.

Bamber, J. L., Vaughan, D., and Joughin, I. (5456). Widespread Complex Flow in the Interior of the Antarctic Ice Sheet. Science, 287:1248-1250.

Beaudoin, B. C., ten Brink, U. S., and Stern, T. A. (1992). Characteristics and processing of seismic data collected on thick, floating ice: Results from the Ross Ice Shelf, Antarctica. Geophysics, 57(10):1359-1372.

Beem, L. H., Tulaczyk, S. M., King, M. A., Bougamont, M., Fricker, H. A., and Christoffersen, P. (2014). Variable deceleration of Whillans Ice Stream, West Antarctica. Journal of Geophysical Research: Earth Surface, 119(2):212-224.

Begeman, C. B., Tulaczyk, S. M., and Fisher, A. T. (2017). Spatially Variable Geothermal Heat Flux in West Antarctica: Evidence and Implications. Geophysical Research Letters, 44(19):9823-9832.

Bell, R. A. I. (1966). A seismic reconnaissance in the McMurco Sound region, Antarctica. Journal of Glaciology, 6(44):209-221.

Bell, R. E., Studinger, M., Shuman, C. A., Fahnestock, M. A., and Joughin, I. (2007). Large subglacial lakes in East Antarctica at the onset of fast-flowing ice streams. Nature, 445:904-907.

Benn, D. I. and Evans, D. J. A. (2010). Glaciers \& Glaciation. Hodder Education, London. 
Bennett, M. R. (2003). Ice streams as the arteries of an ice sheet: their mechanics, stability and significance. Earth-Science Reviews, 61(3-4):309-339.

Bentley, C. R. (1987). Antarctic ice streams: A review. Journal of Geophysical Research: Solid Earth, 92:8843-8858.

Bentley, C. R., Lord, N., and Liu, C. H. (1998). Radar reflections reveal a wet bed beneath stagnant Ice Stream C and a frozen bed beneath ridge BC, West Antarctica. Journal of Glaciology, 44:149-156.

Bernales, J., Rogozhina, I., Greve, R., and Thomas, M. (2017). Comparison of hybrid schemes for the combination of shallow approximations in numerical simulations of the Antarctic Ice Sheet. The Cryosphere, 11:247-265.

Beyer, S., Kleiner, T., Aizinger, V., Rückamp, M., and Humbert, A. (2018). A confined-unconfined aquifer model for subglacial hydrology and its application to the Northeast Greenland Ice Stream. The Cryosphere, 12(12):3931-3947.

Bigg, G. R., Jickells, T. D., Liss, P. S., and Osborn, T. J. (2003). Review the role of the oceans in climate. International Journal of Climatology, 23:1127-1159.

Bindschadler, R. (1983). The Importance of Pressurized Subglacial Water in Separation and Sliding at the Glacier Bed. Journal of Glaciology, 29:3-19.

Bindschadler, R., Vornberger, P., Blankenship, D., Scambos, T., and Jacobel, R. (1996). Surface velocity and Mass balance of Ice Streams D and E, West Antarctica. Journal of Glaciology, 42(142):461-475.

Bindschadler, R. A., Nowicki, S., Abe-Ouchi, A., Aschwanden, A., Choi, H., Fastook, J., Granzow, G., Greve, R., Gutowski, G., Herzfeld, U., Jackson, C., Johnson, J., Khroulev, C., Levermann, A., Lipscomb, W. H., Martin, M. A., Morlighem, M., Parizek, B. R., Pollard, D., Price, S. F., Ren, D., Saito, F., and7 H. Seddik, T. S., Seroussi, H., Takahashi, K., Walker, R., and Wang, W. (2013). Ice-sheet model sensitivities to environmental forcing and their use in projecting future sea level (the SeaRISE project). Journal of Glaciology, 59(214):195-221.

Bingham, R. G. and Siegert, M. J. (2007). Radio-Echo Sounding Over Polar Ice Masses. Journal of Environmental and Engineering Geophysics, 12(1):47-62.

Bingham, R. G. and Siegert, M. J. (2009). Quantifying subglacial bed roughness in Antarctica: implications for ice-sheet dynamics and history. Quaternary Science Reviews, 28(3-4):223-236. 
Blankenship, D. D., Bentley, C. R., Rooney, S. T., and Alley, R. B. (1986). Seismic measurements reveal a saturated, porous layer beneath an active Antarctic ice stream,. Nature, 322:54-57.

Blankenship, D. D., Bentley, C. R., Rooney, S. T., and Alley, R. B. (1987). Till Beneath Ice Stream B. Journal of Geophysical Research, 92:8903-8911.

Bougamont, M., Christoffersen, P., Price, S. F., Fricker, H. A., Tulaczyk, S., and Carter, S. P. (2015). Reactivation of Kamb Ice Stream tributaries triggers century-scale reorganization of Siple Coast ice flow in West Antarctica. Geophysical Research Letters, 42:8471-8480.

Bougamont, M., Tulaczyk, S., and Joughin, I. (2003). Numerical investigations of the slow-down of Whillans Ice Stream,West Antarctica: is it shutting down like Ice Stream C? Annals of Glaciology, 37:239-246.

Boulton, G. S. and Dent, D. L. (1974). The Nature and Rates of Post-Depositional Changes in Recently Deposited Till from South-East Iceland. Geografiska Annaler: Series A, Physical Geography, 56(3-4):121-134.

Boulton, G. S. and Hindmarsh, R. C. A. (1987). Sediment Deformation Beneath Glaciers: Rheology and Geological Consequences. Journal of Geophysical Research, 92(B9):9059-9082.

Boulton, G. S. and Jones, A. S. (1979). Stability of temperate ice caps and ice sheets resting on beds of deformable sediment. Journal of Glaciology, 24(90):29-43.

Boulton, G. S. and Paul, M. A. (1976). The influence of genetic processes on some geotechnical properties of glacial tills. Quarterly Journal of Engineering Geology and Hydrogeology, 9(3):159-194.

Brancolini, G., Cooper, A. K., and Coren, F. (1995). Seismic facies and glacial history in the Western Ross Sea (Antarctica). Geology and Seismic Stratigraphy of the Antarctic Margin, Antarctic Research Series, 68:209-233.

Brisbourne, A. M., Smith, A. M., Vaughan, D. G., King, E. C., Davies, D., Bingham, R. G., Smith, E. C., Nias, I. J., and Rosier, S. H. R. (2017). Bed conditions of Pine Island Glacier, West Antarctica. Journal of Geophysical Research: Earth Surface, 122:419-433. 
Brocq, A. L., Payne, A., Siegert, M., and Alley, R. (2009a). A subglacial water-flow model for West Antarctica. Journal of Glaciology, 55(193):879-888.

Brocq, A. M. L., Hubbard, A., Bentley, M. J., and Bamber, J. L. (2008). Subglacial topography inferred from ice surface terrain analysis reveals a large un-surveyed basin below sea level in East Antarctica. Geophysical Research Letters, 35.

Brocq, A. M. L., Payne, A. J., Siegert, M. J., and Alley, R. B. (2009b). A subglacial water-flow model for West Antarctica. Journal of Glaciology, 55(193):879-888.

Bromirski, P. D. and Stephen, R. A. (2012). Response of the Ross Ice Shelf, Antarctica, to ocean gravity-wave forcing. Annals of Glaciology, 53(60):163-172.

Bromwich, D. H. and Monaghan, J. P. N. A. J. (2011). An Assessment of Precipitation Changes over Antarctica and the Southern Ocean since 1989 in Contemporary Global Reanalyses. Journal of Climate, 24:4189-4209.

Budd, W. F., Jenssen, D., and Smith, I. N. (1984). A Three-Dimensional TimeDependent Model of the West Antarctic Ice Sheet. Annals of Glaciology, 5:29-36.

Budd, W. F., Keage, P. L., and Blundy, N. A. (1979). Emperical studies of ice sliding. Journal of Glaciology, 23:157-170.

Budd, W. F. and Smith, I. H. (1981). The growth and retreat of ice sheets in response to orbital radiation changes. Proc. Symp. Sea Level, Ice and Climatic Change, 131:369-409.

Budd, W. F. and Smith, I. N. (1982). Large-Scale Numerical Modelling of the Antarctic Ice Sheet. Annals of Glaciology, 3:42-49.

Bueler, E. and Brown, J. (2009). Shallow shelf approximation as a "sliding law" in a thermomechanically coupled ice sheet model. Journal of Geophysical Research, 114.

Bueler, E. D., Lingle, C. S., and Brown, J. (2007). Fast computation of a viscoelastic deformable Earth model for ice-sheet simulations. Annals of Glaciology, 46:97-105.

Böhmer, W. J. and Herterich, K. (1990). A Simplified Three-Dimensional Ice-Sheet Model Including Ice Shelves. Annals of Glaciology, 14:17-19.

Calov, R. and Greve, R. (2005). Correspondence: A semi-analytical solution for the positive degree-day model with stochastic temperature variations. Journal of Glaciology, 51:173-175. 
Campbell, W. J. and Rasmussen, L. A. (1969). A heuristic numerical model for three-dimensional timedependent glacier flow. Canadian Journal of Earth Sciences, 6(4):979-986.

Campbell, W. J. and Rasmussen, L. A. (1970). A heuristic numerical model for threedimensional time-dependent glacier flow. de l'Association Internationale d'Hydrologie Scientifique, 86:177-190.

Carson, C. J., McLaren, S., Roberts, J., Boger, S. D., and Blankenship, D. D. (2014). Hot rocks in a cold place: high sub-glacial heat flow in East Antarctica. Journal of the Geological Society, 171:9-12.

Carter, S. P., Blankenship, D. D., Young, D. A., and Holt, J. W. (2009). Using radar-sounding data to identify the distribution and sources of subglacial water: application to Dome C, East Antarctica. Journal of Glaciology, 55(194):1025-1040.

Carter, S. P., Fricker, H. A., and Siegfried, M. R. (2013). Evidence of rapid subglacial water piracy under Whillans Ice Stream, West Antarctica. Journal of Glaciology, 59(218):1147-1162.

Catania, G., Hulbe, C., and Conway, H. (2010). Grounding-line basal melt rates determined using radar-derived internal stratigraphy. Journal of Glaciology, 56(197):545554.

Catania, G., Hulbe, C., Conway, H., Scambos, T. A., and Raymond, C. F. (2012). Variability in the mass flux of the Ross ice streams, West Antarctica, over the last millennium. Journal of Glaciology, 58(210):741-752.

Catania, G. A., Conway, H. B., Gades, A. M., and Raymond, C. F. (2003). Bed reflectivity beneath inactive ice streams in West Antarctica. Annals of Glaciology, $36: 287-291$.

Catania, G. A., Scambos, T. A., Conway, H., and Raymond, C. F. (2006). Sequential stagnation of Kamb Ice Stream, West Antarctica. Geophysical Research Letters, 33.

Christianson, K., Bushuk, M., Dutrieux, P., Parizek, B. R., Joughin, I. R., Alley, R. B., Shean, D. E., Abrahamsen, E. P., Anandakrishnan, S., Heywood, K. J., Kim, T., Lee, S. H., Nicholls, K., Stanton, T., Truffer, M., Webber, B. G. M., Jenkins, A., Jacobs, S., Bindschadler, R., and Holland, D. M. (2016). Sensitivity of Pine Island Glacier to observed ocean forcing. Geophysical Research Letters, 43:10,817-10,825. 
Christianson, K., Parizek, B. R., Alley, R. B., Horgan, H. J., Jacobel, R. W., Anandakrishnan, S., Keisling, B. A., Craig, B. D., and Muto, A. (2013). Ice sheet grounding zone stabilization due to till compaction. Geophysical Reasearch Letters, 40:5406-5411.

Church, J. A., Clark, P. U., Cazenave, A., Gregory, J. M., Jevrejeva, S., Levermann, A., Merrifield, M. A., Milne, G. A., Nerem, R. S., Nunn, P. D., Payne, A. J., Pfeffer, W. T., Stammer, D., and Unnikrishnan, A. S. (2013). Sea level change. In Stocker, T. F., Qin, D., Plattner, G.-K., Tignor, M., Allen, S. K., Boschung, J., Nauels, A., Xia, Y., Bex, V., , and Midgley, P. M., editors, Climate Change 2013: The Physical Science Basis. Contribution of Working Group I to the Fifth Assessment Report of the Intergovernmental Panel on Climate Change, pages 1137-1216. Cambridge, UK. Technical Report.

Clarke, G. K. C. (2005). Subglacial processes. Annual Review of Earth and Planetary Sciences, 33:247-276.

Colleoni, F., Santis, L. D., Siddoway, C. S., Bergamasco, A., Golledge, N. R., Lohmann, G., Passchier, S., and Siegert, M. J. (2018). Spatio-temporal variability of processes across Antarctic ice-bed-ocean interfaces. Nature Communications, 9:2289-2303.

Collins, M., Knutti, R., Arblaster, J., Dufresne, J.-L., Fichefet, T., Friedlingstein, P., Gao, X., Gutowski, W. J., Johns, T., Krinner, G., Shongwe, M., Tebaldi, C., Weaver, A. J., and Wehner, M. (2013). Long-term Climate Change: Projections, Commitments and Irreversibility. In Stocker, T. F., Qin, D., Plattner, G.-K., Tignor, M., Allen, S. K., Boschung, J., Nauels, A., Xia, Y., Bex, V., , and Midgley, P. M., editors, Climate Change 2013: The Physical Science Basis. Contribution of Working Group I to the Fifth Assessment Report of the Intergovernmental Panel on Climate Change, pages 1029-1136. Cambridge, UK. Technical Report.

Conway, H., Catania, G., Raymond, C. F., Gades, A. M., Scambos, T., and Engelhardt, H. (2002). Switch of flow direction in an Antarctic ice stream. Nature, 419:465-467.

Cornford, S. L., Martin, D. F., Graves, D. T., Ranken, D. F., Brocq, A. M. L., Gladstone, R. M., Payne, A. J., Ng, E. G., and Lipscomb, W. H. (2013). Adaptive mesh, finite volume modeling of marine ice sheets. Journal of Computational Physics, 232:529-549.

Cuffey, K. M. and Paterson, W. (2010). The Physics of Glaciers, 4th edition. Academic Press, New York. 
Davies, B. (2015). Antarctic Glaciers. http://www.antarcticglaciers.org.

Davies, B. J., Roberts, D. H., Bridgland, D. R., ÓCofaigh, C., Riding, J. B., Demarchi, B., Penkman, K., and Pawley, S. M. (2012). Timing and depositional environments of a Middle Pleistocene glaciation of northeast England: New evidence from Warren House Gill, County Durham. Quaternary Science Reviews, 44:180-212.

Davies, J. H. and Davies, D. R. (2010). Earth's surface heat flux. Solid Earth, 1:5-24.

Davison, B. J., Sole, A. J., Livingstone, S. J., Cowton, T. R., and Nienow, P. W. (2019). The Influence of Hydrology on the Dynamics of Land-Terminating Sectors of the Greenland Ice Sheet. Frontiers in Earth Science, 7(10).

de Berg, W. J. V., den Broeke, M. R. V., Reijmer, C. H., and Meijgaard, E. V. (2006). Reassessment of the Antarctic surface mass balance using calibrated output of a regional atmospheric climate model. Journal of Geophysical Research, 111(D11):D11104.

de Boer, B., Dolan, A. M., Bernales, J., Gasson, E., Golledge, N. R., Sutter, J., Huybrechts, P., Lohmann, G., Rogozhina, I., Abe-Ouchi, A., Saito, F., and van de Wal, R. S. W. (2015). Simulating the Antarctic ice sheet in the late-Pliocene warm period: PLISMIP-ANT, an ice-sheet model intercomparison project. The Cryosphere, 9:881-903.

de Vries, M. V. W., Bingham, R. G., and Hein, A. S. (2018). A new volcanic province: An inventory of subglacial volcanoes in West Antarctica, Exploration of Subsurface Antarctica: Uncovering Past Changes and Modern Processes. Geological Society, London, Special Publications, 461:231-248.

DeConto, R. M. and Pollard, D. (2016). Contribution of Antarctica to past and future sea-level rise. Nature, 531:591-597.

Denton, G. H. and Marchant, D. R. (2000). The geologic basis for a reconstruction of a grounded ice sheet in McMurdo Sound, Antarctica, at the Last Glacial Maximum. Geografiska Annaler, 82:167-211.

Depoorter, M. A., Bamber, J. L., Griggs, J. A., Lenaerts, J. T. M., Ligtenberg, S. R. M., van den Broeke, M. R., and Moholdt, G. (2013). Calving fluxes and basal melt rates of Antarctic ice shelves. Nature, 502:89-92. 
Determann, J., Thyssen, F., and Engelhardt, H. (1988). Ice thickness and sea depth derived from reflection-seismic measurements on the central part of Filchner-Ronne Ice Shelf, Antarctica. Annals of Glaciology, 11:14-18.

Diez, A., Matsuoka, K., Ferraccioli, F., Jordan, T. A., Corr, H. F., Kohler, J., Olesen, A. V., and Forsberg, R. (2018). Basal Settings Control Fast Ice Flow in the Recovery/Slessor/ Bailey Region, East Antarctica. Geophysical Research Letters, 45.

Dowdeswell, J. A. and Fugelli, E. M. G. (2012). The seismic architecture and geometry of grounding-zone wedges formed at the marine margins of past ice sheets. GSA Bulletin, 124(11-12):1750-1761.

Dowdeswell, J. A., Gorman, M. R., Glazovski, A. F., and Macheret, Y. Y. (1994). Evidence for floating ice shelves in Franz Josef land, Russian High Arctic. Arctic and Alpine Research, 26:86-92.

Dowdeswell, J. A., ÓCofaigh, C., and Pudsey, C. J. (2004). Thickness and extent of the subglacial till layer beneath an Antarctic paleo-ice stream. Geology, 32:13-16.

Downs, J. Z., Johnson, J. V., Harper, J. T., Meierbachtol, T., and Werder, M. A. (2018). Dynamic Hydraulic Conductivity Reconciles Mismatch Between Modeled and Observed Winter Subglacial Water Pressure. Journal of Geophysical Research: Earth Surface, 123(4):818-836.

Drijkoningen, G. G. and Verschuur, D. J. (2003). Seismic Data Processing. Delft University of Technology, Delft.

Dupont, T. K. and Alley, R. B. (2005). Assessment of the importance of ice-shelf buttressing to ice-sheet flow. Geophysics Research Letters, 32.

Dvorkin, J., Prasad, M., Sakai, A., and Lavoie, D. (1999). Elasticity of marine sediments: Rock physics modeling. Geophysical Research Letters, 26(12):1781-1784.

Elsworth, C. E. and Suckale, J. (2016). Rapid ice flow rearrangement induced by subglacial drainage in West Antarctica. Geophysical Research Letters, 43(22):11,69711,707 .

Engelhardt, H. (2004). Ice temperature and high geothermal flux at Siple Dome, West Antarctica, from borehole measurements. Journal of Glaciology, 50(169):251-256.

Engelhardt, H. and Kamb, B. (1998). Basal sliding of Ice Stream B, West Antarctica. Journal of Glaciology, 44(147):223-230. 
Engelhardt, H. and Kamb, B. (2013). Kamb Ice Stream flow history and surge potential. Annals of Glaciology, 54(63):287-298.

Engelhardt, H. F., Harrison, W. D., and Kamb, B. (1987). Basal sliding and conditions at the glacier bed as revealed by bore-hole photography. Journal of Glaciology, 20(84):469-508.

Engelhardt, H. F., Humphrey, N., Kamb, B., and Fahnestock, M. (1990). Physical conditions at the base of a fast moving Antarctic ice stream. Science, 248(4951):57-59.

Evans, D. J. A., Phillips, E. R., Hiemstra, J. F., and Auton, C. A. (2006). Subglacial till: Formation, sedimentary characteristics and classification. Earth-Science Reviews, 78:115-176.

Favier, L., Gagliardini1, O., Durand, G., and Zwinger, T. (2012). A three-dimensional full Stokes model of the grounding line dynamics: effect of a pinning point beneath the ice shelf. The Cryosphere, 6(1):101-112.

Favier, L. and Pattyn, F. (2015). Antarctic ice rise formation, evolution, and stability. Geophysical Research Letters, 42(11):4456-4463.

Feldmann, J., Albrecht, T., Khroulev, C. F. P., and Levermann, A. (2014). Resolutiondependent performance of grounding line motion in a shallow model compared with a full-Stokes model according to the MISMIP3d intercomparison. Journal of Glaciology, 60:353-359.

Feldmann, J. and Levermann, A. (2017). From cyclic ice streaming to Heinrichlike events: the grow-and-surge instability in the Parallel Ice Sheet Model. The Cryosphere, 11:1913-1932.

Fisher, A. T., Mankoff, K. D., Tulaczyk, S. M., Tyler, S. W., Foley, N., and the WISSARD Science Team (2015). High geothermal heat flux measured below the West Antarctic Ice Sheet. Science Advances, 1(6).

Fowler, A. C. (1987). A theory of glacier surges. Journal of Geophysical Research: Solid Earth, 92(B9):9111-9120.

Fretwell, P., Pritchard, H. D., Vaughan, D. G., Bamber, J. L., Barrand, N. E., Bell, R., Bianchi, C., Bingham, R. G., Blankenship, D. D., Casassa, G., Catania, G., Callens, D., Conway, H., Cook, A. J., Corr, H. F. J., Damaske, D., Damm, V., Ferraccioli, F., Forsberg, R., Fujita, S., Gim, Y., Gogineni, P., Griggs, J. A., Hindmarsh, R. C. A., 
Holmlund, P., Holt, J. W., Jacobel, R. W., Jenkins, A., Jokat, W., Jordan, T., King, E. C., Kohler, J., Krabill, W., Riger-Kusk, M., Langley, K. A., Leitchenkov, G., Leuschen, C., Luyendyk, B. P., Matsuoka, K., Mouginot, J., Nitsche, F. O., Nogi, Y., Nost, O. A., Popov, S. V., Rignot, E., Rippin, D. M., Rivera, A., Roberts, J., Ross, N., Siegert, M. J., Smith, A. M., Steinhage, D., Studinger, M., Sun, B., Tinto, B. K., Welch, B. C., Wilson, D., Young, D. A., Xiangbin, C., , and Zirizzotti, A. (2013). Bedmap2: improved ice bed, surface and thickness datasets for Antarctica. The Cryosphere, 7:375-393.

Frezzotti, M., Pourchet, M., Flora, O., Gandolfi, S., Gay, M., Urbini, S., Vincent, C., Becagli, S., Gragnani, R., Proposito, M., Severi, M., Traversi, R., Udisti, R., and Fily, M. (2004). New estimations of precipitation and surface sublimation in East Antarctica from snow accumulation measurements. Climate Dynamics, 23(7-8):803-813.

Frezzotti, M., Pourchet, M., Flora, O., Gandolfi, S., Gay, M., Urbini, S., Vincent, C., Becagli, S., Gragnani, R., Proposito, M., Severi, M., Traversi, R., Udisti, R., and Fily, M. (2005). Spatial and temporal variability of snow accumulation in East Antarctica from traverse data. Journal of Glaciology, 51(172):113-124.

Fricker, H. A., Carter, S. P., Bell, R. E., and Scambos, T. (2014). Active lakes of Recovery Ice Stream, East Antarctica: a bedrock-controlled subglacial hydrological system. Journal of Glaciology, 60(223):1015-1030.

Fricker, H. A. and Scambos, T. (2009). Connected subglacial lake activity on lower Mercer and Whillans Ice Streams, West Antarctica, 2003-2008. Journal of Glaciology, 55(190):303-315.

Fricker, H. A., Scambos, T., Bindschadler, R., and Padman, L. (2007). An active subglacial water system in West Antarctica mapped from space. Science, 315(5818):1544-1548.

Fudge, T. J., Biyani, S. C., Clemens-Sewall, D., and Hawley, R. L. (2019). Constraining Geothermal Flux at Coastal Domes of the Ross Ice Sheet, Antarctica. Geophysical Research Letters, 46.

Fürst, J., Durand, G., Gillet-Chaulet, F., Merino, N., Tavard, L., Mouginot, J., Gourmelen, N., and Gagliardini, O. (2015). Assimilation of Antarctic velocity observations provides evidence for uncharted pinning points. The Cryosphere, 9(4):1427-1443. 
Fürst, J. J., Durand, G., Gillet-Chaulet, F., Tavard, L., Rankl, M., Braun, M., and Gagliardini, O. (2016). The safety band of Antarctic ice shelves. Nature Climate Change, 6:479-482.

Gagliardini, O., Brondex, J., Gillet-Chaulet, F., Tavard, L., Peyaud, V., and Durand, G. (2016). Impact of mesh resolution for MISMIP and MISMIP3d experiments using Elmer/Ice. The Crosphere, 10(1):307-312.

Gagliardini, O., Zwinger, T., Gillet-Chaulet, F., Durand, G., Favier, L., de Fleurian, B., Greve, R., Malinen, M., Martín, C., Råback, P., Ruokolainen, J., Sacchettini, M., Schäfer, M., Seddik, H., and Thies, J. (2013). Capabilities and performance of Elmer/Ice, a new-generation ice sheet model. Geoscientific Model Development, 6:1299-1318.

Genthon, C. and Krinner, G. (2001). Antarctic surface mass balance and systematic biases in general circulation models. Journal of Geophysical Research, 106(D18):2065320664.

Gladstone, R. M., Payne, A. J., and Cornford, S. L. (2010). Parameterising the grounding line in flow-line ice sheet models. The Cryosphere, 4(4):605-619.

Goeller, S., Helm, V., Thoma, M., and Grosfeld, K. (2015). Subglacial hydrology indicates a major shift in dynamics of the West Antarctic Ross Ice Streams within the next two centuries. The Cryosphere, 9:3995-4018.

Goldberg, D., Holland, D. M., and Schoof, C. (2009). Grounding line movement and ice shelf buttressing in marine ice sheets. Journal of Geophysical Research Letters, 114 .

Golledge, N. R., Keller, E. D., Gomez, N., Naughten, K. A., Bernales, J., Trusel, L. D., and Edwards, T. L. (2019). Global environmental consequences of twenty-first-century ice-sheet melt. Nature, 566:65-72.

Golledge, N. R., Kowalewski, D. E., Naish, T. R., Levy, R. H., Fogwill, C. J., and Gasson, E. G. W. (2015). The multi-millennial Antarctic commitment to future sea-level rise. Nature, 526:421-425.

Golledge, N. R., Levy, R. H., McKay, R. M., and Naish, T. R. (2017). East Antarctic ice sheet most vulnerable to Weddell Sea warming. Geophysical Research Letters, 44. 
Golledge, N. R., Marsh, O. J., Rack, W., Braaten, D., and Jones, R. S. (2014). Basal conditions of two Transantarctic Mountains outlet glaciers from observationconstrained diagnostic modelling. Journal of Glaciology, 60(223):855-866.

Gray, L., Joughin, I., Tulaczyk, S., Spikes, V. B., Bindschadler, R., and Jezek, K. (2005). Evidence for subglacial water transport in the West Antarctic Ice Sheetthrough three-dimensional satellite radar interferometry. Geophysical Research Letters, 32(3).

Greve, R. (1997a). Application of a Polythermal Three-Dimensional Ice Sheet Model to the Greenland Ice Sheet: Response to Steady-State and Transient Climate Scenarios. American Meteorological Society, 10:901-918.

Greve, R. (1997b). A continuum-mechanical formulation for shallow polythermal ice sheets. Philosophical Transactions of the Royal Society of London A, 355:921-974.

Gudmundsson, G. H. (2013). Ice-shelf buttressing and the stability of marine ice sheets. The Cryosphere, 7:647-655.

Gudmundsson, G. H., Bauder, A., Lüthi, M., Fischer, U. H., and Funk, M. (1999). Estimating rates of basal motion and internal ice deformation from continuous tilt measurements. Annals of Glaciology, 28:247-252.

Gudmundsson, G. H., Krug, J., Durand, G., Favier, L., and Gagliardini, O. (2012). The stability of grounding lines on retrograde slopes. The Cryosphere, 6:1497-1505.

Halberstadt, A. R. W., Simkins, L. M., Greenwood, S. L., and Anderson, J. B. (2016). Past ice-sheet behaviour: retreat scenarios and changing controls in the Ross Sea, Antarctica. The Cryosphere, 10:1003-1020.

Hamilton, E. L. (1971). Prediction of In-situ Acoustic and Elastic Properties of Marine Sediments. Geophysics, 36(2):266-284.

Haran, T., Bohlander, J., Scambos, T., Painter, T., and Fahnestock, M. (2014). MODIS Mosaic of Antarctica 2008-2009 (MOA2009) Image Map. Data Set. Boulder, Colorado USA: National Snow and Ice Data Center. http://dx.doi.org/10.7265/N5KP8037.

Hellmer, H. H., Jacobs, S. S., and Jenkins, A. (1998). Oceanic erosion of a floating Antarctic glacier in the Amundsen Sea. Ocean, Ice and Atmosphere: Interactions at the Antarctic Continental Margin, Antarctic Research Series, 75:83-99.

Herterich, K. (1988). A Three-Dimensional Model of the Antarctic Ice Sheet. Annals of Glaciology, 11:32-35. 
Hindmarsh, R. C. A. (2006). The role of membrane-like stresses in determining the stability and sensitivity of the Antarctic ice sheets: back pressure and grounding line motion. Philosophical Transactions of the Royal Society of London, 364:1733-1767.

Hindmarsh, R. C. A. and LeMeur, E. (2001). Dynamical processes involved in the retreat of marine ice sheets. Journal of Glaciology, 47(157):271-282.

Hodge, S. M. (1979). Direct Measurement of Basal Water Pressures: Progress and Problems. Journal of Glaciology, 23(89):309-319.

Holland, C. W. and Anandakrishnan, S. (2009). Subglacial seismic reflection strategies when source amplitude and medium attenuation are poorly known. Journal of Glaciology, 55(193):931-937.

Holland, D. M. and Jenkins, A. (1999). Modeling thermodynamic ice-ocean interactions at the base of an ice shelf. Journal of Physical Oceanography, 29:1787-1800.

Holland, P. R., Jenkins, A., and Holland, D. M. (2007). The Response of Ice Shelf Basal Melting to Variations in Ocean Temperature. Journal of Climate, 21:2558-2572.

Horgan, H. J., Alley, R. B., Christianson, K., Jacobel, R. W., Anandakrishnan, S., Muto, A., Beem, L. H., and Siegfried, M. R. (2013a). Estuaries beneath ice sheets. Geology, 41(11):1159-1162.

Horgan, H. J. and Anandakrishnan, S. (2006). Static grounding lines and dynamic ice streams: Evidence from the Siple Coast, West Antarctica. Geophysics Research Letters, 33(18).

Horgan, H. J., Anandakrishnan, S., Jacobel, R. W., Christianson, K., Alley, R. B., Heeszel, D. S., Picotti, S., and Walter, J. I. (2012). Subglacial Lake Whillans Seismic observations of a shallow active reservoir beneath a West Antarctic ice stream. Earth and Planetary Science Letters, 331-332:201-209.

Horgan, H. J., Christianson, K., Jacobel, R. W., Anandakrishnan, S., and Alley, R. B. (2013b). Sediment deposition at the modern grounding zone of Whillans Ice Stream,West Antarctica. Geophysical Research Letters, 40:3934-3939.

Horgan, H. J., Hulbe, C., Alley, R. B., Anandakrishnan, S., Goodsell, B., TaylorOfford, S., and Vaughan, M. J. (2017). Poststagnation Retreat of Kamb Ice Stream's Grounding Zone. Geophysical Research Letters, 44. 
Howat, I. M., Tulaczyk, S., Waddington, E., and Bjärnsson, H. (2008). Dynamic controls on glacier basal motion inferred from surface ice motion. Journal of Geophysical Research, 113.

Hulbe, C. and Fahnestock, M. (2007). Century-scale discharge stagnation and reactivation of the Ross ice streams, West Antarctica. Journal of Geophysical Research, 112.

Hulbe, C. L. and Fahnestock, M. A. (2004). West Antarctic ice-stream discharge variability: mechanism, controls and pattern of grounding-line retreat. Journal of Glaciology, 50(171):471-484.

Hutter, K. (1983). Theoretical glaciology; material science of ice and the mechanics of glaciers and ice sheets. Terra Publishing Company, Dordrecht.

Huybrechts, P. (1990). A 3-D model for the Antarctic ice sheet: a sensitivity study on the glacial-interglacial contrast. Climate Dynamics, 5(2):79-92.

Huybrechts, P. (1998). The Third EISMINT Workshop on Model Intercomparison. Report. European Science Foundation.

Huybrechts, P. (2002). Sea-level changes at the LGM fro mice-dyna mic reconstructions ofthe Greenland and Antarctic ice sheets during the glacial cycles. Quaternary Science Reviews, 21:203-231.

Huybrechts, P. and de Wolde, J. (1999). The dynamic response of the Greenland and Antarctic ice sheets to multiple-century climatic warming. Journal of Climate, $12: 2169-2188$.

Huybrechts, P. and Oerlemans, J. (1988). Evolution of the East Antarctic Ice Sheet: A Numerical Study of Thermo-Mechanical Response Patterns With Changing Climate. Annals of Glaciology, 11:52-59.

Huybrechts, P., Payne, T., and Group, T. E. I. (1996). The EISMINT benchmarks for testing ice-sheet models. Annals of Glaciology, 23:1-12.

Iken, A. (1972). measurements of water pressure in moulins as part of a movement study of the White Glacier, Axel Heiberg Island, Northwest Territories, Canada. Journal of Glaciology, 11:53-58. 
Iken, A. and Bindschadler, R. A. (1986). Combined measurements of Subglacial Water Pressure and Surface Velocity of Findelengletscher, Switzerland: Conclusions about Drainage System and Sliding Mechanism. Journal of Glaciology, 32(110):101-119.

Iverson, N. R., Baker, R. W., Hooke, R., Hanson, B., and Jansson, P. (1999). Coupling between a glacier and a soft bed: I. A relation between effective pressure and local shear stress determined from till elasticity. Journal of Glaciology, 45(149):31-40.

Jacobel, R. W., Welch, B. C., Osterhouse, D., Pettersson, R., and MacGregor, J. A. (2009). Spatial variation of radar-derived basal conditions on Kamb Ice Stream, West Antarctica. Annals of Glaciology, 50(51):10-16.

Jacobs, S. S., Helmer, H. H., Doake, C. S. M., Jenkins, A., and Frolich, R. M. (1992). Melting of ice shelves and the mass balance of Antarctica. Journal of Glaciology, 38(130):375-387.

Jamieson, S. S. R., Vieli, A., Livingstone, S. J., Óofaigh, C., Stokes, C., Hillenbrand, C., and Dowdeswell, J. A. (2012). Ice stream stability on a reverse bed slope. Nature Geoscience, 5(11):799-802.

Jenssen, D. (1977). A Three-Dimensional Polar Ice-Sheet Model. Journal of Glaciology, $18(80): 373-389$.

Jezek, K. C., Bentley, C. R., and Clough, J. W. (1979). Electromagnetic Sounding of Bottom Crevasses on the Ross Ice Shelf, Antarctica. Journal of Glaciology, 24(90):321-330.

Jiskoot, H. (2011). Dynamics of Glaciers. In V.P. Singh, P. S. and Haritashya, U., editors, Encyclopedia of snow, ice and glaciers, pages 245-256. Springer, Dordrecht.

Jordan, T. A., Ferraccioli, F., Armadillo, E., and Bozzo, E. (2013). Crustal architecture of the Wilkes Subglacial Basin in East Antarctica, as revealed from airborne gravity data. Tectonophysics, 585:196-206.

Joughin, I. and Alley, R. B. (2011). Stability of the West Antarctic ice sheet in a warming world. Nature Geoscience, 4:506-513.

Joughin, I., Alley, R. B., and Holland, D. M. (2012). Ice-Sheet Response to Oceanic Forcing. Science, 338(6111):1172-1176. 
Joughin, I., Bindschadler, R. A., King, M. A., Voigt, D., Alley, R. B., Anandakrishnan, S., Horgan, H., Peters, L., Winberry, P., Das, S. B., and Catania, G. (2005). Continued deceleration of Whillans ice stream, West Antarctica. Geophysical Research Letters, 32(22).

Joughin, I., Smith, B. E., and Holland, D. M. (2010). Sensitivity of 21st century sea level to ocean-induced thinning of Pine Island Glacier, Antarctica. Geophysical Research Letters, 37(20).

Joughin, I. and Tulaczyk, S. (2002). Positive Mass Balance of the Ross Ice Streams, West Antarctica. Science, 295(5554):476-480.

Joughin, I., Tulaczyk, S., Bamber, J. L., Blankenship, D., Holt, J. W., Scambos, T., and Vaughan, D. G. (2009). Basal conditions for Pine Island and Thwaites Glaciers, West Antarctica, determined using satellite and airborne data. Journal of Glaciology, $55(190): 245-257$.

Joughin, I., Tulaczyk, S., Bindschadler, R., and Price, S. (2002). Changes in west Antarctic ice stream velocities: Observation and analysis. Journal of Geophysical Research, 107(B11):2289.

Joughin, I., Tulaczyk, S., MacAyeal, D. R., and Engelhardt, H. (2004). Melting and freezing beneath the Ross ice streams, Antarctica. Journal of Glaciology, 50(168):96108.

Joughin, I. R., Tulaczyk, S., and Engelhardt, H. F. (2003). Basal melt beneath Whillans Ice Stream and Ice Streams A and C, West Antarctica. Annals of Glaciology, 26:257262.

Jouvet, G., Picasso, M., Rappaz, J., and Blatter, H. (2008). A new algorithm to simulate the dynamics of a glacier: theory and applications. Journal of Glaciology, 54(188):801-811.

Kamb, B. (2001). Basal zone of the West Antarctic ice streams and its role in lubrication of their rapid motion. American Geophysical Union, Washington, D. C.

Kim, S., Santis, L. D., Hong, J. K., Cottlerle, D., Petronio, L., Colizza, E., Kim, Y., Kim, S. K. H. J., Kim, S., Wardell, N., Geletti, R., Bergamasco, A., McKay, R., Jin, Y. K., and Kang, S. (2018). Seismic stratigraphy of the Central Basin in northwestern Ross Sea slope andrise, Antarctica: Clues to the late Cenozoic ice-sheet dynamics and bottom-current activity. Marine Geology, 395:363-379. 
Kirchner, J. F. and Bentley, C. R. (1979). Lateral density differences from seismic measurements at a site on the Ross Ice Shelf, Antarctica. Journal of Glaciology, 24(90):309-312.

Krabbendam, M. (2016). Sliding of temperate basal ice on a rough, hard bed: creep mechanisms, pressure melting, and implications for ice streaming. The Cryosphere, 10:1915-1932.

Krinner, G., Guicherd, B., Ox, K., Genthon, C., and Magand, O. (2008). Influence of oceanic boundary conditions in simulations of Antarctic climate and surface mass balance change during the coming century. Journal of Climate, 21(5):938-962.

Kyrke-Smith, T. M., Gudmundsson, G. H., and Farrell, P. E. (2017). Can Seismic Observations of Bed Conditions on Ice Streams Help Constrain Parameters in Ice Flow Models? Journal of Geophysical Research: Earth Surface, 122.

Kyrke-Smith, T. M., Katz, R. F., and Fowler, A. C. (2015). Subglacial hydrology as a control on emergence, scale, and spacing of ice streams. Journal of Geophysical Research: Earth Surface, 120:1501-1514.

Larour, E., Seroussi, H., Morlighem, M., and Rignot, E. (2012). Continental scale, high order, high spatial resolution, ice sheet modeling using the Ice Sheet System Model (ISSM). Journal of Geophysical Research, 117.

Lenaerts, J., van den Broeke, M., van de Berg, W., van Meijgaard, E., and Munneke, P. (2012). A new, high-resolution surface mass balance map of Antarctica (1979-2010) based on regional atmospheric climate modeling. Geophysical Research Letters, 39(L04501).

Levy, R. H., Meyers, S. R., Naish, T. R., Golledge, N. R., McKay, R. M., Crampton, J. S., DeConto, R. M., Santis, L. D., Florindo, F., Gasson, E. G. W., Harwood, D. M., Luyendyk, B. P., Powell, R. D., Clowes, C., and Kulhanek, D. K. (2019). Antarctic ice-sheet sensitivity to obliquity forcing enhanced through ocean connections. Nature Geoscience, 12:132-137.

Ligtenberg, S. R. M., de Berg, W. J. V., den Broeke, M. R. V., Rae, J. G. L., and Meijgaard, E. V. (2013). Future surface mass balance of the Antarctic ice sheet and its influence on sea level change, simulated by a regional atmospheric climate model. Climate dynamics, 41(3-4):867-884. 
Ligtenberg, S. R. M., Helsen, M. M., and den Broeke, M. R. V. (2011). An improved semi-empirical model for the densification of Antarctic firn. The Cryosphere, 5:809819.

Lingle, C. S. and Clarke, J. A. (1985). A numerical model of interactions between a marine ice sheet and the solid Earth: application to a West Antarctic ice stream. Journal of Geophysical Research, 90(C1):1100-1114.

Livingstone, S. J., Clark, C. D., Woodward, J., and Kingslake, J. (2013). Potential subglacial lake locations and meltwater drainage pathways beneath the Antarctic and Greenland ice sheets. The Cryosphere, 7:1721-1740.

Livingstone, S. J., ÓCofaigh, C., Stokes, C. R., Hillenbrand, C. D., Vieli, A., and Jamieson, S. S. R. (2012). Antarctic palaeo-ice streams. Earth-Science Reviews, 111(1-2):90-128.

Luthra, T., Anandakrishnan, S., Winberry, J. P., B.Alley, R., and Holschuh, N. (2016). Basal characteristics of the main sticky spot on the ice plain of Whillans Ice Stream, Antarctica. Earth and Planetary Science Letters, 440:12-19.

Luthra, T., Peters, L. E., Anandakrishnan, S., Alley, R. B., Holschuh, N., and Smith, A. M. (2017). Characteristics of the sticky spot of Kamb Ice Stream, West Antarctica. Journal of Geophysical Research: Earth Surface, 122.

Lythe, M. B., Vaughan, D. G., and the BEDMAP Consortium (2001). BEDMAP: A new ice thickness and subglacial topographic model of Antarctica. Journal of Geophysical Research, 106:11335-11351.

Lüthi, M. and Funk, M. (2000). Dating ice cores from a high Alpine glacier with a flow model for cold firn. Annals of Glaciology, 31:69-79.

MacAyeal, D. R. (1997). EISMINT: Lessons in Ice-Sheet Modeling.

MacAyeal, D. R., Rommelaere, V., Huybrechts, P., and Hulbe, C. L. (1996). An ice-shelf model test based on the Ross Ice Shelf, Antarctica. Annals of Glaciology, 23:46-51.

Mahaffy, M. W. (1976). A Three-Dimensional Numerical Model of Ice Sheets: Tests on the Barnes Ice Cap, Northwest Territories. Journal of Geophysical Research, 81(6):1059-1066. 
Marchant, D. R., Lewis, A. R., Phillips, W. M., Moore, E. J., Souchez, R. A., Denton, G. H., Sugden, D. E., Potter, N., and Landis, G. P. (2002). Formation of patterned ground and sublimation till over Miocene glacier ice in Beacon Valley, southern Victoria Land, Antarctica. GSA Bulletin, 114(6):718-730.

Marsh, O. J., Fricker, H. A., Siegfried, M. R., Christianson, K., Nicholls, K. W., Corr, H. F. J., and Catania, G. (2016). High basal melting forming a channel at the grounding line of Ross Ice Shelf, Antarctica. Geophysical Research Letters, 43(1).

Marshall, S. J., White, E. C., Demuth, M. N., Bolch, T., Wheate, R., Menounos, B., Beedle, M. J., and Shea, J. M. (2011). Glacier Water Resources on the Eastern Slopes of the Canadian Rocky Mountains. Canadian Water Resources Journal, 36:109-134.

Martin, D. F., Cornford, S. L., and Payne, A. J. (2019). Millennial-Scale Vulnerability of the Antarctic Ice Sheet to Regional Ice Shelf Collapse. Geophysical Research Letters, 46:1467-1475.

Martin, M. A., Winkelmann, R., Haseloff, M., Albrecht, T., Bueler, E., Khroulev, C., and Levermann, A. (2011). The Potsdam Parallel Ice Sheet Model (PISM-PIK) -Part 2: Dynamic equilibrium simulation of the Antarctic ice sheet. The Cryosphere, 5:727-740.

Martos, Y. M., Catalán, M., Jordan, T. A., Golynsky, A., Golynsky, D., Eagles, G., and Vaughan, D. G. (2017). Heat Flux Distribution of Antarctica Unveiled. Geophysical Research Letters, 44(22):11417-11426.

Matsuoka, K., Skoglund, A., and Roth, G. (2018). Quantarctica. Data Set. Norwegian Polar Institute.

Maule, C. F., Purucker, M. E., Olsen, N., and Mosegaard, K. (2005). Heat Flux Anomalies in Antarctica Revealed by Satellite Magnetic Data. Science, 309(5733):464467.

McCarthy, C., Savage, H., and Nettles, M. (2017). Temperature dependence of ice-onrock friction at realistic glacier conditions. Philosophical Transactions A, 375.

Medley, B., McConnell, J. R., Neumann, T. A., Reijmer, C. H., Chellman, N., Sigl, M., and Kipfstuhl, S. (2018). Temperature and Snowfall in Western Queen MaudLand Increasing Faster Than ClimateModel Projections. Geophysical Research Letters, $45: 1472-1480$. 
Meyer, C. R., Yehya, A., Minchew, B., and Rice, J. R. (2018). A model for thedownstream evolution of temperateice and subglacial hydrology alongice stream shear margins. Journal of Geophysical Research:Earth Surface, 123:1682-1698.

Moholdt, G., Padman, L., and Fricker, H. A. (2014). Basal mass budget of Ross and Filchner-Ronne ice shelves, Antarctica, derived from Lagrangian analysis of ICESat altimetry. Journal of Geophysical Research:Earth Surface, 119(11):2361-2380.

Monaghan, A. J., Bromwich, D. H., and Schneider, D. P. (2008). Twentieth century Antarctic air temperature and snowfall simulations by IPCC climate models. Geophysical Research Letters, 35:L07502.

Morland, L. W. (1984). Thermomechanical balances of ice sheet flows. Geophysical and Astrophysical Fluid Dynamics, 29:237-266.

Morland, L. W. (1987). Unconfined Ice-Shelf Flow. In der Veen, C. J. V. and Oerlemans, J., editors, Dynamics of the West Antarctic Ice Sheet. Springer, Dordrecht.

Morland, L. W. and Zainuddin, R. (1987). Plane and Radial Ice-Shelf Flow with Prescribed Temperature Profile. In der Veen, C. J. V. and Oerlemans, J., editors, Dynamics of the West Antarctic Ice Sheet. Springer, Dordrecht.

Mussett, A. E. and Khan, M. A. (2000). Looking Into the Earth: An Introduction to Geological Geophysics. Cambridge University Press, Cambridge.

Muto, A., Christianson, K., Horgan, H. J., Anandakrishnan, S., and Alley, R. B. (2013). Bathymetry and geological structures beneath the Ross Ice Shelf at the mouth of Whillans Ice Stream, West Antarctica, modeled from ground-based gravity measurements. Journal of Geophysical Research: Solid Earth, 118:4535-4546.

Nick, F. M., Vieli, A., Andersen, M. L., Joughin, I., Payne, A., Edwards, T. L., Pattyn, F., and van de Wal, R. S. W. (2013). Future sea-level rise from Greenland's main outlet glaciers in a warming climate. Nature, 497:235-238.

Nick, F. M., Vieli, A., Howat, I. M., and Joughin, I. (2009). Large-scale changes in Greenland outlet glacier dynamics triggered at the terminus. Nature Geoscience, $2: 110-114$.

Nienow, P. W., Sole, A. J., Slater, D. A., and Cowton, T. R. (2017). Recent Advances in Our Understanding of the Role of Meltwater in the Greenland Ice Sheet System. Current Climate Change Reports, 3:330-344. 
ÓCofaigh, C., Dowdeswell, J. A., Allen, C. S., Hiemstra, J. F., Pudsey, C. J., Evans, J., and Evans, D. J. A. (2005). Flow dynamics and till genesis associated with a marinebased Antarctic palaeo-ice stream. Quaternary Science Reviews, 24(5-6):709-740.

ÓCofaigh, C., Dowdeswell, J. A., Evans, J., and Larter, R. D. (2008). Geological constraints on Antarctic palaeo-ice-stream retreat. Earth Surface Processes and Landforms, 33(4):513-525.

Oerlemans, J. (1982a). Glacial cycles and ice-sheet modelling. Climatic Change, $4(4): 353-374$

Oerlemans, J. (1982b). A model of the Antarctic Ice Sheet. Nature, 297:550-553.

Oerlemans, J. (1982c). Response of the antarctic ice sheet to a climatic warming: A model study. Journal of Glaciology, 2(1).

Oerlemans, J. (1983). A numerical study on cyclic behaviour of polar ice sheets. Tellus, $35 \mathrm{~A}(2)$.

Oerlemans, J. (1988). Simulation of Historic Glacier Variations with a Simple ClimateGlacier Model. Journal of Glaciology, 34(118):333-341.

Oerlemans, J., Anderson, B., Hubbard, A., Huybrechts, P., Jóhannesson, T., Knap, W. H., Schmeits, M., Stroeven, A. P., van de Wal, R. S. W., Wallinga, J., and Zuo, Z. (1998). Modelling the response of glaciers to climate warming. Climate Dynamics, 14(4):267-274.

Padman, L., Siegfried, M. R., and Fricker, H. A. (2018). Ocean Tide Influences on the Antarctic and Greenland Ice Sheets. Reviews of Geophysics, 56(1):142-184.

Palerme, C., Kay, J. E., Genthon, C., L'Ecuyer, T., Wood, N. B., and Claud, C. (2014). How much snow falls on the Antarctic ice sheet? The Cryosphere, 8:1577-1587.

Paolo, F. S., Fricker, H. A., and Padman, L. (2015). Volume loss from Antarctic ice shelves is accelerating. Science, 348:327-331.

Paterson, W. S. B. (1994). The physics of glaciers. Elsevier, Oxford.

Paterson, W. S. B. and Budd, W. F. (1982). Flow parameters for ice sheet modeling. Cold Regions Science and Technology, 6(2):175-177. 
Pattyn, F. (2003). A new three-dimensional higher-order thermomechanical ice sheet model: Basic sensitivity, ice stream development, and ice flow across subglacial lakes. Journal of Geophysical Research, 108.

Pattyn, F. (2008). Investigating the stability of subglacial lakes with a full Stokes ice-sheet model. Journal of Glaciology, 54(185):353-361.

Pattyn, F. (2010). Antarctic subglacial conditions inferred from a hybrid ice sheet/ice stream model. Earth and Planetary Science Letters, 295:451-461.

Pattyn, F. (2017). Sea-level response to melting of Antarctic ice shelves on multicentennial timescales with the fast Elementary Thermomechanical Ice Sheet model (f.ETISh v1.0). The Cryosphere, 11:1851-1878.

Pattyn, F. (2018). The paradigm shift in Antarctic ice sheet modelling. Nature Communications, 9 .

Pattyn, F., Carter, S. P., and Thoma, M. (2016). Advances in modelling subglacial lakes and their interaction with the Antarctic ice sheet. Philosophical Transactions of the Royal Society A, 374 .

Pattyn, F., Huyghe, A., Brabander, S. D., and Smedt, B. D. (2006). Role of transition zones in marine ice sheet dynamics. Journal of Geophysical Research: Earth Surface, 111.

Pattyn, F., Perichon, L., Aschwanden, A., Breuer, B., de Smedt, B., Gagliardini, O., Gudmundsson, G. H., Hindmarsh, R., Hubbard, A., Johnson, J. V., Kleiner, T., Konovalov, Y., Martin, C., Payne, A. J., Pollard, D., Price, S., Rückamp, M., Saito, F., Soucek, O., Sugiyama, S., and Zwinger, T. (2008). Benchmark experiments for higher-order and full Stokes ice sheet models (ISMIP-HOM). The Cryosphere, $2: 111-151$.

Pattyn, F., Perichon, L., Durand, G., Favier, L., Gagliardini, O., Hindmarsh, R. C. A., Zwinger, T., Albrecht, T., Cornford, S. L., Docquier, D., Fürst, J. J., Goldberg, D., Gudmundsson, G. H., Humbert, A., Hütten, M., Huybrechts, P., Jouvet, G., Kleiner, T., Larour, E., Martin, D., Morlighem, M., Payne, A. J., Pollard, D., Rückamp, M., Rybak, O., Seroussi, H., Thoma, M., and Wilkens, N. (2013). Grounding-line migration in plan-view marine ice-sheet models: results of the ice2sea MISMIP3d intercomparison. Journal of Glaciology, 59(215):410-422. 
Pattyn, F., Schoof, C., Perichon, L., Hindmarsh, R. C. A., Bueler, E., de Fleurian, B., Durand, G., Gagliardini, O., Gladstone, R., Goldberg, D., Gudmundsson, G. H., Huybrechts, P., Lee, V., Nick, F. M., Payne, A. J., Pollard, D., Rybak, O., Saito, F., and Vieli, A. (2012). Results of the Marine Ice Sheet Model Intercomparison Project, MISMIP. The Cryosphere, 6(3):573-588.

Payne, A. J., Holland, P. R., Shepherd, A. P., Rutt, I. C., Jenkins, A., and Joughin, I. (2007). Numerical modeling of ocean-ice interactions under Pine Island Bay's ice shelf. Journal of Geophysical Research: Oceans, 112.

Payne, A. J., Huybrechts, P., Abe-Ouchi, A., Calov, R., Fastook, J. L., Greve, R., Marshall, S. J., Marsiat, I., Ritz, C., Tarasov, L., and Thomassen, M. P. A. (2000). Results from the EISMINT model intercomparison: the effects of thermomechanical coupling. Journal of Glaciology, 46(153):227-238.

Peters, L. E. and Anandakrishnan, S. Subglacial conditions at a sticky spot along Kamb Ice Stream, West Antarctica. U. S. Geological Survey and The National Academies.

Peters, L. E. and Anandakrishnan, S. (2007). Subglacial conditions at a sticky spot along Kamb Ice Stream, West Antarctica. U. S. Geological Survey and The National Academies, 097.

Peters, L. E., Anandakrishnan, S., Alley, R. B., and Smith, A. M. (2007). Extensive storage of basal meltwater in the onset region of a major West Antarctic ice stream. Geology, 35(3):251-254.

Peters, L. E., Anandakrishnan, S., Alley, R. B., Winberry, J. P., Voigt, D. E., Smith, A. M., and Morse, D. L. (2006). Subglacial sediments as a control on the onset and location of two Siple Coast ice streams, West Antarctica. Journal of Geophysical Research, 111.

Peters, L. E., Anandakrishnan, S., Holland, C. W., Horgan, H. J., Blankenship, D. D., and Voigt, D. E. (2008). Seismic detection of a subglacial lake near the South Pole, Antarctica. Geophysical Research Letters, 35(L23501).

Pollard, D., DeConto, R. M., and Alley, R. B. (2015). Potential Antarctic Ice Sheet retreat driven by hydrofracturing and ice cliff failure. Earth and Planetary Science Letters, 412:112-121. 
Pollard, D., DeConto, R. M., and Nyblade, A. A. (2005). Sensitivity of Cenozoic Antarctic ice sheet variations to geothermal heat flux. Global and Planetary Change, 49:63-74.

Poulter, T. C. (1947). Seismic measurements on the Ross Ice Shelf - Part 1. Transactions, American Geophysical Union, 28(2):162-170.

Price, S. F., Bindschadler, R. A., Hulbe, C. L., and Joughin, I. R. (2001). Poststagnation behaviour in the upstream regions of Ice Stream C, West Antarctica. Journal of Glaciology, 47:283-294.

Pritchard, H. D., Arthern, R. J., Vaughan, D. G., and Edwards, L. A. (2009). Extensive dynamic thinning on the margins of the Greenland and Antarctic ice sheets. Nature, 461:971-975.

Pritchard, H. D., Ligtenberg, S. R. M., H. A. Fricker, D. G. V., vand den Broeke, M. R., and Padman, L. (2012). Antarctic ice-sheet loss driven by basal melting of ice shelves. Nature, 484:502-505.

Purucker, M. E., Connerney, J. E. P., Blakely, R. J., Bracken, R. E., Nowicki, S., Le, G., Sabaka, T. J., Bonalsky, T. M., Todd, M., Kuang, W., Ravat, D., Ritz, C., Vaughan, A. P. M., Gaina, C., McEnroe, S., and Lesur, V. (2013). Icebase: A suborbital survey to map geothermal heat flux under an ice sheet. EGU General Assembly. Vienna, Austria.

Rasmussen, L. A. and Campbell, W. J. (173). Comparison of Three Contemporary Flow Laws in a Three-Dimensional, Time-Dependent Glacier Model. Journal of Glaciology, 12(66):361-373.

Ravens, J. (2001). Globe Claritas. Seismic processing software manual. Institute of Geological and Nuclear Sciences, 3rd edition.

Rebesco, M., Camerlenghi, A., Geletti, R., and Canals, M. (301-304). Margin architecture reveals the transition to the modern Antarctic ice sheet ca. 3 Ma. Geology, $34(4): 2006$.

Reese, R., Winkelmann, R., and Gudmundsson, H. (2018). Grounding-line flux formula applied as a flux condition in numerical simulations fails for buttressed Antarctic ice streams. The Cryosphere, 12(10):3229-3242. 
Retzlaff, R. and Bentley, C. R. (1993). Timing of stagnation of Ice Stream C, West Antarctica, from short-pulse-radar studies of buried crevasses. Journal of Glaciology, 39:553-561.

Richardson, C., Aarholt, E., Hamran, S., Holmlund, P., and Isaksson, E. (1997). Spatial distribution of snow in western Dronning Maud Land, East Antarctica, mapped by a ground-based snow radar. Journal of Geophysical Research: Solid Earth, 102(B9):20343-20353.

Richardson, M. D. and Briggs, K. B. (1993). On the Use of Acoustic Impedance Values to Determine Sediment Properties. Technical report, Naval Research Lab, Stennis Space Centre, Mississippi, USA.

Rignot, E. (2008). Changes in West Antarctic ice stream dynamics observed with ALOS PALSAR data. Geophysical Research Letters, 35.

Rignot, E., Mouginot, J., and Scheuchl, B. (2011). Ice Flow of the Antarctic Ice Sheet. Science, 333(6048):1427-1430.

Rignot, E. J., Gogineni, S. P., Krabill, W. B., and Ekholm, S. (1997). North and Northeast Greenland ice discharge from satelliteradar interferometry. Science, 276:934-937.

Rintoul, S. R., Silvano, A., Pena-Molino, B., van Wijk, E., Rosenberg, M., Greenbaum, J. S., and Blankenship, D. D. (2016). Ocean heat drives rapid basal melt of the Totten Ice Shelf. Science Advances, 2(12).

Rippin, D. M., Bamber, J. L., Siegert, M. J., Vaughan, D. G., and Corr, H. F. J. (2003). Basal topography and ice flow in the Bailey/Slessor region of East Antarctica. Journal of Geophysical Research, 108.

Rippin, D. M., Bamber, J. L., Siegert, M. J., Vaughan, D. G., and Corr, H. F. J. (2004). The role of ice thickness and bed properties on the dynamics of the enhanced-flow tributaries of Bailey Ice Stream and Slessor Glacier, East Antarctica. Annals of Glaciology, 39:366-372.

Rippin, D. M., Bingham, R. G., Jordan, T. A., Wright, A. P., Ross, N., Corr, H. F. J., Ferraccioli, F., Brocq, A. M. L., Rose, K. C., and Siegert, M. J. (2014). Basal roughness of the Institute and Möller Ice Streams, West Antarctica: Process determination and landscape interpretation. Geomorphology, 214:139-147. 
Ritz, C. (1997). EISMINT Intercomparison Experiment: Comparison of existing Greenland models. homepages.vub.ac.be/phuybrec/eismint/greenland.html.

Robin, G. D. Q. (1953). Summary of seismic shooting investigations in Dronning Maud Land. Journal of Glaciology, 2(13):205-210.

Robin, G. D. Q. (1958). Seismic shooting and related investigations, Norwegian-BritishSwedish Antarctic Expedition 1949-1952.

Rooney, S. T., Blankenship, D. D., Alley, R. B., and Bentley, C. R. (1987). Till beneath ice stream B: 2. Structure and continuity. Journal of Geophysical Research: Solid Earth, 92(B9):8913-8920.

Ross, N., Bingham, R. G., Corr, H. F. J., Ferraccioli, F., Jordan, T. A., Brocq, A. L., Rippin, D. M., Young, D., Blankenship, D. D., and Siegert, M. J. (2012). Steep reverse bed slope at the grounding line of the Weddell Sea sector in West Antarctica. Nature, 5:393-396.

Röthlisberger, H. (1972). Seismic exploration in cold regions. U.S. Army Cold Regions Research and Engineering Laboratory, Hanover.

Rydt, J. D. and Gudmundsson, G. H. (2016). 2016. Journal of Geophysical Research: Earth Surface, 121:865-880.

Saito, F., Abe-Ouchi, A., and Blatter, H. (2003). Effects of first-order stress gradients in an ice sheet evaluated by a three-dimensional thermomechanical coupled model. Annals of Glaciology, 37:166-172.

Santis, L. D., Anderson, J. B., Brancolini, G., and Zayatz, I. (1995). Seismic record of Late Oligocene through Miocene glaciation on the Central and Eastern Continental Shelf of the Ross Sea. Geology and Seismic Stratigraphy of the Antarctic Margin, Antarctic Research Series, 68:235-260.

Santis, L. D., Prato, S., Brancolini, G., Lovo, M., and Torelli, L. (1999). The Eastern Ross Sea continental shelf during the Cenozoic: implications for the West Antarctic ice sheet development. Global and Planetary Change, 23:173-196.

Scambos, T., Fricker, H. A., Liu, C. C., Bohlander, J., Fastook, J., Sargent, A., Massom, R., and Wu, A. M. (2009). Ice shelf disintegration by plate bending and hydro-fracture: Satellite observations and model results of the 2008 Wilkins ice shelf break-ups. Earth and Planetary Science Letters, 280:51-60. 
Scambos, T. A., Bohlander, J. A., Shuman, C. A., and Skvarca, P. (2004). Glacier acceleration and thinning after ice shelf collapse in the Larsen B embayment, Antarctica. Geophysics Research Letters, 31.

Schoof, C. (2003). The effect of basal topography on ice sheet dynamics. Continuum Mechanics and Thermodynamics, 15(3):295-307.

Schoof, C. (2004). Bed topography and surges in ice streams. Geophysical Research Letters, 31.

Schoof, C. (2006). A variational approach to ice stream flow. Journal of Fluid Mechanics, $556: 227-251$.

Schoof, C. (2007a). Ice sheet grounding line dynamics: steady states, stability and hysteresis. Journal of Geophysical Research, 112.

Schoof, C. (2007b). Marine ice-sheet dynamics. Part 1: The case of rapid sliding. Journal of Fluid Mechanics, 573:27-55.

Schoof, C. and Hindmarsh, R. C. A. (2010). Thin-Film Flows with Wall Slip: An Asymptotic Analysis of Higher Order Glacier Flow Models. Quarterly Journal of Mechanics and Applied Mathematics, 63(1):73-114.

Sergienko, O. V., Creyts, T. T., and Hindmarsh, R. C. A. (2014). Similarity of organized patterns in driving and basal stresses of Antarctic and Greenland ice sheets beneath extensive areas of basal sliding. Geophysical Research Letters, 41:3925-3932.

Seroussi, H., Morlighem, M., Larour, E., Rignot, E., and Khazendar, A. (2014). Hydrostatic grounding line parameterization in ice sheet models. The Cryosphere, 8:2075-2087.

Shannon, S. R., Payne, A. J., Bartholomew, I. D., van den Broeke, M. R., Edwards, T. L., Fettweis, X., Gagliardini, O., Gillet-Chaulet, F., Goelzer, H., Hoffman, M. J., Huybrechts, P., Mair, D. W. F., Nienow, P. W., Perego, M., Price, S. F., Smeets, C. J. P. P., Sole, A. J., van de Wal, R. S. W., and Zwinger, T. (2013). Enhanced basal lubrication and the contribution of theGreenland ice sheet to future sea-level rise. Proceedings of the National Academy of Sciences, 110(35):14156-14161.

Shapiro, N. M. and Ritzwoller, M. H. (2004). Inferring surface heat flux distributions guided by a global seismic model: particular application to Antarctica. Earth and Planetary Science Letters, 223(1-2):213-224. 
Shepherd, T., Bamber, J. L., and F.Ferraccioli (2006a). Subglacial geology in Coats Land, East Antarctica, revealed by airborne magnetics and radar sounding. Earth and Planetary Science Letters, 244:323-335.

Shepherd, T., L.Bamber, J., and Ferraccioli, F. (2006b). Subglacial geology in Coats Land, East Antarctica, revealed by airborne magnetics and radar sounding. Earth and Planetary Science Letters, 244(1-2):323-335.

Sheriff, R. E. (2008). Encyclopedic dictionary of applied geophysics. Society of Exploration Geophysicists, Tulsa.

Shreve, R. L. (1972). Movement of Water in Glaciers. Journal of Glaciology, 11(62):205214.

Siegert, M. J. (2008). Antarctic subglacial topography and ice-sheet evolution. Earth Surface Processes and Landforms, 33:646-660.

Siegert, M. J. and Bamber, J. L. (2000). Subglacial water at the heads of Antarctic ice-stream tributaries. Journal of Glaciology, 46(155):702-703.

Siegert, M. J., Carter, S., Tabacco, I., Popov, S., and Blankenship, D. D. (2005a). A revised inventory of Antarctic subglacial lakes. Antarctic Science, 17(3):453-460.

Siegert, M. J., Ross, N., and Brocq, A. M. L. (2016). Recent advances in understanding Antarctic subglacial lakes and hydrology. Philosophical Transactions of the Royal Society A, 374(2059).

Siegert, M. J., Taylor, J., and Payne, A. J. (2005b). Spectral roughness of subglacial topography and implications for former ice-sheet dynamics in East Antarctica. Global and Planetary Change, 45:249-263.

Smedsrud, L. H. and Jenkins, A. (2004). Frazil ice formation in an ice shelf water plume. Journal of Geophysical Research, 109.

Smith, A. M. (1997a). Basal conditions on Rufford Ice Stream, West Antarctica, from seismic observations. Journal of Geophysical Research, 102:543-552.

Smith, A. M. (1997b). Variations in basal conditions on Rutford Ice Stream, West Antarctica. Journal of Glaciology, 43(144):245-255.

Smith, A. M. (2007). Subglacial Bed Properties from Normal-Incidence Seismic Reflection Data. Journal of Environmental and Engineering Geophysics, 12(1):3-13. 
Smith, A. M., Jordan, T. A., Ferraccioli, F., and Bingham, R. G. (2013). Influence of subglacial conditions on ice stream dynamics: seismic and potential field data from Pine Island Glacier, West Antarctica. Journal of Geophysical Research: Solid Earth, 118:1471-1482.

Smith, A. M. and Murray, T. (2009). Bedform topography and basal conditions beneath a fast-flowing West Antarctic ice stream. Quaternary Science Reviews, 28:584-596.

Smith, A. M., Woodward, J., Ross, N., Bentley, M. J., Hodgson, D. A., Siegert, M. J., and King, E. C. (2018). Evidence for the long-term sedimentary environment in an Antarctic subglacial lake. Earth and Planetary Science Letters, 504:139-151.

Smith, B. E., Fricker, H. A., Joughin, I. R., and Tulaczyk, S. (2009). An inventory of active subglacial lakes in Antarctica detected by ICESat (2003-2008). Journal of Glaciology, 55(192):573-595.

Smith, E. C., Smith, A. M., White, R. S., Brisbourne, A. M., and Pritchard, H. D. (2015). Mapping the ice-bed interface characteristics of Rutford Ice Stream, West Antarctica, using microseismicity. Journal of Geophysical Research: Earth Surface, 120:1881-1894.

Smith, J. A., Graham, A. G. C., Post, A. L., Hillenbrand, C., Bart, P. J., and Powell, R. D. (2019). The marine geological imprint of Antarctic ice shelves. Journal of Geophysical Research: Solid Earth, 10.

Stearns, L. A., S., B. E. S. G., and Hamilton (2008). Increased flow speed on a large East Antarctic outlet glacier caused by subglacial floods. Nature Geoscience, $1(12): 827-831$.

Still, H., Campbell, A., and Hulbe, C. (2019). Mechanical analysis of pinning points in the Ross Ice Shelf, Antarctica. Annals of Glaciology, 60:32-41.

Stokes, C. R. and Clarke, C. D. (1999). Geomorphological criteria for identifying Pleistocene ice streams. Annals of Glaciology, 28:67-74.

Sugden, D. E., Marchant, D. R., Potter, N., Souchez, R. A., Denton, G. H., Swisher, C. C., and Tison, J. (1995). Preservation of Miocene glacier ice in East Antarctica. Nature, 376:412-414.

Tabone, I., Blasco1, J., Robinson, A., Alvarez-Solas, J., and Montoya, M. (2018). The sensitivity of the Greenland Ice Sheet to glacial-interglacial oceanic forcing. Climate of the Past, 14:455-472. 
Truffer, M. and Echelmeyer, K. A. (2003). Of isbræ and ice streams. Annals of Glaciology, 36:66-72.

Tsai, V. C., Stewart, A. L., and Thompson, A. F. (2015). Marine ice-sheet profiles and stability under Coulomb basal conditions. Journal of Glaciology, 61(226):205-215.

Tulaczyk, S., Kamb, W. B., and Engelhardt., H. F. (2000). Basal mechanics of Ice Stream B, West Antarctica 2. Undrained plastic bed model. Journal of Geophysical Research, 105:483-494.

Tulaczyk, S. M., Kamb, B., Scherer, R. P., and Engelhardt, H. F. (1998). Sedimentary processes at the base of a West Antarctic ice stream: constraints from textural and compositional properties of subglacial debris. Journal of Sedimentary Research, 68:487-496.

Tulaczyk, S. M., Scherer, R. P., and Clark, C. D. (2001). A ploughing model for the origin of weak tills beneath ice streams: a qualitative treatment. Quaternary International, 86:59-70.

van der Wel, N., Christoffersen, P., and Bougamont, M. (2013). The influence of subglacial hydrology on the flow of Kamb Ice Stream, West Antarctica. Journal of Geophysical Research: Earth Surface, 118:97-110.

van Liefferinge, B. (2018). Thermal state uncertainty assessment of glaciers and ice sheets: Detecting promising Oldest Ice sites in Antarctica. PhD thesis, Université libre de Bruxelles.

van Pelt, W. J. J. and Oerlemans, J. (2012). Numerical simulations of cyclic behaviour in the Parallel Ice Sheet Model (PISM). Journal of Glaciology, 58(208):347-360.

Vardy, M. E. (2015). Deriving shallow-water sediment properties using post-stack acoustic impedance inversion. Near Surface Geophysics, 13(2):143-154.

Vaughan, D. G. and Arthern, R. (2007). Why is it had to predict the future of ice sheets? Science, 315:1503-1504.

Vaughan, D. G., Smith, A. M., Nath, P. C., and Meur, E. L. (2003). Acoustic impedance and basal shear stress beneath four Antarctic ice streams. Annals of Glaciology, $36: 225-232$. 
Vieli, A. and Nick, F. M. (2011). Understanding and Modelling Rapid Dynamic Changes of Tidewater Outlet Glaciers: Issues and Implications. Surveys in Geophysics, 32(45):437-458.

Vieli, A. and Payne, A. (2005). Assessing the ability of numerical ice sheet models to simulate grounding-line migration. Journal of Geophysical Research, 110.

Vogel, S. W., Tulaczyk, S., Kamb, B., Engelhardt, H., Carsey, F. D., Behar, A. E., Lane, A. L., and Joughin, I. (2005). Subglacial conditions during and after stoppage of an Antarctic Ice Stream: Is reactivation imminent? Geophysical Research Letters, 32 .

Waibel, M. S., Hulbe, C. L., Jackson, C. S., and Martin, D. F. (2018). Rate of Mass Loss Across the Instability Threshold for Thwaites Glacier Determines Rate of Mass Loss for Entire Basin. Geophysical Research Letters, 45:809-816.

Webber, B. G. M., Heywood, K. J., Stevens, D. P., Dutrieux, P., Abrahamsen, E. P., Jenkins, A., Jacobs, S. S., Ha, H. K., Lee, S. H., and Kim, T. W. (2017). Mechanisms driving variability in the ocean forcing of Pine Island Glacier. Nature Communications, 8 .

Weertman, J. (1974). Stability of the Junction of an Ice Sheet and an Ice Shelf. Journal of Glaciology, 13(67):3-11.

Weis, M., Greve, R., and Hutter, K. (1999). Theory of shallow ice shelves. Continuum Mechanics and Thermodynamics, 11:15-50.

Whillans, L. M., Bolzan, J., and Shabtaie, S. (1987). Velocity of Ice Streams B and C, Antarctica. Journal of Geophysical Research, 92(B9):8895-8902.

White-Gaynor, A. L., Nyblade, A. A., Aster, R. C., Wiens, D. A., Bromirski, P. D., Gerstoft, P., Stephen, R. A., Hansen, S. E., Wilson, T., Dalziel, I. W., Huerta, A. D., Winberry, J. P., and Anandakrishnan, S. (2019). Heterogeneous upper mantle structure beneath the Ross Sea Embayment and Marie Byrd Land, West Antarctica, revealed by P-wave tomography. Earth and Planetary Science Letters, 513:40-50.

Willis, I. C., Pope, E. L., Vieli, G. J.-M. C. L., Arnold, N. S., and Long, S. (2016). Drainage networks, lakes and water fluxes beneath the Antarctic ice sheet. Annals of Glaciology, 57(72):96-108. 
Wingham, D. J., Shepherd, A., Muir, A., and Marshall, G. J. (2006). Mass balance of the Antarctic ice sheet. Philosophical Transactions of the Royal Society A, 364:16271635 .

Winkelmann, R., Levermann, A., Ridgwell, A., and Caldeira, K. (2015). Combustion of available fossil fuel resources sufficient to eliminate the Antarctic Ice Sheet. Science Advances, 1(8).

Winkelmann, R., Martin, M. A., Haseloff, M., Albrecht, T., Bueler, E., Khroulev, C., and Levermann, A. (2011). The Potsdam Parallel Ice Sheet Model (PISM-PIK) Part 1: Model description. The Cryosphere, 5:715-726.

Winsborrow, M. C. M., Clarke, C. D., and Stokes, C. R. (2010). What controls the location of ice streams? Earth-Science Reviews, 103:45-59.

Wood, M., andI. Fenty, E. R., Menemenlis, D., Millan, R., Morlighem, M., Mouginot, J., and Seroussi, H. (2018). Ocean-induced melt triggers glacier retreat in Northwest Greenland. Geophysical Research Letters, 45:8334-8342.

Wright, A. and Siegert, M. (2012). A fourth inventory of Antarctic subglacial lakes. Antarctic Science, 24(6):659-664.

Yilmaz, O. (2008). Seismic Data Analysis: Processing, Inversion, and Interpretation of Seismic Data. Society of Exploration Geophysicists, Tulsa, 2nd edition.

Zechmann, J. M., Booth, A. D., Truffer, M., Gusmeroli, A., Amundson, J. M., and Larsen, C. F. (2018). Active seismic studies in valley glacier settings: strategies and limitations. Journal of Glaciology, 64(247):796-810.

Zwinger, T., Greve, R., Gagliardini, O., Shiraiwa, T., and Lyly, M. (2007). A full Stokes-flow thermo-mechanical model for firn and ice applied to the Gorshkov crater glacier, Kamchatka. Annals of Glaciology, 45:29-37. 
